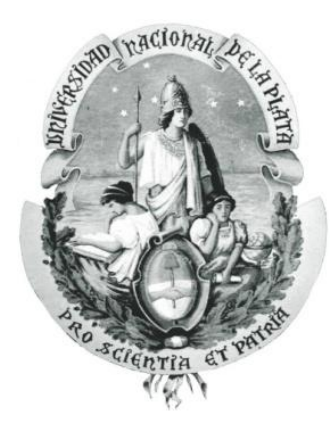

TESIS PARA OPTAR AL GRADO DE DOCTOR

\title{
IMPACTO DE LA SENESCENCIA FOLIAR SOBRE LA PRODUCCIÓN DE FOTOASIMILADOS Y EL RENDIMIENTO DE MAÍZ (Zea mays L.) BAJO CONDICIONES DE ESTRÉS ABIÓTICO
}

\author{
AUTORA: \\ Lic. Mariana Antonietta \\ DIRECTOR: \\ Dr. Juan José Guiamet \\ CO-DIRECTOR: \\ Dr. Horacio Acciaresi
}

\begin{abstract}
Facultad de Cs. Naturales y Museo
Universidad Nacional de La Plata
\end{abstract}

Año: 2012 


\section{DEDICATORIA}

A riesgo de descuidar protocolos, no dedico esta tesis a ningún afecto personal. Todos mis afectos personales saben cuánto agradezco el apoyo que siempre he tenido.

Decido dedicar esta tesis a quienes le dan sentido al tiempo invertido en estos años. Lo hago afrontando una paradoja: probablemente, los mismos que le dan sentido a esta tesis no le encontrarían sentido a esta tesis, si pudieran conocerla. Esto no significa que esta tesis no tenga sentido, significa que es necesario construir un puente. Entonces, dedico esta tesis a quienes tantas veces son convocados en los planteos del problema pero, por algún motivo del que quisiera hacerme responsable, pocas veces son destinatarios de las soluciones. Y decido hacerlo no por ellos, sino por mí. Porque cada detalle es un grano de arena más que contribuye a afianzar el propio compromiso. 


\section{AGRADECIMIENTOS}

Por sobre todas las cosas, agradezco a la suerte. Porque en un mundo pleno de necesidades básicas insatisfechas, tuve la grandiosa suerte de nacer en una familia de clase media, y en un país donde existe la Universidad Pública. Y eso me convierte en una persona privilegiada por el azar.

Agradezco enormemente a mi director, Juan J. Guiamet, por transmitirme una forma humana de hacer ciencia. Por ocuparse con ahínco de alimentar la confianza personal, que tarde o temprano, redunda en el crecimiento personal. También porque cierta dosis de libertad es imprescindible para que afloren nuevas ideas (buenas o malas) y yo tuve la suerte de contar con eso. Por su capacidad para escuchar y sus esfuerzos por comprender incluso lo incomprensible. Me encantaría decir que le agradezco haberme enseñado a escuchar, pero eso es un arte y no se aprende tan rápido. Y obviamente, le agradezco por su total predisposición cada vez que lo necesité. También agradezco a mi codirector, Horacio Acciaresi porque a pesar de situaciones complejas, mantuvo el compromiso de co-dirigirme en esta tesis lo que resulta especialmente valorable.

Agradezco a los compañeros becarios, por todas las experiencias compartidas en esta etapa. Especialmente a Luján, por la mutua contención y el entendimiento implícito y profundo. A Paula Girón, porque el trabajo en conjunto permitió no sólo consumar su tesina de grado, sino también enriquecer esta tesis. A Eduardo, Lorenza y Corina por la predisposición y la ayuda importantísima y de todo tipo (académica, logística, emocional), siempre que la necesité.

Varias instituciones brindaron un apoyo imprescindible para la realización de esta tesis. Agradezco a la Facultad de Cs. Naturales y Museo de la Universidad Nacional de La Plata. Al personal de la Estación Experimental de la Facultad de Agronomía, J. H. Hirschhorn. A la Agencia Nacional de Promoción Científica y Tecnológica, y al CONICET por becarme. La mayor parte de esta tesis fue financiada con el PICT 32827. De forma más general, también quiero agradecer al gobierno nacional, porque por primera vez en muchos años de historia, la ciencia es parte del proyecto político y esto representa un incentivo para trabajar con mayor esmero. 
Agradezco a mis padres, porque inventaron una forma de educarme que resultó en una combinación de responsabilidad y libertad muy interesante, y que disfruto intensamente. A mis hermanos, Alejandra y Juan, porque nos parecemos mucho y creo que me entienden. Al Negro, por la confianza, por la paciencia, por intentar comprender mis necesidades, por extrañarme pero dejarme ir, por todo. A mis compañeros de Construcción, porque formar parte de ese colectivo es crecer y desafiarse a uno mismo. A mis compañeros de Tubo de Ensayo, por permitirme crecer en otros sentidos, y ser el canal de mis sentimientos más íntimos. A Haití, que me prestó su música y su fuerza, y a Cuba por existir. 
ÍNDICE GENERAL

Contenido

Pág.

ABREVIATURAS

VII

RESUMEN

IX

ABSTRACT

$\mathbf{X I}$

\section{CAPÍTULO 1: INTRODUCCIÓN GENERAL}

La producción de alimentos en el contexto mundial

Alternativas para incrementar la producción

4

El mejoramiento en maíz y su relación con la tolerancia al estrés

8

Senescencia foliar y rendimiento en maíz

Senescencia foliar y balance de C

Senescencia foliar y balance de $\mathrm{N}$

19

Posibles implicancias del sistema radical en la demora de la senescencia

Hipótesis y objetivos de trabajo

CAPÍTULO 2: SENESCENCIA FOLIAR Y RENDIMIENTO EN HÍBRIDOS DE MAÍZ BAJO SEQUÍA EN POST-FLORACIÓN

Introducción 29

Materiales y Métodos $\quad 32$

$\begin{array}{ll}\text { Resultados } & 38\end{array}$

$\begin{array}{ll}\text { Discusión } & 56\end{array}$

$\begin{array}{ll}\text { Conclusiones } & 61\end{array}$

CAPÍTULO 3: SENESCENCIA FOLIAR Y RENDIMIENTO EN HÍBRIDOS DE MAÍZ FRENTE A VARIACIONES EN LA DISPONIBILIDAD DE NITRÓGENO

$\begin{array}{ll}\text { Introducción } & 63\end{array}$

$\begin{array}{ll}\text { Materiales y Métodos } & 67\end{array}$

$\begin{array}{ll}\text { Resultados } & 73\end{array}$

$\begin{array}{ll}\text { Discusión } & 95\end{array}$ 
CAPÍTULO 4: SENESCENCIA FOLIAR Y RENDIMIENTO EN HÍBRIDOS DE MAÍZ FRENTE A VARIACIONES EN LA DENSIDAD DE PLANTAS

$\begin{array}{ll}\text { Introducción } & 104\end{array}$

$\begin{array}{ll}\text { Materiales y Métodos } & 107\end{array}$

$\begin{array}{ll}\text { Resultados } & 110\end{array}$

$\begin{array}{ll}\text { Discusión } & 131\end{array}$

$\begin{array}{lr}\text { Conclusiones } & 139\end{array}$

CAPÍTULO 5: ANÁLISIS DEL METABOLISMO DE COMPUESTOS NITROGENADOS

DURANTE LA SENESCENCIA DE MAÍZ

$\begin{array}{lr}\text { Introducción } & 141\end{array}$

$\begin{array}{ll}\text { Materiales y Métodos } & 145\end{array}$

$\begin{array}{lr}\text { Resultados } & 149\end{array}$

$\begin{array}{ll}\text { Discusión } & 161\end{array}$

$\begin{array}{ll}\text { Conclusiones } & 168\end{array}$

CAPÍTULO 6: CONSIDERACIONES FINALES

$\begin{array}{ll}\text { Contrastación de hipótesis } & 169\end{array}$

$\begin{array}{ll}\text { Aportes originales al conocimiento científico } & 171\end{array}$

$\begin{array}{ll}\text { Implicancias para futuras investigaciones } & 174\end{array}$

$\begin{array}{ll}\text { Conclusión general } & 186\end{array}$

$\begin{array}{lr}\text { BIBLIOGRAFÍA } & 188\end{array}$ 


\section{ABREVIATURAS}

SG: Stay green

NSG: No stay green (senescente, estándar, etc.)

$\mathrm{N}$ : nitrógeno.

DDF: días después de floración

MF: madurez fisiológica

AFV: área foliar verde

NG: número de granos por planta.

PG: peso de grano individual.

MS: materia seca 


\section{DECLARACIÓN}

Declaro que el material incluido en esta tesis es, a mi mejor saber y entender, original, producto de mi propio trabajo (salvo que se identifique explícitamente las contribuciones de otros) y que este material no ha sido presentado en forma parcial o total como una tesis en ésta u otra institución.

Mariana Antonietta 


\section{IMPACTO DE LA SENESCENCIA FOLIAR SOBRE LA PRODUCCIÓN DE FOTOASIMILADOS Y EL RENDIMIENTO DE MAÍZ (Zea mays L.) BAJO CONDICIONES DE ESTRÉS ABIÓTICO}

\section{RESUMEN}

El objetivo general de esta tesis fue estudiar si la demora en la senescencia foliar (carácter stay-green, SG) en híbridos de maíz confiere tolerancia del rendimiento al estrés abiótico. Se realizaron ensayos a campo utilizando híbridos contrastantes en la senescencia foliar. Se registró la evolución de la senescencia, la producción neta de fotoasimilados, el rendimiento y sus componentes. Bajo sequía en post-floración, los genotipos SG presentaron mayor producción de fotoasimilados y esto se relacionó con mayor conductancia estomática y con la retención de área foliar verde (AFV). Esta ventaja se tradujo en mayor rendimiento (a través de un mayor peso de grano, PG) en dos ensayos; en el tercer ensayo los genotipos SG presentaron menor partición a espiga por lo que el rendimiento no se diferenció del grupo de híbridos no stay-green (NSG). En condiciones de deficiencias de N, los genotipos SG presentaron mayor producción de fotoasimilados en post-floración mientras las temperaturas mínimas se mantuvieron por encima de $10^{\circ} \mathrm{C}$, pero pérdidas netas de materia seca por debajo de este umbral que no se observaron en los genotipos NSG o con mayor nivel de fertilización. El carácter SG no se relacionó con el rendimiento o con el PG a bajo nivel de $\mathrm{N}$ (18 kg de $\mathrm{N} \mathrm{ha}^{-1}$ ) pero sí al aumentar la dosis de fertilización (100 y $200 \mathrm{~kg}$ de N $\left.\mathrm{ha}^{-1}\right)$. En condiciones de estrés por alta densidad poblacional, se compararon dos genotipos. El genotipo SG presentó menor producción de asimilados, y menor inducción de la senescencia de las hojas basales por sombreo. El genotipo SG demoró la senescencia aún cuando la absorción de $\mathrm{N}$ en post-floración fue menor que en el genotipo NSG. El PG se relacionó con la concentración de $\mathrm{N}$ en granos, y ambos fueron menores en el genotipo SG, resultando en menor rendimiento. En un tercer ensayo, se incorporaron dos genotipos adicionales. En uno de ellos, el carácter SG se mantuvo sólo en las hojas superiores; éste genotipo SG presentó mayor PG y rendimiento en comparación con los otros tres. Finalmente, se analizó la degradación de proteínas foliares durante el llenado. La degradación de proteínas se relacionó positivamente con el PG en condiciones de deficiencias de $\mathrm{N}$ pero inversamente cuando las plantas se fertilizaron con $200 \mathrm{~kg} \mathrm{~N} \mathrm{ha}^{-1}$. Uno de los genotipos SG mostró muy escasa degradación 
de proteínas mientras que en otro SG la degradación aumentó en respuesta a las deficiencias de N. En conclusión, la contribución del carácter SG a la estabilidad del rendimiento depende de la capacidad que presenten los genotipos SG para ajustar la expresión del carácter en función del ambiente (por ejemplo, induciendo la senescencia en respuesta al sombreo, o por deficiencias de $\mathrm{N}$ edáfico).

Palabras claves: maíz; Zea mays L.; tolerancia al estrés; senescencia foliar; postfloración; producción de asimilados; número de granos; peso de grano; estrés hídrico; nitrógeno; densidad poblacional; removilización de $\mathrm{N}$ foliar. 


\title{
DELAYED SENESCENCE EFFECTS ON ASSIMILATE PRODUCTION AND YIELD OF MAIZE (Zea mays L.) UNDER ABIOTIC STRESS CONDITIONS
}

\begin{abstract}
The main objective of this thesis was to determine if delayed leaf senescence (the stay-green trait, SG) increases yield stability in maize single hybrids. Field experiments were performed where maize hybrids selected because of their contrasting phenotypes for senescence progression. Senescence progression, net assimilate production, yield and its components were determined. Under post-silking drought, SG genotypes produced more assimilates, and this was related to higher stomatal conductance and to green leaf area retention (GLA). This led to higher yields (explained by higher kernel weights, KW) in two experiments; in a third experiment, SG genotypes partitioned less assimilates to the ear, so yield was not different from non stay-green (NSG) genotypes. Under $\mathrm{N}$ deficiencies, SG genotypes also had higher assimilate production after silking, but only while minimum temperatures were above $10^{\circ} \mathrm{C}$. When minimum temperatures fell below $10^{\circ} \mathrm{C}$, net dry matter losses were observed in SG genotypes exposed to N deficiencies, but not in NSG genotypes or under higher $\mathrm{N}$ levels. The SG trait did not related to yield, nor to KW under low N (18 $\mathrm{kg} \mathrm{N}$ per ha ${ }^{-1}$ ) but it did related to yield and KW under higher $\mathrm{N}$ levels (100 and $200 \mathrm{~kg}$ $\mathrm{N}$ per $h^{-1}{ }^{1}$ ). Under high population densities, two contrasting maize hybrids were compared. The SG genotype had lower post-silking assimilate production, and poor capacity to induce senescence of basal leaves at low irradiances. Additionally, the SG genotype delayed senescence even though post-silking $\mathrm{N}$ absorption was lower than in the NSG genotype. KW was positively related to kernel $\mathrm{N}$ concentration, and both were lower in the SG genotype, resulting in lower yield. In a third experiment two additional hybrids were included. In one of them the SG character was expressed only in the upper leaves; this genotype showed higher $\mathrm{KW}$ and higher yield at high population densities. Finally, leaf protein degradation after silking was analyzed. Protein degradation related positively to final KW under $\mathrm{N}$ deficiency, but it was negatively related to final $\mathrm{KW}$ when plants where fertilized with $200 \mathrm{~kg} \mathrm{~N} \mathrm{ha}^{-1}$. Under $\mathrm{N}$ deficiencies, one of the SG genotypes scarcely degraded protein at early stages of grain filling but the other SG genotype increased protein degradation in response to $\mathrm{N}$
\end{abstract}


deficiencies. As a conclusion, the contribution of the SG trait to yield stability depends on the ability of the SG genotypes to adjust the expression of this trait as a function of the environment (e.g., by inducing senescence under low irradiances or under $\mathrm{N}$ deficiencies).

Key words: maize; Zea mays L.; stress tolerance; leaf senescence; post-silking; assimilate production; kernel number; kernel weight; drought stress; nitrogen; population density; leaf $\mathrm{N}$ remobilization. 


\section{CAPÍTULO 1}

\section{INTRODUCCIÓN GENERAL}

Todos los seres humanos tienen el derecho a satisfacer sus necesidades vitales.

Declaración Universal de los Derechos Humanos

Considerando el estado actual de la agricultura en el mundo, sería posible alimentar a 12000 millones de personas sin problemas. Dicho de otra manera, toda persona que muere de hambre en la actualidad está siendo, en realidad, asesinada.

Jean Ziegler, Consejo de Derechos Humanos de Naciones Unidas

\section{La producción de alimentos en el contexto mundial}

\subsection{Contexto mundial}

Según recientes predicciones, se espera que para el año 2050 la población mundial alcance los 9.100 millones de habitantes, la mayoría de los cuales nacerá en países que sufren inseguridad alimentaria (Ribaut et al., 2008). De persistir el actual esquema de distribución de los recursos será necesario incrementar en un $70 \%$ la producción mundial de alimentos para evitar que continúe aumentando el número de habitantes en situación de hambre crónica (CIMMYT, Annual Report 2008-2009; Godfray et al., 2010).

La producción mundial de cereales alcanzó las 1750 millones de toneladas en el 2011 (IGC, 2012). Las perspectivas indican un drástico aumento de la demanda de carne, y por lo tanto de cereales para consumo forrajero, como consecuencia directa del crecimiento económico de países emergentes. Según FAO (2008) la demanda de granos para forraje se incrementará de 50 a 640 millones de toneladas anuales para el 2018. En relación a la producción mundial alcanzada en 2011 esto significa que la proporción destinada a forraje crecerá del 2\% al 36\% en diez años.

Estas perspectivas son aún más alarmantes si se considera la creciente demanda de biocombustibles. El etanol representa más del $90 \%$ del total mundial de biocombustibles líquidos, y se produce principalmente a partir de caña de azúcar y de granos de maíz (FAO, 2007). Los biocombustibles líquidos proporcionan alrededor del 
$1 \%$ de la oferta mundial de combustible para el transporte y menos de $0,3 \%$ de total de oferta energética, utilizando alrededor del $1 \%$ de la tierra cultivable del mundo (14 millones de ha) (FAO, 2007). Esto significa que, asumiendo tecnologías de producción similares a las actuales, por cada punto porcentual de sustitución de combustibles fósiles por biocombustibles, será necesario destinar un punto porcentual del total de tierras cultivables a la producción de biocombustibles (FAO, 2007). En la campaña 2007/08 se utilizaron 84 millones de toneladas de grano de maíz para la obtención de etanol y se proyecta que esta demanda aumente a 143 millones de toneladas para el 2018 (Edgerton, 2009).

Este escenario es aún más complicado si se toman en cuenta los efectos del cambio climático. A partir de los registros para el período 1950-2000, las perspectivas indican (con una probabilidad del 66\%) un aumento en la frecuencia de eventos extremos, incluyendo olas de calor, mayor proporción de las precipitaciones representada por lluvias intensas y mayor superficie mundial afectada por sequías (IPCC, 2007). Por cada ${ }^{\circ} \mathrm{C}$ que se incremente la temperatura promedio de las regiones tropicales y sub-tropicales, los rendimientos de trigo caerán alrededor de un $10 \%$ (CIMMYT, Annual Report 2008-2009; Ghannoum, 2009). En este contexto, los cereales con metabolismo $\mathrm{C}_{4}$, menos sensibles a las altas temperaturas, adquirirán aún más importancia (Ghannoum, 2009). Entre éstos, el maíz se ubica entre los más importantes. La producción mundial de maíz durante la campaña 2010-2011 fue de 844 millones de toneladas, representando casi el 50\% de la producción total de cereales (IGC, 2012). Además, en el período 2000-2008 la producción mundial de maíz creció un 39\% mientras, que el trigo y el arroz solo crecieron un $15 \%$ (FAO, 2008).

\subsection{La creciente demanda de alimentos podrá ser parcialmente satisfecha en} las regiones tradicionalmente productoras

Los Estados Unidos son el principal exportador mundial de maíz (54\% del maíz exportado en el mundo, FAO, 2009), y una amplia distancia los separa de la segunda posición, ocupada por la Argentina (15,3\% del maíz exportado en el mundo). Sin embargo, en el período 2000/2010 el consumo industrial de maíz (principalmente para biocombustibles) en Estados Unidos se ha incrementado a una tasa del 20\% anual (USDA, 2010). De persistir esta tendencia es esperable que el aumento de la demanda 
interna reduzca el volumen exportado por Estados Unidos, colocando a la Argentina en una posición todavía más importante como exportador mundial de maíz.

En Argentina, la brecha ente rendimientos reales y potenciales es de alrededor del 60\% (Godfray et al., 2010). Para el período 2000/2010 el rendimiento promedio de cultivo de maíz en Argentina rondó los $6700 \mathrm{~kg} \mathrm{ha}^{-1}$ (USDA, 2010). En este promedio es necesario considerar que, por ejemplo, para la campaña 2009-2010 los rendimientos alcanzaron $8755 \mathrm{~kg} \mathrm{ha}^{-1}$ en la Pcia. de Buenos Aires, pero no superaron los $4519 \mathrm{Kg} \mathrm{ha}^{-1}$ en la Pcia. de La Pampa, una zona marginal para el cultivo (SIIA, 2010). Es posible que estas diferencias se acentúen dado el desplazamiento de la frontera agrícola hacia zonas marginales. Por ejemplo, entre el período 1988-2008 la superficie cultivada en Buenos Aires se redujo un 35\% o aumentó solamente un 4\% en Santa Fe, mientras que en provincias como Chaco la superficie cultivada aumentó un $40 \%$ y hasta un $100 \%$ en Santiago del Estero (Censo Nacional Agropecuario, 2008).

La reducción de la brecha entre rendimientos potenciales y reales podría favorecer el desarrollo agrícola en regiones marginales. En provincias extra-pampeanas el maíz es uno de los principales cereales cultivados, destacando su importancia a escala regional. En relación a la superficie cultivada con cereales para grano (no oleaginosas) en cada provincia, el maíz representa el 97\% en Misiones, el $83 \%$ en Jujuy, el $75 \%$ en San Luis, el $40 \%$ en Chaco, y la tendencia es similar en varias otras (Censo Nacional Agropecuario, 2002). El aporte de estas provincias al balance comercial de granos puede no ser grande, pero la producción local sí podría tener un impacto económico, ya que se reduce el costo de flete y el consumo de energía asociado al mismo.

Un aumento de la producción de maíz en Argentina podrá resultar de una combinación entre la reducción de la brecha entre rendimientos reales y potenciales y de la ampliación de la superficie cultivada hacia zonas marginales. Cualquiera de las dos alternativas implicará mejorar la tolerancia del cultivo al estrés ambiental.

1.3. La creciente demanda de alimentos también podría ser satisfecha directamente en las regiones con inseguridad alimentaria

En los países desarrollados aproximadamente el $75 \%$ de los cereales que se producen son utilizados como alimento para ganado o para uso industrial. Por el 
contrario, en regiones que padecen inseguridad alimentaria, como el África subsahariana, más del $80 \%$ de los cereales que se producen se utilizan para consumo humano (FAO, 2002). Sin embargo, en los últimos 50 años la producción agrícola per cápita aumentó más del $30 \%$ en los países desarrollados mientras que en el África subsahariana cayó cerca del 10\%, retrocediendo a los niveles de 1960 (FAO 2011). Considerando el incremento en rendimientos para el período 1950-2010, éste ha progresado a una tasa de $0,118 \mathrm{tn} \mathrm{ha}^{-1}$ año ${ }^{-1}$ en Estados Unidos pero de 0,011 th ha ${ }^{-1}$ año ${ }^{-1}$ en países como Kenia (FAO, 2011).

Mejorar la producción en las regiones más afectadas por la inseguridad alimentaria podría contribuir a aliviar dicha situación Aún más considerando que el $70 \%$ de las personas que viven con menos de un dólar al día habita en zonas rurales (FAO, 2002). En estas zonas, la producción agrícola se lleva adelante prácticamente sin uso de insumos (fertilizantes, riego, herbicidas, plaguicidas) y suele estar expuesta a estrés ambiental severo (FAO, 2002). Estos contextos productivos con estrés extremo generalmente no son considerados en los planes de mejoramiento realizados por empresas privadas (Bänziger et al., 2006).

Orientar la ecofisiología de cultivos hacia estos escenarios podría generar un impacto positivo en las regiones más postergadas. El $85 \%$ de los productores rurales del mundo dispone de menos de 2 ha de superficie (Bossio et al., 2010) y aún así, los pequeños productores son responsables del $60 \%$ de la agricultura global y proveen el $80 \%$ de los alimentos en los países subdesarrollados (FAO, 2002). El creciente precio de los hidrocarburos, y los costos de flete asociados a la importación de alimento desde las regiones tradicionalmente productoras, suman importancia a la idea de producir directamente en los sitios de consumo.

\section{Alternativas para incrementar la producción}

Un salto productivo capaz de satisfacer una demanda creciente de alimentos podría darse a través de una combinación entre (i) mayor uso de insumos (agua, fertilizantes, herbicidas y plaguicidas), (ii) aumento de la superficie cultivada, (iii) conocimiento aplicado a la optimización del manejo de los cultivos en función del 
ambiente y al mejoramiento genético tendiente hacia una mayor tolerancia al estrés y mejor eficiencia en el uso de los recursos.

\subsection{Aumento del uso de insumos}

El incremento en el uso de insumos sin que aumente su eficiencia de uso, es poco viable considerando la creciente escasez de los insumos tradicionalmente usados en la agricultura (fertilizantes provenientes de fuentes no renovables, energía fósil). La huella ecológica, entendida como el área necesaria para producir los recursos que consumimos y disponer de los desechos que generamos hoy supera en casi $40 \%$ a la capacidad bioproductiva del planeta $y$, de continuar la tendencia, este desfase superará el 100\% hacia el año 2050 (GFN, 2008). Esto implica que en los países desarrollados, la tasa de consumo de recursos supera la capacidad del planeta para regenerarlos y degradar los desechos resultantes.

Con respecto al riego, en zonas expuestas a sequías frecuentes, el uso de agua de riego puede presentar una serie de riesgos ambientales (salinización de suelos, depresión progresiva de las napas, consumo de agua fósil, mayor demanda de energía de bombeo) y sociales (sin controles adecuados, el uso del agua para la agricultura suele afectar gravemente la disponibilidad de agua para las poblaciones locales). En las regiones áridas y semiáridas de los trópicos se calcula que el $12 \%$ de las tierras agrícolas han sido afectadas irreversiblemente por salinización (FAO, 2002).

En relación a los fertilizantes, el uso de este insumo parecería tener que optimizarse, y probablemente también, incrementarse o reducirse dependiendo de la zona. La optimización del manejo de la fertilización será indispensable si se acentúan los efectos del cambio climático. Una menor uniformidad en la distribución de las lluvias pondría en disponibilidad para las plantas altas dosis de fertilizante (especialmente N) en períodos demasiado cortos (IPCC, 2007), exacerbando el proceso de lixiviación. El aumento del uso de fertilizantes podría ser necesario en países subdesarrollados, ya que las tasas de extracción de nutrientes por los cultivos no alcanzan a ser compensadas por la fertilización, deteriorando progresivamente el estado de los suelos (Cruzate \& Casas, 2009). En cambio, en países desarrollados, si bien la captura del $\mathrm{N}$ aplicado depende de las condiciones ambientales, el tipo de suelo y la especie, entre un 50 y $70 \%$ del $\mathrm{N}$ aplicado en la fertilización no es recuperado en la 
cosecha (Kichey et al., 2007). Esto implica no sólo un desperdicio de la energía fósil invertida para producir y trasladar el fertilizante, sino también diversas repercusiones negativas para el ambiente (contaminación de agua subterránea, emisiones de óxido nítrico que agravan el cambio climático, entre otras). En suelos con baja relación $\mathrm{C} / \mathrm{N}$, la fertilización puede aumentar la comunidad de fauna edáfica y consiguientemente, el consumo de la reserva de materia orgánica del suelo (sustancias húmicas).

Otra forma de incremento en el uso de insumos es aumentar el número de cultivos por año; especialmente en regiones que ya no disponen de más tierras arables, como es el caso de Asia (Fig. 1). Esta práctica podría contribuir en un $14 \%$ al incremento requerido de la producción para el 2050 (Bruinsma, 2009). No obstante las limitaciones de esta proyección pueden ejemplificarse con la expansión del cultivo de soja en Argentina. A partir de 1970 la adopción de prácticas de doble cultivo anual (trigo-soja) resultó en una intensificación de los procesos de degradación ambiental y mayor vulnerabilidad de los cultivos a las sequías (Casas, 2001).

\subsection{Aumento de la superficie cultivada}

La superficie cultivada del planeta es alrededor de 1500 millones de ha ${ }^{2}$ (FAO 2002). La superficie potencialmente cultivable (sin considerar selvas, áreas protegidas y áreas urbanizadas) podría sumar 1120 millones de ha $^{2}$ a las tierras actualmente cultivadas, si bien una buena parte de las tierras adicionales están afectadas por baja fertilidad de suelos, contaminación, o corresponden a terrenos montañosos (FAO, 2002). Es presumible que las tierras de alta productividad ya estén en uso, por lo que, aún incrementando la superficie cultivada los incrementos en rendimiento obtenidos serían menores que proporcionales al aumento de superficie. Además, parte del aumento de la superficie cultivada simplemente compensará las pérdidas de tierras agrícolas que ocurren actualmente. Se calcula que entre 2 y 5 millones ha de tierras agrícolas se pierden anualmente debido a la erosión (Bringezu et al., 2010) a lo que se suman las pérdidas por salinización, contaminación por diversos agentes, y el destino de tierras para urbanización. También debe tenerse en cuenta que un aumento de la superficie cultivada será a expensas de reducir la disponibilidad para otros destinos como ser asentamientos humanos y reservas de biodiversidad. 
Se espera que el $80 \%$ del aumento de la superficie cultivada de aquí a 2030, tenga lugar en América Latina y el África subsahariana (FAO, 2002). Sin embargo, una buena parte de esta superficie corresponde a ambientes frágiles y susceptibles a la degradación (Andrade, 2011), o de baja productividad. De aumentar la superficie arable serán necesarios genotipos mejor adaptados a ambientes marginales y con características que minimicen la degradación ambiental.

\subsection{Incorporación de tecnología a través del mejoramiento vegetal}

Según Lee \& Tollenaar (2007), en las últimas cuatro décadas, el $60 \%$ de los aumentos en la producción agrícola estaría explicado por el mejoramiento de los cultivos, y las estimaciones de FAO (2002) son incluso mayores (Fig. 1). Esta tendencia parece mantenerse en el futuro; se estima que el mejoramiento vegetal aportará el 80\% del aumento requerido de la producción agrícola para el 2050 (Bruinsma, 2009). Para que esto sea posible, será necesario reducir las brechas entre rendimientos potenciales y reales que rondan el $30 \%$ en las áreas más tecnificadas y pueden alcanzar el 70\% en el África subsahariana (Fischer y Edmeades, 2010). Además, será necesario hacerlo incrementando la eficiencia en el uso de insumos (agua y fertilizantes) de modo que la reducción de la brecha entre rendimientos reales y potenciales no esté acompañada de un incremento proporcional en el uso insumos.

El mejoramiento vegetal orientado a ambientes con estrés tiene un enorme desafío por delante. Si bien es cierto que la mejora genética ha producido plantas más tolerantes a diversos tipos de estrés, los productores suelen enfrentarse a condiciones ambientales más adversas que aquellas donde se realizó el mejoramiento (Bänziger et al., 1999; Richards, 2000). La selección empírica de genotipos de alto rendimiento suele hacerse en condiciones de estrés leve, ya que el estrés severo aumenta la variabilidad ambiental y la interacción genotipo $\mathrm{x}$ ambiente reduciendo la heredabilidad (Gallais \& Coque, 2005). Esto puede representar un problema cuando los caracteres relacionados a altos rendimientos en condiciones de estrés leve son distintos de los caracteres relacionados a altos rendimientos relativos en condiciones de estrés severo (Gallais \& Coque, 2005). Situaciones de este tipo se manifiestan como puntos de cruce entre distintos genotipos cuando se analiza el rendimiento por ambiente en función de un índice ambiental. 
En esta tesis se dará relevancia a características morfo-fisiológicas que representen una ventaja relativa en ambientes expuestos a estrés abiótico. Las aproximaciones experimentales incluyen sequía en post-floración y déficit nutricional. Además, se realizará una aproximación alternativa en un ambiente de alta productividad donde el estrés se logrará mediante cambios en el manejo (densidad de plantas). Se pretende así contribuir a la identificación de características y procesos presentes en el cultivo de maíz, y relacionados con la eficiencia en el uso de recursos y la tolerancia al estrés.

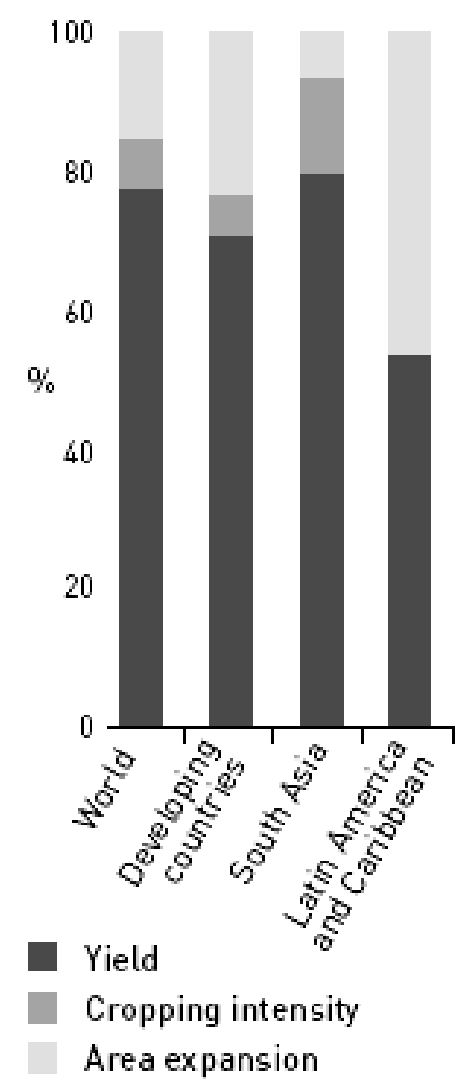

Fig. 1: Fuentes de incremento en la producción agrícola entre 1961 y 1999 expresadas como \% del incremento total en el mundo y por regiones (países en desarrollo, Asia del Sur, Latinoamérica y el Caribe). Se diferencian tres categorías: mejoramiento genético ("yield"), aumento de cultivos por año ("cropping intensity") y expansión de la superficie cultivada (adaptado de FAO, 2002).

\section{El mejoramiento en maíz y su relación con la tolerancia al estrés}

\subsection{Cambios asociados al proceso de mejoramiento en maíz}


A partir de comienzos del Siglo XX, la mejora genética en el cultivo de maíz junto con importantes cambios en las prácticas de manejo han generado grandes incrementos del rendimiento. Entre 1934 y 1991 se han registrado aumentos a tasas de $74 \mathrm{~kg} \mathrm{ha}^{-1}$ año-1 (Duvick, 1997). Se ha estimado que estas ganancias en rendimiento se deben en un $50 \%$ a cambios en el manejo y en un $50 \%$ al mejoramiento genético (Duvick, 2005), estando ambos aspectos fuertemente influenciados entre sí.

Entre los cambios en las prácticas de manejo del cultivo, el aumento en la densidad de plantas es uno de los que más se destaca. Para el período 1960-2000 los incrementos de rendimiento han sido de $110 \mathrm{~kg} \mathrm{ha}^{-1}$ año ${ }^{-1}$ y han estado acompañados de aumentos en la densidad a una tasa de 1000 plantas ha $^{-1}$ año $^{-1}$ (Duvick, 2005). Los aumentos en rendimiento también se vinculan directamente con el aumento en el uso de insumos, especialmente fertilizantes nitrogenados. El uso de fertilizantes nitrogenados ha aumentado en forma exponencial: desde 1,3 millones de toneladas métricas (MMt) en 1930, pasando por 10,2 MMt en 1960, hasta alcanzar las 90 MMt en 2004 (Good et al., 2004).

En relación al mejoramiento del cultivo, se pueden identificar tres aspectos que intervienen en la determinación del rendimiento: (i) el rendimiento potencial por planta, (ii) la tolerancia a diversos factores de estrés biótico y abiótico y (iii) la capacidad de respuesta a insumos (definidos como agua, luz, nutrientes) (Fasoula \& Fasoula, 2002). Muchos autores han demostrado que el rendimiento potencial por planta no ha variado a lo largo del mejoramiento genético (Duvick, 1997; Tokatlidis \& Koutroubas, 2004), aunque en el caso de la Argentina se ha reportado también un incremento del rendimiento individual para genotipos liberados entre 1965 y 1997 (Luque et al., 2006). En cambio, varios autores han demostrado que los nuevos híbridos presentan una mayor tolerancia a diversos factores de estrés. De hecho, la mayoría de las ventajas introducidas durante la mejora se manifiestan en condiciones de alta densidad, i.e., en condiciones de estrés por competencia (Duvick \& Cassman, 1999; Tollenaar \& Wu, 1999).

En el contexto de esta tesis, la "tolerancia al estrés" de un genotipo será definida como su desempeño en términos de rendimiento por individuo $\left(\mathrm{kg} \mathrm{pl}^{-1}\right)$ en un ambiente de menor rendimiento $\left(\mathrm{kg} \mathrm{pl}^{-1}\right)$ en comparación con un ambiente de referencia. De esta forma, la tolerancia al estrés involucrará no sólo el desempeño de 
los genotipos en ambientes de bajos rendimientos de cultivo, sino también en ambientes de alto rendimiento del cultivo pero menor rendimiento por planta (por ej., en alta densidad). Esta definición de "tolerancia al estrés" no tiene en cuenta la estabilidad del rendimiento que podría ser muy alta como consecuencia de un bajo rendimiento potencial (un atributo no deseable en condiciones agronómicas).

Por su parte, la mayor capacidad de respuesta a insumos está estrechamente vinculada a la tolerancia al estrés. En condiciones ambientales sub-óptimas, la capacidad de respuesta a insumos (v.g., fertilizante) ha aumentado, por cuanto los nuevos híbridos, al ser capaces de mitigar otros tipos de estreses que afectarían más severamente a los híbridos antiguos, pueden mejorar el uso de insumos (Duvick \& Cassman, 1999). No obstante, en condiciones óptimas para el cultivo (sembrado a su densidad óptima y sin limitaciones hídricas y nutricionales) el rendimiento potencial del cultivo (en híbridos del norte de EEUU) no ha aumentado desde 1970 (Duvick \& Cassman, 1999).

\subsection{Cambios resultantes del proceso de mejoramiento}

A partir de principios del siglo XX la transición desde líneas de polinización abierta hacia híbridos simples no sólo permitió explotar los beneficios de la heterosis sino que también maximizó la uniformidad genética del stand. Tanto el estrés por competencia generado al aumentar la densidad de plantas (Fasoula \& Fasoula, 2002; Pagano \& Maddonni, 2007) como diversos tipos de estrés ambiental (Rossini et al., 2011), exacerban la variabilidad entre plantas. En este sentido, la introducción de los híbridos simples redujo sustancialmente la variabilidad genética del stand, por lo que la variabilidad observada es principalmente resultado de la variabilidad ambiental. La variabilidad ambiental suele ser lo suficientemente grande como para reducir la uniformidad del stand, disminuyendo la eficiencia en el uso de los recursos y por lo tanto impactando negativamente sobre el rendimiento (Pagano \& Madonni, 2007; Rossini et al., 2011).

Para el período posterior a la introducción de híbridos simples (a partir de 1960 en EEUU) el progresivo aumento de la tolerancia a alta densidad de plantas no puede ser atribuido a la mayor uniformidad genética del stand (Tollenaar \& Lee, 2002) ni tampoco a aumentos en la heterosis (Tollenaar et al., 2004). A lo largo de la mejora, se 
pueden identificar variables morfo-fisiológicas que han permanecido sin cambios (intencionalmente, o por tener un impacto neutro sobre el rendimiento) y otras que han sido modificadas de forma intencional (selección directa) o bien por estar correlacionadas a otras variables que tienen impactos positivos sobre el rendimiento (selección indirecta). Entre las variables que más han cambiado se destacan el porcentaje de proteína en grano (disminución), el porcentaje de almidón (aumento), el tamaño de la panoja (disminución), el ángulo de inserción de las hojas (tendencia a ser más erectas), el intervalo entre floración masculina y floración femenina (más estrecho) y la tasa de senescencia foliar durante el llenado (más lenta) (Duvick, 1997). En lo que refiere al ciclo, los nuevos híbridos muestran una mayor proporción del ciclo representada por el período post-antesis (Duvick, 2005) por lo que cobran importancia las variables fisiológicas que se manifiestan durante esta etapa.

\subsection{Variables asociadas al rendimiento en híbridos modernos de maíz}

En maíz, el incremento en rendimiento se relaciona directamente con aumentos en biomasa; la mayor biomasa de los híbridos modernos se manifiesta a partir de la mitad del llenado (Richards, 2000). Luque et al. (2006) compararon los efectos de la mejora en siete híbridos de maíz argentinos liberados entre 1965 y 1997; las ganancias en rendimiento se relacionaron con un mayor número de granos (NG) por área, y también con la estabilidad del peso de grano (PG); a su vez, esto se relacionó con una mayor acumulación de biomasa en post-floración y una mayor partición a espiga.

Según Richards (2000) los incrementos en rendimiento estarían relacionados con una mayor radiación interceptada, ya que la tasa de fotosíntesis por unidad de área foliar no ha cambiado durante el mejoramiento. Los nuevos híbridos presentan mejor distribución de la luz en el canopeo a través de una menor área foliar en las hojas del estrato superior, lo que aumenta la penetración de luz a los estratos basales, característica importante para afrontar aumentos en la densidad (Valentinuz \& Tollenaar, 2004). No obstante la mayor parte de la mejora en híbridos modernos estaría asociada a la demora de la senescencia foliar (Lee \& Tollenaar, 2007). La demora de la senescencia foliar implicará una prolongación de la actividad fotosintética en post-antesis y por lo tanto, mayor radiación interceptada en post- 
floración (Duvick, 1997; Valentinuz \& Tollenaar, 2004). Tanto la mejora en la distribución de la luz en el canopeo como la mayor duración del área foliar se traducen en una mayor disponibilidad de asimilados durante el llenado de los granos. La disponibilidad de asimilados durante el llenado es especialmente importante en maíz, dado que prácticamente todos los asimilados transferidos al grano son producidos durante el llenado. Esto significa que la removilización de asimilados no representa un aporte significativo de C a los granos (Cliquet et al., 1990; Below et al., 1981; Borrás et al., 2004).

Muchos trabajos demuestran que el NG es el componente que mejor se asocia con el rendimiento, y numerosas evidencias demuestran que el NG es gravemente afectado por eventos de estrés alrededor de floración (Andrade et al., 2000; Paponov et al., 2005). Una vez atravesado el período crítico de determinación del rendimiento para maíz (entre 10 días antes y 10 días después de floración), uno de los componentes numéricos del rendimiento (el NG) ya se encuentra definido por lo que el rendimiento final dependerá del componente restante (el PG). A diferencia de lo que ocurre en otras especies, en maíz, los asimilados producidos antes de floración no representan un aporte significativo para el crecimiento de los granos (Borrás et al., 2004; Kiniry et al., 1992), de lo que se deduce que los granos dependerán principalmente de los asimilados producidos en post-floración.

Borrás et al. (2004) analizaron los resultados de una serie de trabajos y encontraron cambios considerables en el PG de maíz cuando se reduce la disponibilidad de asimilados por grano durante el llenado (Fig. 2), aunque en condiciones no limitantes el PG parecería no responder a un aumento en la disponibilidad de asimilados. La reducción en la disponibilidad de asimilados por grano afecta negativamente el PG. Esta disminución en el PG ha sido atribuida a reducciones tanto en la tasa de llenado (Borras \& Otegui, 2001; Borrell, 2000b) como en la duración del llenado (Echarte et al., 2006). En parte, estas discrepancias podrían estar asociadas al tipo de tratamiento utilizado para modificar la relación fuente/destino. Si la disponibilidad de asimilados está proporcionalmente más afectada por el tratamiento que la demanda de la espiga, un menor PG sería el resultado de una menor duración del llenado. Por ejemplo, en Echarte et al. (2006), el tratamiento de reducción de fuente (defoliación) se implementa a los 27 DDF, cuando tanto el NG como el peso potencial del grano ya han 
sido definidos, y los efectos sobre el PG se manifiestan a través de una menor duración del llenado. En cambio, cuando el tratamiento de reducción de fuente afecta también la demanda potencial de la espiga, los efectos sobre el PG podrían ser el resultado de reducciones en la tasa de Ilenado. Por ejemplo, Borras \& Otegui (2001), manipulan la relación fuente/destino a través de aumentos en la densidad poblacional, y comparan los efectos del tratamiento sobre el PG dentro de una misma categoría de NG, asumiendo que la capacidad de los destinos está determinada solamente por el NG. Sin embargo, es posible que un aumento en la densidad poblacional afecte no sólo el NG sino también (por ejemplo), la disponibilidad de $\mathrm{N}$ por grano y el peso de grano potencial. Por lo tanto, comparaciones dentro de una categoría de NG no necesariamente implicarán similar demanda de la espiga; si el tratamiento de reducción de fuente reduce además la capacidad de demanda de la espiga, la tasa de llenado podría afectarse más que la duración, y explicar el menor PG.

Ya sean la tasa o la duración del llenado el factor involucrado en la reducción del PG, estas evidencias otorgan relevancia al estudio de variables que permitan mantener la disponibilidad de asimilados durante el llenado en ambientes con estrés. Dado que los diversos tipos de estrés anticipan y/o aceleran el proceso normal de senescencia foliar, genotipos que presenten demoras relativas de la senescencia foliar en condiciones de estrés, podrían mejorar la producción de asimilados durante el llenado, y por lo tanto, el rendimiento. 


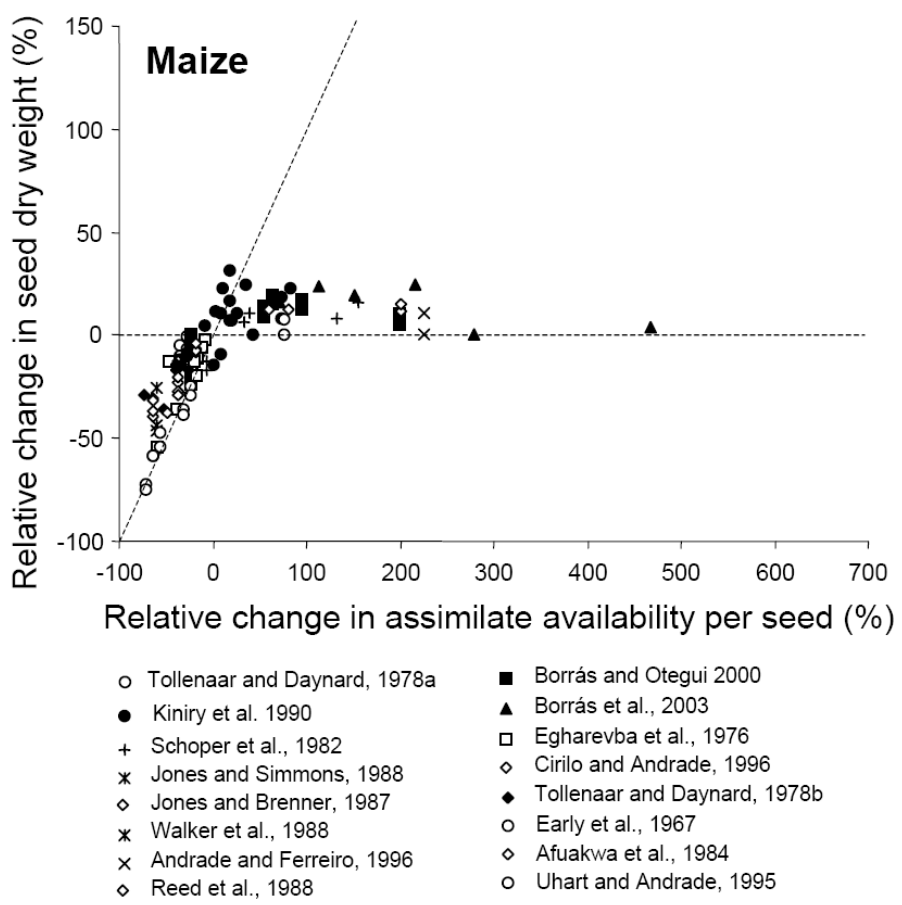

Fig. 2. Relación entre los cambios relativos en el PG de maíz y el cambio relativo de la disponibilidad de asimilados por grano durante el llenado. Las líneas punteadas señalan la pendiente 1 (completa limitación por fuente) y 0 (completa limitación por destinos). Tomado de referencias bibliográficas presentadas por Borrás et al. (2004).

\section{Senescencia foliar y rendimiento en maíz}

\subsection{Definición de senescencia foliar y variabilidad genotípica}

Senescencia es un término general que se aplica a procesos que ocurren en distintos niveles de organización, incluyendo células, tejidos, órganos y organismos (senescencia monocárpica). Se trata de un proceso de degeneración programado genéticamente y que puede ser alterado por diversos factores ambientales (Noodén et al., 1997). A nivel celular, la senescencia es regulada por el núcleo, como se evidencia en el aumento del número de transcriptos de genes asociados a la senescencia durante el transcurso de este proceso (Noodén et al., 1997), y generalmente conduce a la muerte celular. En las hojas, la senescencia se evidencia como el desmantelamiento de cloroplastos, con la consiguiente degradación de clorofila y proteínas, y la removilización del $\mathrm{N}$ liberado hacia otros órganos (por ejemplo, los granos en crecimiento). Desde la perspectiva de la producción de cultivos, la senescencia foliar adquiere importancia por su impacto en (i) la pérdida de actividad fotosintética y (ii) en la removilización de nutrientes, especialmente $\mathrm{N}$, hacia estructuras reproductivas. 
Stay green (SG) es un término general usado para señalar una demora en el inicio de la senescencia de una línea o híbrido en comparación con un genotipo estándar de referencia (Thomas \& Howarth, 2000; Lee \& Tollenaar, 2007). Se distinguen dos categorías para el término SG: funcionales, en los que la demora en la senescencia se corresponde con una prolongación de la actividad fotosintética de la hoja o del canopeo, y "cosméticos" en los que la demora en la senescencia se manifiesta a través de la retención de clorofila pero la fotosíntesis declina a un ritmo normal (Thomas \& Howarth, 2000). Dentro de las variantes funcionales, se incluyen (i) demoras en el momento de inicio de la senescencia, (ii) inicio de la senescencia normal pero a tasas más lentas, o (iii) combinaciones entre ambos tipos. Se han identificado genotipos SG cosméticos en soja (Guiamét et al., 1990), Festuca (Hauck, 1997) y maíz (Ceppi et al., 1987). Los genotipos SG funcionales se han reportado en muchos cultivos de producción extensiva: sorgo (Borrell \& Hammer, 2000), maíz (Ceppi et al., 1987), arroz (Jiang et al., 2004), soja (Pierce et al., 1984), girasol (de la Vega et al., 2011) y trigo (Spano et al., 2003). En Argentina se ha caracterizado el ritmo de declinación de la clorofila y la actividad fotosintética durante el llenado de granos en 8 híbridos simples de maíz y se han identificado híbridos con un carácter SG funcional (Acciaresi et al., 2005).

La expresión del carácter SG puede variar con los ambientes. Por ejemplo, en líneas de sorgo de Etiopía el carácter SG sólo se expresó en condiciones de estrés hídrico (van Oosterom et al., 1996). En cambio, Rajcan \&Tollenaar (1999) evaluaron dos híbridos contrastantes para la senescencia (liberados en 1959 y 1988) en dos niveles de $\mathrm{N}$ y encontraron que las diferencias en la senescencia se mantuvieron en ambas condiciones de disponibilidad de $\mathrm{N}$.

Es escasa la información relacionada con la identidad genética del carácter SG. Se ha sugerido un tipo de herencia dominante para la demora en la senescencia cuando se impide la polinización de la espiga de maíz (Ceppi et al., 1987). Sin embargo, la acumulación de azúcares solubles en hoja que ocurre cuando la senescencia es inducida por ausencia de destinos (Rajcan et al., 1999) puede conducir a fenómenos de senescencia diferentes de los que se observarían en condiciones normales durante el período reproductivo. En arroz se identificaron 46 QTLs asociados al fenotipo SG pero los efectos epistáticos y las interacciones genotipo $\mathrm{x}$ ambiente explicaron más 
variabilidad que cualquiera de los QTLs encontrados (Jiang et al., 2004). He et al. (2005b) encontraron que el contenido de citocininas foliares fue mayor y el contenido de $A B A$ en tallo fue menor (en referencia a la raíz) en un genotipo SG de maíz respecto a otro no stay green (NSG). Además, estos autores encontraron diferencias entre el genotipo SG y el NSG en la expresión de ARNm para proteasas cisteínicas asociadas a la senescencia, por lo que especulan que el control de la senescencia ocurriría a nivel transcripcional (He et al., 2005b). El papel de las hormonas en la demora de la senescencia también ha sido demostrado mediante transgénesis. El carácter SG funcional se ha manifestado en variantes transgénicas de tabaco en las que la producción de citocininas es inducida durante la senescencia (Gan \& Amasino, 1995); las diferencias fenotípicas entre la variedad transgénica y el genotipo salvaje se manifestaron sólo durante la senescencia, y la prolongación de la fotosíntesis en las plantas transgénicos resultó en un aumento del $50 \%$ del peso de las plantas y semillas. No obstante, en otras especies este carácter no estuvo asociado con ventajas en el rendimiento. Jiang et al. (2004) evaluaron 190 líneas doble haploides de arroz (obtenidas de la cruza de un genotipo estándar con uno SG) e identificaron seis QTL asociados al fenotipo SG, pero la correlación entre éstos y el rendimiento a campo fue negativa.

4.2. Carácter SG en maíz y sorgo, y tolerancia del rendimiento al estrés abiótico

En condiciones de estrés durante el llenado de granos, el carácter SG ha sido asociado a mejores rendimientos en maíz y sorgo, que son explicados principalmente a través de un aumento del PG (Bänziger et al., 1999; Borrell \& Hammer, 2000; Borrell et al., 2000b; Tollenaar \& Wu, 1999). No obstante, en algunas situaciones donde el estrés reduzca la duración del llenado (por ej., a través de efectos sobre el tamaño potencial de los destinos), el carácter SG podría tener un impacto menor (o ningún impacto) sobre el PG.

Se ha sugerido que los genotipos SG presentan "tolerancia cruzada" a distintos tipos de estrés (Bänziger et al., 1999; Monneveux et al., 2006). Por ejemplo, líneas de maíz obtenidas a partir de varios ciclos de selección para resistencia a sequía, presentaron también tolerancia a bajos niveles de N (Bänziger et al., 2002). Los 
resultados de la selección se manifestaban desde antesis (menor intervalo entre antesis y aparición de estigmas, y mayor NG) y a partir de las 3 semanas después de antesis a (mayor PG); las poblaciones mejoradas presentaban una demora en la senescencia foliar (Bänziger et al., 2002).

Diversos factores fisiológicos pueden resultar en demoras relativas de la senescencia foliar. En general, el proceso de senescencia está vinculado al balance de carbono (C) y nitrógeno (N) en la planta (Borrell \& Hammer, 2000; Christensen et al., 1981). Durante el llenado, un insuficiente suministro de fotoasimilados y $\mathrm{N}$ a los granos puede aumentar la demanda sobre las hojas, promoviendo la senescencia (Borrás et al., 2003; Borrell \& Hammer, 2000). El carácter SG ha sido relacionado a una alta relación fuente/destino durante el llenado (Rajcan \& Tollenaar, 1999a), y a una mayor disponibilidad de $\mathrm{N}$ en la planta (Rajcan \& Tollenaar, 1999b). Ambos aspectos están sumamente relacionados con la senescencia foliar, ya que una alta relación fuente/destino permitirá abastecer la demanda de $\mathrm{C}$ de los granos manteniendo el suministro de fotoasimilados a la raíz; a su vez, la prolongación de la actividad radical mejorará el abastecimiento de $\mathrm{N}$ a los granos, atenuando la demanda sobre las hojas, y por lo tanto prolongando la duración del área foliar (Rajcan \& Tollenaar, 1999b).

\section{Senescencia foliar y balance de $\mathrm{C}$}

\subsection{Senescencia foliar y relaciones fuente/destino (F/D)}

Algunas evidencias muestran que la senescencia puede acelerarse tanto por una baja relación F/D como por relaciones F/D extremadamente altas, como las que ocurren cuando se impide la fecundación de la espiga (Christensen et al., 1981). Rajcan et al. (1999) compararon la evolución de la senescencia en dos híbridos (uno antiguo de 1959 y otro "moderno" de 1988) bajo tratamientos que modificaban la relación F/D y registraron una aceleración de la senescencia tanto en el tratamiento en que había sido impedida la fecundación de la espiga (alta F/D) como en el tratamiento de desfoliación parcial (baja F/D). El híbrido SG mantuvo mayor contenido de azúcares solubles en todo el rango de relaciones F/D testeadas y demoró la senescencia respecto al híbrido estándar en todos los tratamientos, excepto en el tratamiento de alta relación $F / D$, posiblemente como consecuencia de una alta concentración de 
azúcares en hoja del híbrido SG. Esto sugiere la existencia de una rango de concentración de azúcares en hoja, por encima y por debajo del cual se induce el proceso de senescencia.

Si la demora en la senescencia observada en híbridos SG es la resultante de una mayor relación F/D en términos de C, sería esperable que la mayor F/D se manifieste incluso antes que se revelen las diferencias en el ritmo de senescencia. Una mayor relación F/D podría estar dada por (i) incrementos en el tamaño o eficiencia de la fuente para producir asimilados; (ii) reducciones en la demanda de C por parte de los destinos (menor fijación potencial de granos o menores tasas de llenado).

\subsection{Evidencias de mayor fuente relativa en genotipos SG}

La producción de biomasa es la resultante de la combinación entre intercepción de radiación y eficiencia en el uso de la radiación interceptada. La capacidad de intercepción de luz se relaciona positivamente con el índice de área foliar y la distribución de la luz en el canopeo. Rajcan et al. (1999) reportaron un mayor índice de área foliar en antesis en un híbrido SG moderno (1988) en comparación con otro antiguo (1959) de senescencia estándar: en forma similar, Valentinuz \& Tollenaar (2004) reportan mayor IAF en dos híbridos SG modernos (1980-1990) respecto de otro antiguo y estándar (1950). Es escasa la información disponible respecto a diferencias en la distribución de la luz en el canopeo entre híbridos modernos, aunque sí se ha reportado que la intercepción de luz ha mejorado en comparación con híbridos antiguos (Valentinuz \& Tollenaar, 2004). La eficiencia para interceptar la radiación fotosintéticamente activa está vinculada al contenido de clorofila foliar (Hirel et al., 2007), que probablemente refleja la inversión de $\mathrm{N}$ en el aparato fotosintético de las hojas. Varios trabajos encuentran mayor contenido de clorofila foliar en genotipos SG a lo largo de todo el ciclo a partir de floración (Martin et al., 2005; Rajcan et al., 1999), sugiriendo mayor eficiencia en la intercepción de luz en los genotipos SG.

Con respecto a la eficiencia para convertir la radiación interceptada en biomasa, no existen evidencias claras. En relación a la tasa de fotosíntesis máxima, Ding et al. (2005) compararon una serie de híbridos liberados en distintas épocas y contrastantes para la senescencia y hallaron una mayor tasa fotosintética a saturación lumínica en antesis, mayor actividad de PEPcasa y mayor contenido de proteínas 
solubles en los híbridos antiguos (1950) en antesis. No obstante, esta ventaja desaparecía a partir de la primera semana post floración, producto de la mayor tasa de senescencia en los híbridos antiguos no SG, de manera que a partir de las dos semanas post-antesis el contenido de proteínas foliares y la tasa fotosintética a saturación eran mayores en los híbridos modernos, SG.

\section{Senescencia foliar $\mathbf{y}$ balance de $\mathbf{N}$}

\subsection{Senescencia foliar y balance de $N$}

Borrell et al. (2000b) concluyeron que la expresión del carácter SG es una consecuencia del balance entre la demanda de $\mathrm{N}$ por los granos y el suministro adecuado de $\mathrm{N}$ durante el llenado. Una raíz activa durante el llenado de granos permitiría abastecer una parte importante de la demanda de $\mathrm{N}$ de los granos mediante la absorción de $\mathrm{N}$ en postantesis, retardando el momento en que se inicia la removilización del $\mathrm{N}$ foliar y, entonces, la senescencia (Rajcan \& Tollenaar, 1999b). De esta manera, los genotipos SG de maíz tendrían una mayor eficiencia de uso del $\mathrm{N}$ foliar ya que serían capaces de retener $\mathrm{N}$ foliar para mantener la producción de fotoasimilados y luego redistribuirlo a los órganos de cosecha (Bänziger et al., 1999; Bänziger et al., 2002).

Durante el desarrollo vegetativo, la deficiencia de $\mathrm{N}$ afectará negativamente la expansión del área foliar y, en mayor medida el contenido de $\mathrm{N}$ en hojas (Hirel et al., 2007), reduciendo en consecuencia la eficiencia de uso de la radiación. La intercepción de luz durante el período crítico alrededor de floración se relaciona positivamente con la fijación de granos (Andrade et al., 2000). Así, las deficiencias en N afectan el rendimiento, principalmente a través de la reducción del NG (Gallais \& Coque, 2005).

A partir de floración, el $\mathrm{N}$ adquiere además una importante función en el desarrollo y crecimiento de los granos, determinando el peso potencial del grano. El $\mathrm{N}$ es necesario para los procesos enzimáticos esenciales relacionados con la utilización del C, afecta la determinación del número de células en el endosperma y es un constituyente principal de las proteínas de reserva (Cazetta et al., 1999). En condiciones de deficiencias de N, la mayor parte del $\mathrm{N}$ habrá sido absorbido en prefloración. Por lo tanto, existirá una suerte de equilibrio donde la removilización del $\mathrm{N}$ 
presente en órganos vegetativos deberá satisfacer las demandas de $\mathrm{N}$ en los granos, en detrimento de la asimilación de $\mathrm{C}$ en las hojas.

La tolerancia del rendimiento a deficiencias de $\mathrm{N}$ edáfico se relaciona con la EUN (rendimiento en grano por unidad de $\mathrm{N}$ disponible en el suelo), y puede descomponerse en: (i) la eficiencia de absorción del $\mathrm{N}$ disponible en el suelo (EAbsN), i.e., $\mathrm{N}$ absorbido por unidad de $\mathrm{N}$ disponible en el suelo, y (ii) la eficiencia en la utilización del $\mathrm{N}$ absorbido (EUtN), i.e., rendimiento en granos por cada unidad de $\mathrm{N}$ en la planta (Hirel et al., 2007; Hirel et al., 2005). Mientras que la EAbsN sería más importante en contextos de alta disponibilidad de $\mathrm{N}$, la EUtN sería determinante en contextos deficitarios en N (Gallais \& Hirel, 2004; Gallais \& Coque, 2005; Ma \& Dwyer, 1998). No obstante, existen trabajos donde la EAbs y no la EUtN, es responsable de la mejor EUN en condiciones de baja disponibilidad de N (Presterl et al., 2002).

\subsection{Carácter SG y EAbsN}

En varios trabajos los mayores rendimientos obtenidos en los genotipos SG en condiciones de baja fertilidad no se relacionaron con una mayor EUtN, sino con una mayor EAbsN (Bänziger et al., 1999; Borrell \& Hammer, 2000). La mayor EAbsN de los genotipos SG sería más conspicua en post-floración (Ma \& Dwyer, 1998) dado que es en este período cuando la prolongación del área foliar puede representar ventajas en términos de la actividad de la raíz. Esto es esperable en ambientes donde la disponibilidad de $\mathrm{N}$ edáfico perdura en post-floración. Sin embargo, en ambientes donde la mayor parte del $\mathrm{N}$ edáfico disponible fue absorbido antes de floración, la prolongación de la fotosíntesis a través del carácter SG no tendrá ningún efecto sobre la EAbsN.

\subsection{Carácter SG y EUtN}

Durante el desarrollo vegetativo, una mayor EUtN estará dada por (i) una mayor partición de $\mathrm{N}$ a las hojas (con respecto a tallo), (ii) optimización de la distribución del $\mathrm{N}$ foliar en función de la irradiancia incidente, (iii) mayor tasa fotosintética por unidad de N en la hoja. Borrell \& Hammer (2000) reportaron que los híbridos SG de sorgo particionan mayor cantidad de $\mathrm{N}$ a las hojas en antesis. Por otro lado, He et al. (2003) compararon un híbrido SG con otro senescente; la tasa 
fotosintética por unidad de $\mathrm{N}$ en la hoja fue menor en el híbrido SG pero dado que éste tenía mayor concentración de $\mathrm{N}$ foliar, la fotosíntesis por unidad de área foliar se mantuvo más alta que en el estándar.

Si las deficiencias de $\mathrm{N}$ son severas, o en casos de sequía prolongada que reduzca la absorción de $\mathrm{N}$, a partir de floración los requerimientos de $\mathrm{N}$ de los granos deberán ser satisfechos mediante la removilización del $\mathrm{N}$ en estructuras vegetativas. En este contexto, la EUtN estará relacionada al equilibrio entre (i) sostener la producción de asimilados en detrimento del aporte de $\mathrm{N}$ a los granos, y (ii) promover la senescencia y la removilización de $\mathrm{N}$ en detrimento de la asimilación de $\mathrm{C}$. Una mayor tolerancia de las hojas a bajas concentraciones de $\mathrm{N}$ permitiría removilizar parte del $\mathrm{N}$ foliar sin que por ello se promueva la senescencia (Borrell \& Hammer, 2000).

La concentración crítica de $\mathrm{N}(\% \mathrm{Nc})$ en un órgano y momento del ciclo se define como aquella concentración de $\mathrm{N}$ por encima de la cual se alcanza la mayor acumulación de MS para ese contexto (Plénet \& Lemaire, 2000). La máxima EUtN se lograría cuando, en condiciones de suficiente $\mathrm{N}$ en los granos (i.e. superado el \% Nc en granos alrededor de floración) la removilización de $\mathrm{N}$ desde las hojas se demore para prolongar la fijación de $\mathrm{C}$ en post-floración, mientras que en condiciones de insuficiente $\mathrm{N}$ en granos (por debajo del \% Nc) la removilización desde los órganos vegetativos (acelerando la senescencia foliar) cubra las necesidades de $\mathrm{N}$ del embrión.

Varios trabajos relacionan el carácter SG con una mayor retención de $\mathrm{N}$ en órganos vegetativos a madurez (Borrell et al., 2000b; Ma \& Dwyer, 1998; Rajcan \& Tollenaar, 1999b) indicando menor removilización de N. Es por esto que la EUtN en genotipos SG podría ser menor (Pommel et al., 2006), especialmente en situaciones donde el aporte de $\mathrm{N}$ a los granos depende enteramente de $\mathrm{N}$ removilizado. Las evidencias muestran que no siempre el carácter SG está relacionado a una mayor EUN, o incluso que ambos caracteres pueden estar relacionados negativamente (Martin et al., 2005; Pommel et al., 2006).

En cuatro mutantes SG de trigo el PG fue mayor respecto al genotipo estándar pero, en dos de ellos el contenido de $\mathrm{N}$ por grano fue menor que el estándar, sugiriendo que el carácter SG podría afectar el suministro de $\mathrm{N}$ a los granos (Spano et al., 2003). También en trigo, Uauy et al. (2006) encontraron que en líneas donde está reducida la expresión de un factor de transcripción NAC se demora la senescencia 
foliar y se reducen un $30 \%$ los niveles de proteína, zinc y hierro en grano. Esto podría sugerir la existencia de variabilidad genotípica en la importancia relativa de fuente y destino sobre el control de la removilización de $\mathrm{N}$.

\section{Posibles implicancias del sistema radical en la demora de la} senescencia

Dado que la demora en la senescencia implica una mayor relación F/D en post antesis, los híbridos SG podrían abastecer la demanda de asimilados de los destinos sin merma en el suministro de asimilados hacia otros órganos heterotróficos como la raíz. No obstante, Farrar \& Jones (2000) proponen que el control del suministro de asimilados a la raíz no está determinado únicamente por la oferta de asimilados.

Existen algunas evidencias de un mayor suministro de asimilados a la raíz en genotipos SG. Rajcan \& Tollenaar (1999b) encontraron que la proporción del N en grano procedente de $\mathrm{N}$ absorbido en post-floración se relacionaba positivamente con la relación F/D, i.e. que existe una relación entre la prolongación de la actividad radical en postantesis y el índice F/D. En el mismo sentido, se ha reportado que los genotipos SG presentan mayor concentración de azúcares en la porción basal del tallo de sorgo (Duncan et al., 1981), y mayor materia seca en la porción basal del tallo y en las raíces de maíz (Ta \& Weiland, 1992). En sorgo, el contenido de citocininas en el exudado xilemático fue mayor en los híbridos SG respecto a híbridos de senescencia estándar (Ambler et al., 1992) sugiriendo una prolongación de la actividad radical en los genotipos SG.

Otros trabajos sustentan la idea de una mayor actividad de la raíz durante postantesis en los genotipos SG. Se ha reportado que los genotipos SG acumulan más $\mathrm{N}$ en postantesis (Borrell et al., 2000b; He et al., 2003; Ma \& Dwyer, 1998; Martin et al., 2005; Rajcan \& Tollenaar, 1999b). Sin embargo, otros estudios encontraron que la acumulación de $\mathrm{N}$ en postantesis no se relaciona con la demora en la senescencia (Subedi \& Ma, 2005).

Distintas estrategias pueden conducir a una mayor absorción de nutrientes y agua en la raíz en post-antesis. Entre ellas cabe mencionar: (i) un incremento en la biomasa de raíces en postantesis (determinada por la longevidad y/o crecimiento de 
raíces en esta etapa del ciclo); (ii) el patrón de arquitectura radical y su versatilidad en función de las características del suelo; (iii) una mayor actividad de raíz por unidad de biomasa (determinada principalmente por la longitud específica de raíces y la eficiencia de absorción por unidad de raíz). He et al. (2001) compararon la biomasa de raíces en dos híbridos y distintas dosis de $\mathrm{N}$, y reportaron que ésta fue mayor en el híbrido SG a $250 \mathrm{~kg}_{\text {de } \mathrm{N} \text { ha }}{ }^{-1}$ pero, sorprendentemente, fue menor que en el estándar en el tratamiento sin fertilizar (aún cuando en este tratamiento el híbrido SG rindió más). En una comparación entre un híbrido SG y otro estándar, He et al. (2003) reportaron una mayor tasa de absorción de $\mathrm{N}$ por unidad de raíz en el híbrido SG. En trigo se ha encontrado que un genotipo tolerante a sequía presentaba mayor crecimiento de raíces en postantesis en comparación con un genotipo de referencia (Manschadi et al., 2006). Aunque la biomasa y longitud total de raíces fueron similares en ambos genotipos, el genotipo tolerante a presentó más biomasa de raíces a mayor profundidad (Manschadi et al., 2006).

\section{Hipótesis y objetivos de trabajo}

Se ha sugerido que el carácter SG se asocia a una mayor tolerancia al estrés hídrico (Richards, 2006). Esto ha sido confirmado en condiciones agronómicas para híbridos de sorgo (Borrell et al., 2000b) y líneas de maíz (Chapman \& Edmeades, 1999; Bänziger et al., 1999). El carácter SG también ha sido asociado a mayor tolerancia frente a deficiencias nutricionales en sorgo (Borrell et al., 2000b), en líneas de maíz (Bänziger et al., 1999; Bänziger et al., 2002) y en híbridos de maíz de distinto año de liberación (Ma \& Dwyer, 1998; Rajcan \& Tollenaar, 1999a). Hasta el momento, son escasos los trabajos donde se comparan híbridos SG de similar año de liberación, es decir, donde el efecto del carácter SG pueda analizarse independientemente de otros cambios asociados al mejoramiento. Entre éstos, los reportes indican que las ventajas del carácter SG sobre el rendimiento se manifiestan también entre híbridos modernos (Mi et al., 2003; He et al., 2005). Tampoco existen estudios que involucren híbridos de maíz variando la fuente de estrés, es decir, donde se analice la relación entre el carácter SG y la tolerancia cruzada al estrés. El aporte original de esta tesis, pretende 
ser entonces, abordar el estudio del carácter SG en híbridos modernos de maíz, en condiciones agronómicas y variando la fuente y los niveles de estrés ambiental.

En la Fig. 3, se esquematiza el problema general, y su vinculación con los contenidos desarrollados en esta tesis. La inseguridad alimentaria se asocia ineludiblemente a procesos de empobrecimiento. Las perspectivas futuras indican que algunos factores tenderán a impactar negativamente sobre la distribución (biocombustibles) mientras que otros afectarán ambos, producción y distribución (cambio climático, degradación ambiental, escasez de insumos). En este contexto, la demanda de alimentos podrá ser satisfecha (dependiendo de variables del mercado) mediante un incremento de la producción en las regiones tradicionalmente exportadoras (por ejemplo, Argentina), o bien, mediante un incremento de la producción en zonas de baja productividad expuestas a inseguridad alimentaria. Cualquiera de las dos alternativas implicará reducir la brecha entre los rendimientos reales y potenciales, y/o adaptar la producción a zonas marginales (por aumento de la superficie cultivada), y en general para ambas, mejorar la eficiencia en el uso de insumos. Es decir, mejorar la tolerancia de los cultivos al estrés ambiental.

Es a partir de este marco conceptual donde cobra sentido analizar la variabilidad genotípica para la tolerancia al estrés en genotipos actualmente cultivados de maíz. Esta variabilidad puede ser la resultante de diversas características morfofisiológicas; entre ellas, esta tesis se concentrará en el estudio de la senescencia foliar. El impacto de la senescencia foliar sobre el rendimiento en condiciones de estrés abiótico será considerado de forma integrada en el Capítulo 6. Para poder analizar este aspecto, se realizaron ensayos a campo donde el estrés abiótico estuvo representado por un factor principal (agua, Capítulo 2 y nitrógeno, Capítulo 3) o por factores múltiples (densidad poblacional, Capítulo 4). En el Capítulo 5 se analiza la relación entre el carácter SG y el balance de $\mathrm{N}$ foliar durante la senescencia, aspecto que se relaciona transversalmente con los capítulos anteriores. 


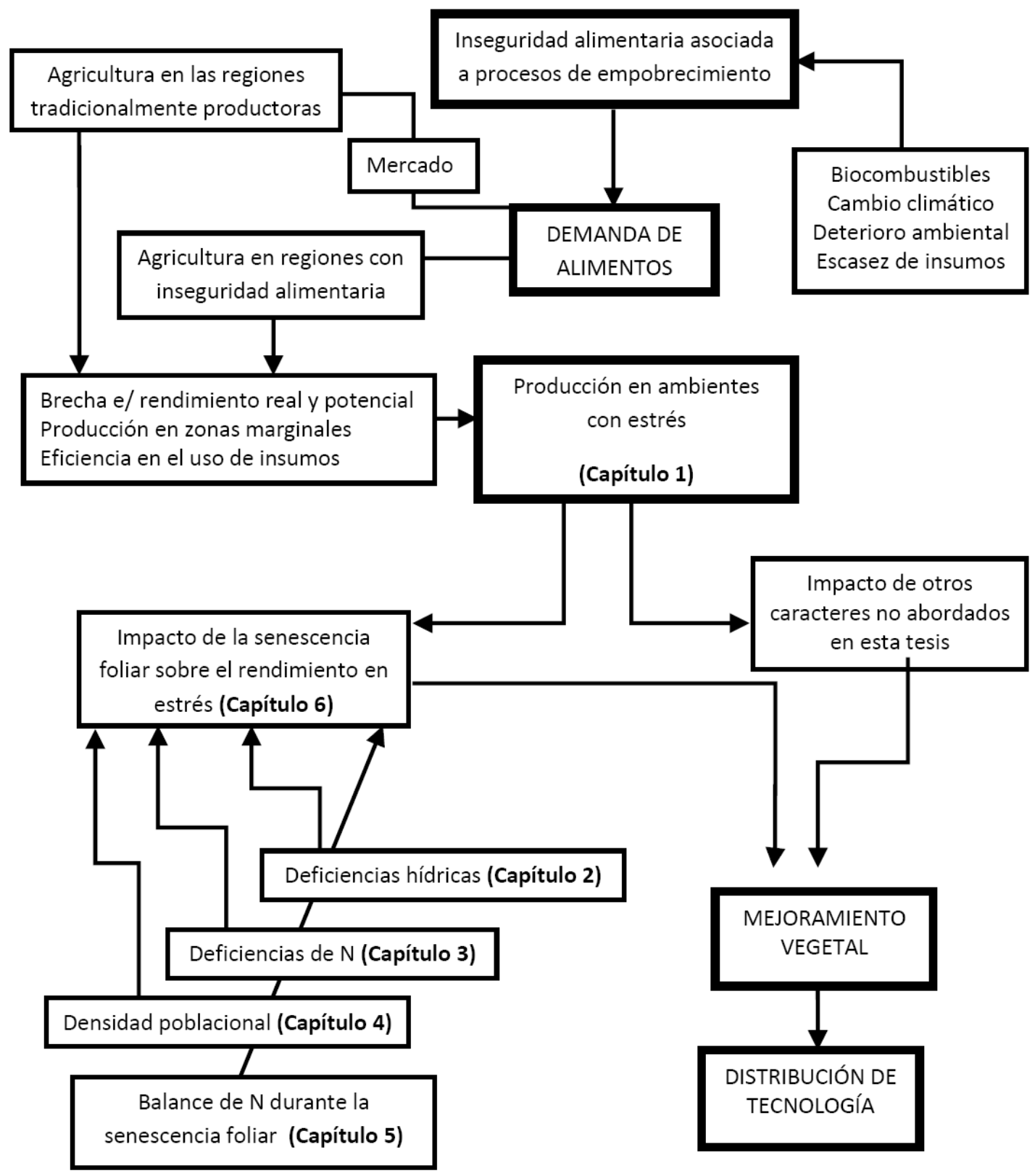

Fig. 3: Esquema que ilustra la vinculación entre el problema original, el objeto de estudio y los distintos objetivos a través de los cuales será estudiado. 


\section{Hipótesis general}

El mantenimiento de la producción de fotoasimilados en genotipos SG de maíz resultará en una mayor tolerancia del rendimiento frente a algunas situaciones de estrés abiótico.

\section{Hipótesis específicas}

(1) En condiciones de sequía en post-floración, la demora en la senescencia foliar está asociada a mayor producción de fotoasimilados y mayor rendimiento.

(1.1.) En condiciones de sequía en post-floración, los genotipos SG presentan mayor producción de fotoasimilados en post-floración.

(1.2.) En condiciones de sequía en post-floración, los genotipos SG presentan mayor rendimiento.

(2) En condiciones de deficiencias de nitrógeno, la demora en la senescencia foliar está asociada a mayor producción de fotoasimilados y mayor rendimiento.

(2.1.) En condiciones de deficiencias de nitrógeno, los genotipos SG presentan mayor producción de fotoasimilados en post-floración.

(2.2.) En condiciones de deficiencias de nitrógeno, los genotipos SG presentan mayor rendimiento.

(3) En condiciones de alta densidad poblacional, la demora en la senescencia foliar está asociada a mayor producción de fotoasimilados y mayor rendimiento.

(3.1.) En condiciones de alta densidad poblacional, los genotipos SG presentan mayor producción de fotoasimilados en post-floración.

(3.2.) En condiciones de alta densidad poblacional, los genotipos SG presentan mayor rendimiento.

(4) La demora en la senescencia está relacionada con una menor eficiencia de removilización del $\mathrm{N}$ foliar. 
(4.1.) El aumento de la fertilización con N, al demorar la senescencia foliar, reduce la eficiencia de removilización del $\mathrm{N}$ foliar.

(4.2.) Dentro del canopeo, la eficiencia de removilización del $\mathrm{N}$ foliar es menor en las hojas del estrato superior (cuya senescencia es más tardía).

(4.3.) Los genotipos SG presentan menor eficiencia de removilización del $\mathrm{N}$ foliar.

\section{Objetivo general}

Caracterizar la senescencia foliar en genotipos de maíz. Determinar la relación entre la demora en la senescencia foliar y la producción neta de fotoasimilados y el rendimiento frente a algunas situaciones de estrés ambiental.

\section{Objetivos específicos}

(1) Determinar la producción neta de fotoasimilados y el rendimiento en condiciones de sequía en post-floración, en genotipos variables para el carácter SG.

(2) Determinar la producción neta de fotoasimilados y el rendimiento en condiciones deficiencias de $\mathrm{N}$, en genotipos variables para el carácter SG.

(3) Determinar la producción neta de fotoasimilados y el rendimiento en distintas densidades poblacionales, en genotipos variables para el carácter SG.

(4) Analizar el metabolismo del $\mathrm{N}$ foliar durante el llenado en genotipos variables para el carácter SG.

Para contrastar las hipótesis planteadas se realizaron de ensayos a campo, utilizando híbridos simples comerciales de maíz. En todos los ensayos los híbridos fueron caracterizados según la duración del área foliar verde en post-floración como SG, moderadamente SG y no SG (NSG). Las principales variables medidas incluyeron: la evolución de la senescencia en términos de pérdida de área foliar verde y contenido de clorofila, desde floración y hasta madurez fisiológica; el patrón de acumulación de biomasa en términos de peso seco por compartimento (hojas, tallos y espigas) desde 
floración y hasta madurez fisiológica; el rendimiento y sus componentes a cosecha; y la acumulación de $\mathrm{N}$ por compartimento desde antesis y hasta madurez fisiológica.

Cada capítulo hace referencia a un objetivo específico (Capítulo 2, objetivo 1;

Capítulo 3, objetivo 2; Capítulo 4, objetivo 3; Capítulo 5, Objetivo 4). En cada capítulo se incluye una sección de Introducción, Materiales y Métodos, Resultados, Discusión, y Conclusiones. En el Capítulo 6 se contrastan las hipótesis planteadas, y se discuten los aportes originales al conocimiento científico y las perspectivas para futuras investigaciones. 


\section{CAPÍTULO 2}

\section{SENESCENCIA FOLIAR Y RENDIMIENTO EN HÍBRIDOS DE MAÍZ \\ BAJO SEQUÍA EN POST-FLORACIÓN}

\section{Introducción}

\subsection{Importancia del estrés hídrico en la producción agrícola}

Para el año 2025, más de la mitad de la población mundial estará habitando en regiones sometidas a déficit hídrico (Rijsberman, 2006). Es decir, regiones donde más del $40 \%$ del agua presente en ríos, lagos y acuíferos subterráneos, es retirada del ciclo ambiental. Esta situación podría empeorar bajo los efectos del cambio climático; precipitaciones más erráticas implicarán mayor duración de períodos con ausencia de lluvias (IPCC, 2007). Por otro lado, la progresiva degradación de los suelos no promete detenerse en el mediano plazo. La pérdida de materia orgánica de los suelos reduce la capacidad de retención hídrica y aumenta el escurrimiento por cementación, disminuyendo la productividad hídrica agrícola ( $\mathrm{kg}$ de materia seca por $\mathrm{mm}$ de agua) (Bossio et al., 2010). Así, aún en zonas donde las precipitaciones pueden compensar la evapotranspiración estacional, es esperable una pérdida de la productividad hídrica agrícola.

El uso de agua para riego ha reducido el agua disponible para uso doméstico y sanitario, generando graves problemas en muchas regiones. El nivel de muchos acuíferos se está retrayendo progresivamente, y muchos ríos ya no llegan al mar (Rijsberman, 2006). Además, al menos el $20 \%$ de las tierras irrigadas sufre de salinización secundaria o anegamiento (Bossio et al., 2010). De persistir el uso de riego en algunas regiones, será necesario adoptar genotipos y estrategias de manejo que conduzcan a un uso del agua más sustentable. Es decir, a una mayor eficiencia en el uso del agua (rendimiento en granos/mm de agua consumido por el cultivo durante el ciclo) (Kang et al., 2000).

En Argentina, los episodios de déficit hídrico son comunes en muchas regiones productoras de maíz y se manifiestan antes y durante el período de llenado. En la zona maicera núcleo (v.g., Pergamino) en una serie de 18 años, y para el período comprendido entre 15 días antes y 60 días después de floración en siembras de 
mediados de octubre, las precipitaciones compensaron la evapotranspiración potencial solamente en 3 años, mientras que en 14 años se registró un déficit promedio de 136 mm, y de más de $150 \mathrm{~mm}$ en 6 años (Antonietta M., con datos del Servicio Meteorológico Nacional).

\subsection{Los efectos fisiológicos del estrés hídrico. SG y tolerancia al estrés} hídrico

Episodios de sequía alrededor de floración reducen el número de granos y pueden causar caídas del rendimiento de más de un 80\% (Andrade \& Sadras, 2000). En maíz el PG presenta una baja respuesta al aumento de la disponibilidad de asimilados durante el llenado, pero una alta respuesta a su reducción (Borrás et al., 2004). Una vez atravesado el período crítico para maíz, la persistencia de la sequía o el inicio de un período de sequía, afectará negativamente el llenado de granos, y por lo tanto, el peso final de granos y el rendimiento.

Según Blum (2009), la principal estrategia para aumentar la producción de asimilados en condiciones de estrés hídrico es maximizar la extracción de agua y su evaporación por la vía estomática. Esto implica que la disponibilidad de asimilados esta directamente asociada a la transpiración, i.e., el consumo neto de agua del cultivo integrado en un período de tiempo. Además, la producción de asimilados estará influida por el patrón diario de consumo de agua por el cultivo. Genotipos con similar consumo de agua neto diario, pero diferencias en el patrón diario de consumo de agua pueden diferir en la producción de asimilados bajo sequía (Hirasawa \& Hsiao, 1999).

La conductancia estomática (Gs) es afectada por condiciones ambientales como la irradiancia y el déficit de presión de vapor (Tardieu \& Davies, 1992; Hirasawa \& Hsiao, 1999). Además, Gs dependerá del ambiente interno de la hoja (concentración interna de $\mathrm{CO}_{2}$, temperatura foliar, etc.) que en último término es producto de características morfo-fisiológicas intrínsecas del tejido (ángulo de inserción de la hoja, contenido de $\mathrm{N}$ y clorofila, capacidad fotosintética máxima, etc.). No obstante, en condiciones de sequía prolongada, es de esperar que Gs esté directamente asociada al status hídrico de la planta que a su vez es censado mediante el contenido de ABA en xilema (Tardieu et al., 1992). 
La sequía reduce la producción de asimilados a través de efectos negativos sobre (i) la eficiencia en el uso de la radiación interceptada, y (ii) la radiación interceptada por el cultivo. La eficiencia en el uso de la radiación interceptada se reduce debido a la inhibición de la actividad fotosintética, que puede ocurrir tanto por limitantes estomáticas (Lal \& Edwards, 1996) como enzimáticas (Ghannoum, 2009). Una estrecha relación entre Gs y la fotosíntesis neta sugeriría limitantes estomáticas mientras que un desacople en esta relación puede sugerir limitantes enzimáticas.

Por otra parte, el estrés hídrico en postantesis promueve la senescencia foliar, reduciendo la radiación interceptada por el cultivo (Ribaut et al., 2009). En situaciones de estrés hídrico prolongado, es esperable que plantas capaces de extender la duración del área foliar presenten mayor intercepción de radiación y mayor eficiencia en el uso de la radiación, y por lo tanto mayor producción de fotoasimilados durante el período de llenado de granos. En este Capítulo, se analizan los efectos de la sequía sobre la senescencia foliar en distintos genotipos y se estudia el impacto de la senescencia foliar sobre la producción de fotoasimilados en post-floración.

\subsection{Fundamento y planteo de la hipótesis}

Se ha sugerido que, en condiciones de estrés hídrico, los genotipos SG de sorgo y maíz presentan mayores rendimientos en comparación con genotipos de senescencia estándar (Borrell et al., 2000b; Messmer et al., 2011; Richards, 2006). En este Capítulo, las hipótesis que se intentan contrastar son las siguientes:

(1) En condiciones de sequía en post-floración, la demora en la senescencia foliar está asociada a mayor producción de fotoasimilados y mayor rendimiento.

(1.1.) En condiciones de sequía en post-floración, los genotipos SG presentan mayor producción de fotoasimilados en post-floración.

(1.2.) En condiciones de sequía en post-floración, los genotipos SG presentan mayor rendimiento.

El objetivo general fue determinar la tolerancia del rendimiento al déficit hídrico en post-floración en híbridos SG y NSG. Para ello, se realizaron experimentos en diferentes sitios, donde el tratamiento principal consistió en la disponibilidad 
hídrica en post-floración y el tratamiento secundario fue la variabilidad para el carácter SG que se logró empleando híbridos variables en la duración del AFV en postfloración.

\section{Materiales y Métodos}

\subsection{Diseño de los experimentos}

Se realizaron tres experimentos (Experimentos I, II y III) a fin de determinar si la duración del área foliar verde (AFV) en post-floración confiere una ventaja en términos de rendimiento en ambientes con estrés hídrico en el período de post-floración. Los tratamientos consistieron en (i) disponibilidad hídrica a partir de floración y (ii) híbridos variables en la duración del AFV.

En todos los experimentos las plantas crecieron con riego suplementario hasta ca. 7 días antes de floración femenina. A partir de ese momento, en los experimentos I y II la mitad de las parcelas fue regada hasta madurez fisiológica mientras que la mitad restante permaneció en secano hasta culminar el ciclo. En el Exp. III todas las parcelas fueron regadas hasta floración y a partir de entonces, mantenidas en secano hasta el final del ciclo. Se utilizaron híbridos simples comerciales con un ciclo similar (días a madurez relativa). Para los híbridos de los que se disponía de datos de ensayos previos del grupo con adecuada disponibilidad hídrica, el criterio de selección fue la duración funcional del área foliar verde (AFV) en post-floración: los híbridos AX878, AX882 y NK880, previamente caracterizados como SG y el híbrido DK682, previamente caracterizado como NSG. Dos híbridos más fueron incorporados: AW190 y NK795, para los cuales no se contaba con una caracterización previa sobre el comportamiento de la senescencia foliar. Los ensayos presentaron un diseño de parcelas divididas, donde la parcela principal fue el tratamiento hídrico y la sub-parcela los distintos híbridos distribuidos al azar. Se realizaron tres réplicas por tratamiento. Cuando fue necesario, se aplicaron herbicidas e insecticidas convencionales.

Experimento I: El ensayo se condujo en la localidad de San Pedro, Buenos Aires en un campo de producción. Los híbridos DK682, AX878, AX882 y NK880 fueron sembrados manualmente el 7 de Noviembre de 2007. La densidad final fue de $80000 \mathrm{pl}$ $\mathrm{ha}^{-1}$. Las parcelas consistieron de 4 surcos de $8 \mathrm{~m}$ de largo y distanciados a $0,7 \mathrm{~m}$. A la 
siembra el ensayo fue fertilizado con $64 \mathrm{~kg}$ de N ha- ${ }^{-1}$ (46 $\mathrm{kg}$ de N ha ${ }^{-1}$ en forma de urea + $18 \mathrm{~kg}$ de $\mathrm{N} \mathrm{ha}^{-1}$ en forma de fosfato diamónico, FDA) y $18 \mathrm{~kg}$ de $\mathrm{P}$ ha $^{-1}$ (en forma de FDA). La emergencia de estigmas ocurrió +/- 1 día alrededor del 24-1-08. El suelo se clasifica como argiudol típico, de textura fína, illítica (USDA). Se caracteriza por ser profundo, con alta fertilidad natural, muy alto contenido de materia orgánica y alta capacidad de acumulación de agua (Panigatti, 2010). Se aplicó riego por goteo, pero no fue posible estimar la cantidad de agua adicionada a lo largo del experimento.

Experimento II: El ensayo se condujo en la Estación Experimental de la Facultad de Agronomía de la UNLP, situada en Los Hornos, Buenos Aires. Seis híbridos contrastantes en el carácter SG fueron sembrados el 27 de Octubre de 2008: AW190, AX878, AX882, DK682, NK795 y NK880. La siembra se realizo en forma manual, a dos semillas por golpe. Las plántulas emergieron 7 días después de la siembra y fueron raleadas en V1 hasta obtener una densidad final de $80000 \mathrm{pl} \mathrm{ha}^{-1}$. Las parcelas consistieron de 4 surcos de $10 \mathrm{~m}$ de largo distanciados a 0,7m. Se fertilizó con $80 \mathrm{~kg}$ de $\mathrm{P} \mathrm{ha}^{-1}$ (en forma de superfosfato triple, SPT) en presiembra, y $92 \mathrm{~kg} \mathrm{de} \mathrm{N} \mathrm{ha}^{-1}$ (en forma de urea), repartidos en dos dosis, V3 y V6. La emergencia de estigmas ocurrió +/- 1 día alrededor del 10-1-09. El suelo en esta zona se clasifica como argiudol típico de textura fina (USDA) con presencia de arcillas expandibles; en términos de producción de cultivos presenta características similares al suelo descripto para San Pedro. En las parcelas regadas, se aplicó una cantidad de agua suficiente para cubrir aproximadamente al menos el $80 \%$ de la evapotranspiración potencial.

Experimento III: El ensayo se condujo la localidad de Nueva Galia, San Luis. Los mismos seis híbridos usados para el Exp. Il fueron sembrados mecánicamente el 12 de Diciembre de 2010 a una densidad de $80000 \mathrm{pl} \mathrm{ha}^{-1}$. Las parcelas fueron regadas hasta floración; luego, se mantuvieron en secano hasta el final del ciclo. Las parcelas consistieron de 4 surcos de 4,8 $\mathrm{m}$ de longitud y distanciados a 0,7 $\mathrm{m}$. Se realizaron 3 repeticiones por tratamiento. Se fertilizó con $23 \mathrm{~kg} \mathrm{~N} \mathrm{ha}^{-1}$ y $60 \mathrm{~kg} \mathrm{P} \mathrm{ha}^{-1}$ (aplicados en forma de FDA a la siembra). Las emergencia de estigmas ocurrió +/- 1 día alrededor del 18-2-11. El suelo se clasifica como Ustortent típico, de textura franco gruesa (USDA). Es un suelo con alto contenidos de arenas (>70\%), bajo contenido de materia orgánica (1\%), excesivamente drenado, con secuencia de horizontes A-AC-C, pobre estructura y 
susceptibilidad a erosión (Panigatti, 2010) pero sin limitaciones en profundidad (G. Videla, comunicación personal).

\subsection{Datos meteorológicos y Fenología}

En los tres experimentos se dispuso de información diaria para temperaturas medias, evapotranspiración (método de Penmann) y precipitaciones. El tiempo térmico se calculó como la diferencia entre la temperatura media diaria y una temperatura base de $8^{\circ} \mathrm{C}$ (Ritchie \& NeSmith, 1991). Dada la importancia que tiene la temperatura sobre el desarrollo del maíz, las distintas variables morfo-fisiológicas se presentan en escala de tiempo térmico acumulado a partir de $R_{1}$.

La fecha de emergencia se registró cuando el $50 \%$ de las plantas emergieron sobre la superficie del suelo. La fecha de floración femenina (R1) se determinó cuando el $50 \%$ de las plantas de una parcela presentó estigmas visibles. La fecha de madurez fisiológica (MF) se determinó cuando el $50 \%$ de las plantas observadas presentaron la formación de la capa negra en granos de posición media dentro de la espiga.

\subsection{Evolución de la senescencia foliar}

Para monitorear el desarrollo de la senescencia foliar se realizaron muestreos destructivos a partir de floración. Las plantas cosechadas fueron seleccionadas en una zona representativa de la parcela, sobre los dos surcos centrales. En cada muestreo destructivo se cosecharon dos plantas por repetición, por lo que en cada tratamiento (disponibilidad hídrica $x$ genotipo) el número total de plantas muestreadas $(n)$ fue de seis plantas por tratamiento.

En estas plantas, se midió el valor de SPAD con un medidor SPAD 502 (Minolta, EEUU) para cada hoja individual a lo largo de toda la planta (o sólo en la hoja adyacente a la espiga en el Exp. I). Para cada hoja el valor de SPAD se midió en al menos 5 puntos de la porción verde, representando la variabilidad dentro de la lámina y se registró el valor promedio. En los experimentos. II y III, donde se midió el contenido de clorofila en cada hoja, para calcular el valor de SPAD promedio por planta, las hojas secas $(S P A D=0)$ fueron incorporadas al cálculo del promedio. De este modo se evitó la sobre-estimación del valor promedio de SPAD en los genotipos NSG, en comparación con los genotipos SG donde se retienen hojas viejas, parcialmente 
senescentes y con menores valores de SPAD. Varios autores han reportado la validez del valor SPAD como estimador del contenido de clorofila foliar en maíz (Martin et al., 2005; Rajcan \& Tollenaar, 1999b; Sadras et al., 2000).

El AFV de cada hoja individual a lo largo de la planta fue registrada con un medidor de área Licor 3000 (Li-Cor, Nebraska, USA). En las hojas parcialmente senescidas, la porción seca de la hoja fue recortada y reservada para ser pesada, midiéndose sólo el área de la porción verde. En trabajos previos (Borrell et al., 2000a) se ha utilizado el AFV por planta hacia el final del llenado (ca. 45 DDF) como variable para cuantificar la expresión del carácter SG por lo que en el presente Capítulo esta variable será considera con el mismo propósito.

\subsection{Acumulación de materia seca}

La materia seca (MS) se determinó a partir de los muestreos destructivos realizados en cada experimento desde $R_{1}$ hasta MF. Las plantas fueron fraccionadas en (i) caña + vainas + panoja, (ii) láminas foliares ("hojas") y (iii) espiga y fueron secadas en estufa de aire forzado a $60^{\circ} \mathrm{C}$ hasta peso constante, y pesadas.

Los cálculos que involucran variables de MS en función del tiempo (asimilación neta, crecimiento de espiga, removilización) se realizaron en base a los promedios de 2 plantas por repetición (parcela). La removilización de MS se calculó como la diferencia de MS vegetativa (MS hojas + MS cañas + MS vainas) entre ca. 7 días después de $R_{1}$ Y MF; por lo tanto valores de removilización positivos suponen transferencia neta de MS vegetativa a la espiga. La asimilación neta durante el llenado se calculó como la diferencia entre MS total a madurez fisiológica y MS total alrededor de $R_{1}$. En los experimentos I y III, la cosecha final de plantas se realizó alrededor de los 46 DDF. Por lo tanto el cálculo de asimilación neta y removilización se realizó entre los 12 y 46 DDF en el Exp. I (MS total corresponde a 46 DDF); entre 6 DDF y MF en Exp. II (MS total corresponde a MF, 65 DDF); entre 20 y 46 DDF en Exp. III (MS total corresponde a 46 DDF). En el Exp. II, dado que se registraron precipitaciones a mediados del llenado, la asimilación neta también fue calculada sólo para el período de estrés (ca., entre 6 y 33 DDF). En todos los casos la cosecha de espigas correspondientes al rendimiento sí fue realizada en MF. 
Para el cálculo del rendimiento por hectárea se cosecharon las espigas de 20 plantas consecutivas de los surcos centrales de la parcela (60 plantas por tratamiento). Luego las espigas se trillaron a máquina y se tomó una alícuota que fue secada en estufa a $60^{\circ} \mathrm{C}$ hasta peso constante para calcular el rendimiento a $0 \%$ de humedad. El peso de grano individual (PG) se calculó a partir de la relación entre el número de granos y el peso de granos total de 6 plantas cosechadas por tratamiento. El número de granos (NG) final se calculó a partir del PG y el rendimiento final, obtenido de 60 plantas por tratamiento.

\subsection{Medidas de conductancia estomática y fluorescencia}

A partir de floración, en los tres experimentos se hicieron medidas de conductancia estomática ( $\mathrm{Gs}, \mathrm{mmol} \mathrm{H}_{2} \mathrm{O} \mathrm{m} \mathrm{m}^{-2} \mathrm{~s}^{-1}$. La Gs varía con las condiciones ambientales, principalmente en respuesta a los cambios en la irradiancia y en el déficit de presión de vapor entre la mañana (hasta las 11 am) y el período posterior (Hirasawa \& Hsiao, 1999; Tardieu \& Davies, 1992). Por este motivo, las mediciones se realizaron en distintos momentos del día: mañana (de 9 a 11 am), mediodía (12 a 14 pm) y tarde (15 a 17 pm). En cada experimento, el número de mediciones varió (tres mediciones en el Exp. I, una medición en el Exp. II y tres mediciones en el Exp. III). Se midieron 6 plantas por tratamiento ( 2 plantas de los surcos centrales en cada parcela). Las mediciones fueron hechas en la porción media iluminada de la hoja de la espiga (hoja $0)$, en una posición intermedia entre la nervadura principal y el borde de la lámina, sobre la cara abaxial con un porómetro SC-1 (Decagon, USA). Determinaciones previas indicaron que en las hojas de maíz la Gs es muy similar en ambas caras (abaxial y adaxial) de la hoja.

Sólo en el Exp. II, en el sitio exacto de medición de Gs pero sobre la cara adaxial, se midió el rendimiento cuántico del fotosistema II con un fluorímetro modulado de la clorofila (FMS2, Hansatech, UK). La actividad de transporte fotosintético de electrones (ETR) fue calculada a partir del rendimiento cuántico del fotosistema II utilizando las fórmulas descriptas en Maxwell y Johnson (2000):

$\Phi$ FSII x PAR x Abs x 0,5. 
Donde $\Phi$ FSII es el rendimiento cuántico del fotosistema II, PAR es la radiación fotosintéticamente activa medida por el sensor del fluorímetro, Abs es la absorbancia de la hoja y 0,5 un factor que toma en cuenta el hecho de que la radiación absorbida se reparte entre los fotosistemas I y II.

Para el cálculo de ETR se estimó la absorbancia de la hoja en función de su contenido de clorofila (medida con el SPAD502) utilizando la ecuación:

Absorbancia: $0,008 *$ Unidades de SPAD + 0,356

Esta ecuación fue obtenida midiendo la absorbancia de hojas con distintos contenidos de clorofila con una esfera integradora en el Instituto de Luminotecnica (La Plata, CICBA).

\subsection{Análisis estadístico}

Los datos se analizaron con el software STATISTICA 5.1. (StatSoft, Inc.). Las distintas variables se analizaron mediante ANOVA, donde los tratamientos (disponibilidad hídrica e híbrido, o sólo híbrido en el Exp. III) se usaron como factores fijos, mientras que cada variable dependiente se analizó por separado. Cuando se presentaron efectos significativos de los tratamientos, o interacción entre ellos, las diferencias se analizaron mediante el test de diferencias mínimas significativas (DMS, P $<0,05)$ y se señalan en los gráficos mediante letras. En los gráficos de barras, las líneas encima del las barras indican el error estándar de la media.

Con el fin de establecer si las diferencias observadas entre híbridos tienen o no relación con el carácter SG, para algunas variables en particular (explicitadas en la sección de Resultados) se realizó un análisis de covarianza. En este capítulo, el AFV hacia el final del llenado fue la variable elegida como "indicadora" del comportamiento SG y por lo tanto, fue la covariable utilizada en el análisis de covarianza. A través del análisis de covarianza se intentarán conocer no sólo los impactos directos del carácter SG sobre algunas variables (v.g., el PG) sino también la asociación indirecta que podría existir entre el carácter SG y otras variables (v.g., el NG) que se definen antes de que se manifieste el carácter SG. En definitiva, si el carácter SG fuera resultante de una variable particular (v.g., mayor absorción de recursos edáficos) que se expresa antes en el ciclo, es esperable que exista una relación indirecta entre el carácter SG y otros atributos influidos por esta variable. 
En el análisis de covarianza se mantuvieron las variables independientes (disponibilidad hídrica e híbrido, o sólo híbrido en el Exp. III). Cuando el efecto de la covariable sobre la variable dependiente fue significativo, se asume que no existen efectos genotípicos excepto aquellos relacionados con la covariable.

La relación entre variables se analizó mediante regresiones lineales y polinómicas. La significancia de estas relaciones se analizó con el test de suma de cuadrados de modelo completo vs. suma de cuadrados residuales considerándose significativas cuando $P<0,05$. En los gráficos de regresiones, se presenta el valor del coeficiente $r^{2}$, acompañado de ${ }^{*}$ cuando $P<0,05$. En los casos en que se comparan parámetros de distintas regresiones (ordenada al origen y pendiente), sólo se compararon regresiones significativas y la comparación se realizó por medio del análisis de variables apareadas ("dummy variable analysis").

\section{Resultados}

\subsection{Condiciones meteorológicas}

La intensidad del déficit hídrico (DH) puede caracterizarse en función del balance hídrico (BH) acumulado desde floración y hasta MF. En el Exp. I (Fig. 1A), el BH diario acumulado fue negativo durante todo el período de llenado de granos, y la intensidad del DH entre floración y 40 DDF fue en promedio, de $-1,9 \mathrm{~mm}$ diarios. También en el Exp. II (Fig. 1B) el BH diario acumulado presentó valores negativos durante todo el período de llenado de granos, y la intensidad del DH entre floración y 40 DDF fue, en promedio, $-3 \mathrm{~mm}$ diarios. En cambio, en el Exp. III (Fig. 1C) el BH diario acumulado fue negativo sólo en 10 días y positivo en 46 días, resultando en un BH positivo $(0,4 \mathrm{~mm}$ diarios entre floración y $40 \mathrm{DDF})$. Cabe señalar que en el Exp. III, la evapotranspiración potencial post-floración fue menor que en los experimentos I y II, debido a las menores temperaturas (esperables en siembra tardía). Sin embargo, dado que la capacidad de retención hídrica del suelo varió considerablemente entre los experimentos, la estimación del DH experimentado por el cultivo sobre la base solamente de datos meteorológicos podría conducir a errores. En este sentido, es posible que el $\mathrm{DH}$ ocurrido en el Exp. III sea mayor al estimado a partir de las variables meteorológicas. 

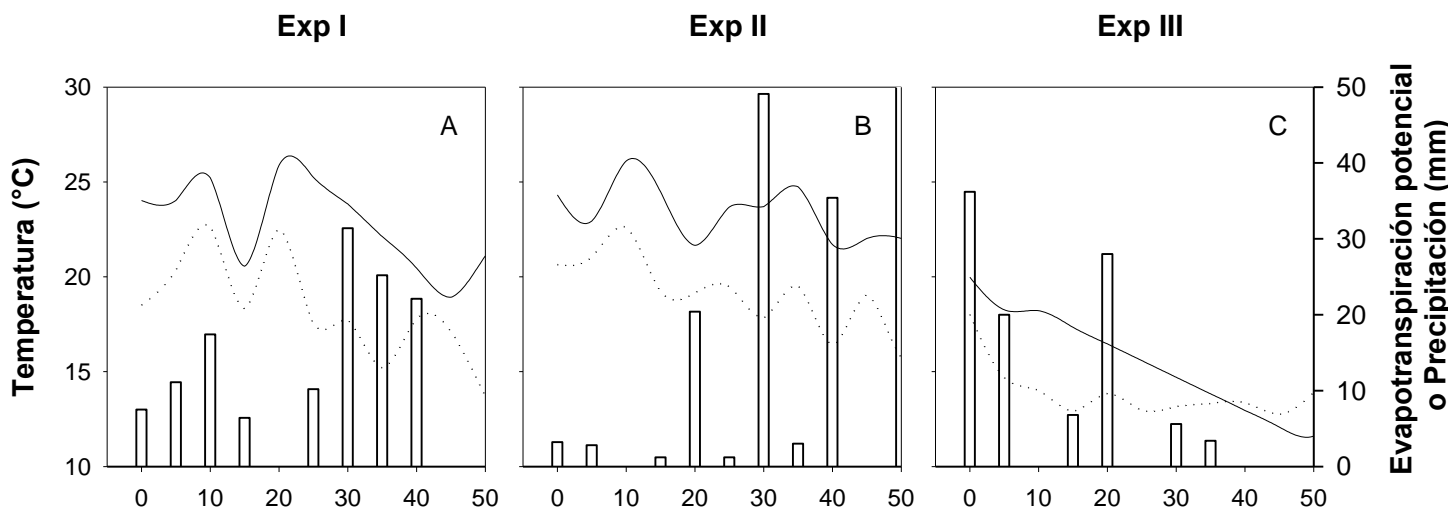

Días después de floración

Fig. 1: Condiciones meteorológicas desde floración en los experimentos I (A, San Pedro), II (B, Los Hornos) y III (C, San Luis). La temperatura media (líneas llenas) se presenta como el promedio cada 5 días, mientras que la evapotranspiración potencial (líneas punteadas) y las precipitaciones (barras) se presentan como la suma cada 5 días.

\section{2. Área foliar verde (AFV)}

El AFV alrededor de floración (previo al inicio del tratamiento hídrico) no estuvo significativamente afectada por el híbrido en el Exp. I pero sí en el Exp. II $(P<0,05)$. Como se observa en las Fig. 2C y 2D los híbridos DK682 y NK880 (y NK795 sólo en las parcelas bajo riego), presentaron menor AFV alrededor de floración. No obstante, estas diferencias no se mantuvieron durante el transcurso del llenado. En el Exp. III no se dispone de datos de AFV en floración; a los 21 DDF aún no se manifestaban diferencias entre híbridos para el AFV (Fig. 2E).

A partir de floración, la sequía en postantesis aceleró la senescencia respecto al tratamiento regado. Los efectos de la sequía sobre el AFV se manifestaron a los 27 y 46 DDF en el Exp. I (Fig. 2A y 2B) y a los 48 DDF en el Exp. II (Fig. 2C y 2D). La retención de AFV en estadios intermedios (27 DDF en Exp. I) o avanzados (48-47 DDF en experimentos II y III) del llenado varió significativamente dependiendo del híbrido. En general, los híbridos AX878, AX882 y NK880 presentaron una demora en la senescencia respecto de los híbridos AW190, NK795 y DK682.

Dado que el carácter SG adquiere relevancia en condiciones de sequía, se consideró el AFV retenida en sequía y en estadíos avanzados del llenado (45-48 DDF) para categorizar a los híbridos en función de su carácter SG. Considerando como 
variable dependiente el AFV retenida en secano en los experimentos II y III (donde están representados los seis híbridos) y como variable independiente, el híbrido, los híbridos se diferenciaron en dos grupos homogéneos (DMS < 0,05): SG (AX878, AX882 y NK880) y NSG (AW190, NK795 y DK682).

\subsection{Contenido de clorofila}

Como era esperable, la sequía en postantesis aceleró la pérdida de clorofila (Fig. 3). El ANOVA detectó efectos significativos de la sequía sobre el valor de SPAD de la hoja adyacente a la espiga (“hoja 0") en el Exp. I (a los 12 y 46 DDF) y sobre el valor SPAD promedio por planta en el Exp. II (a los 48 DDF).

Por otra parte, el contenido de clorofila varió significativamente entre híbridos en los tres experimentos acompañando las tendencias observadas para el AFV. El valor de SPAD en estadíos iniciales o intermedios del llenado varió significativamente entre híbridos (a los 12 DDF en Exp. I, 6 DDF en Exp. II y 21 DDF en Exp. III) pero no existió una tendencia diferencial entre el grupo SG y NSG. En estadíos avanzados del llenado y considerando los resultados de secano (Figs. 3B, 3D y 3E), los efectos del híbrido se mantuvieron y, en este caso sí, el grupo SG (AX878, AX882 y NK880) presentó mayores valores de SPAD que el grupo NSG (AW190, DK682 y NK795). En el Exp. I (Fig. 3B) las diferencias entre el híbrido NSG (DK682) y uno de los híbridos SG (NK880) no fueron significativas a los 46 DDF. 


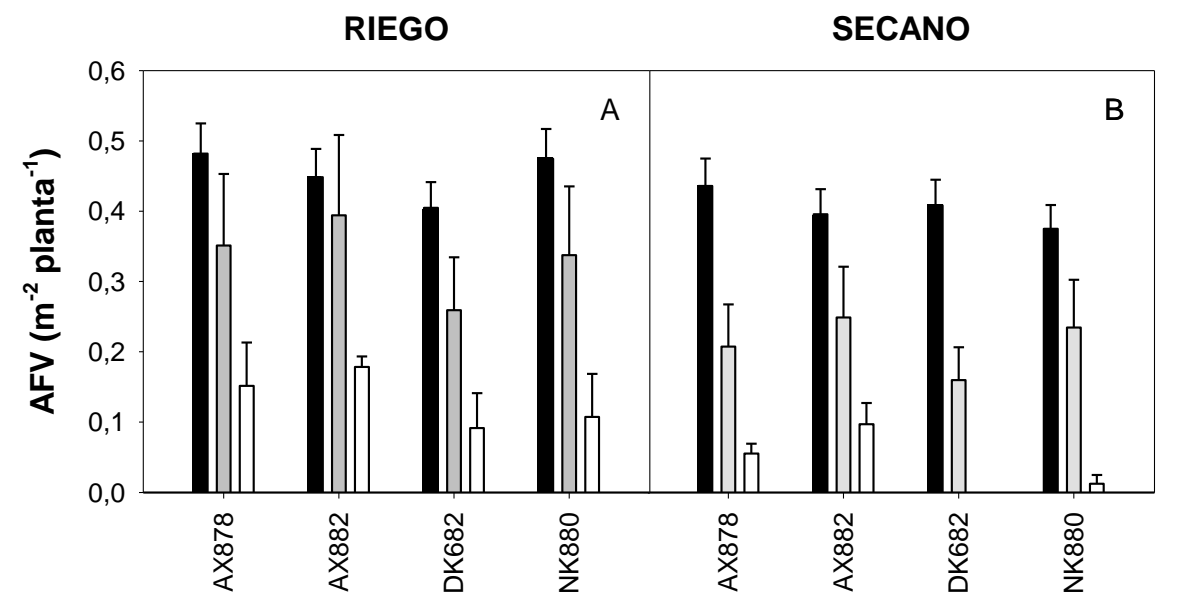

12 DDF

$P$ (Sequía) $\square N S$

$\mathrm{P}$ (Híbrido) $\square \mathrm{NS}$

$\mathrm{P}(\mathrm{S} \times \mathrm{H}) \mathrm{NS}$

$\square 27$ DDF

$\mathrm{P}$ (Sequía) $\square^{* *}$

$\mathrm{P}$ (Híbrido) $\square^{*}$

$\mathrm{P}(\mathrm{S} \times \mathrm{H}) \mathrm{NS}$

$\square 46$ DDF

$\mathrm{P}$ (Sequía) ${ }^{*}$

$P$ (Híbrido) NS

$\mathrm{P}(\mathrm{S} \times \mathrm{H}) \mathrm{NS}$

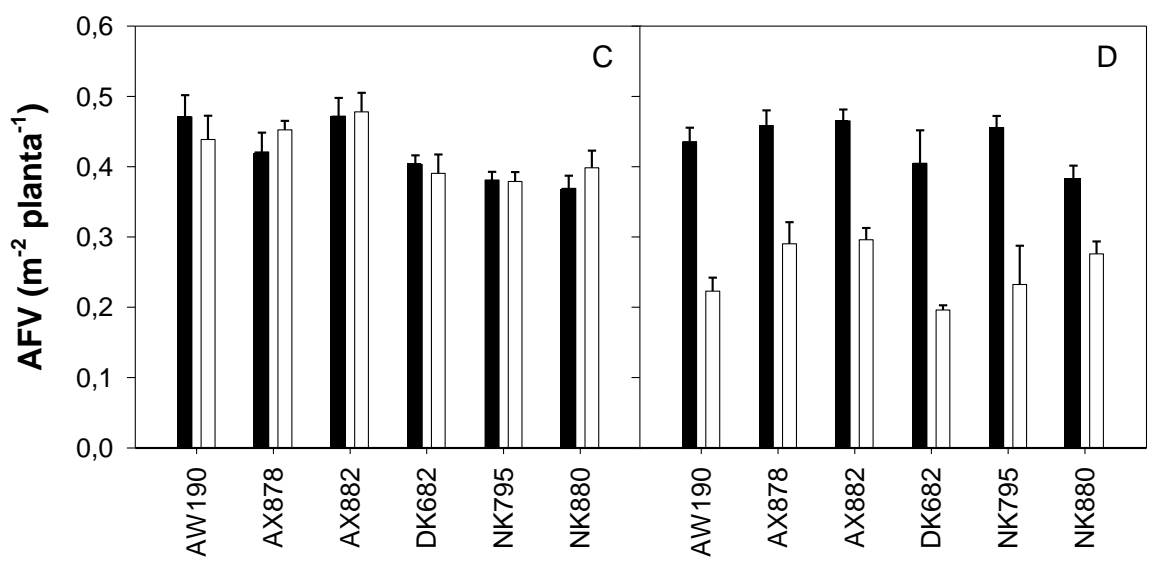

6 DDF

$\mathrm{P}$ (Sequía) $\square \mathrm{NS}$

$\mathrm{P}$ (Híbrido) $\square^{* * *}$

$\mathrm{P}(\mathrm{S} \times \mathrm{H}) \quad \mathrm{NS}$

$\square 48$ DDF

$\mathrm{P}$ (Sequía) ***

$\mathrm{P}$ (Híbrido) $\square^{* * *}$

$\mathrm{P}(\mathrm{S} \times \mathrm{H}) \mathrm{NS}$

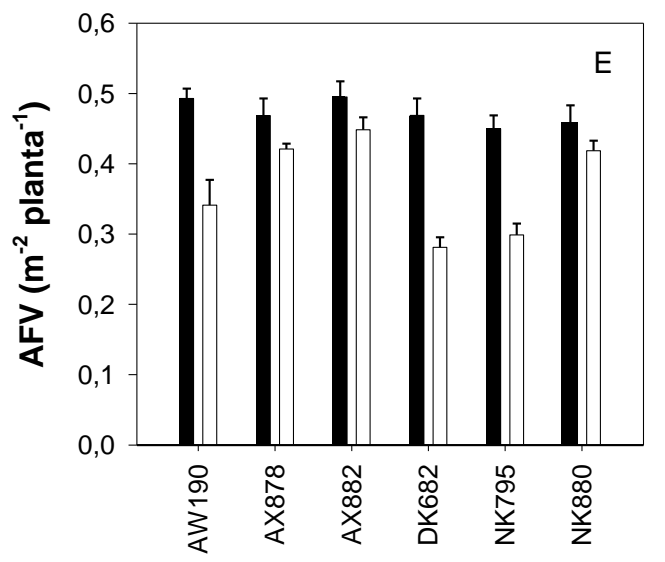

21 DDF

$\mathrm{P}$ (Híbrido) $\square$ NS

47 DDF

$\mathrm{P}$ (Híbrido) ***

Fig. 2: Área foliar verde por planta en distintos estadíos del llenado de granos, en el Exp. I (a los 12, 27 y 46 DDF) en riego (A) y secano (B); en el Exp. II (a los 6 y 48 DDF) en riego (C) y secano (D); y en el Exp. III (a los 21 y 47 DDF) en secano (E). Las barras representan el promedio de 6 plantas por tratamiento y las líneas por encima de las barras indican el error estándar. NS, no significativo; ${ }^{*} \mathrm{P}<0,05 ; * * \mathrm{P}<0,01 ;{ }^{* * *} \mathrm{P}<$ 0,001 . 


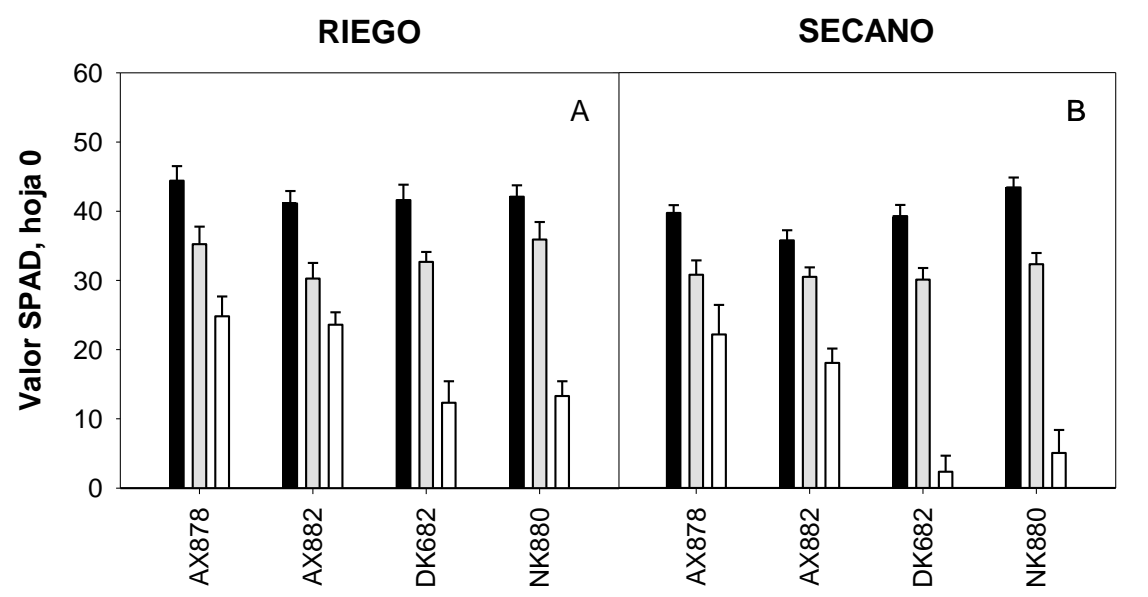

12 DDF

$\mathrm{P}$ (Sequía) $\square^{*}$ $\mathrm{P}$ (Híbrido)

$\mathrm{P}(\mathrm{S} \times \mathrm{H}) \mathrm{NS}$

27 DDF

$\mathrm{P}$ (Sequía) $\square+$

$\mathrm{P}$ (Híbrido) $\square \mathrm{NS}$

$\mathrm{P}(\mathrm{S} \times \mathrm{H}) \mathrm{NS}$

46 DDF

$\mathrm{P}$ (Sequía) $\square * *$

$\mathrm{P}$ (Híbrido) ${ }^{* * *}$

$\mathrm{P}(\mathrm{S} \times \mathrm{H}) \mathrm{NS}$

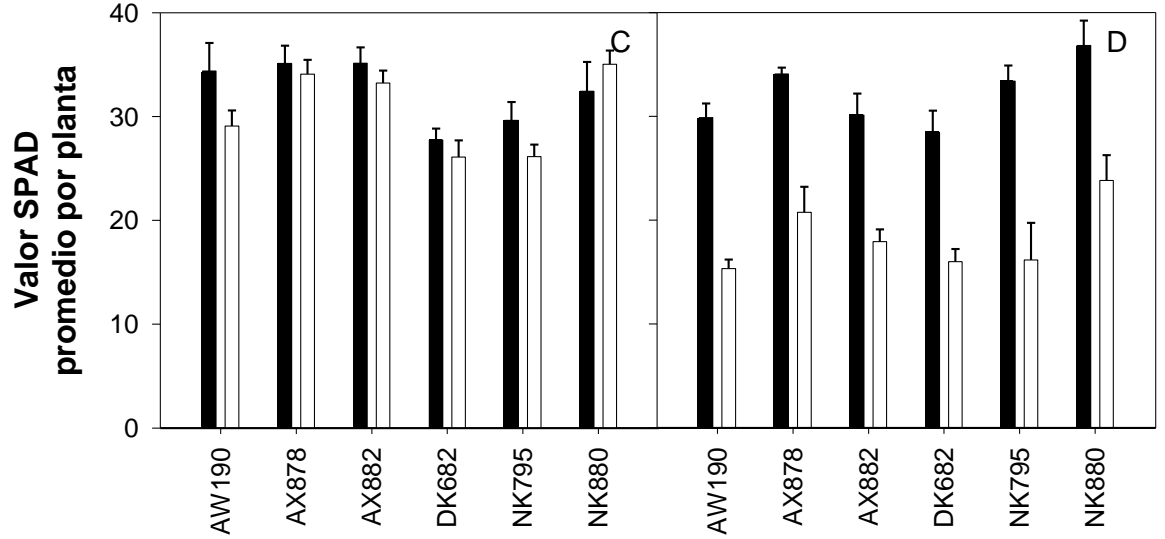

6 DDF

P (Sequía) $\square$ NS

$\mathrm{P}$ (Híbrido)

$\mathrm{P}(\mathrm{S} \times \mathrm{H}) \mathrm{NS}$

48 DDF

$\mathrm{P}$ (Sequía) ${ }^{* * *}$

$\mathrm{P}$ (Híbrido) $\square^{* * *}$

$\mathrm{P}(\mathrm{S} \times \mathrm{H}) \mathrm{NS}$

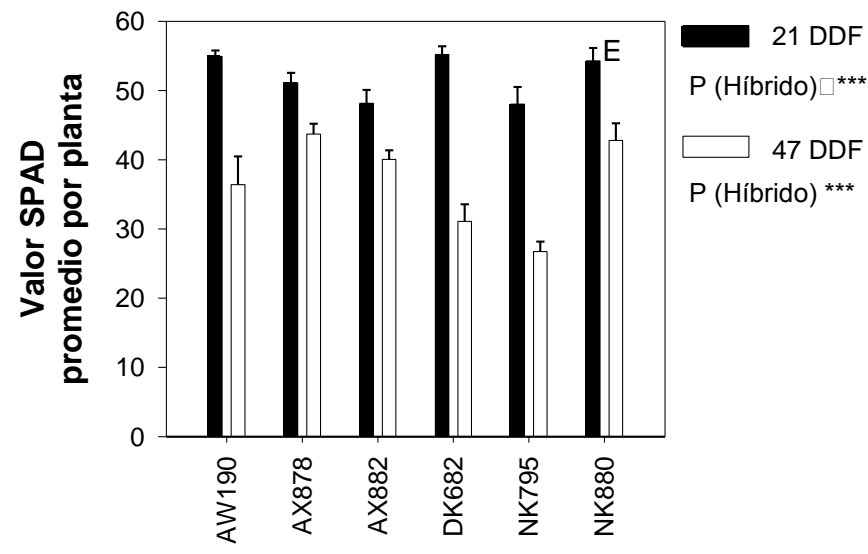

Fig. 3: Valores de SPAD en distintos estadíos del llenado de granos, en el Exp. I (a los 12, 27 y 46 DDF) en riego (A) y secano (B); en el Exp. II (a los 6 y 48 DDF) en riego (C) y secano (D); y en el Exp. III (a los 21 y 47 DDF) en secano (E). En el Exp. I el valor de SPAD fue medido sólo en la hoja 0 mientras que en los experimentos II y III el SPAD se midió en todas las hojas de la planta (se muestra el promedio por planta). Las barras representan el promedio de 6 plantas por tratamiento y las líneas por encima de las barras indican el error estándar. NS, no significativo; ${ }^{*} \mathrm{P}<0,05 ;{ }^{* *} \mathrm{P}<0,01 ;{ }^{* *} \mathrm{P}<$ 0,001 . 


\subsection{Rendimiento y Componentes}

A fines de analizar la relación entre el carácter SG y los rendimientos observados en secano, se realizó un análisis de covarianza considerando los datos de los tres experimentos, utilizando como factor fijo el híbrido, como covariable el AFV retenida hacia el final del llenado de granos y como variable dependiente, el rendimiento en secano. Se detectaron efectos de la covariable AFV con un valor de $P=$ 0,064, pero no del híbrido. Por lo tanto, se asume que las diferencias en rendimiento observadas entre híbridos están explicadas por la variabilidad en el carácter SG (Tabla 1). De la misma forma, la covariable afectó con un valor de $P<0,05$ al NG y $P G$, y con un $\mathrm{P}<0,1$ a la asimilación neta durante el llenado de granos (Tabla 1). Vale destacar que el PG se asoció al carácter SG, sino que también estuvo afectado por el híbrido con un valor de $\mathrm{P}<0,07$ (Tabla 1). Esto indica que, si bien el carácter SG contribuyó positivamente al PG, existieron diferencias en el PG no explicadas por el carácter SG (i.e., diferencias intrínsecas a los híbridos).

Tabla 1: Efecto de la covariable AFV a los 46-48 DDF sobre el rendimiento, el número de granos (NG), el peso de grano (PG), la materia seca por planta (MS), la removilización y la asimilación neta durante el llenado de granos. Se analizaron conjuntamente los datos de los tres experimentos considerando sólo los datos de secano.

\begin{tabular}{cccccccc}
\hline Exp. & Factor & $\begin{array}{c}\text { Rend. } \\
\left(\mathrm{Kg} \mathrm{ha}^{-1}\right)\end{array}$ & NG & PG & $\begin{array}{c}\text { MS total } \\
\left(\mathrm{g} \mathrm{pl}^{-1}\right)\end{array}$ & $\begin{array}{c}\text { Remov. } \\
\left(\mathrm{g} \mathrm{pl}^{-1}\right)\end{array}$ & $\begin{array}{c}\text { As. } \\
\text { Neta } \\
\left(\mathrm{g} \mathrm{pl}^{-1}\right)\end{array}$ \\
\hline $\begin{array}{c}\text { Exps } \\
\text { I, II y III }\end{array}$ & Covariable & 0,064 & 0,003 & 0,024 & 0,193 & 0,356 & 0,094 \\
(SECANO) & Híbrido & 0,963 & 0,484 & 0,070 & 0,263 & 0,602 & 0,599 \\
& Exp. $\mathrm{H}$ H & 0,601 & 0,937 & 0,454 & 0,817 & 0,103 & 0,592 \\
\hline
\end{tabular}


En los experimentos I y II la sequía redujo el rendimiento $(P<0,05)$ un $17 \%$ con respecto al tratamiento regado (Tabla 2). Los rendimientos en riego no predijeron la respuesta al secano en el Exp. I pero sí en el Exp. II. En ninguno de los tres experimentos el ANOVA detectó efectos significativos del híbrido (Tabla 2). En los experimentos I y II, los efectos de la sequía sobre el rendimiento se expresaron a través del PG. En el Exp. I, el PG cayó un 20\% como consecuencia de la sequía. Respecto al tratamiento regado, la caída del PG en secano fue de un $25 \%$ en el híbrido NSG y de un $17 \%$ en promedio, en el grupo SG (Tabla 2). Bajo riego el PG en el híbrido NSG fue similar al del resto de los híbridos. En el Exp. II el PG se redujo un $12 \%$ con respecto al tratamiento regado. Los híbridos SG presentaron en promedio, mayores PG tanto en riego como en secano. Por este motivo, la caída del PG como consecuencia de la sequía fue del $12 \%$ tanto en el grupo SG como en el grupo NSG (Tabla 2).

En el Exp. III el aporte relativo de cada componente del rendimiento varió dependiendo del híbrido con un valor de $\mathrm{P}<0,1$ (Tabla 2). La relación negativa entre NG y PG (Fig. 10A, $P<0,0001, n=36$ ) permite inferir que el PG alcanzado en cada híbrido dependió, al menos en parte, del NG fijado, dificultando la comparación de componentes del rendimiento entre los distintos híbridos. 
Tabla 2. Rendimiento, número de granos (NG), peso de grano (PG), materia seca (MS), removilización y asimilación neta (As. Neta) durante el llenado de granos. Para cada tratamiento se presenta el promedio de 6 plantas.

\begin{tabular}{|c|c|c|c|c|c|c|c|c|}
\hline Exp. & $\begin{array}{l}\text { Trat. } \\
\text { Hídrico }\end{array}$ & Híbrido & $\begin{array}{l}\text { Rendimiento } \\
\left(\mathrm{kg} \mathrm{ha}^{-1}\right)\end{array}$ & $N G \mathrm{pl}^{-1}$ & $\begin{array}{l}\text { PG (mg } \\
\text { grano }^{-1} \text { ) }\end{array}$ & $\begin{array}{l}\text { MS total } \\
\left(\mathrm{g} \mathrm{pl}^{-1}\right)\end{array}$ & $\begin{array}{l}\text { Remov. } \\
\left(\mathrm{g} \mathrm{pl}^{-1}\right)\end{array}$ & $\begin{array}{l}\text { As. Neta } \\
\left(\mathrm{g} \mathrm{pl}^{-1}\right)\end{array}$ \\
\hline \multirow{11}{*}{ I (SP) } & \multirow{4}{*}{ RIEGO } & AX878 & 6188,9 & 370 & 209 & 259 & $-12,5$ & 99,1 \\
\hline & & AX882 & 6533,3 & 366 & 225 & 301 & $-26,6$ & 160,1 \\
\hline & & DK682 & 6674,6 & 402 & 209 & 205 & 15,6 & 57,8 \\
\hline & & NK880 & 6350,8 & 356 & 222 & 243 & 4,8 & 75,7 \\
\hline & \multirow{4}{*}{ SECANO } & AX878 & 5455,6 & 356 & 192 & 199 & 25,4 & 21,5 \\
\hline & & AX882 & 5342,9 & 379 & 177 & 163 & 27,9 & 8,3 \\
\hline & & DK682 & 4911,1 & 400 & 154 & 128 & 52,5 & $-36,0$ \\
\hline & & NK880 & 5704,8 & 415 & 172 & 179 & 25,4 & 20,5 \\
\hline & \multicolumn{2}{|c|}{ P (Sequía) } & 0,004 & 0,545 & 0,001 & 0,005 & 0,004 & 0,003 \\
\hline & \multicolumn{2}{|c|}{ P (Híbrido) } & 0,891 & 0,661 & 0,201 & 0,160 & 0,119 & 0,180 \\
\hline & \multicolumn{2}{|l|}{$\mathrm{P}(\mathrm{S} \times \mathrm{H})$} & 0,408 & 0,679 & 0,250 & 0,500 & 0,601 & 0,442 \\
\hline \multirow{15}{*}{ II (LH) } & \multirow{6}{*}{ RIEGO } & AW190 & 11407 & 514 & 278 & 257 & 3,4 & 136,6 \\
\hline & & AX878 & 14055 & 574 & 310 & 279 & $-3,3$ & 175,1 \\
\hline & & AX882 & 13184 & 553 & 301 & 245 & 2,5 & 147,3 \\
\hline & & DK682 & 11785 & 522 & 281 & 226 & 6,4 & 127,9 \\
\hline & & NK795 & 12680 & 580 & 276 & 222 & 3,8 & 136,9 \\
\hline & & NK880 & 15595 & 711 & 276 & 266 & $-12,3$ & 179,7 \\
\hline & \multirow{6}{*}{ SECANO } & AW190 & 10123 & 533 & 237 & 230 & 0,6 & 133,4 \\
\hline & & AX878 & 11193 & 545 & 266 & 244 & $-0,9$ & 140,5 \\
\hline & & AX882 & 11772 & 563 & 264 & 232 & 4,7 & 128,0 \\
\hline & & DK682 & 10532 & 510 & 258 & 226 & $-10,8$ & 136,5 \\
\hline & & NK795 & 10183 & 540 & 243 & 216 & 17,6 & 102,1 \\
\hline & & NK880 & 11472 & 564 & 253 & 256 & $-7,8$ & 156,2 \\
\hline & \multicolumn{2}{|c|}{ P (Sequía) } & 0,002 & 0,396 & 0,001 & 0,233 & 0,551 & 0,749 \\
\hline & \multicolumn{2}{|c|}{ P (Híbrido) } & 0,139 & 0,536 & 0,251 & 0,057 & 0,148 & 0,390 \\
\hline & \multicolumn{2}{|l|}{$P(S \times H)$} & 0,735 & 0,837 & 0,963 & 0,679 & 0,257 & 0,301 \\
\hline \multirow{7}{*}{ III (SL) } & \multirow{6}{*}{ SECANO } & AW190 & 8535 & 506 & 213 & 215 & 15,3 & 55,0 \\
\hline & & AX878 & 8291 & 500 & 209 & 233 & 10,9 & 83,9 \\
\hline & & AX882 & 7646 & 562 & 187 & 224 & $-3,7$ & 90,4 \\
\hline & & DK682 & 7419 & 438 & 214 & 179 & 21,6 & 29,5 \\
\hline & & NK795 & 6889 & 450 & 196 & 177 & 14,5 & 42,2 \\
\hline & & NK880 & 7040 & 506 & 174 & 218 & 7 & 67 \\
\hline & \multicolumn{2}{|c|}{$\mathrm{P}$ (Híbrido) } & 0,172 & 0,091 & 0,090 & 0,018 & 0,012 & 0,004 \\
\hline
\end{tabular}




\subsection{Asimilación neta durante el llenado de granos}

La asimilación neta en post-antesis fue afectada por la sequía en el Exp. I, no fue afectada por ninguno de los tratamientos en el Exp. II, o fue afectada por el híbrido en el Exp. III (Tabla 2). En secano, los híbridos SG acumularon en promedio $52 \mathrm{~g}$ (Exp. I), 18 g (Exp. II) y 38 g (Exp. III) de MS más por planta en comparación con el/ los híbridos estándar. Esto puede observarse en la Tabla 1, donde la asimilación neta presentó efectos de la covariable AFV con un valor de $P<0,1$.

La MS total por planta a cosecha fue afectada por el tratamiento hídrico en el Exp. I pero no en el Exp. II. Esto es esperable considerando que, si bien en ambos experimentos se registraron lluvias a partir de estadíos intermedios del llenado de granos (Fig. 1), en el Exp. II las plantas en secano retuvieron mayor AFV hasta estadíos avanzados del llenado de granos (Fig. 2). En el Exp. I, en secano, la MS a cosecha de los híbridos SG fue un $30 \%$ superior (diferencias no significativas) que la alcanzada por el híbrido NSG, DK682. Sólo en los experimentos II y III la MS total acumulada varió entre híbridos (con un valor de $\mathrm{P}=0,057$ en Exp. II o $\mathrm{P}<0,05$ en Exp. III) (Tabla 2). En los experimentos II y III, en secano los híbridos SG alcanzaron entre un 8\% (Exp. II) y un 15\% (Exp. III) más MS total que los híbridos estándar.

3.6. La conductancia estomática (Gs) se relacionó con el carácter SG y explicó parte de la variación encontrada en la asimilación neta

Para conocer si el carácter SG se relacionó con la Gs, se realizó un análisis de covarianza. En los tres experimentos se encontró asociación entre el carácter SG y Gs, especialmente cuando se consideraron los menores valores de Gs registrados en cada experimento.

En el Exp. I, Gs se midió al mediodía en tres momentos durante el llenado (12, 27 y 46 DDF). La sequía redujo $(P<0.05)$ Gs a los 12 y 27 DDF. En ambos estadíos fenológicos, la Gs en sequía se asoció $(\mathrm{P}<0.05)$ con la covariable indicadora del carácter SG (a los 27 DDF también se registraron efectos significativos del híbrido). Por ejemplo, a los 12 DDF (Gs promedio al mediodía de $40 \mathrm{mmol} \mathrm{m}^{-2} \mathrm{~s}^{-1}$ ), los valores de Gs alcanzados en secano por los tres híbridos SG fueron en promedio 44 mmoles $\mathrm{m}^{-2} \mathrm{~s}^{-1}$ mientras que el híbrido NSG DK682 presentó valores de Gs de 29 mmoles $\mathrm{m}^{-2} \mathrm{~s}^{-1}$. La 
acumulación neta de MS durante el período de estrés (entre los 12 y 27 DDF) no se relacionó con Gs a los $12 \operatorname{DDF}(P=0,32)$ pero sí a los $27 \operatorname{DDF}(P<0,05, n=8$, Fig. 4A).

En el Exp. II la sequía afectó la Gs a los 23 DDF $(P<0,05)$ en los tres momentos del día (mañana, mediodía y tarde). Bajo secano, los efectos de la covariable AFV fueron significativos $(P<0,05)$ en los tres momentos del día indicando nuevamente una relación entre el carácter SG y la Gs. Por ejemplo, al mediodía y a la tarde, Gs fue un $28 \%$ (70 vs. 50 mmoles $\mathrm{m}^{-2} \mathrm{~s}^{-1}$ ) y $18 \%$ (60 vs 50 mmoles $\mathrm{m}^{-2} \mathrm{~s}^{-1}$ ) mayor en el grupo SG (AX878, AX882 y NK880) respecto al NSG (AW190, DK682 y NK795). La acumulación neta de MS durante el período de estrés (entre 6 y 33 DDF) se relacionó con Gs medida a los 23 DDF al mediodía $\left(r^{2}=0,48, P<0,05, n=12\right)$ y a la tarde (Fig. 4B). A la tarde, los valores de Gs registrados fueron menores y la relación entre Gs y la acumulación neta durante el período de estrés presentó una pendiente mayor en comparación con la relación para Gs al mediodía $\left(0,36\right.$ vs $0,14 \mathrm{~g}$ de $\mathrm{MS}$ asimilados por cada $\mathrm{mmol} \mathrm{m}^{-2} \mathrm{~s}^{-1}$ extra de Gs).

En el Exp. III, los efectos de la covariable no fueron significativos a los 20 DDF al mediodía (cuando Gs fue en promedio de $200 \mathrm{mmol} \mathrm{m}^{-2} \mathrm{~s}^{-1}$ ) ni a la tarde (cuando los valores de Gs promedio fueron de $93 \mathrm{mmol} \mathrm{m}^{-2} \mathrm{~s}^{-1}$ ). A los 46 DDF tampoco se registraron efectos de la covariable al mediodía (cuando Gs fue en promedio, $88 \mathrm{mmol}$ $\mathrm{m}^{-2} \mathrm{~s}^{-1}$ ) mientras que a la tarde (Gs promedio de $30 \mathrm{mmol} \mathrm{m}^{-2} \mathrm{~s}^{-1}$ ), la covariable se asoció con Gs con un valor de $\mathrm{P}<0,1$. Por ejemplo, a los 46 DDF a la tarde, la Gs promedio del grupo SG presentó valores 20\% mayores que el grupo NSG (34 mmoles $\mathrm{m}^{-2} \mathrm{~s}^{-1}$ vs. 27 mmoles $\mathrm{m}^{-2} \mathrm{~s}^{-1}$, respectivamente). La asimilación neta de MS entre los 20 y 46 DDF se relacionó con Gs medida a los 46 DDF a la tarde (Fig. 4C). 


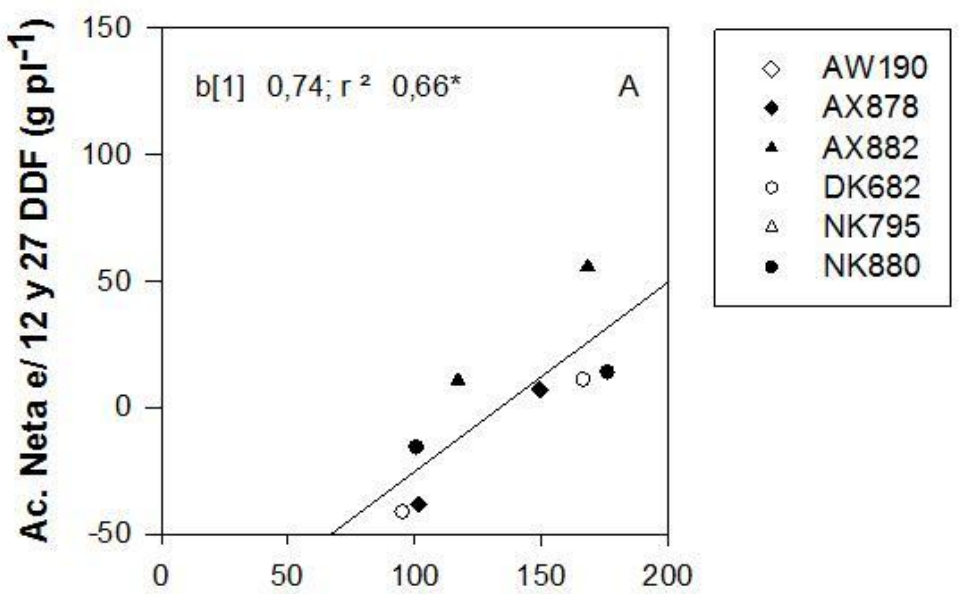

Gs (mmoles m-2 s-1) a los 27 DDF

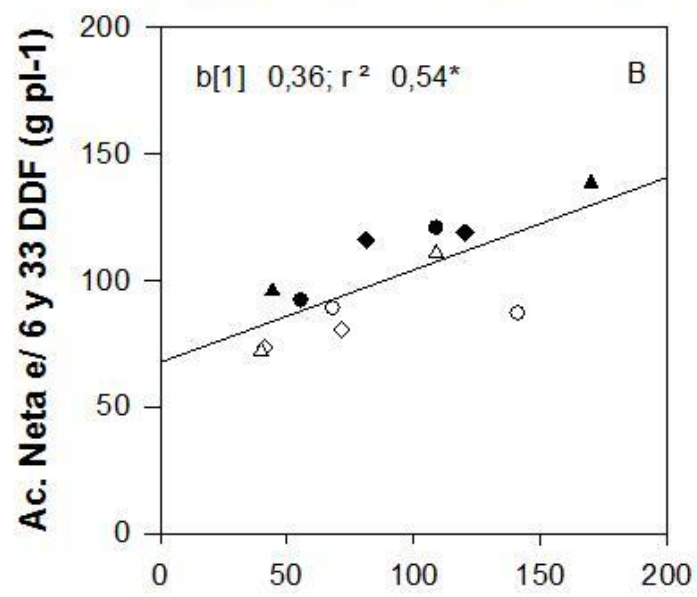

Gs (mmoles $\left.m^{-2} s^{-1}\right)$ a los 23 DDF

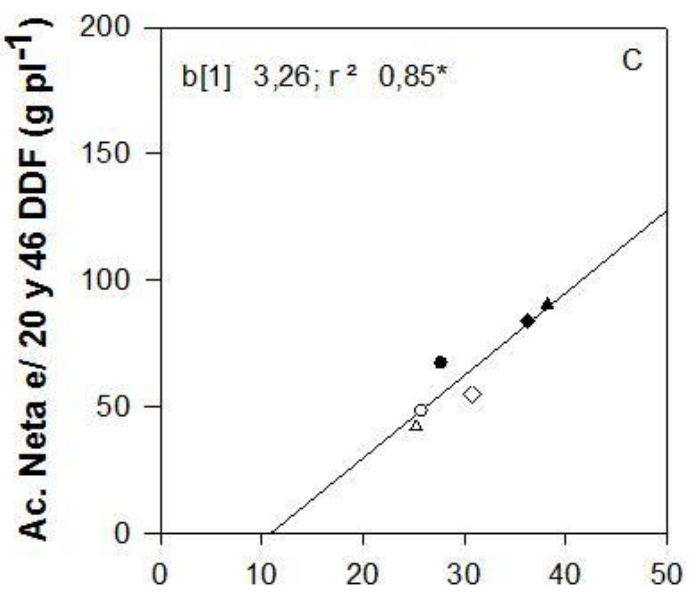

Gs (mmoles $\left.\mathrm{m}^{-2} \mathrm{~s}^{-1}\right)$ a los 46 DDF

Fig. 4: Relación entre la conductancia estomática (Gs) y la acumulación neta en el Exp. I (A), II (B) y III (C). En el Exp. I (A), Gs fue medida alrededor del mediodía a los 27 DDF y la acumulación neta corresponde al período entre 12 y 27 DDF. En el Exp. II (B), Gs fue medida a la tarde a los 23 DDF y la acumulación neta corresponde al período entre 6 y 33 DDF. En el Exp. III (C), Gs fue medida a la tarde (E) a los 46 DDF y la acumulación neta corresponde al período entre 20 y 46 DDF. 
3.7. La tasa de transporte fotosintético de electrones (ETR) se relacionó con el carácter SG

En los tres experimentos, la relación hallada entre Gs y la asimilación neta de C durante el período de estrés sugiere que en parte, la actividad fotosintética estuvo asociada a Gs. Es decir que, en condiciones de sequía, existieron limitantes estomáticas para la fotosíntesis. En el Exp. II se realizaron mediciones de la tasa de transporte fotosintético de electrones (ETR) que sustentan esta idea (Fig. 5). ETR medida a los 23 DDF se relacionó con Gs al mediodía y a la tarde (Figs. 5B y $5 \mathrm{C}$ ), pero no a la mañana (Fig. 5A). La relación entre ETR y Gs mostró una tendencia polinómica al mediodía: la respuesta de ETR a Gs disminuyó cuando los valores de Gs superaron los 200 mmoles $\mathrm{m}^{-2} \mathrm{~s}^{-1}$ (Fig. 5B). La relación entre ETR y Gs fue lineal a la tarde, cuando los valores de Gs se mantuvieron por debajo de los 200 mmoles $\mathrm{m}^{-2} \mathrm{~s}^{-1}$ (Fig. 5C). Esto indica que, cuando Gs cae por debajo de un umbral (que dependerá, entre otros factores, de la demanda de agua atmosférica), Gs puede ser estimadora de la actividad fotosintética (i.e., que ocurren limitaciones estomáticas de la fotosíntesis).

Además, en el Exp. II, ETR a los 23 DDF se asoció con la covariable indicadora del carácter SG al mediodía $(P<0,1)$ y a la tarde $(P<0,05)$. A la mañana, el efecto de la covariable no fue significativo pero sí se detectaron efectos del híbrido $(P<0,05)$. Como puede observarse en la Fig. 6A, a la mañana y considerando sólo los puntos correspondientes a secano (los puntos encerrados en el círculo), se observó una tendencia hacia mayores valores de ETR en el grupo SG. El grupo SG presentó una mayor ETR (Fig. 6A) incluso cuando Gs no es limitante (Fig. 5A), es decir que el carácter SG pudo haber estado asociado con menores limitaciones no estomáticas de la fotosíntesis. 

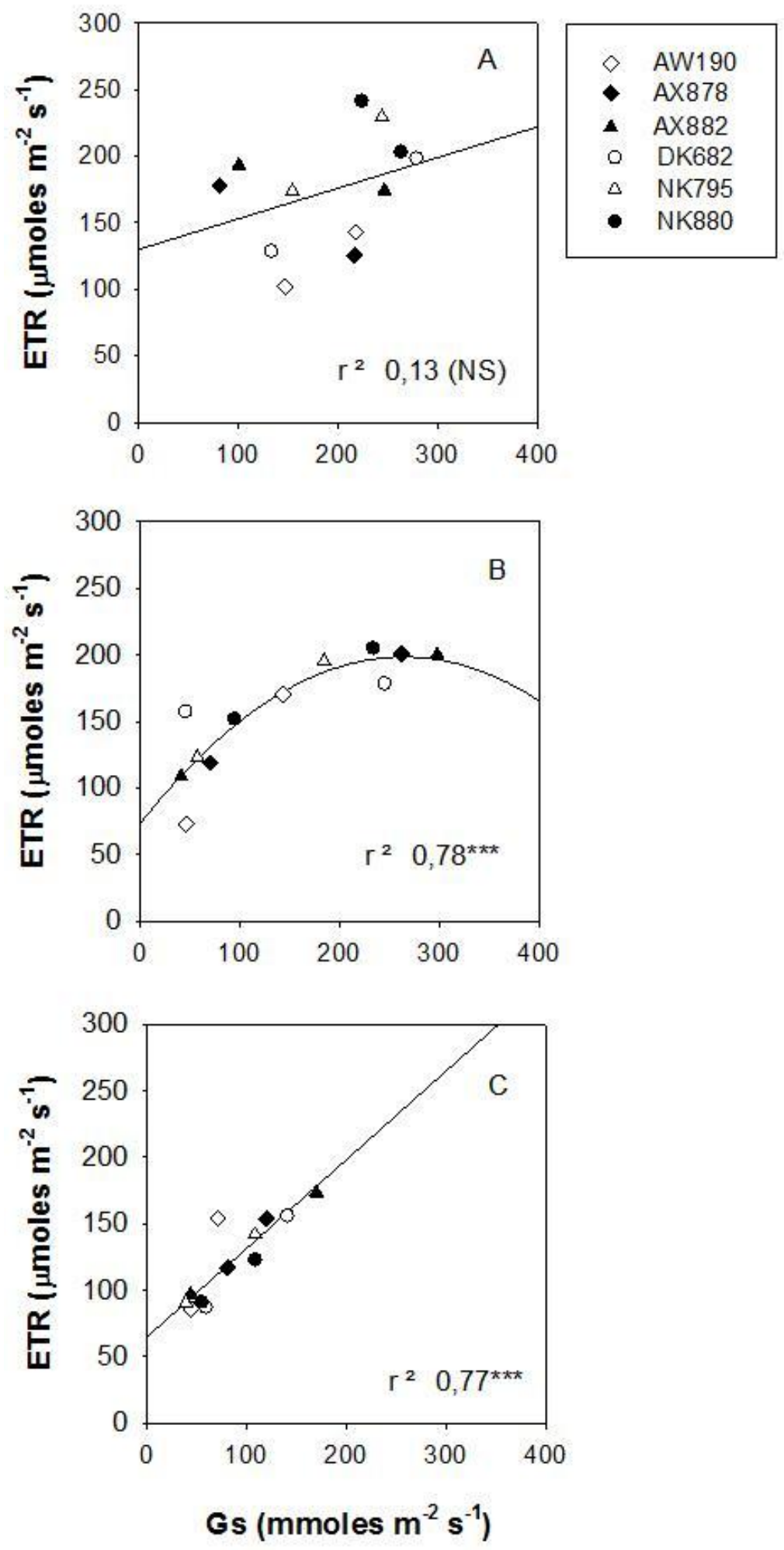

Fig. 5: Exp. II, relación entre conductancia estomática (Gs) y tasa de transporte fotosintético de electrones (ETR), a los 23 DDF medida a la mañana (A), al mediodía (B) y a la tarde (C). Cada punto representa el promedio de 6 mediciones por tratamiento. 

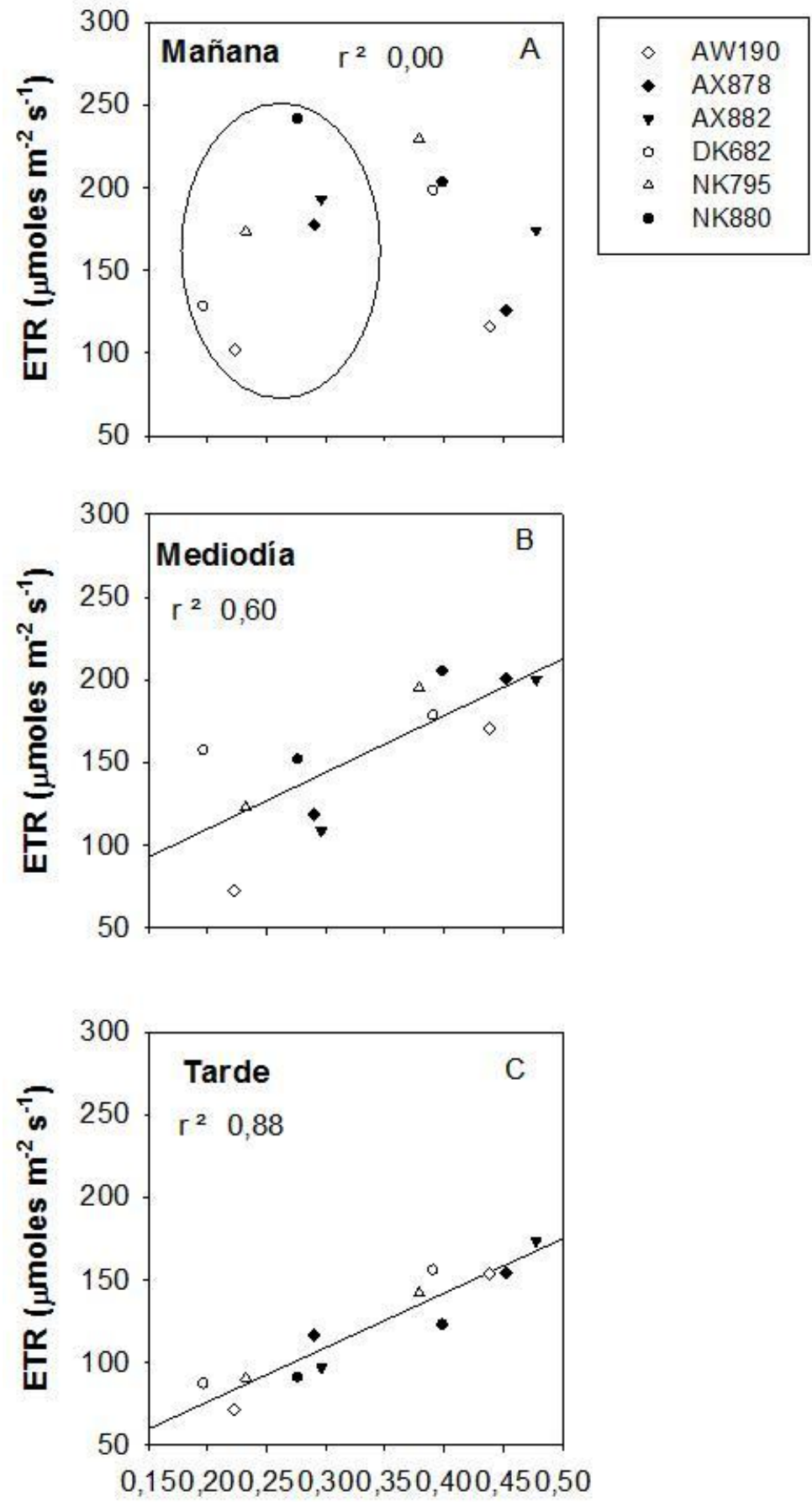

Carácter SG (AFV ca. 45 DDF)

Fig. 6: Relación entre el carácter SG (usando como indicador cuantitativo, el AFV retenida a los 45 DDF) y los valores de ETR medidos a los 23 DDF en el Exp. II, en la hoja de la espiga, en tres momentos del día (mañana, A; mediodía, B; tarde, C). Cada punto representa el promedio de 6 plantas por tratamiento ( $n=12$ en cada regresión). 
3.8. La asimilación neta en post-floración se relacionó con la retención de AFV

El AFV retenida hacia el final del llenado de granos está vinculada con la intercepción de luz, y por lo tanto, con la asimilación neta en este período. En los tres experimentos, el AFV por planta en estadíos avanzados del llenado de granos se relacionó positiva y significativamente con la asimilación neta en ese período (Fig. 7). En el Exp. I, el AFV alcanzada hacia el final del llenado de granos fue menor que en los experimentos II y III, y la pendiente de esta relación fue marcadamente más alta ( $880 \mathrm{~g}$ $\mathrm{pl}^{-1}$ por cada $\mathrm{m}^{-2}$ de AFV, Fig. 7A). En el Exp. II, la pendiente de la relación fue la menor y la ordenada al origen fue la mayor de los tres experimentos (Fig. 7B), en correspondencia con los mayores rendimientos alcanzados incluso en secano en este experimento. En el Exp. III la pendiente alcanzada fue intermedia pero el período considerado fue menor (Fig. 7C). Dada la mayor retención de AFV en el grupo SG, no resulta sorprendente que éstos se hayan ubicado en el extremo superior de la regresión. 

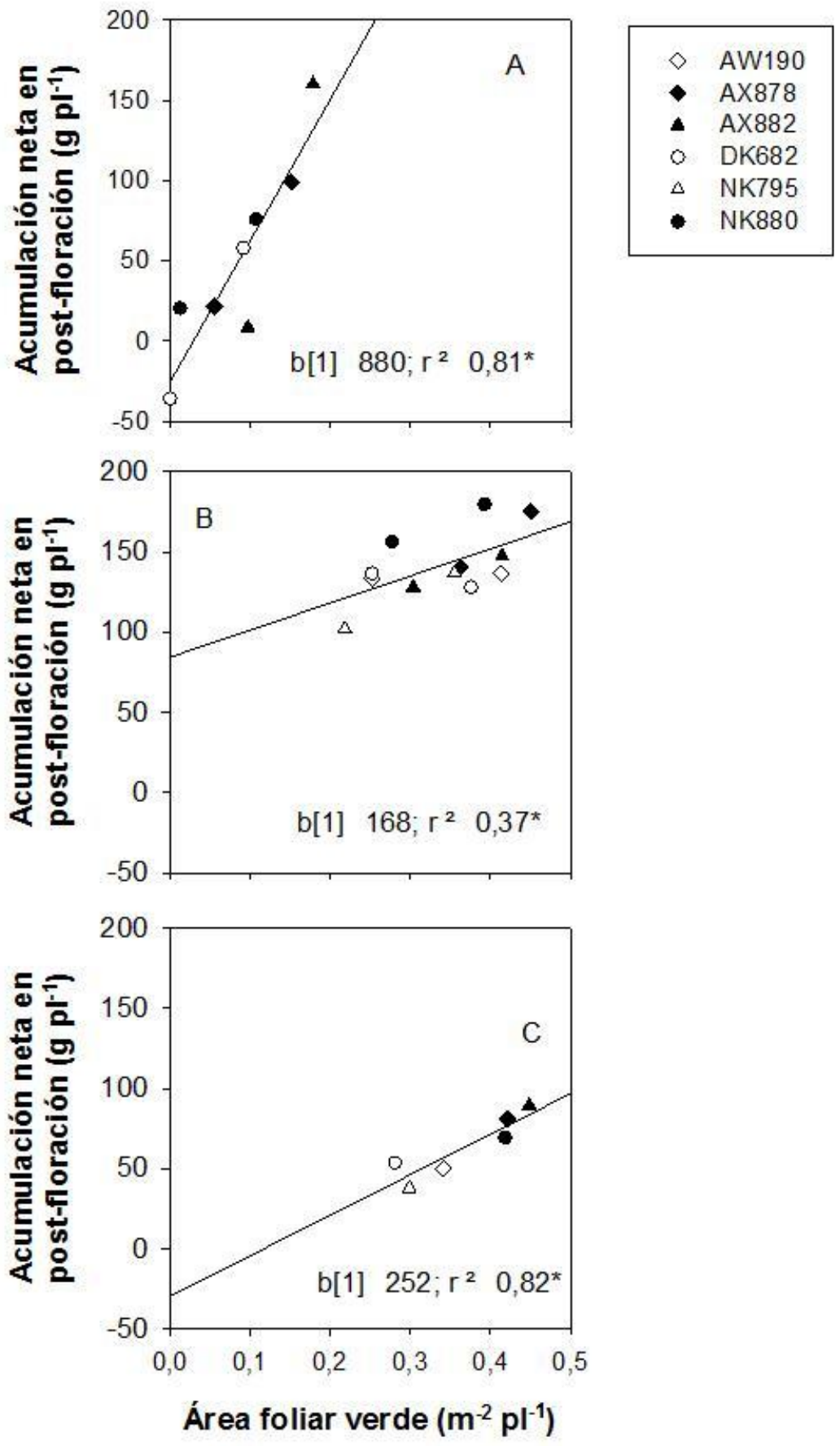

Fig. 7: Relación entre la acumulación neta de materia seca en post-floración y el área foliar verde hacia el final del llenado de granos (46-48 DDF) en el Exp. I (A, acumulación entre 12 y 48 DDF) $n=8$; en el Exp. II (B, acumulación entre 6 y 65 DDF) $n=12$; en el Exp. III (C, acumulación entre 20 y 46 DDF) $n=6$. Cada punto representa un tratamiento, y es el promedio de 6 plantas. 


\subsection{Partición a espiga}

La removilización de MS entre antesis y cosecha fue afectada sólo por la sequía en el Exp. I, no fue afectada por ninguno de los tratamientos en el Exp. II, o fue afectada por el híbrido en el Exp. III (Tabla 2). Asumiendo que no existieron pérdidas por respiración, en el Exp. I, la MS proveniente de la removilización en secano, aportó unos $30 \mathrm{~g}$ al crecimiento de la espiga (promedio entre híbridos) mientras que en riego, la MS vegetativa aumentó unos $4 \mathrm{~g}$ hacia cosecha indicando que no existió removilización neta. En secano, el híbrido NSG removilizó el doble de MS en comparación con el promedio de los híbridos SG (Tabla 2). En el Exp. III, el ANOVA detectó diferencias $(P<0,05)$ entre híbridos; comparando entre grupos, el grupo SG removilizó en promedio 4,8 g mientras que este valor aumentó a 17 g en el grupo NSG (Tabla 2).

En la Fig. 8 se observa que, por un lado, los híbridos SG presentaron mayor asimilación neta en post-floración respecto al híbrido NSG (Fig. 8A) o a los híbridos NSG (Figs. $8 \mathrm{~B}$ y $8 \mathrm{C}$ ). Por otro lado, también se observa que, en general los puntos correspondientes a los híbridos NSG se encuentran por encima de la relación 1:1 entre asimilación neta y crecimiento de espiga. En cambio, los puntos correspondientes a los híbridos SG nunca están por encima de la relación 1:1. Esto indica menor partición a espiga en el grupo SG y explicaría en parte, por qué la mayor asimilación neta del grupo SG en el Exp. III no se traduce en mayor rendimiento.

Se efectuó un análisis más detallado para analizar la determinación del rendimiento en el Exp. III. La Fig. 9A muestra que el PG y el NG se relacionaron negativamente $(P<0,0001, n=36)$. Sin embargo, no se encontró una relación entre el índice fuente/destino (asimilación neta por grano fijado) y el PG (Fig. 9B). Es decir, en el Exp. III el PG estuvo limitado por factores independientes de la relación fuente/destino. 

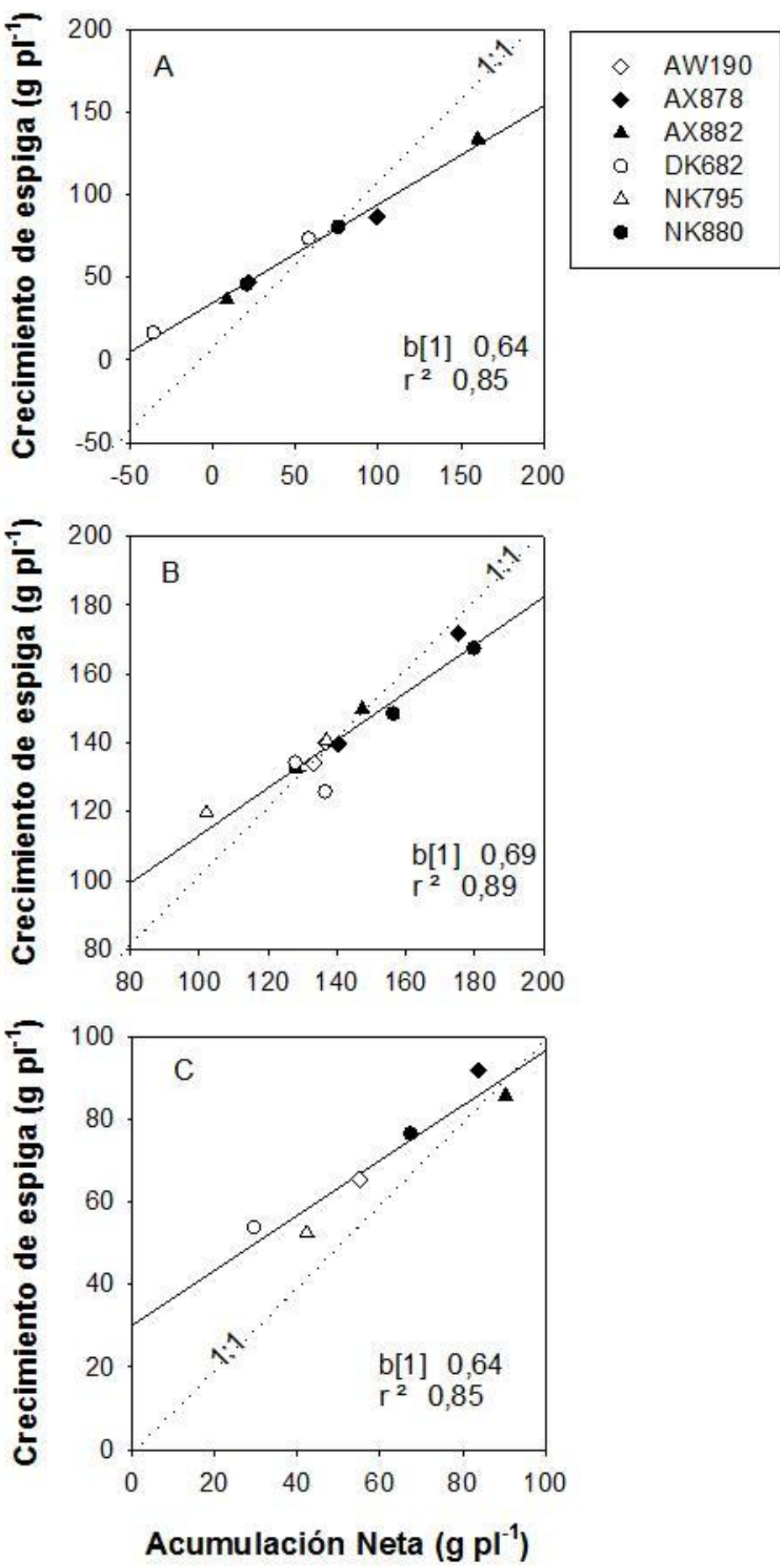

Fig. 8: Relación entre la acumulación neta de materia seca y el crecimiento de la espiga en el Exp. I ( $A$, para el período entre 12 y 46 DDF), Exp. II (B, entre 6 DDF y 65 DDF) y Exp. III (C, entre 20 y 46 DDF). 


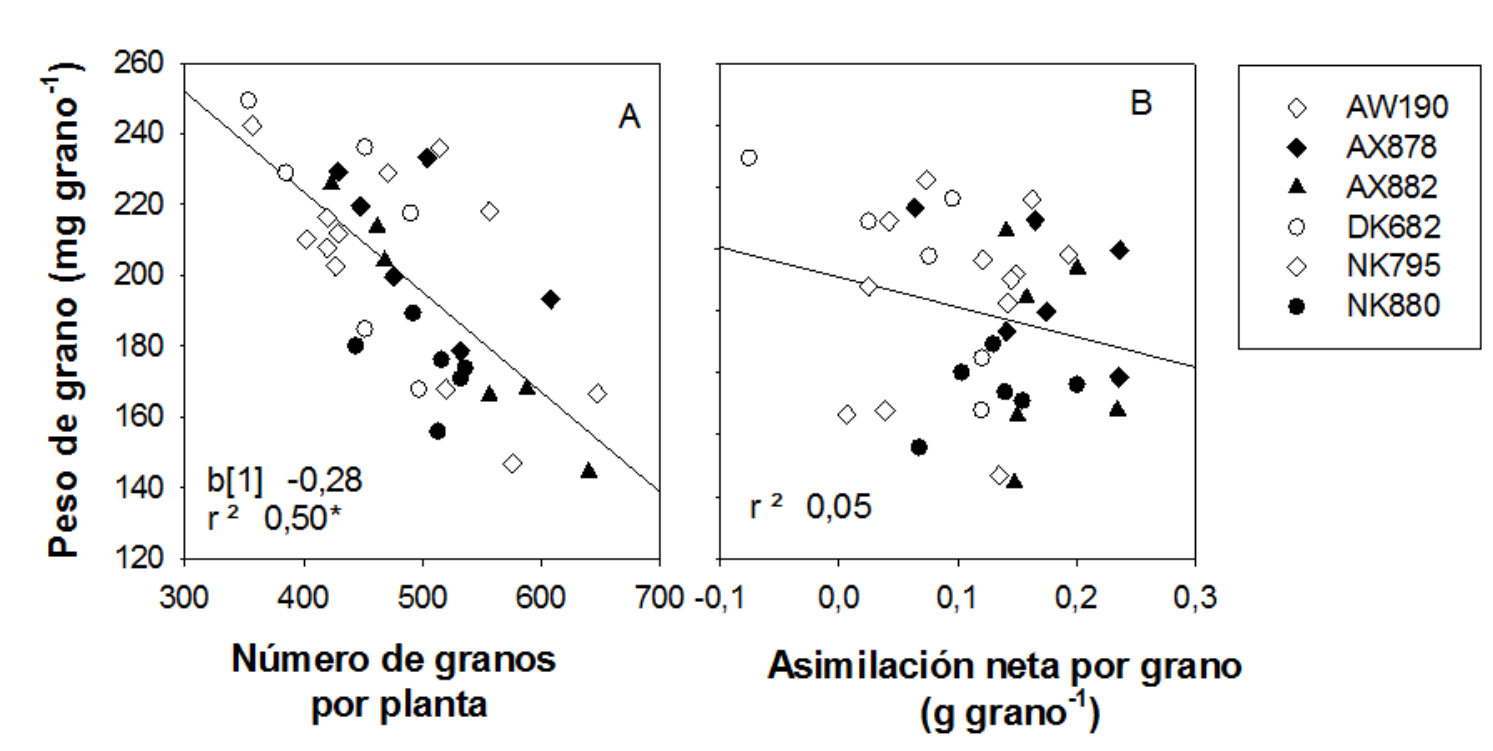

Fig. 9: Relación entre número de granos y peso de grano en el Exp. III (A) y entre la relación fuente/destino (asimilación neta por grano fijado) y el peso de grano en el Exp. III (B). Cada dato representa una planta.

\section{Discusión}

\subsection{Estabilidad del carácter SG en sequía}

El AFV a floración no predijo la duración del AFV en estadíos avanzados del llenado de granos. En estadíos avanzados del llenado de granos, el comportamiento de los híbridos varió ligeramente entre experimentos. Por ejemplo, en el Exp. I, el híbrido SG NK880 prácticamente no se diferenció del híbrido NSG DK682, pero sí lo hizo en los experimentos II y III. Esto reafirma la existencia de la ya reportada interacción $\mathrm{G} \times \mathrm{E}$ para el carácter SG (Borrell et al., 2000a; Pommel et al., 2006; van Oosterom et al., 1996). Por otra parte, Borrell et al. (2000a) han sugerido que en sorgo, la expresión del carácter SG sería máxima bajo condiciones ambientales que permitan un buen desarrollo del AFV en floración combinadas con un estrés hídrico severo en postantesis. Los resultados presentados en este Capítulo también muestran que la expresión del carácter SG es acentúa en condiciones de sequía en post-floración.

\subsection{Efectos de la sequía sobre el rendimiento y relación con el carácter SG}

Evidencias previas sugieren que el carácter SG puede representar ventajas de rendimiento en sorgo expuesto a sequía durante el período de llenado (Borrell et al., 2000b). También se han reportado ventajas asociadas al carácter SG en líneas de maíz 
seleccionadas para tolerancia a la sequía (Bänziger et al., 1999). Sin embargo, hasta el momento son escasos los trabajos donde se analizan ventajas del carácter SG en híbridos de maíz actuales, y esto destaca la originalidad de los resultados presentados en este capítulo.

En los tres experimentos y en condiciones de secano, la covariable AFV tuvo efectos sobre el rendimiento, indicando una ventaja del carácter SG. Sin embargo, mientras que en los experimentos I y II las ventajas del grupo SG se relacionaron con ambos componentes del rendimiento, NG y PG (Exp. I) o con mayor PG (Exp. II), en el Exp. III las ventajas del grupo SG fueron menos evidentes y sólo se relacionaron con aumentos en el NG. La relación entre el carácter SG y el NG sugiere que aquellos factores involucrados en la demora de la senescencia también pueden tener efectos en estadíos tempranos del período reproductivo. Por ejemplo, si una mayor capacidad de extracción de agua y $\mathrm{N}$ fuera el factor que en último término conduce al fenotipo SG, sería esperable que en condiciones de sequía los genotipos SG presenten mayor resistencia al estrés y menor aborto de granos. Bänziger et al. (2002) estudiaron líneas de maíz en un rango de ambientes deficitarios en $\mathrm{N}$, y reportaron mayores rendimientos en los genotipos SG, que se asociaron a mayor NG y mayor PG. LoS autores proponen que el mayor NG en genotipos SG sería consecuencia de mayor disponibilidad de asimilados alrededor de floración. Similares resultados han sido reportados en sorgo, donde el NG se relacionó significativamente con la retención de AFV a madurez y/o con la tasa de senescencia (Borrell et al., 2000). Una explicación complementaria es que el mayor NG en genotipos SG podría estar relacionado al contenido de citocininas. Se ha reportado un mayor contenido de citocininas en genotipos SG de sorgo en condiciones de deficiencias de N (Ambler et al., 1992) y en genotipos SG de maíz (He, 2005). Las citocininas podrían reducir el aborto de flores. Young et al. (2004) expresaron una enzima clave en la síntesis de citocininas (isopentenil-transferasa, IPT) bajo el control de un promotor inducible durante la senescencia (SAG-12). La expresión de la enzima IPT se observó alrededor de floración, y redujo el aborto de pistilos y de la flor basal de la espiguilla resultando en dos flores funcionales por espiguilla. A partir de estos resultados, Young et al. (2004) sugieren que las citocininas podrían tener un papel importante sobre el destino de los pistilos 
durante el desarrollo de las espiguillas, y a través de esta vía, sobre la determinación del número de flores potencialmente viables.

Considerando que en el Exp. III el grupo SG presentó mayor asimilación neta, mayor relación fuente/destino, mayor MS total y menor partición a espiga en comparación con el grupo NSG, se especula que el llenado de granos estuvo limitado por otros factores distintos a la disponibilidad de fotoasimilados. En parte, el bajo PG encontrado en el grupo SG pudo estar relacionado a limitaciones por deficiencia de $\mathrm{N}$ en los destinos (Below et al., 2000; Cazetta et al., 1999). Esto podría ser esperable contemplando que en el Exp. III: (i) la fertilización nitrogenada fue baja ( $23 \mathrm{~kg} \mathrm{~N} \mathrm{ha}^{-1}$ ) y (ii) la textura arenosa del suelo implica que el $\mathrm{N}$ aplicado en la fertilización probablemente es pobremente retenido en las partículas del suelo y altamente susceptible al lavado. Considerando el ítem (ii) es altamente probable que después de floración, el $\mathrm{N}$ disponible para el llenado de granos dependió enteramente de la removilización del $\mathrm{N}$ foliar, de modo que la retención del $\mathrm{N}$ foliar, actuando a favor de la asimilación de $\mathrm{C}$, pudo haber ocurrido en detrimento de la disponibilidad de $\mathrm{N}$ en los granos.

4.3. Posibles mecanismos involucrados en la asimilación neta durante el Ilenado de granos

En los tres experimentos realizados, el grupo SG presentó mayor asimilación neta durante el llenado de granos (experimentos I y III) o al menos durante el período de estrés (Exp. II). Estas diferencias podrían estar relacionadas tanto a una mayor eficiencia de uso de la radiación interceptada como a una mayor radiación interceptada durante el período de llenado de granos.

La inhibición de la fotosíntesis $\mathrm{C}_{4}$ en condiciones de estrés hídrico ha sido atribuida tanto a efectos directos del cierre estomático y a Gs (Lal \& Edwards, 1996) como a factores no estomáticos (Ghannoum, 2009). Además, Gs puede tener influencia sobre la fotosíntesis mediante la reducción de la temperatura del canopeo, por lo que variaciones en Gs también pueden manifestarse como aparentes limitaciones no estomáticas (Richards, 2000). En este capítulo, la importancia de los factores estomáticos se manifiesta en la relación hallada entre la asimilación neta durante el 
período de estrés (o en estadíos intermedios del llenado de granos para el Exp. III) y Gs, especialmente cuando se consideraron las mediciones de Gs en el rango inferior durante ese período (Fig. 4). Hirasawa \& Hsiao (1999) reportaron que la tasa fotosintética de maíz a la tarde fue menor que a la mañana, pero estas diferencias se anularon al aumentar la concentración interna de $\mathrm{CO}_{2}$ en la cámara de medición: la tasa fotosintética a la tarde fue igual a la de la mañana si se aumentaba la Ci de 300 a 1000 micromoles mol$^{-1}$, sugiriendo limitaciones estomáticas de la fotosíntesis. Además, las curvas de asimilación neta vs. concentración interna de $\mathrm{CO}_{2}$ fueron idénticas entre mañana y tarde, aún con grandes variaciones en el déficit de presión de vapor (Hirasawa \& Hsiao, 1999). Lal \& Edwards (1996) encontraron que el índice J/A (relación entre tasa de transporte de electrones y asimilación de $\mathrm{CO}_{2}$ ), aumenta en maíz y amaranto bajo condiciones de estrés, sugiriendo que la fotosíntesis está limitada por $\mathrm{CO}_{2}$. En los muestreos donde se registraron los menores valores de Gs, el grupo SG presentó mayores valores de Gs que el grupo NSG, sugiriendo un mayor consumo de agua en el grupo SG. Este es un aporte novedoso al conocimiento existente hasta el momento, ya que (según nuestro conocimiento) no existían evidencias previas donde se analizara Gs en híbridos de maíz diferentes para el carácter SG.

Siendo que en plantas $C_{4}$ la fotorrespiración no es un destino alternativo de electrones (Ghannoum, 2009) se puede asumir que ETR es un indicador directo de la actividad fotosintética (Earl \& Tollenaar, 1999) y por lo tanto, de la inhibición de la actividad fotosintética en condiciones de sequía (Ripley et al., 2007). Los resultados presentados en este capítulo indican mayores valores de ETR a la mañana respecto al mediodía o a la tarde (Fig. 5A vs. 5B O 5C). Hirasawa \& Hsiao (1999) también reportaron máximas tasas fotosintéticas de maíz alrededor de las 11 hs, y una diminución a partir de entonces. La reducción de la fotosíntesis a partir del mediodía ha sido relacionada con limitantes estomáticas (Hirasawa \& Hsiao, 1999) asociadas al déficit de presión de vapor (independientemente del contenido de agua del suelo). Esto concuerda con los resultados presentados en este capítulo, ya que la relación entre ETR y Gs fue polinómica al mediodía (Fig. 5B) y lineal a la tarde (Fig. 5C), aún cuando se incluyó en el análisis al tratamiento regado. Si bien a la mañana no se detectó relación entre ETR y Gs, los datos presentados no permiten determinar la ocurrencia de limitaciones no estomáticas. Ripley et al. (2007) sugieren que las 
limitantes metabólicas de la fotosíntesis en condiciones de sequía severa son más importantes en la vía $C_{4}$ respecto a la vía $C_{3}$. Las limitantes metabólicas han sido atribuidas a cambios en el contenido (Tezara et al., 2002) y actividad (Tenhunen,1984) de Rubisco, reducciones en la síntesis de ATP y la regeneración de RuBP (Flexas \& Medrano, 2002), menor contenido de clorofila y menor eficiencia fotoquímica (Ögren \& Öquist, 1985; da Silva \& Arrabacxa, 2004). Sólo el contenido de clorofila fue medido en este capítulo y a los 23 DDF fue menor en secano y en el grupo NSG (datos no mostrados).

Sumado a las diferencias en la eficiencia de uso de la radiación interceptada, las diferencias en asimilación neta pueden estar asociadas también a la intercepción total de radiación durante el llenado de granos. La sequía reduce la radiación interceptada a través de sus efectos sobre la senescencia foliar (Earl \& Davies, 2003). En este capítulo se muestra que los híbridos SG presentaron mayor retención de AFV y mayor contenido de clorofila en estadíos avanzados del llenado de granos. Resulta esperable que aquellos genotipos que logren prolongar la duración del AFV intercepten mayor radiación y asimilen mayor cantidad de MS durante el llenado de granos (Fig. 7). Según (Richards, 2000) la arquitectura del canopeo adquiere relevancia cuando el índice de área foliar (IAF) excede un valor de 3, especialmente cuando el máximo crecimiento del cultivo ocurre durante el verano. Esto significa que para IAF mayores a 3, el autosombreo entre hojas comienza a tener un rol importante. En los resultados de este capítulo, el IAF en estadíos avanzados del llenado de granos (calculado a partir del rango presentado en la Fig. 7 y a una densidad de $8 \mathrm{pl} \mathrm{m}^{-2}$ ) varió en un rango aproximado entre 0 y 1,6 en el Exp. I (Fig. 7A) y entre 2 y 4 en los experimentos II y III (Figs. 7B y 7C). Esto explicaría la mayor pendiente encontrada en el Exp. I respecto a los experimentos II y III para la relación entre AFV y asimilación neta. Además, esto implica que las ventajas del carácter SG se expresarían más intensamente cuanto mayor es la tasa de senescencia, ya que cuanto menor sea el follaje remanente, mayor será el aporte relativo de cada unidad de AFV a la fotosíntesis del canopeo.

\subsection{Partición a espiga y relación con el carácter SG}

En general existe una fuerte relación negativa entre la asimilación neta durante el llenado de granos y la removilización de reservas hacia la espiga (Borras \& Otegui, 
2001). En sorgo, (Borrell et al., 2000b) discuten si la menor utilización de reservas del tallo en los genotipos SG implica un costo sobre el rendimiento y concluyen que no porque en su estudio, los híbridos SG alcanzaron entre 25 y $50 \%$ más rendimientos que los híbridos NSG. La tasa relativa de senescencia se relacionó positivamente con la removilización de reservas en condiciones de estrés durante todo el ciclo (Borrell et al., 2000b).

Los resultados presentados en este capítulo parecerían sugerir una menor partición de asimilados a la espiga en el grupo de híbridos SG (Fig. 8). Considerando que en los experimentos I y II el grupo SG alcanzó mayor PG en secano respecto al grupo NSG, la menor partición a espiga observada en estos experimentos podría estar relacionada con que en el grupo SG los destinos alcanzaron su tamaño potencial y por lo tanto el excedente de asimilados se acumuló en la MS vegetativa. En contraposición, la menor partición a espiga observada en el Exp. III en los híbridos SG no se relaciona a un alto PG (que permitiera suponer que los granos alcanzaron su tamaño potencial). Es posible que en este experimento, los destinos pudieron estar limitados por nitrógeno. Esto explicaría por qué los componentes del rendimiento se relacionaron en forma negativa (Fig. 9A) aún cuando la relación fuente/destino no se relacionó con el PG (Fig. 9B).

\section{Conclusiones}

Los genotipos estudiados presentaron diferencias en la duración del AFV y del contenido de clorofila, distinguiéndose dos grupos (SG y NSG). En los tres experimentos y en condiciones de estrés el grupo SG presentó mayor asimilación neta de MS durante el llenado de granos. Dado que la asimilación neta se asoció con Gs, y que Gs se asoció con el carácter SG, la mayor asimilación neta en los híbridos SG podría estar, en parte, asociada a una mayor Gs (y menores limitantes estomáticas de la fotosíntesis). Además, ETR en secano a la mañana no se relacionó con Gs y sí se relacionó con el carácter SG, sugiriendo menores limitantes no estomáticas de la fotosíntesis en este grupo. También la mayor asimilación neta del grupo SG es atribuible a una mayor retención de AFV en estadíos avanzados del llenado de granos. Esto implica que el carácter SG estuvo asociado a una mayor eficiencia de uso de la 
radiación interceptada, y a una mayor radiación interceptada durante el llenado de granos.

Las diferencias en asimilación neta resultaron en ventajas del rendimiento en secano en dos de los tres experimentos evaluados. En el tercer experimento, el grupo SG no presentó mayor rendimiento, y a pesar de presentar mayor relación fuente/destino que el grupo NSG, el PG fue menor. En este caso, la disponibilidad de fotoasimilados durante el llenado de granos no explica las diferencias observadas en rendimiento. Se sugiere que limitaciones de tipo nutricionales en los destinos pudieron haber restringido el uso de los fotoasimilados disponibles, y el crecimiento de los granos en el Exp. III. Este aspecto será analizado en los capítulos siguientes. 


\section{CAPÍTULO 3}

\section{SENESCENCIA FOLIAR Y RENDIMIENTO EN HÍBRIDOS DE MAÍZ FRENTE A VARIACIONES EN LA DISPONIBILIDAD DE NITRÓGENO}

\section{Introducción}

\subsection{Importancia del problema}

El uso de fertilizantes nitrogenados ha aumentado en forma exponencial: desde 1,3 millones de toneladas métricas (MMt) en 1930, a 10,2 MMt en 1960, alcanzando las 90 MMt en 2004 y proyectándose a las 240 MMt para el año 2050 (Good et al., 2004). El constante aumento del precio de los hidrocarburos, y consiguientemente de los fertilizantes nitrogenados, plantean el interrogante de cómo serán satisfechas estas demandas en el futuro. Tanto un uso excesivo como un uso insuficiente (que no llegue a reponer la cantidad de $\mathrm{N}$ extraída por lo cultivos) de fertilizantes implican un deterioro ambiental.

En Argentina, y asumiendo que en soja la fijación biológica del nitrógeno atmosférico representa un $50 \%$ del $\mathrm{N}$ extraído por el cultivo, (i.e., sin considerar la proporción de $\mathrm{N}$ fijado en el balance de extracción de nutrientes), Cruzate \& Casas (2009) calcularon que en la campaña 2006-07 sólo se aportó mediante fertilización el $40 \%$ del $\mathrm{N}$ extraído en total por los principales cultivos (soja, girasol, maíz, trigo, arroz y sorgo). Esto deja en evidencia un planteo agrícola no sustentable que redunda en una pérdida progresiva del capital suelo. Para evitar que la situación siga empeorando, será necesario reponer al menos el total de los nutrientes extraídos por lo cultivos.

En el contexto productivo será necesario combinar prácticas sustentables de uso del suelo, con genotipos que presenten mayor eficiencia en el uso de nutrientes. El requerimiento de nutrientes de un genotipo dependerá directamente de cuál sea su destino de uso. Un aumento en el índice de cosecha de N (alto contenido de proteínas) sería deseable si el grano es utilizado en la dieta humana, especialmente en contextos con pobre acceso a otras fuentes de proteína. No obstante, cuando no es necesario un alto contenido de proteína en granos, un bajo ICN (considerando la permanencia del rastrojo en el campo) sumado a una alta eficiencia de absorción y utilización del $\mathrm{N}$ optimizaría el uso de este insumo. 
Este escenario plantea la necesidad de orientar la mejora hacia cultivos con mejor eficiencia de uso del $\mathrm{N}$. La eficiencia en el uso del $\mathrm{N}$ se define como el rendimiento en grano por unidad de $\mathrm{N}$ disponible en el suelo (Ribaut et al., 2008). La EUN es la resultante de la eficiencia de absorción del $\mathrm{N}$ disponible en el suelo (EAbsN), y la eficiencia de utilización del $\mathrm{N}$ (EUtN, rendimiento alcanzado por unidad de $\mathrm{N}$ absorbido) (Hirel et al., 2007; Hirel et al., 2005). Ciampitti \& Vyn (2012) analizaron datos publicados del rendimiento del maíz frente a variaciones en la oferta de $\mathrm{N}$, discriminándolos según el año de liberación de los híbridos (híbridos de la "vieja era", 1940-1990, y de la "nueva era", 1991-2011). Estos autores concluyen que el proceso de mejora ha resultado en una mayor EUtN (principalmente a través de una dilución del contenido de proteína en grano) y mayor EAbsN (a nivel de cultivo, mientras que a nivel de planta esta variable no ha cambiado). No obstante, es necesario destacar que los rendimientos promedio de estos trabajos fueron un $67 \%$ mayores al promedio mundial para esos años (Ciampitti \& Vyn, 2012). En este contexto, la aparente mayor EUN en híbridos modernos podría estar relacionada a que en ambientes con estrés medio- bajo, el aumento de la densidad de plantas mejora la eficiencia en el uso del insumo, limitando la extrapolación de estas conclusiones a ambientes con estrés más severo.

Entre las principales especies cultivadas, el maíz es uno de los que mayor variabilidad genética presenta en la respuesta del rendimiento a la disponibilidad de $\mathrm{N}$ (Wang et al., 1999). Se ha reportado variabilidad genotípica de la respuesta del rendimiento a la disponibilidad de N (Gallais \& Coque, 2005; Hirel et al., 2007; Paponov et al., 2005). Esto implica que genotipos adaptados a ambientes deficientes en $\mathrm{N}$ no muestran la misma ventaja relativa en ambientes ricos en $\mathrm{N}$.

\subsection{Variables que definen el rendimiento bajo deficiencias de $N$}

Un ideotipo debería combinar alta EAbsN y alta EUtN; además, si el objetivo del productor incluye características nutricionales del grano (como fuente de proteínas), el genotipo ideal también debería presentar un alto índice de cosecha de $N$ (ICN). La EAbsN y la EUtN suelen relacionarse en forma negativa (Gallais \& Coque, 2005). En parte, la variabilidad genética encontrada puede explicarse porque la importancia relativa de los componentes que definen la EUN varía en función de la disponibilidad 
de $\mathrm{N}$ : en ambientes con alta disponibilidad de $\mathrm{N}$, la EAbsN adquiere más importancia relativa mientras que en ambientes deficientes en $\mathrm{N}$ la EUtN es la que mejor define el rendimiento (Gallais \& Coque, 2005). Se han detectado QTLs para rendimiento que colocalizan con QTLS para caracteres relacionados con la EUN; a baja disponibilidad de $\mathrm{N}$, la variación encontrada para QTLs relacionados con la EUtN tiene una importancia mayor que la variación encontrada para EAbsN (Gallais \& Coque, 2005). El análisis se hace más complejo aún, considerando que se ha reportado interacción genotipo $x$ disponibilidad de N para la EAbsN (Pommel et al., 2006; He et al., 2001). En el Capítulo 5 se profundiza sobre el metabolismo de compuestos nitrogenados durante la senescencia, un aspecto involucrado en la EUtN.

\subsection{Efectos fisiológicos de la deficiencia de $\mathrm{N}$ durante el ciclo del cultivo}

En maíz, la deficiencia de $\mathrm{N}$ durante el período vegetativo reduce el contenido de clorofila por unidad de área foliar $y$, en menor medida, la expansión foliar, resultando en una disminución de la radiación interceptada (Hirel et al., 2007; Uhart \& Andrade, 1995). Además, dado que el contenido de $\mathrm{N}$ foliar se relaciona con la capacidad fotosintética (Hikosaka, 2005; Paponov et al., 2005), las deficiencias en N también impactan negativamente sobre la eficiencia de uso de la radiación interceptada (Hirel et al., 2007; Uhart \& Andrade, 1995). A partir de floración, la deficiencia de $\mathrm{N}$ acelera la senescencia foliar, reduciendo aún más la intercepción lumínica y la eficiencia de uso de la radiación.

La deficiencia de $\mathrm{N}$ en floración y post-floración afectará negativamente el rendimiento a través de sus dos componentes, NG y PG. EI NG es afectado de forma indirecta través de la reducción en la disponibilidad de fotoasimilados durante el período crítico (Uhart \& Andrade, 1995). En cambio, el PG es afectado directamente por la deficiencia de $\mathrm{N}$, especialmente durante las dos semanas post-floración cuando se determina el PG potencial (Gallais \& Coque, 2005).

Los efectos del $\mathrm{N}$ sobre el crecimiento y desarrollo de los granos ocurren a través de variaciones en la actividad de enzimas específicas (Below et al., 2000; Cazetta et al., 1999; Gallais \& Coque, 2005). En experimentos in vitro, el aumento del suministro de $\mathrm{N}$ promovió la actividad de invertasas, sacarosa sintasa y aspartato amino-transaminasa (Cazetta et al., 1999). Entre éstas, las invertasas tendrían un rol 
principal. La transferencia de asimilados desde el floema a los granos ocurre principalmente por vía apoplástica (Doehlert et al., 1988), por lo cual, el aumento del gradiente de concentración de sacarosa entre el floema y los granos facilita la transferencia de asimilados. Las invertasas apoplásticas, a través del clivaje de sacarosa en hexosas, estarían involucradas en mantener este gradiente (Koch et al., 1996) y por lo tanto, en la utilización de los asimilados disponibles (Below et al., 2000). Se han encontrado que QTLs relacionados a la EUN co-localizan con genes que codifican para invertasas en maíz (Gallais \& Coque, 2005).

Especialmente a partir de floración, tanto la asimilación primaria de $\mathrm{N}$ por la raíz como la removilización de $\mathrm{N}$ desde las hojas senescentes contribuyen a abastecer la demanda de $\mathrm{N}$ de los destinos (Hirel et al., 2007). En esta etapa, el $\mathrm{N}$ absorbido por la raíz puede representar hasta un $60 \%$ del N aportado a los granos (Coque \& Gallais, 2007). El aporte restante proviene de reservas de $\mathrm{N}$ removilizadas desde las hojas durante la senescencia foliar, que pueden representar hasta el $70 \%$ del $\mathrm{N}$ presente en la planta (Gallais \& Coque, 2005). Se ha reportado una relación negativa entre la removilización de $\mathrm{N}$ y la absorción de $\mathrm{N}$ en postantesis (Gallais \& Hirel, 2004). Esto se explica porque la removilización está relacionada con la degradación de proteínas en hojas senescentes, mientras que la absorción está vinculada con hojas fotosintéticamente activas y por lo tanto, capaces de abastecer con C a la raíz

\subsection{Fundamentos y planteo de la hipótesis}

Los resultados del Capítulo 2, muestran que la demora en la senescencia de los genotipos SG se traduce en una mayor disponibilidad de fotoasimilados durante el llenado. Esto permitiría mantener el suministro de fotoasimilados a los granos abasteciendo al mismo tiempo la demanda de $\mathrm{C}$ de la raíz, y por lo tanto manteniendo la absorción de $\mathrm{N}$ edáfico en post-floración (Ma \& Dwyer, 1998). La absorción de $\mathrm{N}$ en post-floración, aliviaría la demanda de $\mathrm{N}$ por lo granos, retrasando el inicio de la senescencia, i.e., una retroalimentación positiva sobre la expresión del carácter SG. Existen evidencias de que los genotipos SG de maíz y sorgo presentan mayores rendimientos que genotipos estándar en ambientes que presentan deficiencias de $\mathrm{N}$ (Bänziger et al., 1999; Bänziger et al., 2002; Borrell \& Hammer, 2000; Ma \& Dwyer, 
1998; Rajcan \& Tollenaar, 1999a). Las hipótesis planteadas para el presente capítulo son:

(2) En condiciones de deficiencias de nitrógeno, la demora en la senescencia foliar está asociada a mayor producción de fotoasimilados y mayor rendimiento.

(2.1.) En condiciones de deficiencias de nitrógeno, los genotipos SG presentan mayor producción de fotoasimilados en post-floración.

(2.2.) En condiciones de deficiencias de nitrógeno, los genotipos SG presentan mayor rendimiento.

\section{Materiales y Métodos}

\subsection{Diseño experimental}

Se realizaron dos ensayos a fin de determinar si la senescencia demorada de híbridos SG de maíz confiere una ventaja en rendimiento en ambientes con estrés por baja disponibilidad de N. En total se realizaron 12 tratamientos que consistieron en combinaciones de (i) Disponibilidad de $\mathrm{N}$ e (ii) Híbridos. El tratamiento de disponibilidad de $\mathrm{N}$ consistió en la aplicación de tres dosis de $\mathrm{N}$ en forma de urea: 0 , 100 y $200 \mathrm{~kg}$ de $\mathrm{N}$ ha ${ }^{-1}$ que serán mencionados como N0, N100 y N200 respectivamente. Todos los tratamientos recibieron además, $18 \mathrm{~kg}$ de $\mathrm{N}_{\text {ha }}{ }^{-1}$ en forma de fosfato diamónico (FDA, ver detalles para cada experimento) a la siembra. Los genotipos (4 híbridos simples de maíz) fueron seleccionados en base a su comportamiento contrastante en la demora de la senescencia foliar bajo condiciones de estrés hídrico (Capítulo 2). El comportamiento de estos híbridos bajo sequía en post-floración permitió clasificar a AW190 y DK682 como NSG y a AX878 y NK880 como SG.

Los ensayos se realizaron durante las campañas 2010-11 y 2011-12 en la Estación Experimental "Julio Hirschhorn" de la Facultad de Agronomía de la Universidad Nacional de La Plata, situada en Los Hornos, Pcia. de Buenos Aires. Las parcelas consistieron en 4 surcos distanciados a 0,7 m entre sí, y tuvieron una superficie de $19,6 \mathrm{~m}^{-2}$ (2,8 $\mathrm{m}$ de ancho $\times 7 \mathrm{~m}$ de largo). Se realizaron cuatro 
repeticiones para cada combinación de nivel de $\mathrm{N} x$ híbrido. El diseño del ensayo correspondió a un diseño de bloques donde el nivel de $\mathrm{N}$ fue aleatorizado en la parcela principal mientras que los híbridos fueron aleatorizados en cada sub-parcela. Para evitar efectos residuales del fertilizante aplicado entre un ensayo y el siguiente, la superficie total del ensayo correspondiente al Exp. I fue delimitada en sus vértices. Esto permitió que en el Exp. II, la disposición de los tratamientos ( $\mathrm{N}$ x Híbrido) correspondiera exactamente a la disposición del Exp. I. El suelo corresponde a un argiudol típico (Soil Conservation Service 1994). En el 2010 se tomaron muestras de suelo en el lote para estimar contenido de $\mathrm{P}$ y $\mathrm{N}$. Antes de la siembra el contenido de $\mathrm{N}$ total en los primeros $20 \mathrm{~cm}$ de suelo fue de $1430 \mathrm{ppm}$ y el contenido de $\mathrm{P}$ fue de 6 ppm. Esto equivale a $2860 \mathrm{~kg}$ de $\mathrm{N}$ total por ha ${ }^{-1}$ en los primeros $20 \mathrm{~cm}$ de suelo.

En ambos ensayos las semillas fueron sembradas en forma manual (dos semillas por hoyo) y raleadas entre 10 y 20 días después de emergencia (DDE) hasta lograr una densidad final de $80000 \mathrm{pl} \mathrm{ha}^{-1}$. Las parcelas se mantuvieron regadas durante todo el ciclo, y libres de malezas mediante aplicación de herbicidas cuando fue necesario.

\section{Experimento l:}

Las semillas fueron sembradas el 12-11-2010. La emergencia ocurrió el 20-112010. Todas las parcelas fueron fertilizadas en $\mathrm{V} 2$ con $45 \mathrm{~kg} \mathrm{P} \mathrm{ha}^{-1}$ y $18 \mathrm{~kg} \mathrm{~N} \mathrm{ha}{ }^{-1}$ (aplicado en forma de FDA). En V3, los tratamientos N100 y N200 fueron fertilizados con $100 \mathrm{~kg}_{\text {de } \mathrm{N} \mathrm{ha}}{ }^{-1}$. En V6, se aplicaron $100 \mathrm{~kg}$ de $\mathrm{N} \mathrm{ha}^{-1}$ (en forma de urea) en el tratamiento N200. La emergencia de estigmas $\left(R_{1}\right)$ ocurrió +/- 2 días alrededor del 3101-2011.

\section{Experimento II:}

Las semillas fueron sembradas el 26-10-11. La emergencia ocurrió el 3-11-2011. Todas las parcelas fueron fertilizadas en emergencia con $45 \mathrm{~kg} \mathrm{P} \mathrm{ha}^{-1}$ y $18 \mathrm{~kg} \mathrm{~N} \mathrm{ha}{ }^{-1}$ (aplicado en forma de FDA). En V3, los tratamientos N100 y N200 fueron fertilizados con $100 \mathrm{~kg}_{\text {de } \mathrm{N} \mathrm{ha}}{ }^{-1}$. En V7 el tratamiento N200 recibió una segunda dosis de urea

correspondiente a $100 \mathrm{~kg}$ de $\mathrm{N}$ ha ${ }^{-1}$. La emergencia de estigmas $\left(\mathrm{R}_{1}\right)$ ocurrió +/- 2 días alrededor del 07-1-2012.

\subsection{Mediciones generales}


El procedimiento para efectuar las mediciones que se enumeran a continuación, ha sido descripto en el Capítulo 2. A partir de floración, se realizaron muestreos destructivos periódicos hasta madurez fisiológica (MF). La fecha de madurez fisiológica se determinó cuando el $50 \%$ de las plantas medidas en cada tratamiento $(n=8)$ presentó la formación de capa negra en granos de la porción media de la espiga. Para cada tratamiento y fecha de muestreo, se cosecharon 2 plantas por parcela, por lo que todos los promedios presentados corresponden a 8 plantas por tratamiento. En cada muestreo destructivo se analizó la progresión de la senescencia foliar en términos de AFV y mediciones de SPAD a lo largo del perfil vertical de la planta.

A partir de los muestreos destructivos se analizó el patrón de acumulación de MS desde floración. La removilización, la acumulación de MS, y el crecimiento de espiga se calcularon en base al promedio de 8 plantas por tratamiento, como se describe en el Capítulo 2. En ambos experimentos, la acumulación de MS presentó un patrón característico para cada nivel de $\mathrm{N}$ y genotipo. Por este motivo, se realizó un análisis complementario que consistió en dividir el período de acumulación de MS en dos sub-períodos definidos por la ocurrencia de temperaturas mínimas inferiores a $10^{\circ} \mathrm{C}$. Evidencias previas demuestran que entre los 9 y $10^{\circ} \mathrm{C}$, se reduce sustancialmente la tasa de intercambio fotosintético (Dwyer \& Tollenaar, 1989) y la actividad de enzimas específicas (Du et al., 1999; Naidu et al., 2003). El rendimiento se calculó sobre la base de las espigas de 20 plantas consecutivas muestreadas en los dos surcos centrales de cada parcela (10 plantas por surco, 80 plantas por tratamiento). Los componentes NG y PG, se calcularon como se describe en el Capítulo 2.

\subsection{Registro no destructivo de la senescencia foliar}

A partir de floración, 8 plantas por tratamiento (2 plantas por parcela) fueron identificadas a fines de realizar un registro no destructivo (visual) de la evolución de la senescencia. La senescencia foliar se registró semanalmente (o 2 veces por semana a partir de aprox. 30 DDF) en términos de porcentaje de tejido muerto (seco) en cada hoja de la planta. El AFV de cada hoja se calculó como la diferencia entre el AFV de la hoja medida en el primer muestreo destructivo (c.a. 7 DDF) y el área foliar 
representada por el porcentaje de hoja senescente y seca estimado en forma visual. Como convención, se hará referencia a las distintas hojas de la planta siguiendo el siguiente criterio: la hoja adyacente a la espiga se denominará "hoja 0"; las hojas por encima de la espiga serán denominadas consecutivamente con números positivos (hoja +1 , +2 , etc.) y las hojas por debajo de la espiga serán denominadas consecutivamente con números negativos (hoja -1, -2, etc.). Para el procesamiento de los datos y la expresión de los resultados, se fraccionó el canopeo en tres estratos representando cada uno de ellos aproximadamente un tercio del AFV total de la planta en madurez: estrato superior (hojas $+7 \mathrm{a}+1$ ), estrato medio (hojas 0 a -2 ) y estrato inferior (hojas -3 a -7).

Durante el período reproductivo, frecuentemente pueden distinguirse una fase inicial, relativamente lenta, de disminución del AFV, seguida por una fase más rápida en estadíos avanzados del Ilenado (Borrás et al., 2003; de la Vega et al., 2011). El momento en que la tasa de senescencia se acelera ("punto de quiebre, PQ" de la relación entre AFV y tiempo térmico) ha sido utilizado previamente como indicador de carácter SG (v.g., Borrell et al., 2000), y será utilizado en este Capítulo con el mismo fin EI PQ se calculó mediante una regresión por partes entre el AFV (registro visual) y el tiempo térmico acumulado desde floración. Para esto se utilizó un software (Infostat, 2009) que ajusta la serie de datos a una regresión en dos tramos. La ordenada al origen del segundo tramo de la regresión (es decir, el valor de $\mathrm{x}$ donde comienza el segundo tramo), es el PQ. En la serie de datos de AFV se consideraron solamente valores desde floración hasta alcanzar ca. el $10 \%$ del AFV máxima a fines de evitar que valores muy bajos de AFV hacia el final del ciclo alteraran el ajuste del segundo tramo de la regresión. Completado el ciclo del cultivo, es posible registrar valores menores al $10 \%$ del AFV, pero mayores que 0 , durante períodos prolongados de tiempo, aún cuando el llenado de los granos ha finalizado. Es evidente que esta pequeña área foliar remanente no tiene importancia fisiológica en el llenado, y por eso se evitó incorporarla al análisis de la evolución del AFV.

\subsection{Intercepción de radiación}

La intercepción de luz medida al mediodía es un buen indicador de la intercepción de radiación por el canopeo a lo largo del día (Earl \& Davis, 2003) y puede 
ser estimada como la inversa de la transmitancia aparente (i.e., sin considerar la reflexión de luz por el canopeo). La transmitancia de luz a través del canopeo se registró con un ceptómetro de $1 \mathrm{~m}$ de longitud (Accupar Model 80, Decagon devices). Las mediciones se realizaron en las 2 hs alrededor del mediodía, a nivel del suelo y a distintas alturas del canopeo (hoja +3 , hoja 0 y hoja -3 ) atravesando el ceptómetro en diagonal entre los dos surcos centrales de cada parcela; se obtuvieron 8 valores por tratamiento ( $\mathrm{N}$ x Híbrido). Los valores de transmitancia se expresaron como porcentaje respecto a la irradiancia incidente por encima del canopeo.

\subsection{Eficiencia fotosintética}

A partir de floración, se realizaron mediciones instantáneas de la fluorescencia modulada de la clorofila para estimar la tasa de transporte fotosintético de electrones en el fotosistema II (ETR) con un fluorímetro modulado de la clorofila (FMS2, Hansatech, UK). Las mediciones se realizaron en 8 plantas por tratamiento ( 2 plantas por parcela), seleccionando plantas sobre los surcos centrales de cada parcela. En estos experimentos se esperaba que los tratamientos impactaran fuertemente en la capacidad fotosintética de las hojas, y que las limitaciones estomáticas tuvieran menos importancia, ya que las parcelas estuvieron regadas durante todo el ciclo. Por este motivo, la actividad fotosintética sólo se midió alrededor del mediodía cuando, debido a la mayor irradiancia, se esperaba que las diferencias genotípicas se expresaran con mayor intensidad. Las mediciones se hicieron sobre porciones de la hoja que estuvieran expuestas a luz directa en su posición natural. ETR fue medida en las 2 horas alrededor del mediodía en la porción media de la hoja de la espiga y en una posición intermedia entre la nervadura principal y el borde de la hoja.

La tasa de transporte fotosintético de electrones se calculó como en Maxwell y Johnson (2000) según la fórmula: $\quad$ Ф FSII x PAR x Abs x 0,5

Donde $\Phi$ FSII es el rendimiento cuántico del fotosistema II, PAR es la radiación fotosintéticamente activa medida por el sensor del fluorímetro, Abs es la absorbancia de la hoja y 0,5 un factor que toma en cuenta el hecho de que la radiación absorbida se reparte entre los fotosistemas I y II.

Como la absorbancia de las hojas puede variar sustancialmente entre tratamientos (fundamentalmente dosis de $\mathrm{N}$ ) y durante la senescencia, previo al inicio 
de estas mediciones se determinó la relación entre los valores de SPAD de una hoja (se tomaron para esto sectores de hojas homogéneas) y su absorbancia verdadera medida con una esfera integradora (gentileza del Laboratorio de Luminotecnia, CICBA). Sobre el sitio de medición de ETR se midió el SPAD de la hoja, a fin de ajustar las mediciones de ETR en función de la absorbancia de cada hoja en particular según la fórmula:

$$
\text { Abs }=0,008 \text { Unidades SPAD }+0,356 \quad\left(R^{2}=0,926\right)
$$

\subsection{Análisis Estadístico}

Los datos se analizaron con el software STATISTICA 5.1. (StatSoft, Inc.). Las diferencias entre experimentos se analizaron mediante ANOVA; se utilizaron como factores fijos el experimento, la dosis de $\mathrm{N}$ y el híbrido, y como variable dependiente cada una de las variables de interés. En cada experimento, los efectos de los distintos tratamientos también fueron analizados mediante ANOVA, donde los factores fijos correspondieron a la dosis de $\mathrm{N}$ y el híbrido y la variable dependiente a cada una de las variables de interés en cada experimento. Cuando se presentaron efectos significativos de los tratamientos, o interacción entre ellos, las diferencias se analizaron mediante el test de diferencias mínimas significativas (DMS). En los gráficos o tablas donde se presentan letras, las mismas letras corresponden a grupos homogéneos para DMS $(P<$ $0,05)$.

A fines de detectar el impacto del carácter SG sobre variables asociadas al rendimiento, se realizó un análisis de covarianza utilizando el PQ (una variable indicadora del carácter SG) como covariable. Dado que la covariable no es un factor fijo, no es posible analizar los efectos diferenciales de la covariable simultáneamente en más de un tratamiento. Por este motivo, el análisis de covarianza se realizó para todos los tratamientos de $\mathrm{N}$ y alternativamente, sólo para el tratamiento NO. De esta forma, se evitó que diferencias genotípicas que ocurran en ambientes con baja o nula deficiencia de $\mathrm{N}$ (N100, N200) sobrevaluen la importancia del carácter SG en ambientes con deficiencia moderada- alta (NO).

Otros detalles del análisis estadístico se describen en el Capítulo 2. 


\section{Resultados}

\subsection{Caracterización meteorológica}

Las condiciones climáticas variaron entre experimentos. En el Exp. I (Fig. 1A), las temperaturas medias fueron más bajas, las temperaturas máximas no superaron los $30^{\circ} \mathrm{C}$, y las temperaturas mínimas fueron inferiores a los $10^{\circ} \mathrm{C}$ a partir de los 40 DDF. En cambio, en el Exp. II (Fig. 1B) las temperaturas medias fueron mayores, las máximas superaron los $30^{\circ} \mathrm{C}$ hasta los $40 \mathrm{DDF}$, y las mínimas se mantuvieron por encima de $10^{\circ} \mathrm{C}$ hasta aprox. los 70 DDF.
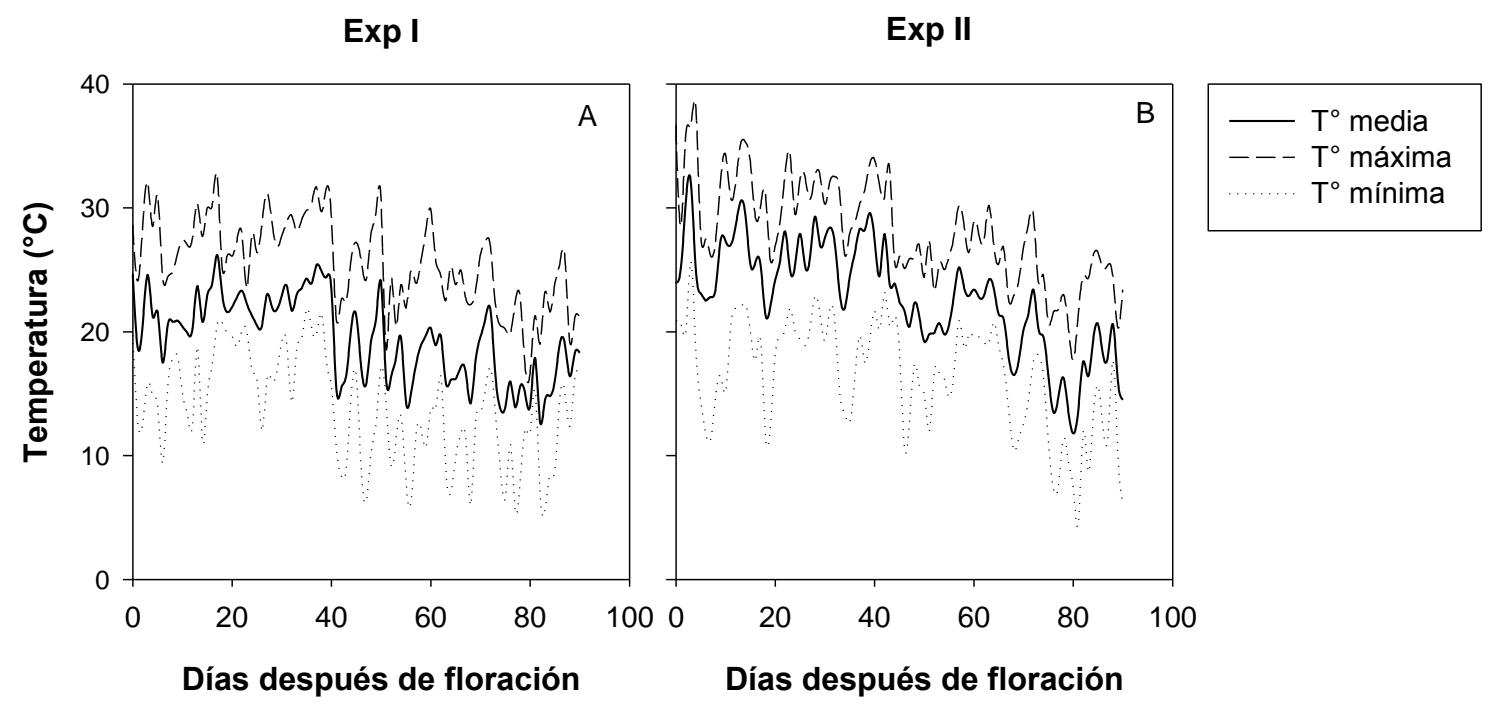

Fig. 1: Temperaturas máximas, medias y mínimas diarias desde floración y hasta madurez fisiológica en los experimentos I (A) y II (B). 


\subsection{Evolución de la senescencia foliar}

En ambos experimentos, el AFV a floración aumentó $(P<0,05)$ con el nivel de $N$ (Figs. 2 y 3). En el Exp. I existió interacción $\mathrm{N}$ x híbrido, y en el Exp. II se detectaron efectos del híbrido para el AFV a floración. El AFV a floración fue significativamente menor en DK682 respecto a los demás híbridos en el tratamiento NO del Exp. I (0,40 vs $\left.0,47 \mathrm{~m}^{-2} \mathrm{pl}^{-1}\right)$ mientras que en el Exp. II las diferencias entre híbridos se redujeron $(0,39$ vs $\left.0,34 \mathrm{~m}^{-2} \mathrm{pl}^{-1}\right)$.

En ambos experimentos, la senescencia foliar se aceleró conforme se redujo la disponibilidad de $\mathrm{N}$ (Figs. 2 y 3). En las Figs. 2 y 3 puede observarse un cambio en la evolución de la senescencia, con una primera fase inicial lenta, y una fase final más rápida. En ambos años el ANOVA detectó efectos significativos $(P<0,05)$ del $\mathrm{N}$ y el híbrido para el inicio de la fase rápida de senescencia. El inicio de la fase rápida de senescencia ocurrió más temprano en el tratamiento NO de ambos experimentos, mientras que no hubo diferencias entre N100 y N200 (Figs. 4A y 4B). Con respecto a los híbridos, en ambos años la fase rápida de senescencia comenzó más temprano en el híbrido NSG DK682; el híbrido AW190 (NSG en el Capítulo 2) presentó un comportamiento moderadamente SG y no se diferenció de AX878 (SG en el Capítulo 2). El híbrido SG NK880, en ambos experimentos, fue el que comenzó la fase rápida de senescencia más tardíamente (Figs. 4C y 4D). A partir de estos resultados, en este Capítulo, los híbridos serán caracterizados como NSG (DK682), moderadamente SG (AW190 y AX878) y SG (NK880). 


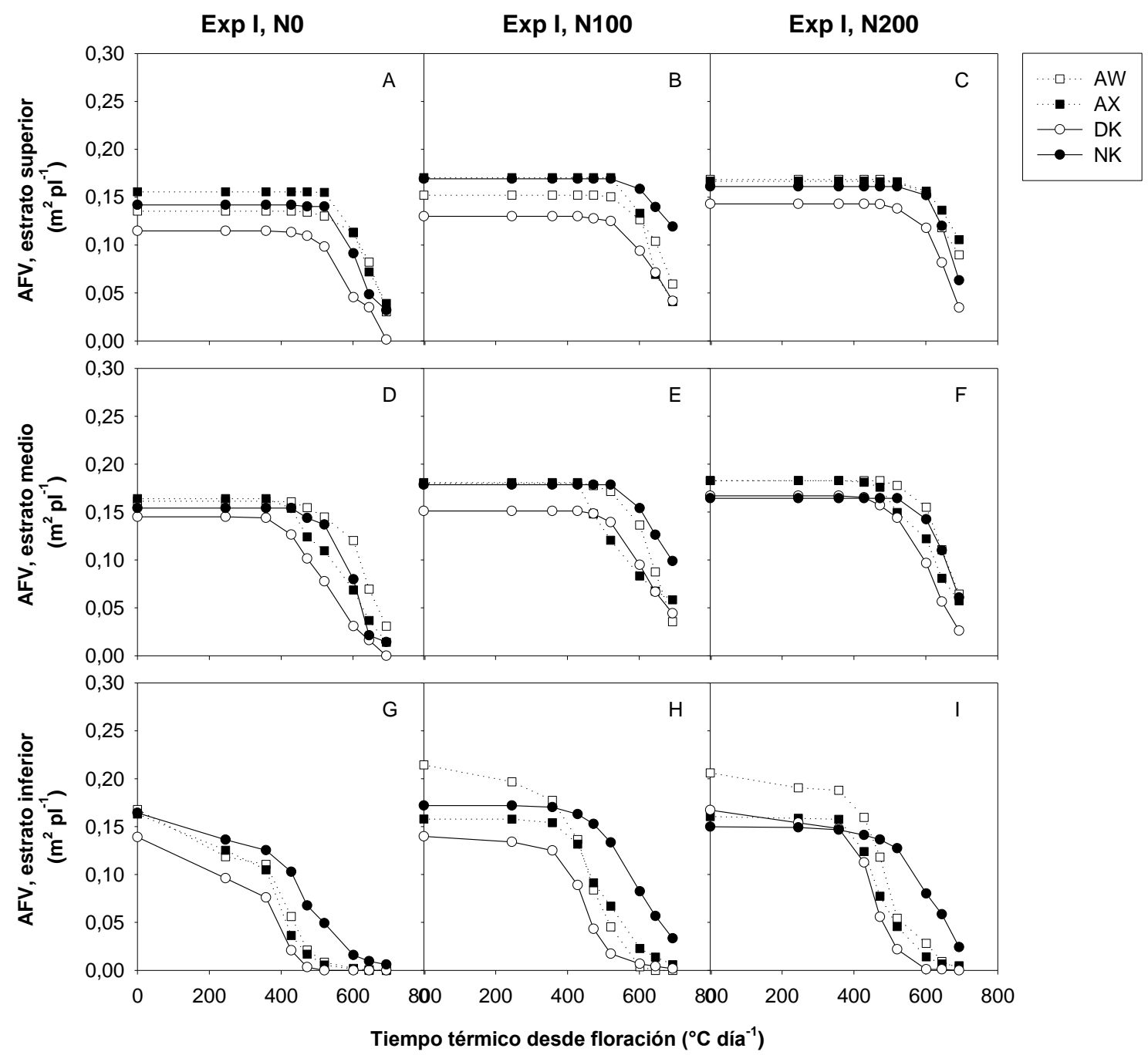

Fig. 2: Exp. I, progresión de la senescencia en términos de área foliar verde (AFV) en los tratamientos $\mathrm{NO}(\mathrm{A}, \mathrm{D}, \mathrm{G}), \mathrm{N} 100(\mathrm{~B}, \mathrm{E}, \mathrm{H})$ y N200 (C, F, I) en cuatro híbridos (referencias en el gráfico). Para cada tratamiento se muestran tres estratos del canopeo: superior $(A, B, C)$, medio $(D, E, F)$ e inferior $(G, H, I)$. Cada punto es el promedio de 8 plantas. 


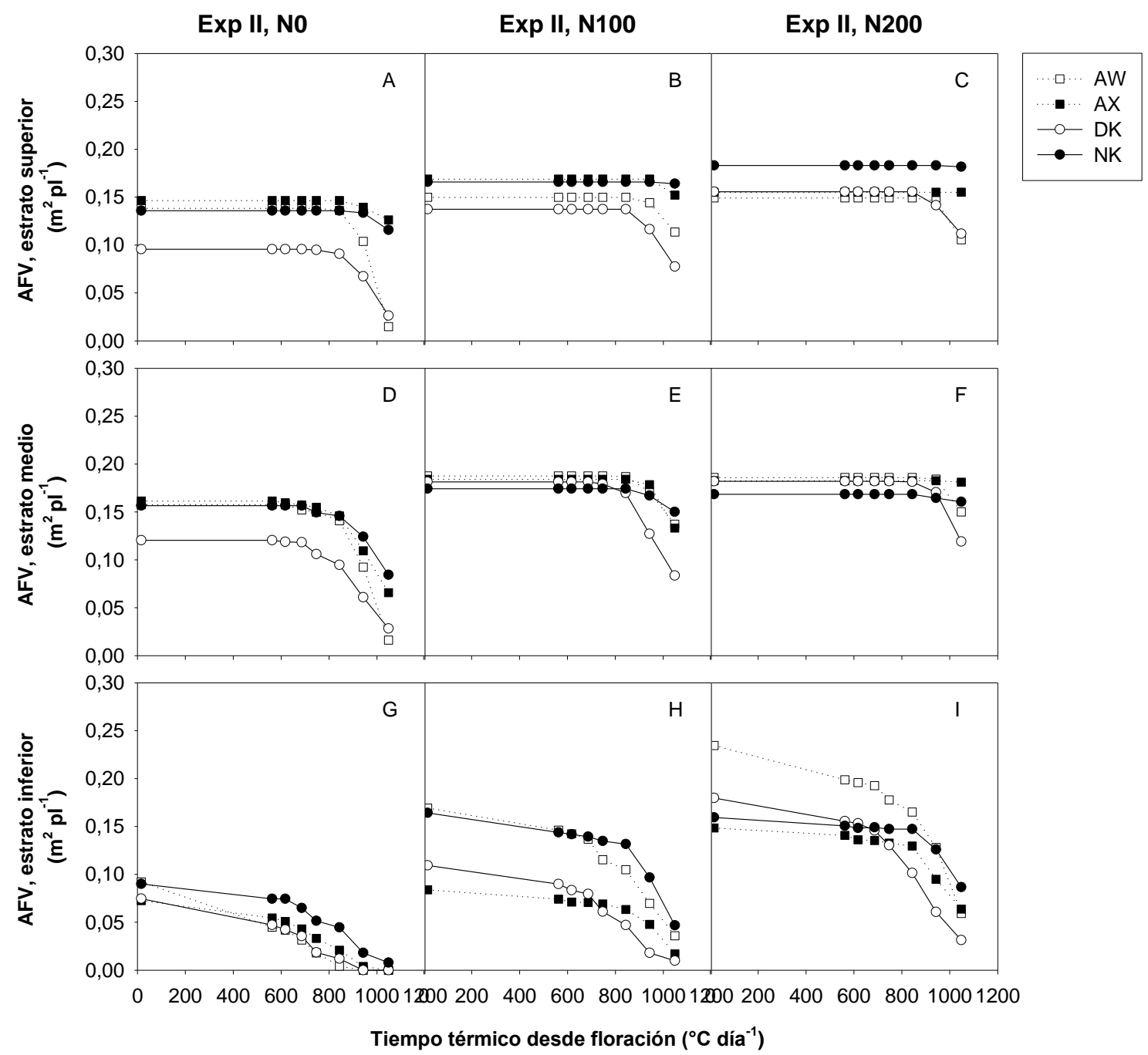

Fig. 3: Exp. II, progresión de la senescencia en términos de área foliar verde (AFV) en los tratamientos NO (A, D, G), N100 (B, E, H) y N200 (C, F, I) en cuatro híbridos (referencias en el gráfico). Para cada tratamiento se muestran tres estratos del canopeo: superior $(A, B, C)$, medio $(D, E, F)$ e inferior $(G, H, I)$. Cada punto es el promedio de 8 plantas. 


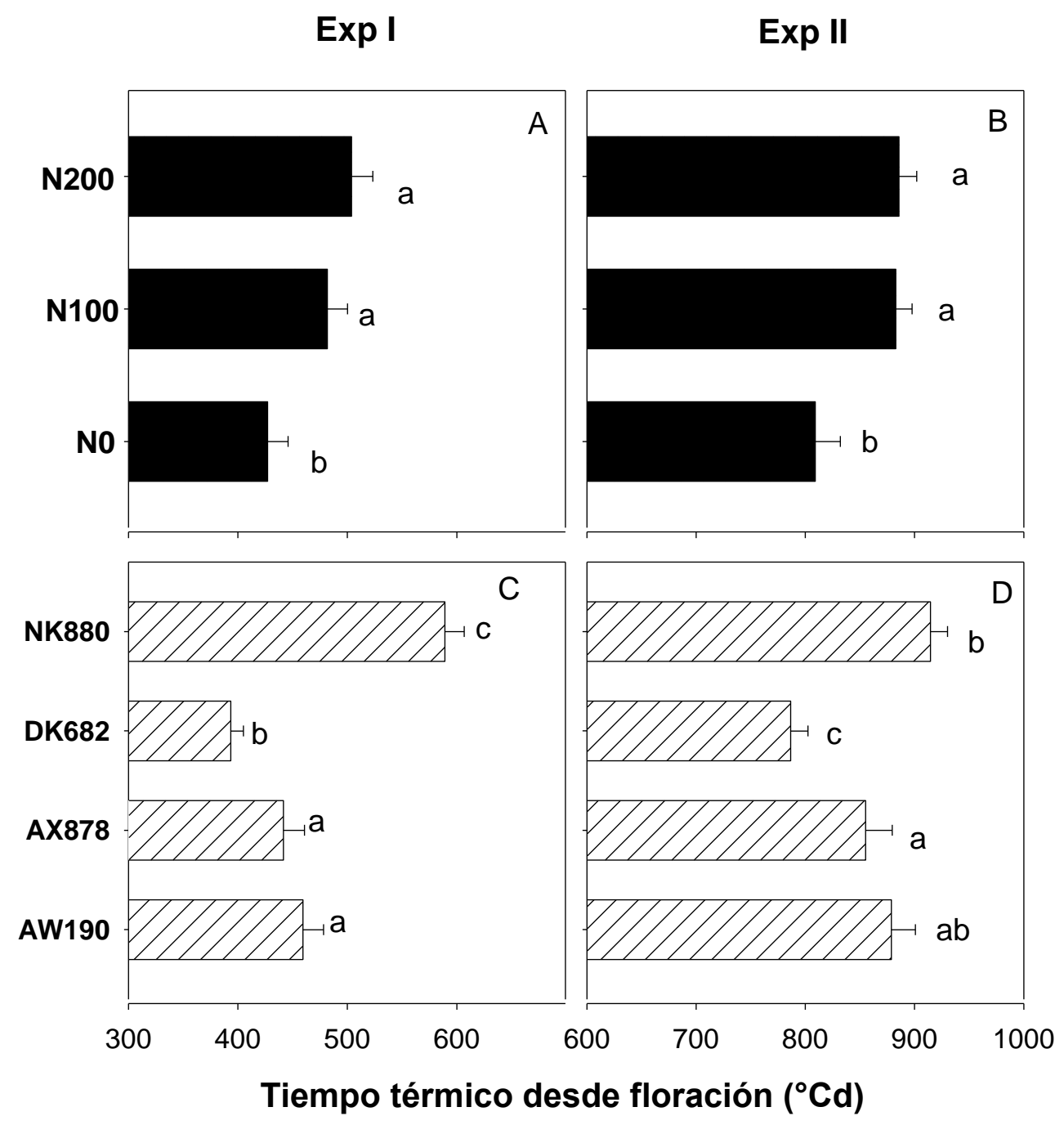

Fig. 4: Comienzo de la fase rápida de senescencia en cada nivel de $N(n=32)$ en los experimentos I (A) y II (B) y en cada híbrido $(n=24)$ en los experimentos I (C) y II (D). 


\subsection{Contenido de clorofila}

En ambos experimentos, el contenido de clorofila (promedio por planta y estimado a partir del valor SPAD) fue afectado significativamente por la dosis de $\mathrm{N}$ y por el híbrido, desde floración y hasta los 60 DDF $(P<0,05)$. Como era esperable, a partir de floración el contenido de clorofila cayó más rápidamente en el tratamiento NO (Figs. 5 y 6$)$.

En el tratamiento N0, los híbridos SG (NK880) y moderadamente SG (AW190 y AX878) presentaron mayores contenidos de clorofila en floración en todos los estratos en el Exp. I (Figs. 5A, 5D, 5G) pero no en el Exp. II (Figs. 6A, 6B, 6G). Según se observa en la Fig. 5, la variación entre híbridos se redujo conforme aumentó la dosis de N (por ej. Figs. 5D, 5E y 5F). Por otro lado, dentro de cada dosis de $\mathrm{N}$, las diferencias entre híbridos variaron según el estrato: en las Figs. $5 G$ y $6 G$ se observa que aún en el estrato inferior, el híbrido NK880 mantuvo altos contenidos de clorofila hacia mediados del llenado mientras que en AW190 y AX878 estos valores decayeron. Sin embargo, AW190 y AX878 mantuvieron el contenido de clorofila del estrato superior a niveles similares a los de NK880 (Fig. 5A y 6A). Similares diferencias entre híbridos dependiendo del estrato, se observan para la dosis N100 en el Exp. I (Figs. 5B y 5H) y en el Exp. II (Figs. 6B y $6 \mathrm{H}$ ).

Hacia el final del llenado, el híbrido SG NK880, retuvo un mayor contenido de clorofila incluso en el tratamiento NO. Esta tendencia se mantuvo en todas las dosis de $\mathrm{N}$ y se acentuó aún más en el estrato superior (Figs. 5A, 5B, 5C; Figs. 6A, 6B, 6C). 


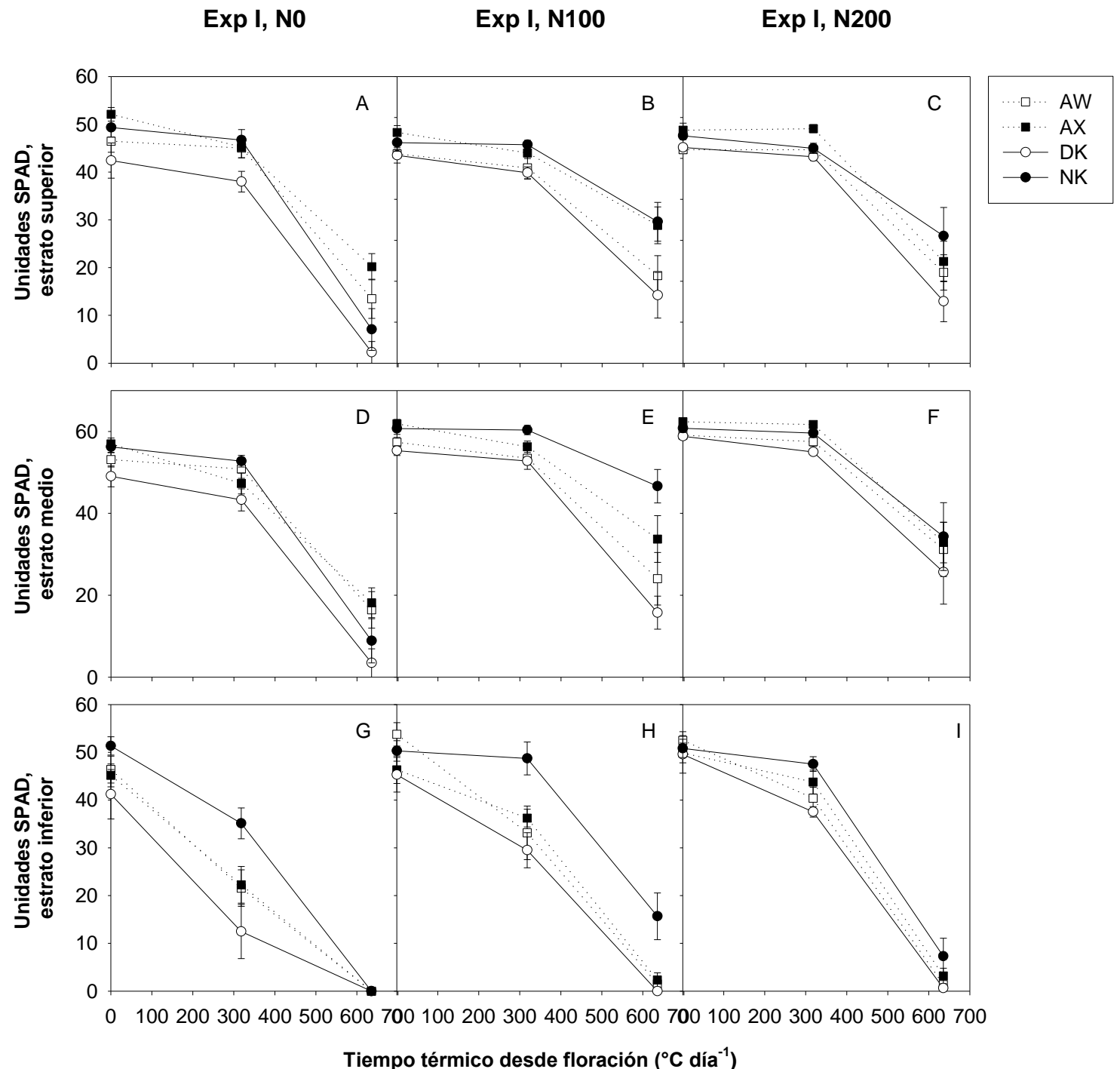

Fig. 5: Exp. I, progresión de la senescencia en términos del contenido de clorofila foliar (unidades SPAD) en los tratamientos NO (A, D, G), N100 (B, E, H) y N200 (C, F, I) en cuatro híbridos (referencias en el gráfico). Para cada tratamiento se muestran tres estratos del canopeo: superior $(A, B, C)$, medio $(D, E, F)$ e inferior $(G, H, I)$. Cada punto es el promedio de 8 plantas. 


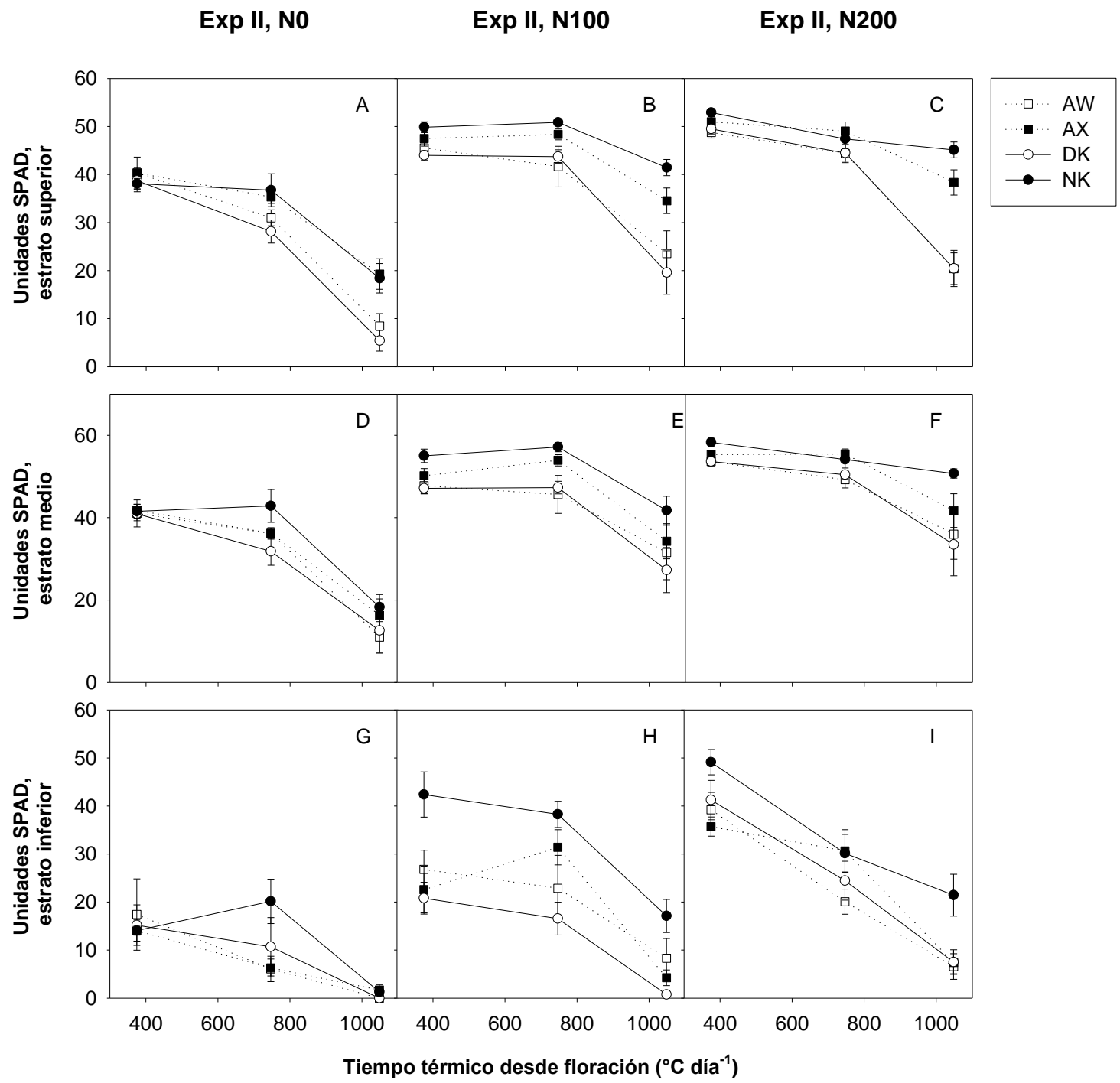

Fig. 6: Exp. II, progresión de la senescencia en términos del contenido de clorofila foliar (unidades SPAD) en los tratamientos NO (A, D, G), N100 (B, E, H) y N200 (C, F, I) en cuatro híbridos (referencias en el gráfico). Para cada tratamiento se muestran tres estratos del canopeo: superior $(A, B, C)$, medio $(D, E, F)$ e inferior $(G, H, I)$. Cada punto es el promedio de 8 plantas. 


\subsection{Intercepción de luz por el canopeo}

La transmitancia de luz a través del canopeo es un estimador de la intercepción de luz por el cultivo. En ambos experimentos la transmitancia se redujo $(P<0,05)$ al aumentar la dosis de N (i.e., aumentó la intercepción) y varió significativamente entre híbridos. Estos efectos fueron significativos en las distintas alturas del canopeo (hoja 0, hoja -3 y a nivel del suelo).

En el Exp. I, a los 15 DDF, la transmitancia se redujo al aumentar la dosis de $\mathrm{N}$ (Fig. 7A y 7C). A nivel del suelo la menor transmitancia de luz se registró en las parcelas del híbrido SG NK880; valores intermedios se registraron en AX878 (que no se diferenció significativamente de NK880) y AW190, mientras que los menores valores (DMS $<0,05$ ) se registraron en las parcelas del híbrido NSG DK682.

En el Exp. II, a los 50 DDF nuevamente el aumento de la dosis de $\mathrm{N}$ redujo la transmitancia de luz (Figs. 7B y7D). A nivel del suelo existió interacción entre tratamientos $(\mathrm{N} \times \mathrm{H})$ : en N0, la transmitancia de luz fue significativamente menor en los híbridos AX878, NK880 y AW190, respecto a DK682 (DMS > 0,05). Esta tendencia se corresponder con el inicio más temprano de la senescencia en DK682. En cambio, en N200, la transmitancia fue menor en AX878 y NK880 respecto a AW190 y DK682. 
Exp I
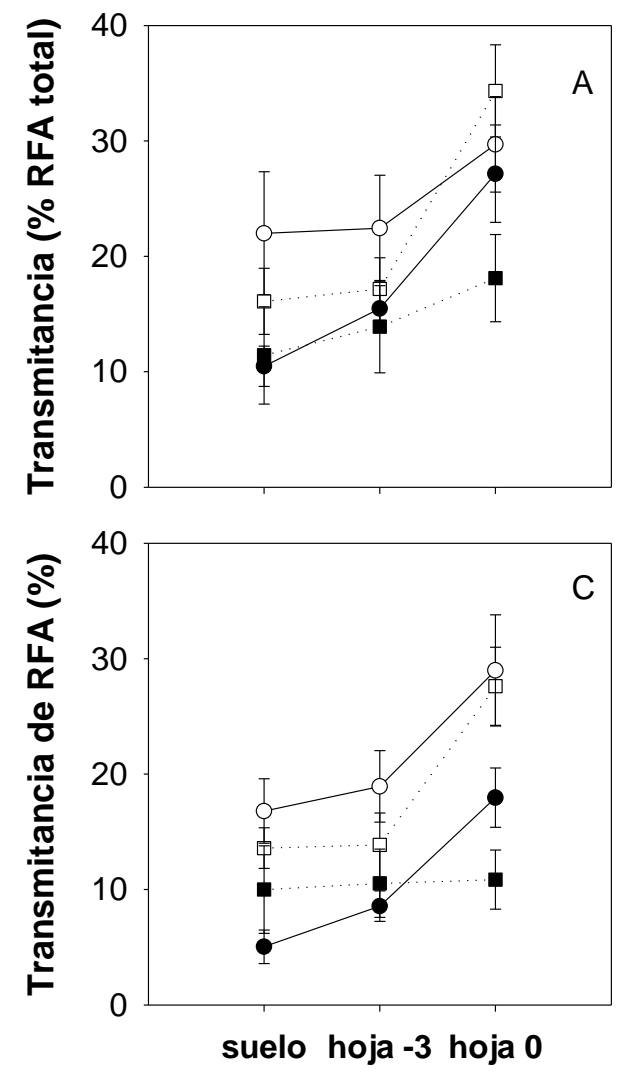

Exp II
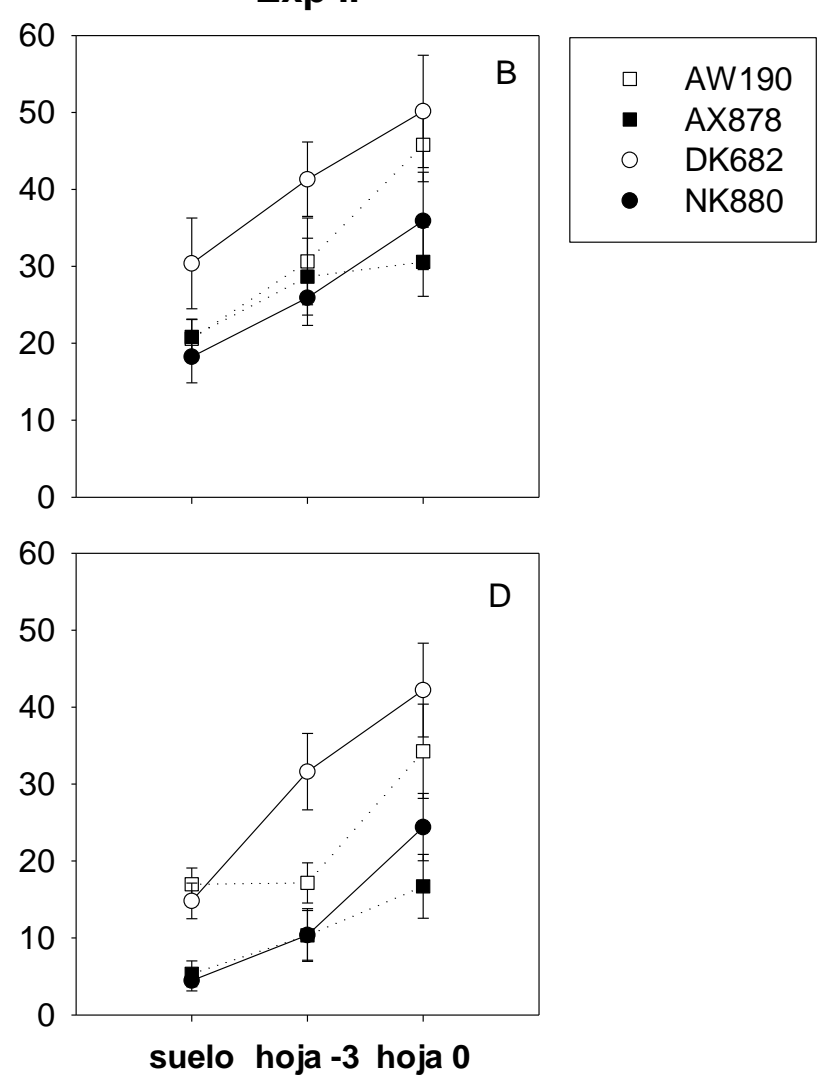

Altura en el canopeo

Fig. 7: Porcentaje de luz transmitida (\% de la radiación fotosintéticamente activa, RFA, total incidente) a nivel del suelo, de la hoja -3 y de la hoja 0 (espiga) en el Exp. I a los 15 $\operatorname{DDF}(A, C)$ y en el Exp. II a los $50 \operatorname{DDF}(B, D)(B, D)$ en los tratamientos NO $(A, B)$ y N200 (C, D). Cada punto es el promedio de 8 mediciones en cada tratamiento. 


\subsection{Rendimiento y componentes}

Utilizando el PQ como covariable, no se presentaron efectos significativos de la covariable sobre el rendimiento ya sea considerando las tres dosis de $\mathrm{N}$ o sólo la de máximo estrés (NO) (Tabla 1). Al analizar la relación entre el PQ y el rendimiento, se observó una relación positiva en condiciones de moderado (N100, Fig. 8C) y alto (N200, Fig. 8E) nivel de fertilización pero en condiciones de deficiencia de N (N0, Fig. 8A) la relación presentó una tendencia polinómica negativa. Se destaca además que, en NO, la relación entre el rendimiento y el PQ varió entre años. Se detectó interacción significativa Exp. x N (Tabla 1) porque en el Exp. II el rendimiento del tratamiento NO fue menor (DMS < 0,05). En NO del Exp. I se presentaron PQ más tempranos y rendimientos mayores, mientras que en NO del Exp. II los PQ se retrasaron pero, sorprendentemente, los rendimientos fueron menores (Fig. 8A).

Las tendencias observadas en la relación PQ-rendimiento se correspondieron más con el PG que con el NG (datos no mostrados). Utilizando el PQ como covariable, el PQ presentó efectos significativos sobre el PG al considerar las tres dosis de $\mathrm{N}$, pero no cuando sólo se analizó la dosis N0 (Tabla 1). En condiciones de moderado-alto nivel de fertilización (Figs. 8D, 8F), el carácter SG impactó positivamente sobre el PG; sin embargo, en condiciones de baja fertilización (NO), la relación entre el carácter SG y el PG se satura y se vuelve negativa a altos PQ (Fig. 8B).

En ambos experimentos la deficiencia de $\mathrm{N}$ redujo significativamente el rendimiento (Tabla 2). Promediando experimentos, en respuesta a la fertilización, el rendimiento aumentó un $26 \%$ al pasar de N0 a N100, mientras que entre N100 y N200, el rendimiento prácticamente no varió (aumentó un 3,5\%). Promediando entre experimentos, entre N100 y N0 la caída del rendimiento estuvo explicada por ambos componentes numéricos ( $13 \%$ de reducción en NG y $13 \%$ de reducción en PG, calculado de la Tabla 2). Sin embargo, la respuesta de los componentes varió dependiendo del híbrido. Comparando la caída de cada componente entre N100 y N0, en los híbridos DK682 (NSG) y AW190 (moderadamente SG) el NG cayó más (17-18\%) que el PG (-8-10\%). En cambio, en los híbridos NK880 (SG) y AX878 (moderadamente SG), el NG cayó comparativamente menos (9-10\%) que el PG (17-18\%). 
Tabla 1: Análisis de covarianza, utilizando como covariable el inicio de la fase rápida de senescencia, y combinando datos de (i) 2 experimentos, 3 dosis de $\mathrm{N}$ y 4 híbridos o (ii) 2 experimentos, 1 dosis de $\mathrm{N}$ y 4 híbridos. Se muestran los resultados para rendimiento $\left(\mathrm{kg} \mathrm{ha}^{-1}\right)$, número de granos (NG), peso de granos (PG) y MS total.

\begin{tabular}{|c|c|c|c|c|c|c|}
\hline Exps & & Factor & $\mathrm{Kg} \mathrm{ha}^{-1}$ & NG & $P G$ & MS total \\
\hline \multirow{8}{*}{ (i) } & \multirow{8}{*}{$\begin{array}{c}\text { No, } \\
\text { N100 } \\
y \\
\text { N200 }\end{array}$} & $P Q$ & NS & NS & $*$ & NS \\
\hline & & Exp & NS & NS & NS & NS \\
\hline & & $\mathrm{N}$ & $* * *$ & $* * *$ & $* * *$ & $* * *$ \\
\hline & & $\mathrm{H}$ & NS & NS & $* *$ & NS \\
\hline & & $\operatorname{Exp} \times N$ & $* *$ & $*$ & NS & NS \\
\hline & & $\operatorname{Exp} \times \mathrm{H}$ & NS & NS & + & NS \\
\hline & & $\mathrm{N} \times \mathrm{H}$ & NS & NS & NS & NS \\
\hline & & $\operatorname{Exp} \times \mathrm{N} \times \mathrm{H}$ & NS & NS & NS & NS \\
\hline \multirow{4}{*}{ (ii) } & \multirow{4}{*}{ NO } & $P Q$ & NS & NS & NS & NS \\
\hline & & Exp & NS & NS & NS & NS \\
\hline & & $\mathrm{H}$ & NS & NS & NS & NS \\
\hline & & $\operatorname{Exp} \times \mathrm{H}$ & NS & NS & NS & NS \\
\hline
\end{tabular}



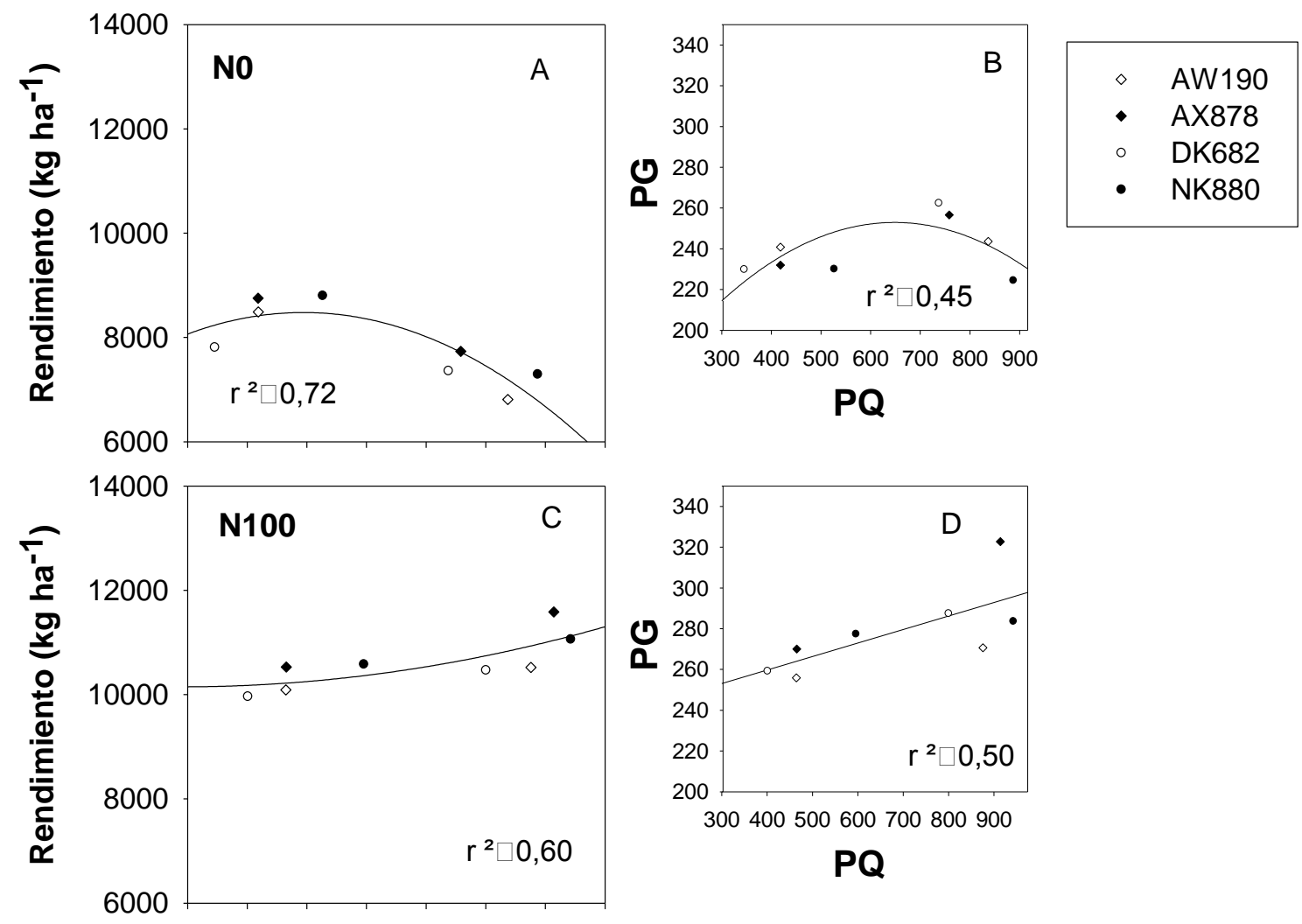

PQ
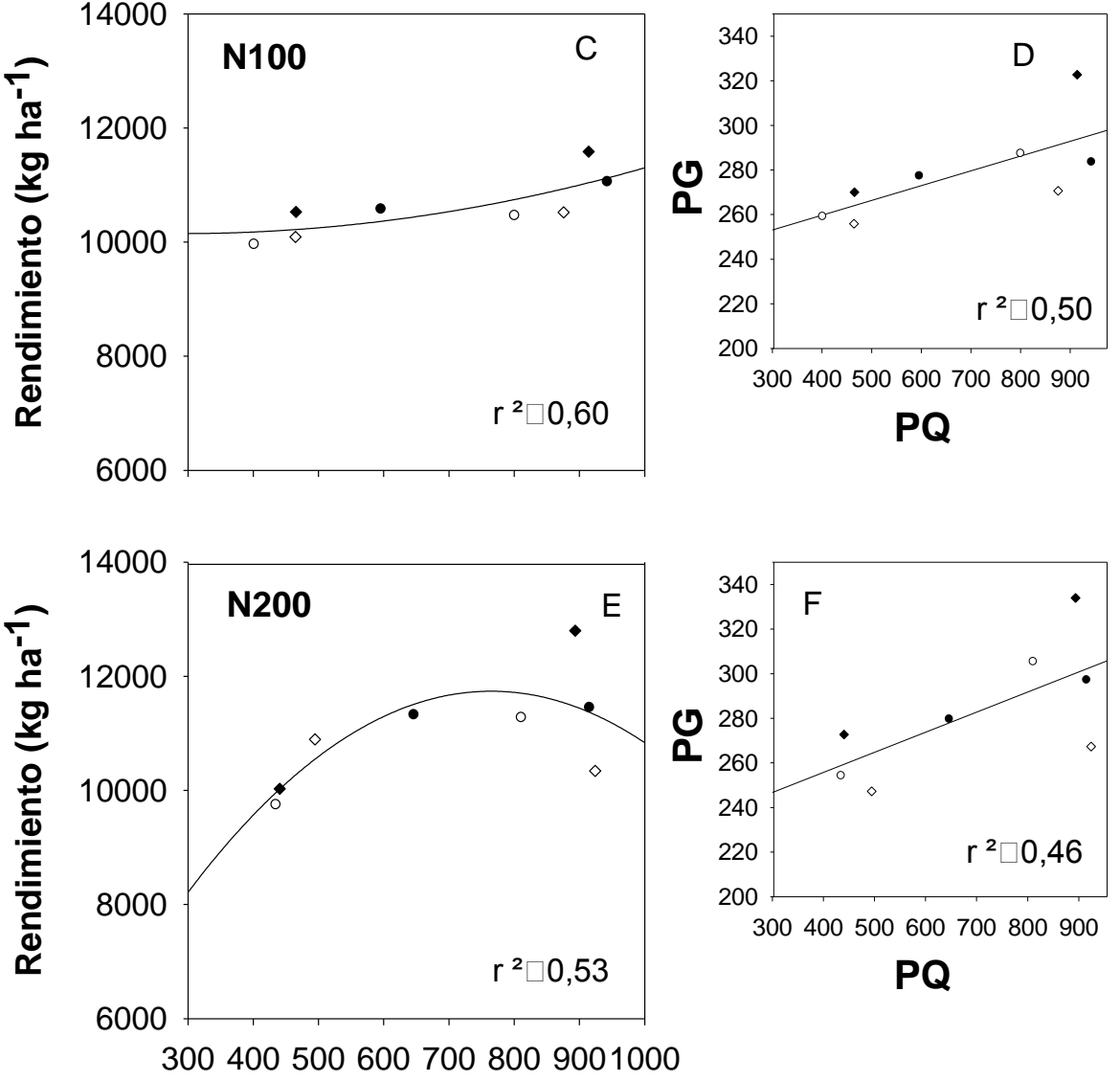

$P Q$

Fig. 8: Relación entre el carácter $S G(P Q)$ y el rendimiento $(A, C, E)$ en los distintos niveles de $\mathrm{N}$, y relación entre el carácter $\mathrm{SG}(\mathrm{PQ})$ y el $\mathrm{PQ}(\mathrm{B}, \mathrm{D}, \mathrm{F})$. Cada punto representa el promedio de un tratamiento ( $\mathrm{N}$ x Híbrido) en cada experimento. 
Tabla 2: Rendimiento ( $\mathrm{Kg} \mathrm{ha}^{-1}$ ), número de granos por planta (NG), peso de grano (PG), MS total a cosecha e índice de cosecha (IC). Para cada tratamiento se presenta el promedio de 8 plantas (excepto rendimiento, que fue calculado a partir de las espigas de 80 plantas).

\begin{tabular}{|c|c|c|c|c|c|c|c|}
\hline Exp. & Dosis N & Híbrido & Kg ha-1 & NG & PG (mg) & $\begin{array}{l}\text { MS total } \\
\left(\mathrm{g} \mathrm{pl}^{-1}\right)\end{array}$ & IC \\
\hline \multirow{15}{*}{1} & \multirow{4}{*}{ NO } & AW190 & 8490 & 447 & 241 & 216 & 0,49 \\
\hline & & AX878 & 8753 & 479 & 232 & 194 & 0,57 \\
\hline & & DK682 & 7814 & 426 & 230 & 209 & 0,47 \\
\hline & & NK880 & 8804 & 479 & 234 & 208 & 0,53 \\
\hline & \multirow{4}{*}{ N100 } & AW190 & 10089 & 492 & 256 & 252 & 0,50 \\
\hline & & AX878 & 10530 & 492 & 270 & 260 & 0,51 \\
\hline & & DK682 & 9969 & 483 & 259 & 247 & 0,51 \\
\hline & & NK880 & 10584 & 478 & 278 & 258 & 0,51 \\
\hline & \multirow{4}{*}{ N200 } & AW190 & 10895 & 553 & 247 & 262 & 0,52 \\
\hline & & AX878 & 10030 & 460 & 273 & 266 & 0,47 \\
\hline & & DK682 & 9755 & 480 & 254 & 244 & 0,50 \\
\hline & & NK880 & 11335 & 507 & 280 & 242 & 0,58 \\
\hline & \multicolumn{2}{|c|}{$\mathrm{N}$} & 0,000 & 0,086 & 0,011 & 0,000 & 0,682 \\
\hline & \multicolumn{2}{|c|}{$\mathrm{H}$} & 0,025 & 0,434 & 0,595 & 0,798 & 0,287 \\
\hline & \multicolumn{2}{|c|}{$\mathrm{N} \times \mathrm{H}$} & 0,492 & 0,336 & 0,889 & 0,723 & 0,259 \\
\hline \multirow{15}{*}{ II } & \multirow{5}{*}{ NO } & AW190 & 6811 & 349 & 244 & 250 & 0,34 \\
\hline & & AX878 & 7732 & 374 & 257 & 244 & 0,40 \\
\hline & & DK682 & 7361 & 352 & 262 & 241 & 0,38 \\
\hline & & NK880 & 7298 & 400 & 225 & 240 & 0,38 \\
\hline & & AW190 & 10522 & 486 & 271 & 314 & 0,42 \\
\hline & \multirow{2}{*}{ N100 } & AX878 & 11585 & 451 & 323 & 328 & 0,44 \\
\hline & & DK682 & 10470 & 460 & 288 & 265 & 0,49 \\
\hline & & NK880 & 11063 & 488 & 284 & 307 & 0,45 \\
\hline & \multirow{4}{*}{ N200 } & AW190 & 10341 & 485 & 267 & 295 & 0,44 \\
\hline & & AX878 & 12801 & 480 & 334 & 308 & 0,52 \\
\hline & & DK682 & 11285 & 462 & 306 & 313 & 0,45 \\
\hline & & NK880 & 11459 & 483 & 297 & 339 & 0,42 \\
\hline & \multicolumn{2}{|c|}{$N$} & 0,000 & 0,000 & 0,000 & 0,000 & 0,001 \\
\hline & \multicolumn{2}{|c|}{$\mathrm{H}$} & 0,063 & 0,700 & 0,000 & 0,255 & 0,245 \\
\hline & \multicolumn{2}{|c|}{$\mathrm{N} \times \mathrm{H}$} & 0,908 & 0,966 & 0,107 & 0,108 & 0,486 \\
\hline
\end{tabular}


3.6. La asimilación neta en post-floración se relacionó con mayor intercepción de radiación, a través de la retención de AFV

El ANOVA no detectó diferencias significativas entre híbridos para la asimilación neta hasta cosecha (74 DDF en Exp. I y 80 DDF en Exp. II), en ninguno de los dos experimentos ( $P=0,629$ en el Exp. I y $P=0,229$ en el Exp. II). Distintas evidencias muestran que algunas enzimas claves de la fotosíntesis en plantas $C_{4}$ son altamente lábiles a temperaturas inferiores a los $10^{\circ} \mathrm{C}$ (Naidu et al., 2003). Por lo tanto, la asimilación neta también se analizó discriminando dos períodos durante el llenado que fueron definidos según las temperaturas mínimas estuvieran por encima o por debajo del umbral de $10^{\circ} \mathrm{C}$. Así, en el Exp. I se consideraron los períodos previos y posterior a 44 DDF (Fig. 1A) y en el Exp. II se consideraron los períodos previos y posterior a 60 DDF (Fig. 1B).

Tomando el período previo al inicio de temperaturas mínimas inferiores a $10^{\circ} \mathrm{C}$ (Fig. 1) sí se evidenció una ventaja a favor de los SG, especialmente en el tratamiento NO. En el Exp. I, considerando el período entre 0 y 44 DDF (ver Fig. 1A), la asimilación neta en NO fue máxima en el híbrido SG NK880 (127 $\left.\mathrm{g} \mathrm{pl}^{-1}\right)$ y mínima en el híbrido NSG DK682 (113 $\mathrm{g} \mathrm{pl}^{-1}$ ) con valores dentro de este rango para los moderadamente SG (AX878 y AW190). En el Exp. II, tomando el período entre 20 y 60 DDF (ver Fig. 1B) la asimilación neta en NO también alcanzó valores máximos en el SG NK880 (89 $\left.\mathrm{g} \mathrm{pl}^{-1}\right)$ y mínimos en el NSG DK682 (41 $\mathrm{g} \mathrm{pl}^{-1}$ ). Utilizando como covariable el PQ, la asimilación neta en NO para el período previo al inicio de bajas temperaturas presentó efectos $(P<0,05)$ de la covariable, indicando que los genotipos que más demoraron el inicio de la fase rápida de senescencia (Fig. 4) presentaron mayor asimilación neta en NO.

Estas diferencias se reflejan en la relación hallada entre la asimilación neta durante el llenado y el PQ (Fig. 9). En el Exp. I, esta relación fue positiva hasta los 44 DDF (Fig. 9A, $\mathrm{P}<0,05$ ). Sin embargo, a partir de los $44 \mathrm{DDF}$, la relación entre la asimilación neta y el PQ fue negativa (Fig. 9C, P<0,05). En el Exp. II, la relación fue positiva hasta los 60 DDF (Fig. 9B, $\mathrm{P}<0,05$ ); a partir de entonces no existió relación entre la asimilación neta y el PQ (Fig. 9D). 
Exp I
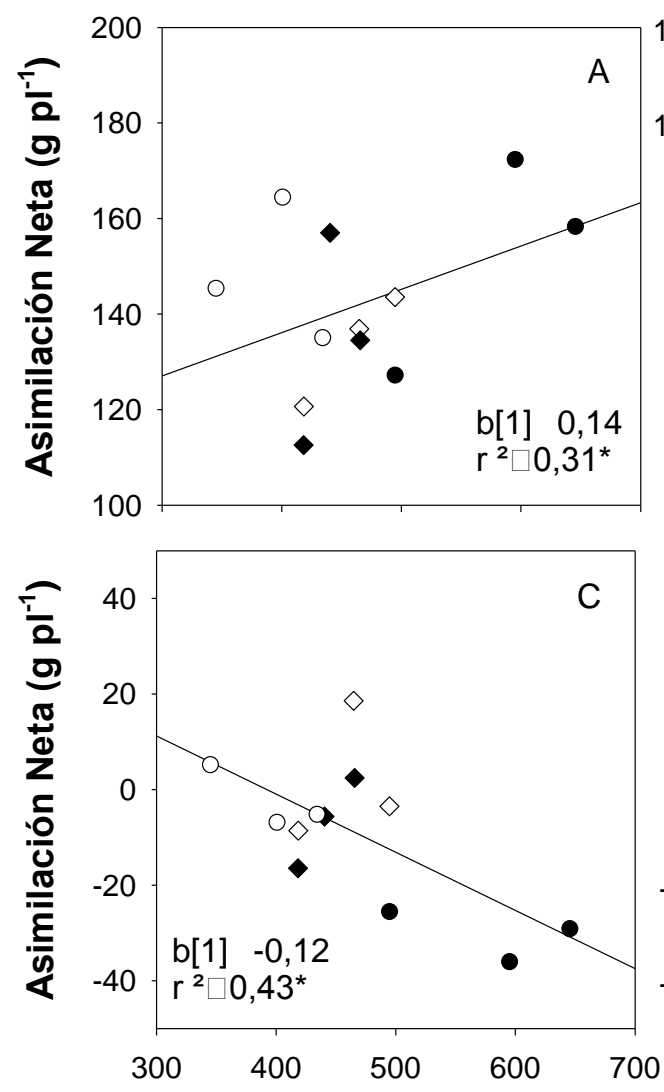

Inicio de fase rápida de senescencia $\left({ }^{\circ} \mathrm{Cd}\right.$ desde floración)
Exp II
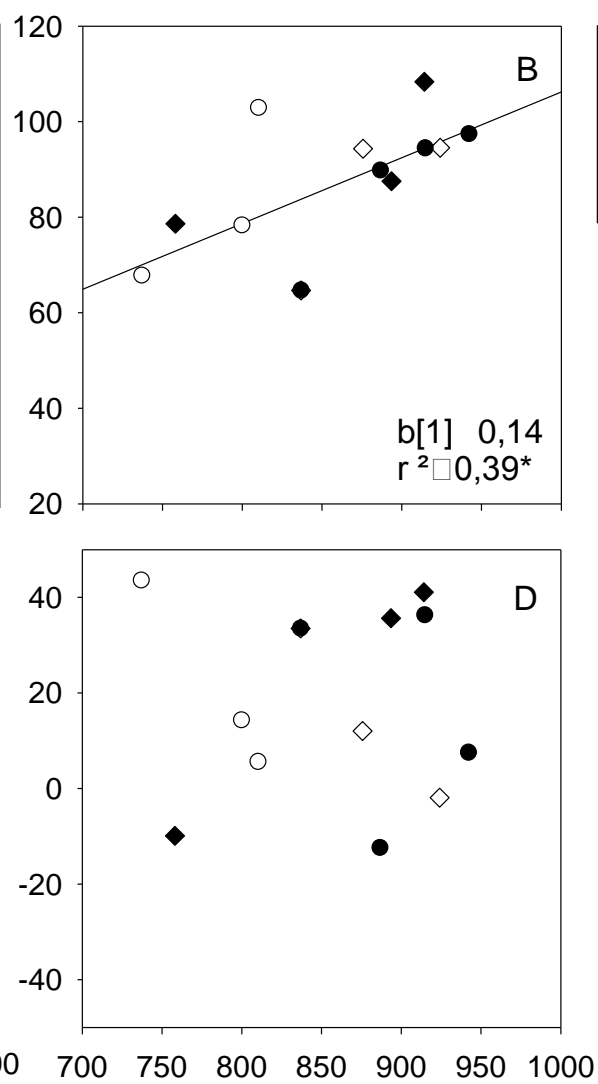

$\diamond \quad A W 190$

- AX878

○ DK682

- NK880

Fig. 9: Regresión entre el inicio de la fase rápida de senescencia en la planta y la asimilación neta en dos períodos del llenado. En cada regresión, $n=12$ y cada punto corresponde al promedio por tratamiento ( $\mathrm{N} x$ Híbrido). En el Exp. I, la asimilación neta se calculó entre 0 y 44 DDF (A) y entre 44 y 74 DDF (C). En el Exp. II, la asimilación neta se calculó entre los 20 y 60 DDF (B) y entre 60 y 80 DDF (D). 


\subsection{La asimilación neta en post-floración se relacionó con mayor eficiencia}

de uso de la radiación interceptada, a través del transporte fotosintético de electrones

En maíz, la tasa de transporte fotosintético de electrones (ETR) (Maxwell \& Johnson, 2000) se correlaciona positiva y estrechamente con la fotosíntesis neta (Earl \& Tollenaar, 1999). En el Exp. I se realizaron mediciones de ETR a fines de identificar posibles diferencias genotípicas, que deberán ser evaluadas más detalladamente en ensayos posteriores. En el tratamiento NO, ETR (promedio entre híbridos) fue un $20 \%$ menor que en N100 mientras que no existieron diferencias entre N100 y N200. A los 31 DDF, el ANOVA detectó interacción entre dosis de $\mathrm{N}$ e híbrido para ETR $(P<0,05)$. En N0, el híbrido NK880 presentó valores de ETR significativamente mayores que el resto de los híbridos (Fig. 10A). En N0, los menores valores se registraron en AW190, mientras que AX878 y DK682 presentaron valores intermedios. En los tratamientos N100 y N200, no existieron diferencias significativas entre híbridos (Fig. 10A). Además, puede observarse que la respuesta de ETR a la dosis de N entre N0 y N100 fue significativa en algunos híbridos (AW190 y DK682) pero no significativa en otros (AX878 y NK880).

Dado que ETR fue corregida en función de la absorbancia de la hoja, se analizaron los valores de SPAD en el punto de medición de ETR a fin de conocer si las diferencias encontradas en ETR estuvieron directamente asociadas al contenido de clorofila. El ANOVA detectó efectos significativos de la dosis y del híbrido pero no hubo interacción entre factores para el valor de SPAD. Esto indica que diferencias genotípicas en el contenido de clorofila a N100 y N200 no impactaron sobre ETR, ya que ETR no varió entre híbridos a N100 y N200. En NO, los valores de SPAD en la zona de medición (Fig. 10B) se correspondieron parcialmente con los resultados de ETR. El híbrido NK880 presentó valores significativamente mayores que el resto. Sin embargo, los menores valores se registraron en DK682 mientras que AX878 y AW190 presentaron valores intermedios. 


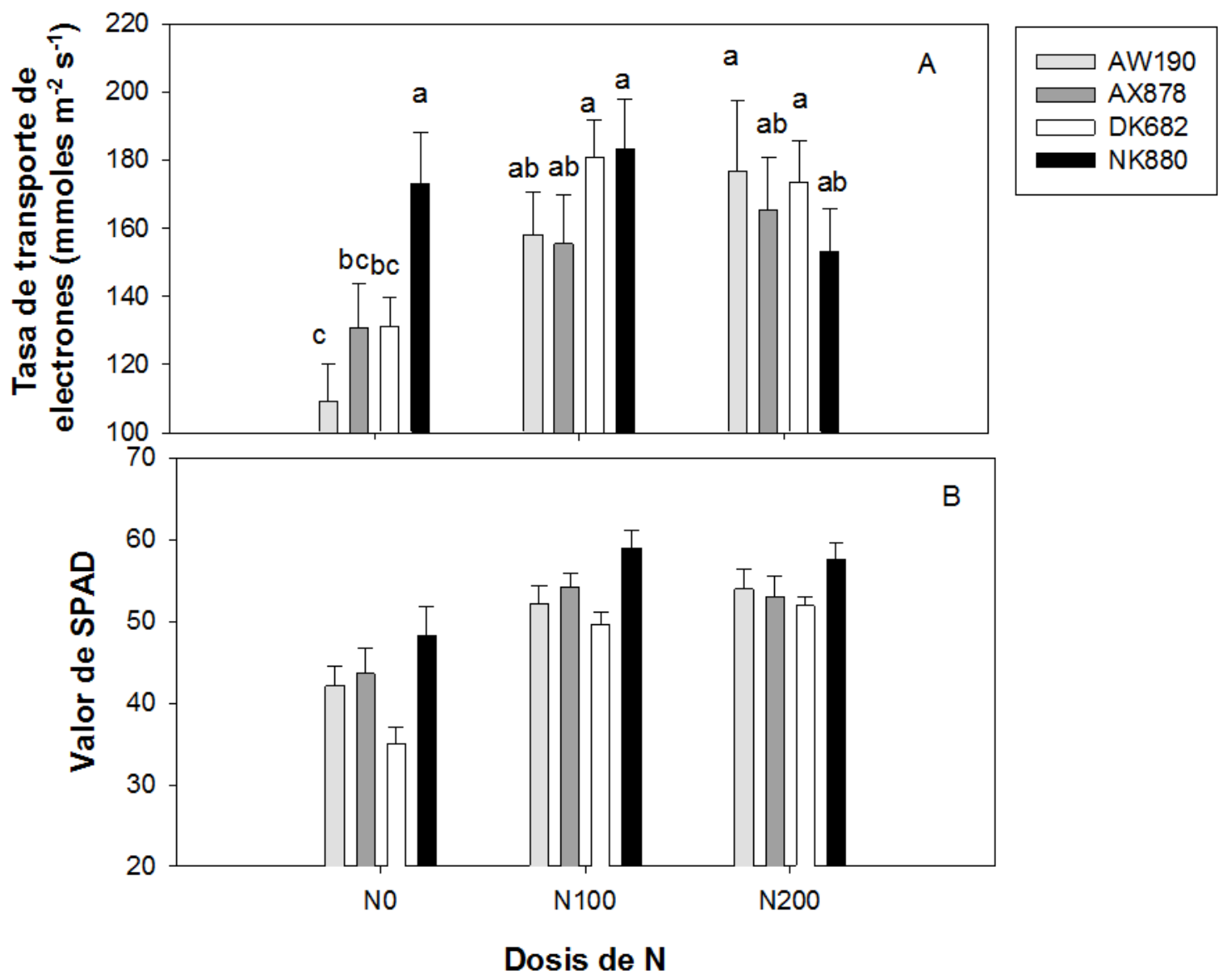

Fig. 10: (A) Exp. I, tasa de transporte fotosintético de electrones (ETR) medida en la hoja de la espiga, a los 31 DDF en cada dosis de $\mathrm{N}$ e híbrido ( $\mathrm{n}=8$ en cada tratamiento). Los valores de ETR están corregidos por la absorbancia de la hoja. Las barras indican el error estándar y las letras indican grupos homogéneos (DMS $<0,05$ ). (B) Valores de SPAD medidos en la hoja de la espiga, a los 31 DDF en cada dosis de $\mathrm{N}$ e híbrido ( $\mathrm{n}=8$ en cada tratamiento). Las barras indican el error estándar. 


\subsection{Pérdidas de MS hacia el final del llenado}

La MS por planta a floración en el Exp. I fue afectada por el nivel de $N(P<0,05)$ pero no por el híbrido $(P<0,12)$; en NO la MS por planta a floración varió entre 103 y $114 \mathrm{~g} \mathrm{pl}^{-1}$ para AW190, AX878 y NK880, mientras que sólo alcanzó $93 \mathrm{~g} \mathrm{pl}^{-1}$ en el NSG DK682. En el Exp. II, la MS por planta al comienzo del Ilenado $\left(400^{\circ} \mathrm{Cd}, 20 \mathrm{DDF}\right)$ fue afectada tanto por el nivel de $N(P<0,001)$ como por el híbrido $(P<0,001)$ :

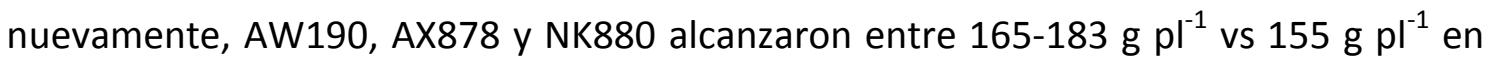
DK682. Por lo tanto, cuando existieron diferencias en el llenado temprano, la tendencia en ambos experimentos fue de mayor MS total en los híbridos SG y moderadamente SG. Sin embargo, esto no se vio reflejado en la MS total a cosecha.

La MS total alcanzada a cosecha (promedio de cada experimento) fue mayor en el Exp. II (Tabla 2), lo que es esperable considerando que en el Exp. II la siembra ocurrió 17 días antes (27/10) que en el Exp. I (12/11). En ambos experimentos, la MS total por planta a cosecha fue afectada por el nivel de N (Tabla 2). Promediando entre experimentos, al aumentar la dosis de $\mathrm{N}$ entre N0 y N100, la MS total aumentó alrededor de un $20 \%$, mientras que entre N100 y N200 prácticamente no varió (2\% de aumento). En ninguno de los dos experimentos la MS total a cosecha varió significativamente entre híbridos, ni existió una tendencia relacionada al carácter SG (Tabla 2).

Al analizar la evolución de la MS total durante el llenado se observa que la MS total por planta se redujo hacia el final del llenado, especialmente en el tratamiento NO (Fig. 11A y 11D). En el Exp. l, esta reducción se observó entre los 44 y 74 DDF (i.e., entre 621 y $921^{\circ} \mathrm{Cd}$ ) y en el Exp. II entre los 60 y 80 DDF (i.e., entre 1048 y $1248{ }^{\circ} \mathrm{Cd}$ ). Esto coincide con los registros de temperaturas mínimas inferiores a $10^{\circ} \mathrm{C}$, que ocurrieron a partir de los 40 DDF en el Exp. I (Fig. 1A) y a partir de los 60 DDF en el Exp. II (Fig. 1B). Analizando ambos experimentos juntos, las pérdidas de MS hacia el final del llenado variaron entre híbridos con un valor de $P=0,09$. En el híbrido NSG DK682 y en el moderadamente SG AW190, no se observaron pérdidas de MS total hacia el final del llenado en NO. En cambio, el moderadamente SG AX878 y en el SG NK880, estas pérdidas se evidenciaron en el tratamiento NO de ambos experimentos, y también en N100 y N200 del Exp. I en NK880, (Figs. 11C y 11E). 
$\operatorname{Exp} I$
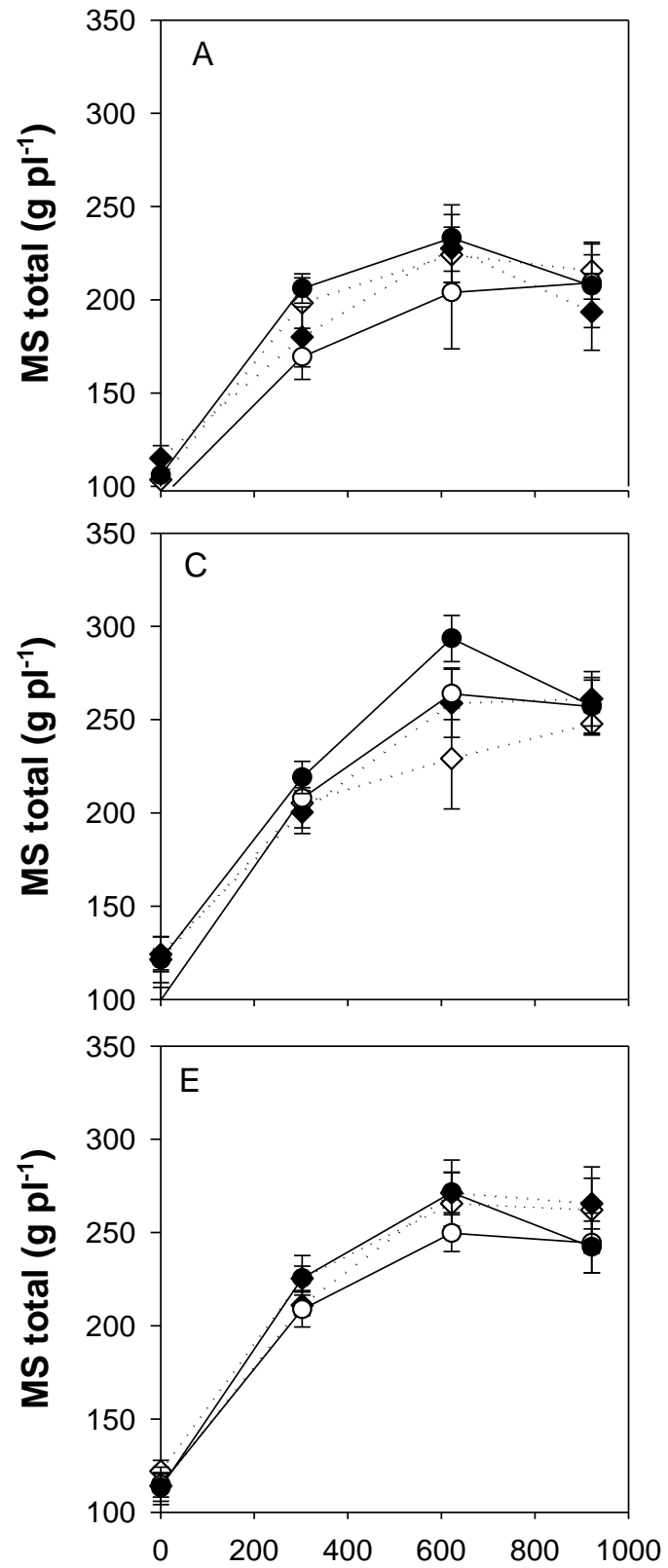

Exp II
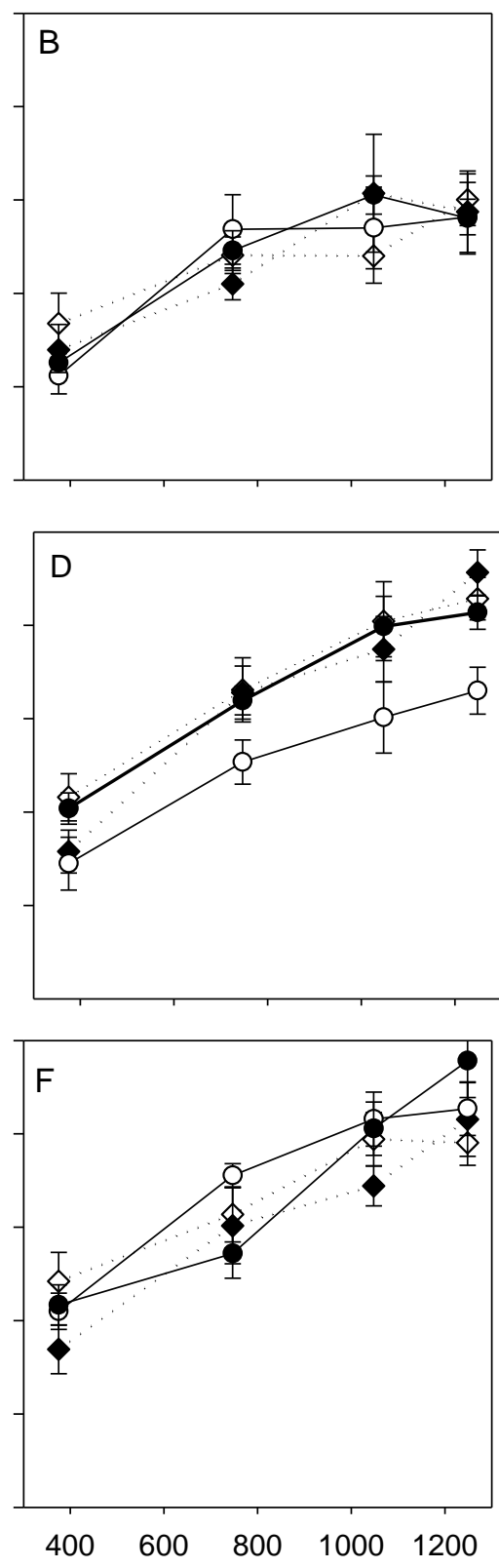

200

Tiempo térmico desde floración $\left({ }^{\circ} \mathrm{Cd}\right)$

Fig. 11: Variación de la MS total (hojas, cañas y espigas) durante el llenado de granos, en el Exp. I (A, C, E) y II (B, D, F), y en los tratamientos NO (A, B), N100 (C, D), y N200 (E, $F)$. Las barras indican el error estándar. 
Similar tendencia se observó cuando se analizó el cambio de la MS de la espiga en el período de bajas temperaturas, en relación con la MS alcanzada a cosecha en cada tratamiento (Fig. 12). Especialmente en el tratamiento N0, la MS de la espiga fue mayor antes del comienzo de las bajas temperaturas que a cosecha, indicando posibles pérdidas de rendimiento, en ambos experimentos (Figs. 12A y 12B). En el Exp. I, donde las bajas temperaturas comenzaron más temprano en el llenado, las pérdidas de MS de espiga del híbrido NK880 se mantienen en las tres dosis de $\mathrm{N}$ mientras que para el resto de los híbridos, únicamente se evidencian en NO.

Las pérdidas de MS total observadas en el tratamiento NO de ambos experimentos (Figs. $11 \mathrm{~A}$ y $11 \mathrm{~B}$ ) se relacionaron significativamente con la MS total acumulada previo al comienzo de las bajas temperaturas (Fig. 13A y 13B). En ambos experimentos, en general, los residuales correspondientes a los híbridos SG se ubicaron por debajo de la línea de tendencia. Es decir que, para similar MS total acumulada, las pérdidas de MS total fueron mayores en los híbridos SG (posiblemente indicando mayor costo de mantenimiento).

\subsection{Las pérdidas de MS reducen la variabilidad entre tratamientos en el IC}

En el Exp. I, el IC no estuvo afectado por la dosis de $\mathrm{N}$ ni el híbrido. En cambio, en el Exp. Il existieron efectos significativos de la dosis de $\mathrm{N}$ (Tabla 2). El IC en el tratamiento NO (promedio entre híbridos) se redujo un 27\% entre el Exp. I y el Exp. II. Esto se debe a que en el Exp. II en NO el rendimiento se redujo un 14\% mientras que la MS total a cosecha fue un $14 \%$ mayor. Sin embargo, es necesario destacar que la aparentemente mayor MS total en el Exp. II en NO, responde en parte a que las pérdidas de MS observadas al final del llenado fueron más importantes en el Exp. I (Figs. $11 \mathrm{~A}$ y $11 \mathrm{~B}$ ), reduciendo la MS total a cosecha y aumentando en consecuencia, el IC. 


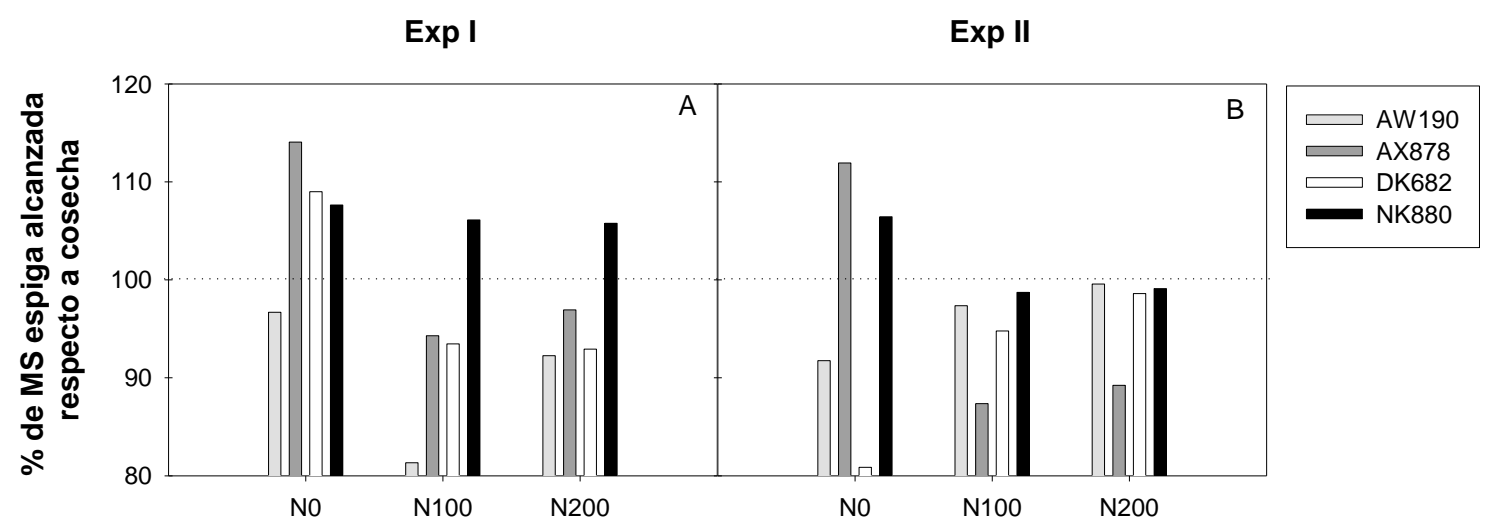

Fig. 12: Peso seco de espigas previo al inicio del período de bajas temperaturas expresado como \% del PS alcanzado a cosecha. En el Exp. I (A), el PS espiga corresponde a los 44 DDF y en el Exp. II (B), a los 60 DDF. Cada dato es el promedio de 8 plantas por tratamiento.

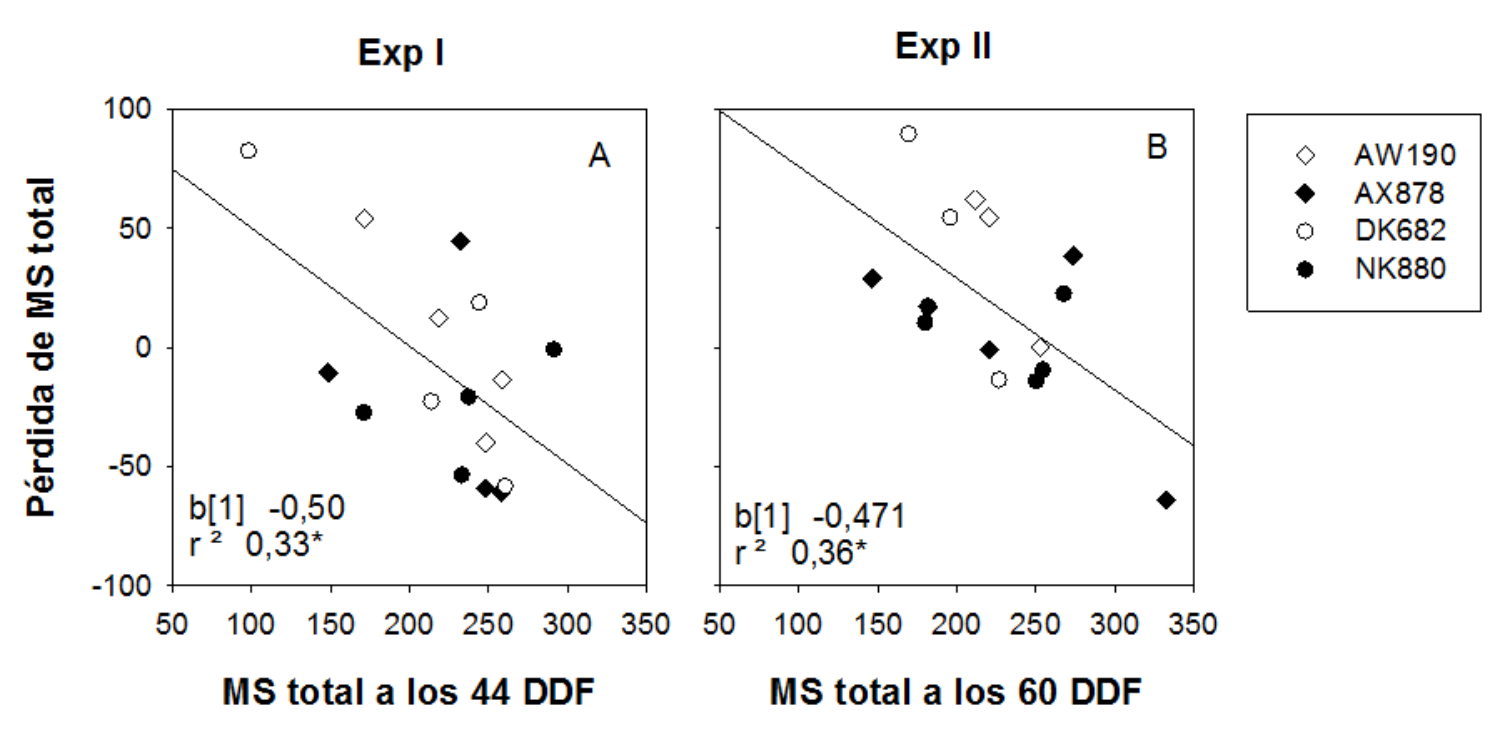

Fig. 13: Regresión entre la MS total acumulada previo al inicio del período de bajas temperaturas (44 DDF en Exp. I y 60 DDF en Exp. II), y las pérdidas de MS total calculadas para el período de bajas temperaturas en el tratamiento NO del Exp. I (A) y del Exp. II (B). Las pérdidas de MS fueron calculadas entre 44 y 74 DDF en Exp. I, y entre 60 y 80 DDF en Exp. II. Cada punto representa una repetición (promedio de dos plantas). 


\section{Discusión}

\subsection{Evolución de la senescencia foliar}

En coincidencia con reportes previos, (Hirel et al., 2007; Uhart \& Andrade, 1995), la deficiencia de $\mathrm{N}$ redujo la expansión foliar durante el desarrollo vegetativo, sin diferencias en el número de hojas y esto quedó reflejado en una menor AFV alcanzada en floración en el tratamiento NO. Por otro lado, el AFV a floración mostró variabilidad genotípica sugiriendo distinta sensibilidad de la expansión foliar al déficit de $\mathrm{N}$, o bien, distinta capacidad de absorber $\mathrm{N}$ durante el período vegetativo.

El carácter SG puede ser descripto en función del AFV retenida a madurez fisiológica (Borrell et al., 2000), como se vio en el Capítulo 2. Esto es práctico y útil, especialmente cuando no existen las condiciones para realizar muestreos con relativa frecuencia. Sin embargo, en algunos casos es difícil establecer en qué momento hacia el final del llenado las diferencias en AFV reflejan mejor las diferencias observadas durante el transcurso de la senescencia foliar. Incluso, distintos genotipos pueden retener similar AFV a madurez a pesar de que la evolución de la senescencia foliar durante el período de llenado haya sido distinta (por ej. Figs. 2D, 2G). En el período post-floración, la declinación del AFV comienza lentamente, pero luego (400-600 o 800-900 @ C día ${ }^{-1}$ desde floración, en el Exp. I y II, respectivamente) el ritmo de senescencia aumenta sustancialmente. El inicio de la fase rápida de senescencia (PQ) es otro parámetro que permite evaluar los efectos de la dosis de $\mathrm{N}$ y la variabilidad genotípica sobre la senescencia del canopeo. EI PQ de todos los tratamientos ocurrió más temprano en el Exp. I respecto al Exp. II. En ambos experimentos, el inicio de la fase rápida de senescencia se adelantó en el tratamiento NO. Borrell et al. (2000) reportaron adelantos en el $\mathrm{PQ}$ de sorgo en respuesta a un tratamiento de estrés hídrico. Tanto la variación entre años como la variación entre tratamientos del PQ contrasta con lo reportado por Borrás et al. (2003) para maíz. Según estos autores, el inicio de la senescencia a escala de planta entera es un carácter altamente conservado, y pobremente afectado por las condiciones ambientales. Las discrepancias entre nuestros resultados y lo reportado por Borrás et al. (2003) se pueden explicar porque la dosis de $\mathrm{N}$ empleada por Borrás et al. (2003) en su tratamiento de máximo estrés (200 kg de $\mathrm{N} \mathrm{ha}^{-1}$ y $12 \mathrm{pl} \mathrm{m}^{-2}$ ) fue de 1,66 g de $\mathrm{N}$ por planta mientras que en nuestros 
resultados la dosis de $\mathrm{N}$ en el tratamiento de máximo estrés (18 $\mathrm{kg}_{\text {de }} \mathrm{N} \mathrm{ha}^{-1}$ y $8 \mathrm{pl} \mathrm{m}^{-2}$ ) fue de 0,22 g de $\mathrm{N}$ por planta. Es decir que, en nuestros ensayos, la variación del PQ entre tratamientos de fertilización es esperable dado que la dosis de $\mathrm{N}$ utilizada en el tratamiento de mayor estrés (NO) fue sustancialmente menor. Por otra parte, en nuestros ensayos, la variación encontrada entre genotipos también es esperable, considerando que los híbridos utilizados fueron seleccionados precisamente por sus diferencias para el carácter SG.

En general, el fenotipo SG correspondió con lo observado en el Capítulo 2: los híbridos previamente caracterizados como SG por su comportamiento en ambientes con sequía en post-floración, mantuvieron este carácter en el tratamiento NO. Sin embargo, el híbrido AW190, previamente caracterizado por tener senescencia estándar en condiciones de estrés hídrico, mostró un comportamiento moderadamente SG en ambos experimentos. Esto implica que la manifestación del carácter SG de un genotipo (en comparación con otros genotipos de referencia) puede variar dependiendo del tipo de estrés abiótico, y éste es un resultado novedoso.

\subsection{Contenido de clorofila}

Se ha reportado que en especies con metabolismo $\mathrm{C}_{4}$, las deficiencias de $\mathrm{N}$ afectan más el contenido de $\mathrm{N}$ por unidad de área foliar ( $\mathrm{N}$ foliar específico) que la expansión del área foliar (Lemaire et al., 2008). La disminución del contenido de $\mathrm{N}$ foliar específico es acompañada por una reducción del contenido de clorofila foliar (Hirel et al., 2007). Esto concuerda con los resultados presentados, especialmente en el Exp. II. Por ejemplo, considerando el estrato medio entre NO y N100, la variación en el AFV al comienzo del llenado fue en general, menor (Figs. 3D y 3E, exceptuando al híbrido DK682) que la variación en el contenido de clorofila (Figs. 6D y 6E).

Los efectos del híbrido para el contenido de clorofila en floración indican que las diferencias entre híbridos se expresan incluso antes de que el carácter SG se manifieste, como ya ha sido sugerido en sorgo (Borrell \& Hammer, 2000). El contenido de clorofila refleja con bastante precisión el contenido de $\mathrm{N}$ en una hoja en particular (Hirel et al., 2005; Paponov et al., 2005). Así, el mayor contenido de clorofila en floración observado en el Exp. I para los híbridos SG podría estar asociado a mayores contenidos de $\mathrm{N}$ por planta en floración, como ha sido reportado para maíz SG 
(Pommel et al., 2006) o bien a una mayor partición del $\mathrm{N}$ hacia las hojas en floración, algo que ha sido demostrado en sorgo (Borrell \& Hammer, 2000). Por supuesto, será necesario determinar los contenidos de $\mathrm{N}$ foliar para confirmar estas hipótesis.

Según Thomas \& Howarth (2000) una variante del fenotipo SG podría ser la resultante de diferencias iniciales (a floración) en el contenido de clorofila sin diferencias en el ritmo de degradación de la clorofila. Considerando el tratamiento N0, esto se observa para el comportamiento de los genotipos en el Exp. I (Figs. 5A, 5D, 5G), pero no en el Exp. II en el que similares valores iniciales de clorofila resultaron en distinta evolución de la senescencia (Figs. 6A, 6D, 6G).

A partir de floración y hasta madurez fisiológica el híbrido SG NK880 y mantuvieron un mayor contenido de clorofila que los híbridos estándar, en coincidencia con trabajos previos (Martin et al., 2005). Dado que el contenido de clorofila se relaciona directamente con el contenido de $\mathrm{N}$ foliar, estos resultados sugieren una mayor retención de $\mathrm{N}$ foliar a madurez en genotipos SG, en concordancia con reportes previos en maíz (He et al., 2001; Ma \& Dwyer, 1998; Pommel et al., 2006) y sorgo (Borrell \& Hammer, 2000). Incluso en el tratamiento NO el híbrido SG retuvo más clorofila a madurez fisiológica, especialmente en el estrato superior. Cuando el carácter SG se manifiesta en condiciones de déficit de $\mathrm{N}$, la baja removilización del $\mathrm{N}$ foliar podría penalizar el llenado de los granos (Ma \& Dwyer, 1998). En el Capítulo 5 se analizará la relación entre variables asociadas al metabolismo del $\mathrm{N}$ durante la senescencia y el PG.

Las diferencias observadas en AFV y contenido de clorofila foliar se correspondieron con las diferencias en intercepción de luz por el canopeo. Es decir, la intercepción de luz fue menor en el tratamiento N0, respecto a N200. Comparando híbridos, la intercepción de luz fue mayor en los híbridos SG o moderadamente SG (NK880, AX878 y AW190). Es esperable que estas diferencias (ya sea entre tratamientos como entre híbridos para un mismo tratamiento), se hayan acentuado conforme avanzó la senescencia. 


\subsection{Rendimiento y sus componentes}

El carácter SG y el rendimiento se relacionaron polinómicamente en NO, sugiriendo que la expresión del carácter más allá de cierto umbral puede impactar negativamente sobre el rendimiento. Por otro lado, al aumentar la dosis de N (N100 y N200) la relación observada sugiere que el carácter SG contribuye positivamente al rendimiento. Independientemente de la dosis de $\mathrm{N}$ considerada, los efectos del carácter SG sobre el rendimiento parecen haber ocurrido a través de cambios en el PG. Esto constituye un aporte original al conocimiento existente, ya que muy pocos trabajos analizan la contribución del carácter SG al rendimiento en híbridos contemporáneos, y las escasas evidencias existentes no son concluyentes. He et al. (2001) compararon híbridos contemporáneos diferentes para el carácter SG y reportaron claramente mayores rendimientos en el híbrido SG, cuando se aplicaron dosis moderadas y altas de $\mathrm{N}$ (el rendimiento del SG es 3,8\% mayor en el tratamiento sin fertilizar, y hasta $31 \%$ superior en el tratamiento fertilizado con $250 \mathrm{~kg}$ de N ha ${ }^{-1}$ ). En cambio, Mi et al. (2003) sí reportan ventajas de hasta un 45\% entre un híbrido SG y otro NSG en condiciones de bajo N. Sin embargo, los autores no caracterizan las diferencias en la expresión del carácter SG y resulta difícil atribuir diferencias tan grandes de rendimiento sólo al carácter SG. La magnitud de las diferencias de rendimiento en el trabajo de Mi et al. (2003) tal vez responda más a distinto potencial de rendimiento entre los híbridos elegidos. Martin et al. (2005) compararon un híbrido SG y uno estándar modernos, fertilizados con $170 \mathrm{~kg}$ de $\mathrm{N} \mathrm{ha}^{-1} \mathrm{y}$ reportaron que ambos tuvieron similares rendimientos y contenido de $\mathrm{N}$ en granos, pero menor EUtN y mayor EAbsN en el híbrido SG. Ma \& Dwyer (1998) compararon un híbrido estándar antiguo y otro SG y moderno; el híbrido SG presentó mayores rendimientos en 0, 100 y $200 \mathrm{~kg} \mathrm{~N}$ $\mathrm{ha}^{-1}, \mathrm{y}$ esto se relacionó con una mayor EUN a partir de la segunda semana de postfloración. Cabe destacar que en la comparación de híbridos modernos y antiguos, varios procesos distintos pueden estar implicados, más allá de la demora de la senescencia en los genotipos modernos.

Entre N100 y NO (promedio entre experimentos), tanto el NG como el PG se redujeron un 14\%. Esto contrasta con reportes previos donde el NG se redujo más que el PG en respuesta a una deficiencia de N. Por ejemplo, Gallais \& Hirel (2004) reportaron caídas del $32 \%$ en el NG y $9 \%$ en el PG al variar la dosis entre 170 y $50 \mathrm{~kg}$ de 
$\mathrm{N}$ ha ${ }^{-1}$. Se ha demostrado la existencia de variabilidad genotípica para los efectos del déficit de $\mathrm{N}$ sobre los componentes del rendimiento; en este sentido Paponov et al. (2005) comparan la caída de rendimiento para el rango entre 200 y $0 \mathrm{~kg} \mathrm{de} \mathrm{N} \mathrm{ha}^{-1}$; en uno de los genotipos estudiados por estos autores el NG cae $40 \%$ y el PG un $12 \%$; en cambio, en el otro genotipo, el NG cae un $8 \%$ y el PG un $22 \%$. Este tipo de diferencias se observan en los resultados presentados en este capítulo. Por ejemplo entre N100 y N0, el NG cae alrededor de un $20 \%$ y el PG cae un $10 \%$ en los NSG (DK682) y moderadamente SG (AW190) mientras que en el otro híbrido moderadamente SG (AX878) y el SG (NK880), la tendencia se invierte: el NG cae un $10 \%$ y el PG cae un $20 \%$. Es decir, al acentuarse el carácter SG, el PG se ve proporcionalmente más afectado que el NG.

\subsection{Asimilación neta en post-floración}

La relación hallada entre la asimilación neta previa al inicio de las bajas temperaturas (mínimas inferiores a $10^{\circ} \mathrm{C}$ ) y el $\mathrm{PQ}$ (Figs. 9A y $9 \mathrm{~B}$ ) indica que, la demora en la senescencia en este período tuvo un impacto positivo sobre la asimilación neta.

Por otro lado, la tasa de transporte fotosintético de electrones (ETR) informa sobre la funcionalidad de las hojas (Earl \& Tollenaar, 1999). La disminución de ETR en el tratamiento N0, comparado con N100 o N200, indica una menor actividad fotosintética que puede estar relacionada a un menor contenido de proteínas en los fotosistemas (aspecto que será analizado en el Capítulo 5). En N0, la tasa fotosintética de NK880 no se diferenció de la alcanzada en N100 y N200, y fue significativamente superior a la del resto de los genotipos. La respuesta de ETR a la fertilización fue más pronunciada en los híbridos NSG o moderadamente SG (DK682 y AW190) que en el moderadamente SG (AX878) y SG (NK880). Los efectos de la deficiencia de N sobre ETR podrían deberse a una menor absorbancia de la hoja o bien a una menor eficiencia fotosintética por unidad de N. El hecho de que los valores de SPAD no se correspondan directamente con los de ETR, sugiere que las diferencias en ETR responder principalmente a diferencias en la eficiencia fotosintética por unidad de N. Echarte et al. (2008) reportaron que, en condiciones de deficiencia de $\mathrm{N}$, la tasa de intercambio de $C$ (fotosíntesis neta) en maíz se reduce principalmente por una disminución en la 
eficiencia de asimilación neta por contenido de $\mathrm{N}$ foliar (aún cuando la absorbancia también disminuye).

4.5. Evolución de la MS total hacia el final del llenado y posibles pérdidas por respiración

La relación negativa o neutra encontrada entre el inicio de la fase rápida de senescencia y la asimilación neta a partir de los 44 DDF en el Exp. I y de los 60 DDF en el Exp. II (Figs. 8C y 8D) sugiere que la demora de la senescencia más allá de una duración óptima afectó negativamente la MS total. El inicio del período de asimilación neta negativa o neutra coincidió con el comienzo de temperaturas mínimas inferiores a $10^{\circ} \mathrm{C}$ (Figs. $1 \mathrm{~A}$ y $1 \mathrm{~B}$ ). Dwyer \& Tollenaar (1989) reportaron reducciones del $30 \%$ en la tasa de intercambio fotosintético de carbono en híbridos de maíz expuestos a temperaturas mínimas de $9,6^{\circ} \mathrm{C}$ en el campo. Varios reportes muestran que una enzima clave en la fotosíntesis $\mathrm{C}_{4}$, la piruvato ortofosfato dikinasa (PPDK), es altamente lábil a temperaturas inferiores a $10^{\circ} \mathrm{C}$ (Du et al., 1999; Naidu et al., 2003). Los efectos de las bajas temperaturas sobre la fotosíntesis, sumado a la retención de hojas metabólicamente activas (asociadas al carácter SG), podrían haber repercutido negativamente sobre el balance de $\mathrm{C}$ a través de la respiración.

Las pérdidas de materia seca asociadas a la respiración pueden representar alrededor del $50 \%$ del carbono asimilado por un cultivo de maíz (Earl \& Tollenaar 1998). Se ha postulado que cuando las temperaturas son frías, pueden ocurrir pérdidas netas de MS vegetativa debido a la respiración de azúcares solubles (Frei, 2000). Earl \& Tollenaar (1998) testearon el efecto de temperaturas nocturnas sobre la tasa respiratoria, colocando plantas individuales durante 8 hs en oscuridad a temperaturas contrastantes de $20^{\circ} \mathrm{C}$ y $8^{\circ} \mathrm{C}$; la tasa respiratoria de las hojas durante las primeras horas de la mañana fue un $40 \%$ más alta en las plantas que habían permanecido a $8^{\circ} \mathrm{C}$ durante la noche. Por otro lado, Ying et al. (2000) reportaron que la tasa de fotosintética se redujo un $20 \%$ después de la exposición de las plantas a una noche de $4^{\circ} \mathrm{C}$, pero a un $30 \%$ si las plantas eran expuestas a tres noches consecutivas de bajas temperaturas, lo que implica que el efecto de las temperaturas mínimas se potencia si éstas ocurren consecutivamente. En el presente capítulo, la evolución de la MS total durante el llenado reveló una pérdida de MS total en los estadíos finales, y más 
acentuada en el Exp. I (Fig. 9) que coincidió con registros de temperaturas mínimas inferiores a $10^{\circ} \mathrm{C}$ : a partir de los 40 DDF en el Exp. I (Fig. 1A) y a partir de los 60 DDF en el Exp. II (Fig. 1B). El hecho de que estas pérdidas se hayan manifestado también en la MS espiga (Fig. 10) sugiere que este fenómeno podría tener un impacto directo sobre el PG, penalizando en consecuencia, el rendimiento.

En la Fig. 10 se observa que estas pérdidas fueron más importantes en el tratamiento N0, y prácticamente no se detectaron en N100 y N200 (excepto en el híbrido SG NK880 donde persistieron en todos los tratamientos del Exp. I). El N cumple un rol específico sobre la capacidad de los destinos para utilizar el C, y las deficiencias de $\mathrm{N}$ en los destinos restringen la tasa de transporte de asimilados desde la fuente (Below et al., 2000; Cazetta et al., 1999). Por lo tanto, si las deficiencias nutricionales afectan más la fuerza de los destinos que la capacidad de la fuente (algo que podría ocurrir en los híbridos SG), la relación fuente/destino podría aumentar, con la consiguiente acumulación de carbohidratos solubles en tejidos vegetativos. Guitman et al. (1991) reportaron mayor acumulación de carbohidratos en hojas de trigo frente a deficiencias nutricionales en comparación con las fertilizadas. La respiración de hojas maduras durante la noche puede estar muy influida por los niveles de asimilados acumulados durante el día (Earl \& Tollenaar, 1998). Evidencias previas muestran mayor acumulación de carbohidratos solubles en hojas de híbridos SG en comparación con híbridos estándar (He et al., 2001; Rajcan et al., 1999) y estas diferencias se incrementan conforme aumenta la relación fuente-destino (Rajcan et al., 1999).

La acumulación de azúcares en las hojas hacia el final del llenado inhibe la fotosíntesis (Goldschmidt \& Huber, 1992; Paul \& Foyer, 2001). En las hojas, la tasa de síntesis de los productos finales de la fotosíntesis (sacarosa, almidón, aminoácidos) determina la tasa a la cual el Pi (fósforo inorgánico) es reciclado nuevamente a la vía fotosintética, por lo tanto, cualquier mecanismo que restringa la utilización de las triosas fosfato, podría restringir la tasa de fotosíntesis (Paul \& Foyer, 2001). Goldschmidt \& Huber (1992) demostraron que el metabolismo extra-cloroplástico de los carbohidratos también está relacionado con la inhibición de la fotosíntesis. En un conjunto de especies donde la transferencia de azúcares al floema estuvo bloqueada por un tratamiento de anillado del floema ("phloem girdling"), Goldschmidt \& Huber (1992) demostraron que la inhibición de la fotosíntesis se relacionó directamente con 
la acumulación de almidón, e inversamente con la actividad de la enzima invertasa. En este caso, una mayor actividad de invertasas reduce la acumulación de sacarosa y aumenta el contenido de hexosas libres, las que regularían negativamente el Ciclo de Calvin (Goldschmidt \& Huber, 1992). Considerando estas evidencias, los resultados presentados en este capítulo podrían interpretarse en función de una inhibición de la fotosíntesis por acumulación de azúcares en hojas, que podría haber exacerbado las pérdidas respiratorias de MS, especialmente en el tratamiento N0, y en los híbridos con mayor expresión del carácter SG.

Complementariamente a la interpretación precedente, la mayor MS total asociada al carácter SG también pudo haber contribuido a exacerbar las pérdidas de MS, como queda expuesto en la Fig. 12. En climas fríos una alta MS total puede relacionarse negativamente con el rendimiento debido a que una mayor MS implica mayores costos respiratorios de mantenimiento (Frei, 2000; Ying et al., 2000). En un tratamiento de estrés por sombreado desde 7 días después de floración, Kiniry et al. (1992) calcularon que los costos de mantenimiento en maíz representaron el 0,8\% de la MS total por día. Asumiendo que una planta de $250 \mathrm{~g}$ pierda el $0,8 \%$ de su MS total por día, en un período de 30 días las pérdidas alcanzarían los 53 g. Valores semejantes pueden observarse para el híbrido SG (NK880) en el Exp. I, Fig. 11A, pero notablemente menores en el híbrido NSG (DK682). Estas diferencias probablemente estén asociadas al mayor costo respiratorio asociado al carácter SG, dada la mayor retención de hojas metabólicamente activas (Earl \& Tollenaar, 1998), y con mayor contenido de proteínas (McCree, 1983) un aspecto que será abordado en el Capítulo 5.

\section{Conclusiones}

Los resultados presentados en este Capítulo muestran que el carácter SG también se expresa en condiciones de déficit de N. Los genotipos caracterizados como SG bajo estrés hídrico (AX878 y NK880, Capítulo 2) mantuvieron el fenotipo cuando se testearon frente a deficiencias de $\mathrm{N}$; además, el fenotipo SG se manifestó

moderadamente en un genotipo caracterizado como estándar bajo estrés hídrico 
(AW190, Capítulo 2). Esto muestra que la manifestación del fenotipo SG puede variar dependiendo del tipo de estrés que experimente el cultivo.

El carácter SG se asoció claramente con el rendimiento en condiciones de moderada- alta disponibilidad de $\mathrm{N}$, pero no en condiciones de deficiencia de $\mathrm{N}$. Similar tendencia se observó entre el carácter SG y el PG, por lo que se sugiere que frente a deficiencias de N, el carácter SG pudo implicar una penalidad sobre el PG. El carácter SG estuvo relacionado a una mayor asimilación neta durante post-floración, a través de la demora en la senescencia foliar (i.e. de la radiación interceptada durante el ciclo) y también a través de una mayor eficiencia de uso de la radiación interceptada (ETR). El hecho de que esto no se haya visto reflejado en la MS total a cosecha se relacionó con pérdidas de MS al final del Ilenado.

Las pérdidas de MS hacia el final del llenado coincidieron con el comienzo de temperaturas mínimas inferiores a $10^{\circ} \mathrm{C}$, y se manifestaron en condiciones de deficiencias de $\mathrm{N}$, y especialmente, en el híbrido SG. El hecho de que estas pérdidas se evidencien sólo bajo deficiencias de $\mathrm{N}$ estaría relacionado con una inhibición de la fotosíntesis por acumulación de azúcares en hojas, asociada a una menor tasa de asimilación de $\mathrm{C}$ en los destinos por restricción de $\mathrm{N}$. Las posibles restricciones de $\mathrm{N}$ en los destinos asociadas al carácter SG serán abordadas en los capítulos siguientes, en el contexto de alta densidad poblacional (Capítulo 4) y frente a deficiencias de $\mathrm{N}$ (Capítulo 5).

El hecho de que estas pérdidas se asocien al carácter SG podría estar vinculado por un lado, a una exacerbación de los efectos mencionados (mayor restricción de $\mathrm{N}$ en los destinos y mayor acumulación de azúcares en hojas respecto a los híbridos NSG). Por otro lado, las pérdidas se exacerbarían con el carácter SG debido a los mayores costos respiratorios como consecuencia de: (i) la mayor MS total, (ii) la retención de hojas metabólicamente activas (aspecto analizado en el Capítulo 4) y (iii) con mayor contenido de proteínas (como será mostrado en el Capítulo 5). 


\section{CAPÍTULO 4 \\ SENESCENCIA FOLIAR Y RENDIMIENTO EN HÍBRIDOS DE MAÍZ \\ FRENTE A VARIACIONES EN LA DENSIDAD DE PLANTAS}

\section{Introducción}

\subsection{Importancia del problema}

Los incrementos en rendimiento del cultivo de maíz registrados en las últimas décadas han sido posibles gracias a una fuerte asociación entre cambios en el manejo del cultivo y mejoramiento genético. Cuando se analizan los cambios introducidos en el manejo del cultivo, la densidad poblacional es uno de los factores que más ha variado (Tollenaar \& Lee, 2002; Tollenaar et al., 2006). Por ejemplo, en el período 1960-2000 y en EE.UU., los incrementos en rendimiento de $110 \mathrm{~kg} \mathrm{ha}^{-1}$ año ${ }^{-1}$ han sido acompañados por incrementos de $1000 \mathrm{pl} \mathrm{ha}^{-1}$ año $^{-1}$ (Duvick, 2005).

La mayor tolerancia de los híbridos modernos a la densidad poblacional es parte de un proceso de mejoramiento orientado a perfeccionar el desempeño de las plantas frente a diversas situaciones de estrés biótico y abiótico (Tollenaar \& Lee, 2002; Tokatlidis \& Koutroubas, 2004). Varios autores acuerdan en que, en las últimas ocho décadas, el mejoramiento genético no ha aumentado el potencial de rendimiento por planta; en cambio, sí ha aumentado la tolerancia de los híbridos a mayores densidades poblacionales (Duvick, 1997; Tokatlidis \& Koutroubas, 2004; Tokatlidis et al., 2005). Una excepción han sido los híbridos argentinos, en los que el mejoramiento también ha resultado en mayor rendimiento por planta (Luque et al., 2006). De persistir esta tendencia, resulta relevante la identificación de mecanismos fisiológicos asociados a la tolerancia del rendimiento a altas densidades.

La densidad óptima depende de la interacción genotipo $x$ ambiente. Se ha postulado que los híbridos modernos son altamente dependientes de la densidad, exhibiendo un rango de densidad óptima más estrecho y variable que los híbridos antiguos (Fasoula \& Fasoula, 2002; Tokatlidis \& Koutroubas, 2004; Tokatlidis et al., 2005). Esta característica puede resultar un problema en sitios sujetos a estrés ambiental ocasional (sequía, déficits nutricionales asociados a sequía o a exceso de lluvias, etc.), donde resulta difícil definir la densidad óptima a priori. Asimismo, 
híbridos que presenten densidades sub-óptimas menores, tendrán mayor capacidad de compensar, por ej., problemas en la emergencia del cultivo. En estos contextos, serían deseables híbridos con rangos de densidades óptimas más amplios (Tokatlidis et al., 2011).

\subsection{Efectos fisiológicos del estrés por densidad}

El aumento de la densidad poblacional es acompañado por un aumento del estrés por competencia resultando en una disminución de los recursos disponibles por planta (Tollenaar et al., 2006). Cuando el aumento de la densidad no alcanza a compensar la merma del rendimiento por planta (i.e., densidades supra óptimas), el estrés por competencia se manifiesta en la reducción del rendimiento por unidad de área (Tokatlidis et al., 2011). Si bien las densidades supra óptimas tienen efectos sobre los dos componentes del rendimiento (número y peso de granos), el número de granos suele ser el componente más intensamente afectado (Ciampitti \& Vyn, 2011). Por otro lado, si la competencia entre plantas es alta se acentúa la variabilidad del stand. Cuando la variabilidad entre plantas es muy grande empeora la eficiencia en el uso de los recursos porque las plantas dominantes ejercen un consumo de lujo (Tollenaar \& Wu, 1999; Ciampitti \& Vyn, 2011).

Cuando se presentan situaciones de estrés ambiental, el carácter SG ha sido relacionado con una mayor estabilidad del rendimiento en sorgo (Borrell \& Hammer, 2000) y maíz (Bänziger et al., 2002; Ma \& Dwyer, 1998; Rajcan \& Tollenaar, 1999a). En híbridos canadienses de maíz, expuestos a distintos tipos de estrés, la senescencia demorada estuvo acompañada por mayor absorción de agua y nutrientes y mayor suministro de fotoasimilados al grano, resultando en mejores rendimientos que híbridos de senescencia normal (Tollenaar \& Wu, 1999). Bänziger et al. (2002) compararon una serie de poblaciones de maíz obtenidas de una sucesión de ciclos de selección para tolerancia a estrés hídrico, en ambientes con distintos niveles de nitrógeno. Las poblaciones seleccionadas por su mayor rendimiento en sequía también presentaron mayor rendimiento frente a deficiencias de $\mathrm{N}$; esto se asocio con un mayor peso de grano, y con una demora en la senescencia. A partir de estas evidencias, se ha propuesto el concepto de "tolerancia cruzada" a distintos tipos de estrés (Bänziger et al., 2002). 


\subsection{Fundamento y planteo de la hipótesis}

La mayor densidad poblacional reduce la disponibilidad de insumos (agua, nutrientes y luz) para cada planta y genera una situación de estrés combinada. Se ha reportado que el carácter SG se asocia con una mayor tolerancia al estrés hídrico (Borrell et al., 2000; Messmer et al., 2011; Richards, 2006) y esto concuerda parcialmente con los resultados obtenidos en el Capítulo 2 de esta tesis. El carácter SG también ha sido asociado a mayor tolerancia frente a deficiencias nutricionales (Bänziger et al., 1999; Bänziger et al., 2002; Borrell \& Hammer, 2000; Ma \& Dwyer, 1998; Rajcan \& Tollenaar, 1999) aunque los resultados obtenidos en el Capítulo 3 relativizan estas evidencias. Además, en condiciones de alta densidad poblacional, se exacerba la competencia por luz y se acelera la senescencia (Borrás et al., 2003), reduciendo la radiación interceptada durante el ciclo del cultivo. Estos efectos podrían ser parcialmente compensados por una prolongación del período de intercepción de radiación asociada al carácter SG.

La hipótesis que se pretende contrastar en este Capítulo es la siguiente:

(3) En condiciones de alta densidad poblacional, la demora en la senescencia foliar está asociada a mayor producción de fotoasimilados y mayor rendimiento.

(3.1.) En condiciones de alta densidad poblacional, los genotipos SG presentan mayor producción de fotoasimilados en post-floración.

(3.2.) En condiciones de alta densidad poblacional, los genotipos SG presentan mayor rendimiento. 


\section{Materiales y Métodos}

\subsection{Diseño experimental}

Se realizaron tres experimentos (Exps I, II y III) a fin de determinar si la demora en la senescencia foliar se relaciona con mayores rendimientos cuando aumenta la densidad poblacional. Los tratamientos consistieron en (i) densidad de plantas y, (ii) híbridos variables en la duración del AFV. Se utilizaron híbridos simples de maíz similares en días a madurez fisiológica y contrastantes para el carácter SG. Los híbridos utilizados fueron caracterizados en el Capítulo 3: DK682 (NSG), AW190 y AX878 (moderadamente SG), y NK880 (SG).

Los experimentos fueron conducidos en La Plata, en la Estación Experimental de la Facultad de Cs. Agrarias y Forestales (Universidad Nacional de La Plata). El suelo correspondió a un argiudol típico (clasificación USDA). Previo a la implantación del Exp. I, la concentración de $\mathrm{N}$ total en los primeros $20 \mathrm{~cm}$ de suelo fue de $1630 \mathrm{ppm}$ y la concentración de $\mathrm{P}$ fue de 5,88 ppm. Los tratamientos fueron distribuidos según un diseño de bloques completos con tres repeticiones, donde la densidad fue aleatorizada en la parcela principal, y los genotipos en la sub-parcela. Las parcelas cubrieron una superficie de 4 surcos de 6,5 $\mathrm{m}$ de largo distanciados a 0,7 m (excepto en el Exp. I donde las parcelas fueron de 5 surcos).

En todos los ensayos las semillas fueron sembradas en forma manual (tres semillas por hoyo) y raleadas en post-emergencia; no se detectaron problemas en la emergencia por lo que en todos los casos la densidad final se correspondió con la densidad del tratamiento. Las plantas fueron regadas durante todo el ciclo para evitar limitaciones hídricas severas. En los tres experimentos se aplicaron herbicidas e insecticidas convencionales toda vez que fue necesario. En los tres experimentos se registró la fecha de floración femenina, que presentó una variación de +/- 3 días entre tratamientos. Se realizaron tres (Exp. I) o cuatro (Exps II y III) repeticiones por tratamiento. Las particularidades de cada experimento se describen a continuación.

Experimento I: Las semillas fueron sembradas el 27 de octubre de 2008. Los híbridos DK682 y NK880 fueron sembrados a 6,8 y $10 \mathrm{pl} \mathrm{m}^{-2}$. Las plantas fueron fertilizadas con $18 \mathrm{~kg}$ de $\mathrm{P} \mathrm{ha}^{-1}$ (superfosfato triple) en pre-siembra y $100 \mathrm{~kg} \mathrm{de} \mathrm{N} \mathrm{ha}^{-1}$ (urea) en V7. 
Experimento II: Las semillas fueron sembradas el 29 de octubre de 2009. Los híbridos DK682 y NK880 fueron sembrados a 7, 8, 9 y $10 \mathrm{pl} \mathrm{m}^{-2}$. Las plantas fueron fertilizadas con $120 \mathrm{~kg}$ de $\mathrm{N} \mathrm{ha}^{-1}$ (urea), repartido en dos dosis (40 kg en V3 y $80 \mathrm{~kg}$ en V7) y $100 \mathrm{~kg}$ de $\mathrm{P} \mathrm{ha}{ }^{-1}$ (fosfato diamónico, FDA, en V3).

Experimento III: Las semillas fueron sembradas el 12 de noviembre de 2010. Los híbridos AW190, AX878, DK682 y NK880 fueron sembrados a 8 y $10 \mathrm{pl} \mathrm{m}^{-2}$. Las plantas fueron fertilizadas con $46 \mathrm{~kg}$ de $\mathrm{P} \mathrm{ha}{ }^{-1}$ (DAP, en V3) y $218 \mathrm{~kg}$ de $\mathrm{N}$ (urea y DAP, en V3 y V7).

\subsection{Mediciones generales}

El procedimiento para efectuar las mediciones que a continuación se enumeran, ha sido descripto para el Capítulo 2. A partir de floración, se realizaron muestreos destructivos periódicos hasta madurez fisiológica. Para cada tratamiento y fecha de muestreo, 2 plantas por parcela fueron cosechadas por lo que todos los promedios presentados corresponden a 6 (Exp. I) u 8 (Exps II y III) plantas por tratamiento. En cada muestreo destructivo se analizó la progresión de la senescencia foliar en términos de AFV y mediciones de SPAD a lo largo de toda la planta. La metodología empleada para medir intercepción de radiación se describe en el Capítulo 3.

A partir de los muestreos destructivos se analizó el patrón de acumulación de MS desde floración (Exps I y II) o sólo las variables de MS a madurez fisiológica (MF, Exp. III). El rendimiento por planta, NG y PG, la removilización y acumulación de MS, y el crecimiento de espiga se calcularon en base al promedio de 6-8 plantas por tratamiento a cosecha. El rendimiento se calculó sobre la base de las espigas de 20 plantas consecutivas muestreadas en los surcos centrales de cada parcela (60-80 plantas por tratamiento).

\subsection{Análisis del contenido de Nitrógeno}

Adicionalmente, en este capítulo se realizaron mediciones de la concentración de $\mathrm{N}$ total en cada compartimento según el método semi-micro Kjedahl (LANAIS N-15, Universidad Nacional del Sur, Bahía Blanca). En cada tratamiento (densidad x híbrido) cada medición se realizó en una muestra compuesta ( 2 plantas), y se analizaron 3 
muestras (réplicas) por tratamiento. En cada Experimento, los análisis de $\mathrm{N}$ se realizaron para plantas cosechadas alrededor de floración y hacia el final del llenado, en tres compartimentos: hojas (láminas), cañas (incluyendo vainas) y espigas (o granos para las plantas cosechadas en MF).

El contenido total de $\mathrm{N}$ por compartimento se calculó como el producto entre la concentración de $\mathrm{N}$ y el peso seco de cada compartimento. La absorción de $\mathrm{N}$ durante el período post antesis se calculó como la diferencia de $\mathrm{N}$ total (suma de los tres compartimentos, i.e., caña + panoja, hojas y espiga) entre el muestreo final y el primer muestreo.

\subsection{Mediciones de respiración foliar}

En el Exp. III se realizaron mediciones de respiración foliar. La respiración foliar se midió en la hoja de la espiga ("hoja 0"), y la tercer hoja por debajo de la espiga ("hoja -3"); las muestras fueron tomadas con sacabocado de $11 \mathrm{~cm}^{2}$ en la porción media de la hoja (evitando la nervadura) y aclimatadas en oscuridad durante 20 minutos en una atmósfera saturada de humedad para evitar la deshidratación. La respiración fue medida como consumo de $\mathrm{O}_{2}$ utilizando un electrodo tipo Clark.

\subsection{Análisis Estadístico}

Para conocer el efecto de los tratamientos (Densidad x Híbrido) se realizó un ANOVA de factores fijos, donde los factores correspondieron a la densidad y al híbrido, y la variable dependiente a cada una de las variables analizadas. Para el análisis de la tasa respiratoria, la posición de la hoja también se incluyó como factor fijo, por lo tanto el análisis presentó tres factores fijos (Densidad x Híbrido x Posición de Hoja) y una variable independiente (la tasa respiratoria).

Otros aspectos referidos a los análisis estadísticos se detallan en la sección Materiales y Métodos del Capítulo 2. 


\section{Resultados}

\subsection{Condiciones meteorológicas}

Las condiciones meteorológicas variaron entre experimentos (Fig. 1). Las temperaturas medias fueron mayores en el Exp. I (Fig. 1A) y menores, especialmente hacia el final del ciclo, en los Exps II y III (Fig. 1B y 1C). Especialmente en el Exp. III, a partir de los 40 DDF se destacan temperaturas mínimas menores que en los experimentos previos.

\subsection{Senescencia del canopeo}

El aumento de la densidad aceleró la senescencia del canopeo en los tres experimentos y en todos los híbridos (Fig. 2). En la Fig. 2 puede apreciarse un cambio en la evolución del AFV que marca el inicio de la fase rápida de senescencia (punto de quiebre, $P Q$ ) del canopeo entre los 320 y $1100{ }^{\circ} \mathrm{C}$ día, dependiendo de la densidad, híbrido y estrato considerado.

EI PQ fue significativamente afectado por los tratamientos, dependiendo del estrato considerado (Tabla 1). En los Exps I y II, la densidad adelantó el PQ del estrato inferior (Figs 2G, 2H, P $<0,05$ ), y el híbrido SG (NK880) presentó siempre PQ más tardíos (i.e., demora en el inicio de la senescencia rápida) que el híbrido NSG (DK682). En el estrato medio (Figs 2D, 2E), la densidad no tuvo efectos significativos sobre el PQ pero las diferencias entre híbridos persistieron. En el estrato superior (Figs 2A, 2B), los resultados entre Exps variaron. En el Exp. I se detectó interacción entre tratamientos: el PQ del estrato superior en el híbrido SG (NK880) no varió con el aumento de la densidad mientras que el PQ del híbrido NSG (DK682) se demoró al aumentar la densidad, alcanzando un valor idéntico al del híbrido SG (Tabla 1). En el Exp. II el PQ del estrato superior sólo varió entre híbridos, manteniendo el híbrido NK880 su comportamiento SG en todas las densidades (Tabla 1). En relación al PQ de la planta entera, el aumento de la densidad tuvo efectos sólo en el Exp. I, retrasando el inicio del PQ; las diferencias entre híbridos se mantuvieron en ambos Exps. (Tabla 1). Si se considera solamente la máxima densidad testeada $\left(10 \mathrm{pl} \mathrm{m}^{-2}\right)$ se evidencia que en el Exp. I, los híbridos no se diferenciaron en el PQ de la planta entera. En el Exp. III, se detectó interacción entre tratamientos para el PQ del estrato inferior y medio (Tabla 
1). En el estrato inferior (Fig. 2I) NK880 presentó los mayores $P Q$ tanto a $8 \mathrm{pl} \mathrm{m}^{-2}$ (diferenciándose del resto de los híbridos, $\mathrm{P}<0,05$ ) como a $10 \mathrm{pl} \mathrm{m}^{-2}$ (diferenciándose de AW190, P <0,05). En el estrato medio (Fig. 2F) el PQ de AW190 y NK880 presentó mayores valores en general, que el de AX878 y DK682. EI PQ del estrato superior (Fig. 2C) sólo fue significativamente afectado por el híbrido, siendo en ambas densidades, mayor en los híbridos SG (AX878 y NK880). A partir de estas diferencias, se encontró que la relación entre el $\mathrm{PQ}$ de los diferentes estratos varío con la densidad. Por ejemplo la relación entre $P Q$ del estrato superior / $P Q$ del estrato inferior aumentó de 1,67 a 2,02 al cambiar de 8 a $10 \mathrm{pl} \mathrm{m}^{-2}$ en el híbrido AX878. A $10 \mathrm{pl} \mathrm{m}^{-2}$ esta relación varió entre 1,94 y 2,02 para los híbridos AW190 y AX878 respectivamente, y entre 1,69 y 1,72 para los híbridos DK682 y NK880 respectivamente (calculado a partir de datos en Tabla 1).

Exp I

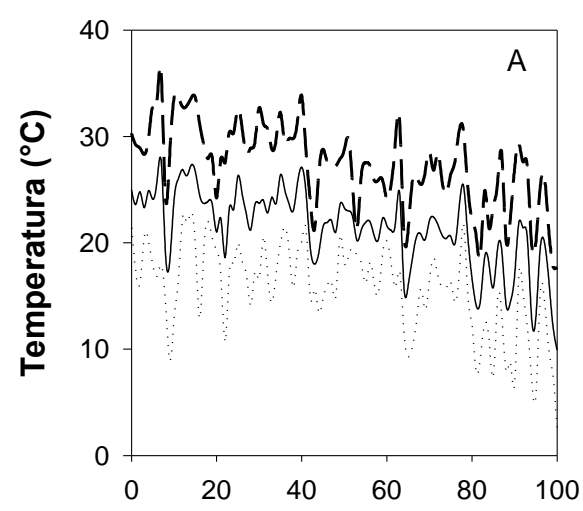

Exp II

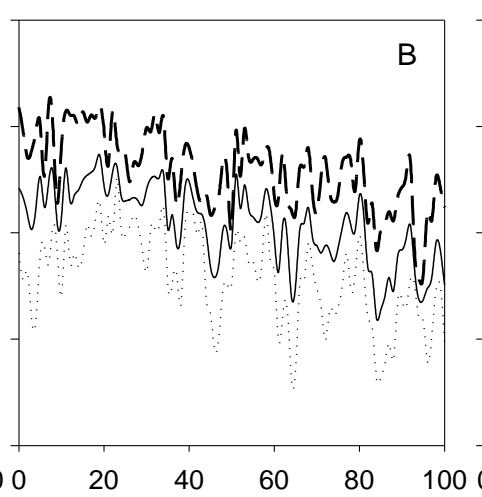

Exp III

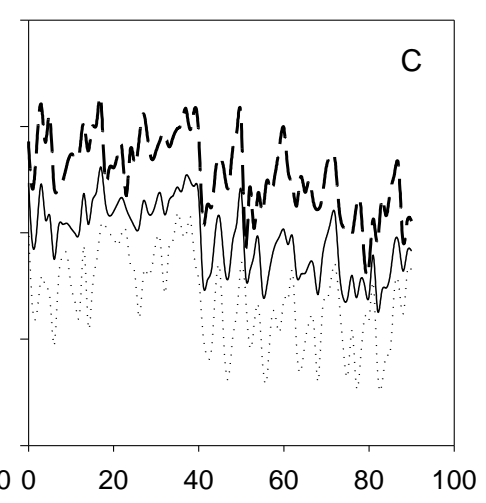

Días después de floración

Fig. 1: Temperaturas medias (línea llena), máximas (línea interrumpida) y mínimas (línea punteada) diarias desde floración en el Exp. I (A), Exp. II (B) y Exp. III (C). 
Exp I
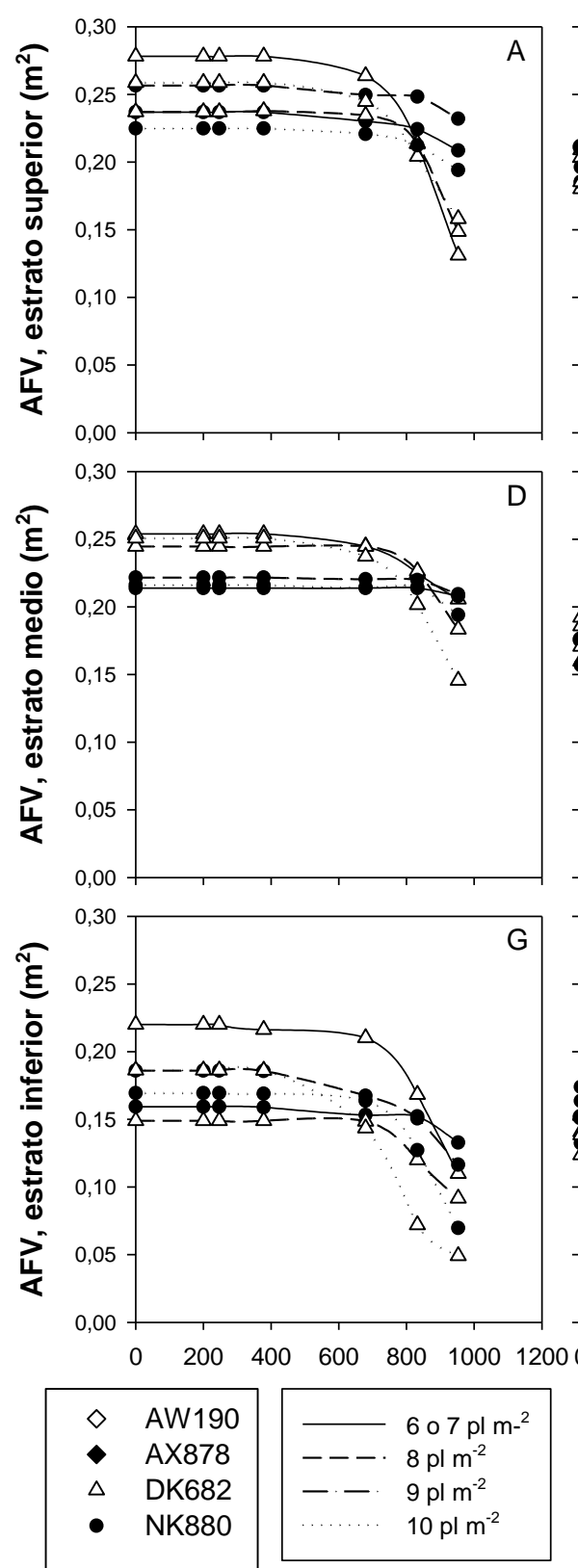

Exp II
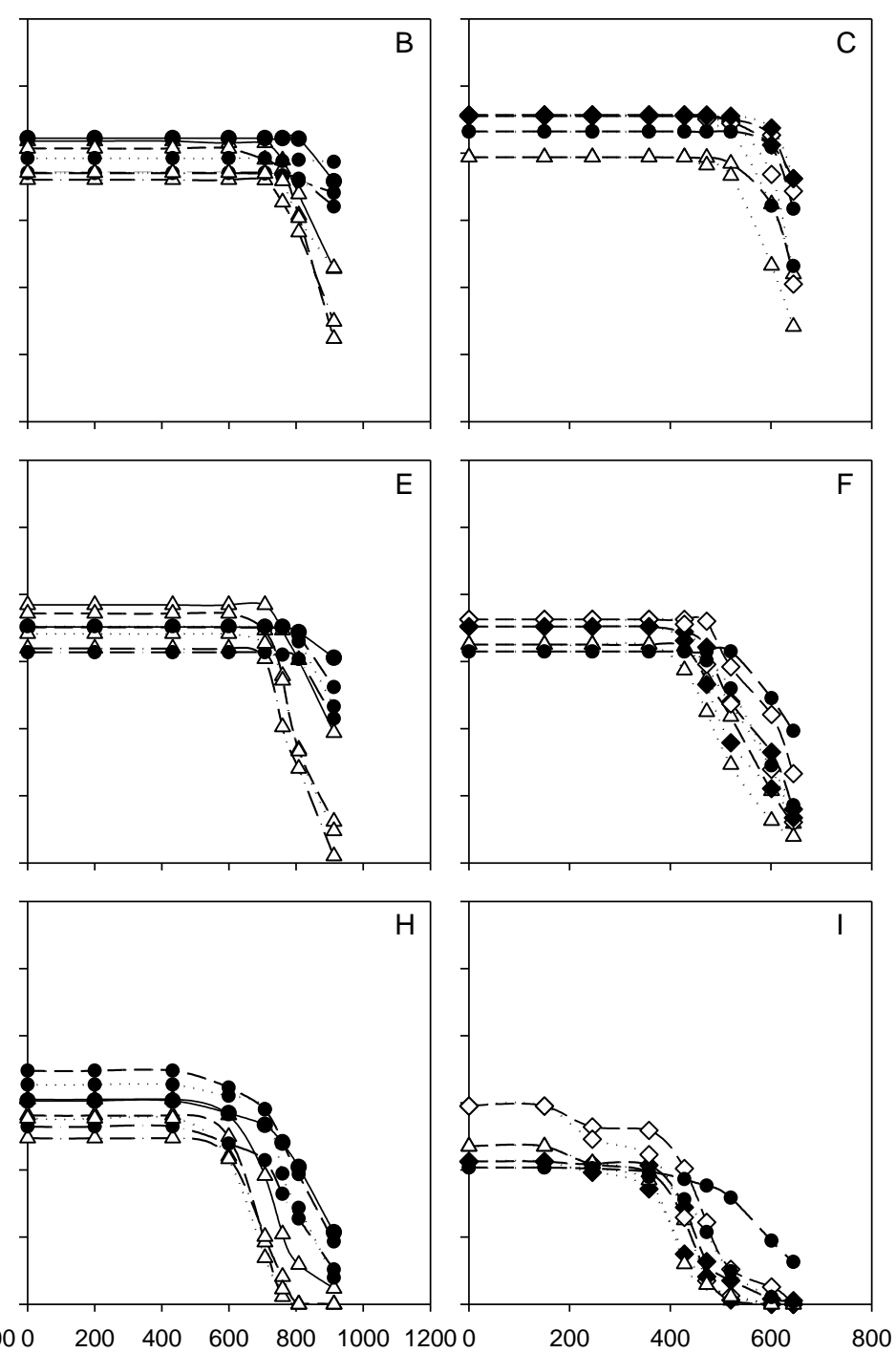

Tiempo térmico desde floración $\left({ }^{\circ} \mathrm{Cd}\right)$

Fig. 2: Evolución de la senescencia en los tres experimentos, expresada como pérdida de AFV en el estrato superior (A, B, C), medio (D, E, F) e inferior (G, H, I). Las distintas densidades se indican con líneas mientras que los símbolos indican el híbrido. Cada punto es el promedio de 6 (Exp. I) u 8 (Exps. II y III) plantas. 
Tabla 1: Inicio de la fase rápida de senescencia en cada estrato del canopeo o en la planta entera, en los tres experimentos. Los datos corresponden al promedio de 6 (Exp. I) u 8 (Exps. II y III) plantas por tratamiento. Resultados del ANOVA: NS, no significativo; $+\mathrm{P}<0,1 ;{ }^{*} \mathrm{P}<0,05:{ }^{*} \mathrm{P}<0,01 ; * * * \mathrm{P}<0,001$.

\begin{tabular}{|c|c|c|c|c|c|c|}
\hline \multirow{2}{*}{ Exp. } & \multirow{2}{*}{$\mathrm{Pl} \mathrm{m}{ }^{-2}$} & \multirow{2}{*}{ Híbrido } & \multicolumn{4}{|c|}{ Inicio de la fase rápida de senescencia $\left({ }^{\circ} \mathrm{Cd}\right)$} \\
\hline & & & Inferior & Medio & Superior & Planta \\
\hline \multirow{9}{*}{1} & \multirow{2}{*}{6} & DK & 927 & 1058 & 773 & 910 \\
\hline & & NK & 995 & 1060 & 1037 & 1027 \\
\hline & \multirow{2}{*}{8} & DK & 817 & 956 & 867 & 923 \\
\hline & & NK & 915 & 1074 & 1076 & 1071 \\
\hline & \multirow{2}{*}{10} & DK & 538 & 887 & 1097 & 1072 \\
\hline & & NK & 736 & 1076 & 1097 & 1077 \\
\hline & \multicolumn{2}{|c|}{$P$ (Densidad) } & $* * *$ & NS & $* * *$ & $*$ \\
\hline & \multicolumn{2}{|c|}{$P$ (Híbrido) } & $*$ & $*$ & $* * *$ & $* *$ \\
\hline & \multicolumn{2}{|c|}{$P(\mathrm{D} \times \mathrm{H})$} & NS & NS & $* * *$ & NS \\
\hline \multirow{11}{*}{ II } & \multirow{2}{*}{7} & DK & 599 & 767 & 756 & 600 \\
\hline & & NK & 780 & 897 & 956 & 857 \\
\hline & \multirow{2}{*}{8} & DK & 525 & 671 & 768 & 626 \\
\hline & & NK & 701 & 839 & 952 & 818 \\
\hline & \multirow{2}{*}{9} & DK & 525 & 691 & 756 & 628 \\
\hline & & NK & 701 & 817 & 916 & 797 \\
\hline & \multirow{2}{*}{10} & DK & 440 & 682 & 767 & 589 \\
\hline & & NK & 704 & 852 & 945 & 778 \\
\hline & \multicolumn{2}{|c|}{$P$ (Densidad) } & $* * *$ & NS & NS & NS \\
\hline & \multicolumn{2}{|c|}{$P$ (Híbrido) } & $* * *$ & $* * *$ & $* * *$ & $* * *$ \\
\hline & \multicolumn{2}{|c|}{$P(\mathrm{D} \times \mathrm{H})$} & NS & NS & NS & NS \\
\hline \multirow{11}{*}{ III } & \multirow{4}{*}{8} & AW & 420 & 518 & 592 & 468 \\
\hline & & AX & 372 & 470 & 624 & 410 \\
\hline & & DK & 369 & 445 & 573 & 403 \\
\hline & & NK & 509 & 635 & 622 & 578 \\
\hline & \multirow{4}{*}{10} & AW & 305 & 511 & 592 & 463 \\
\hline & & $A X$ & 324 & 447 & 656 & 376 \\
\hline & & DK & 334 & 495 & 566 & 368 \\
\hline & & NK & 378 & 512 & 648 & 462 \\
\hline & \multicolumn{2}{|c|}{$P$ (Densidad) } & $* * *$ & NS & NS & $* *$ \\
\hline & \multicolumn{2}{|c|}{$P$ (Híbrido) } & $* * *$ & $* * *$ & $* * *$ & $* * *$ \\
\hline & \multicolumn{2}{|c|}{$P(\mathrm{D} \times \mathrm{H})$} & * & * & NS & NS \\
\hline
\end{tabular}




\subsection{Contenido de clorofila}

La evolución de la senescencia también se analizó en términos del contenido de clorofila foliar (estimado a partir del valor de SPAD). En general, el aumento de la densidad poblacional redujo el contenido de clorofila en todos los estratos de la planta (Fig. 3). Sin embargo, estos efectos fueron menos acentuados en el estrato superior.

En ambos Exps., la densidad redujo significativamente el valor de SPAD (a los 36 y 50 DDF en el Exp. I y a los 50 DDF en el Exp. II) en el estrato inferior y medio (Figs 3C, 3D, 3E, 3F) pero no en el estrato superior (Fig. 3A, 3B). En cambio, en ambos Exps. los efectos del híbrido sí se mantuvieron en todos los estratos y estadíos de senescencia, teniendo siempre el híbrido SG (NK880) mayores valores de SPAD que el híbrido NSG (DK682).

\subsection{Intercepción de luz}

En los tres experimentos, el aumento de la densidad poblacional incrementó la intercepción de luz por el canopeo (Fig. 4). La intercepción de luz también varió entre híbridos $(P<0,05)$ incluso en estadíos previos a la ocurrencia del $P Q$ (i.e., antes de que se manifiesten las diferencias en senescencia foliar). En el Exp. I, la transmitancia de luz se midió a distintas alturas del canopeo. Se detectaron efectos significativos del híbrido a la altura de la hoja -3 y a nivel del suelo (Fig. 4B). En la Fig. 4B se destaca que en NK880, entre el 60 y 70\% del PAR incidente fue interceptado por hojas en posiciones superiores a la tercera hoja por debajo de la espiga

En los Exps. I y II, se observa que en todas las densidades testeadas, el híbrido SG (NK880) interceptó mayor irradiancia en comparación con el híbrido estándar a los 7 DDF (Exp. I, Fig. 4A) y a los 18 DDF (Exp. II, Fig. 4C). En el Exp. III, a los 31 DDF y a 8 pl $\mathrm{m}^{-2}$ AW190, AX878 y NK880 interceptaron mayor irradiancia en comparación con DK682 (Fig. 4D). A $10 \mathrm{pl} \mathrm{m}^{-2}$, AX878 y NK880 interceptaron comparativamente más radiación que AW190 y DK682. 


\section{Exp I}
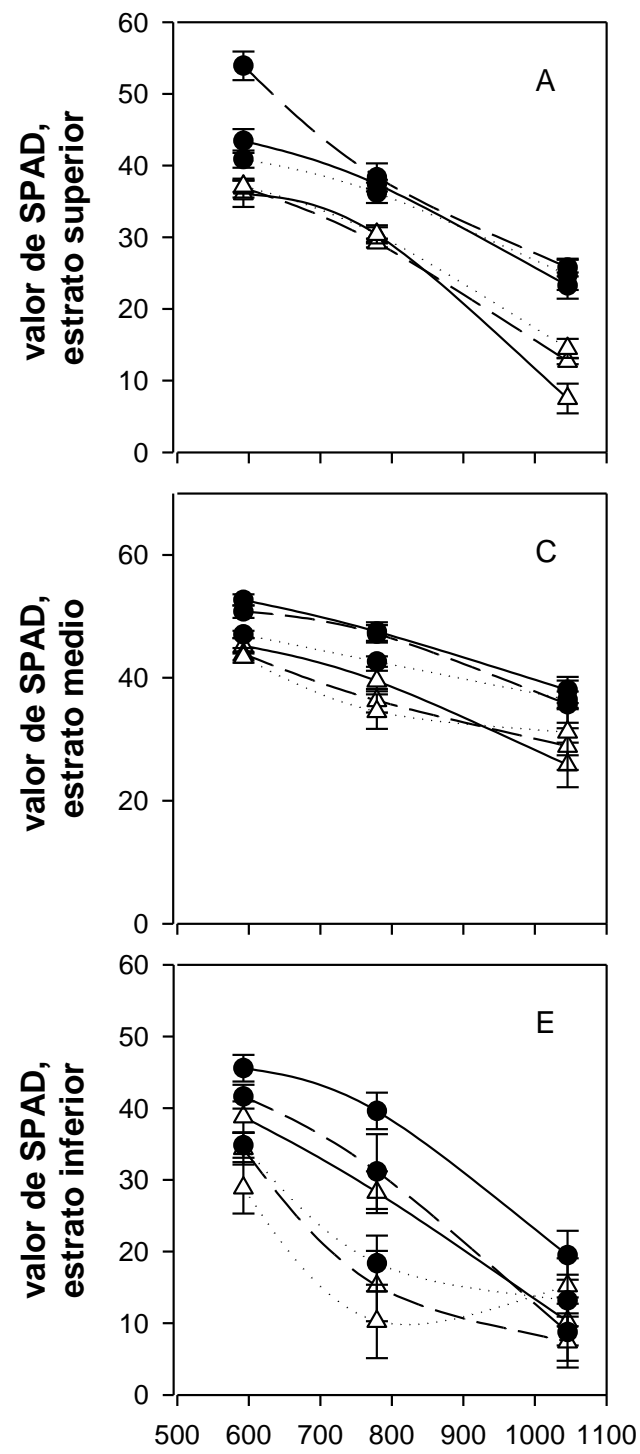

Exp II

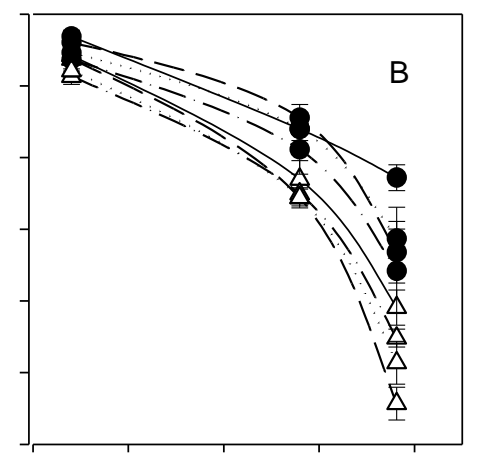

$$
\begin{aligned}
& -6 \circ 7 \mathrm{pl} \mathrm{m}-2 \\
& \text { - - } 8 \mathrm{pl} \mathrm{m}^{-2} \\
& \text {-. } 9 \mathrm{pl} \mathrm{m}^{-2}
\end{aligned}
$$
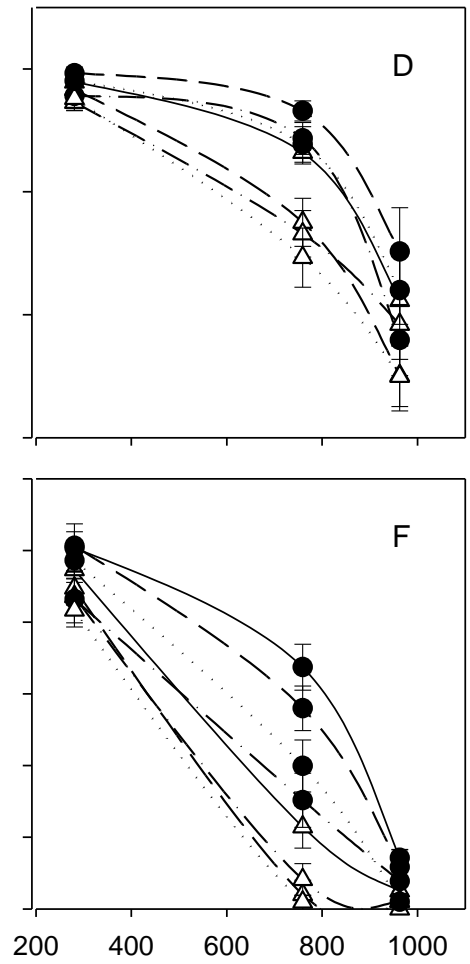

Tiempo térmico desde floración $\left({ }^{\circ} \mathrm{Cd}\right)$

Fig. 3: Evolución de la senescencia foliar en los Exps. I y II, expresada como valor de SPAD en el estrato superior $(A, B)$, medio $(C, D)$ e inferior $(E, F)$. Las distintas densidades se indican con líneas mientras que los símbolos indican el híbrido. Cada punto es el promedio de 6 (Exp. I) u 8 (Exp. II) plantas. 

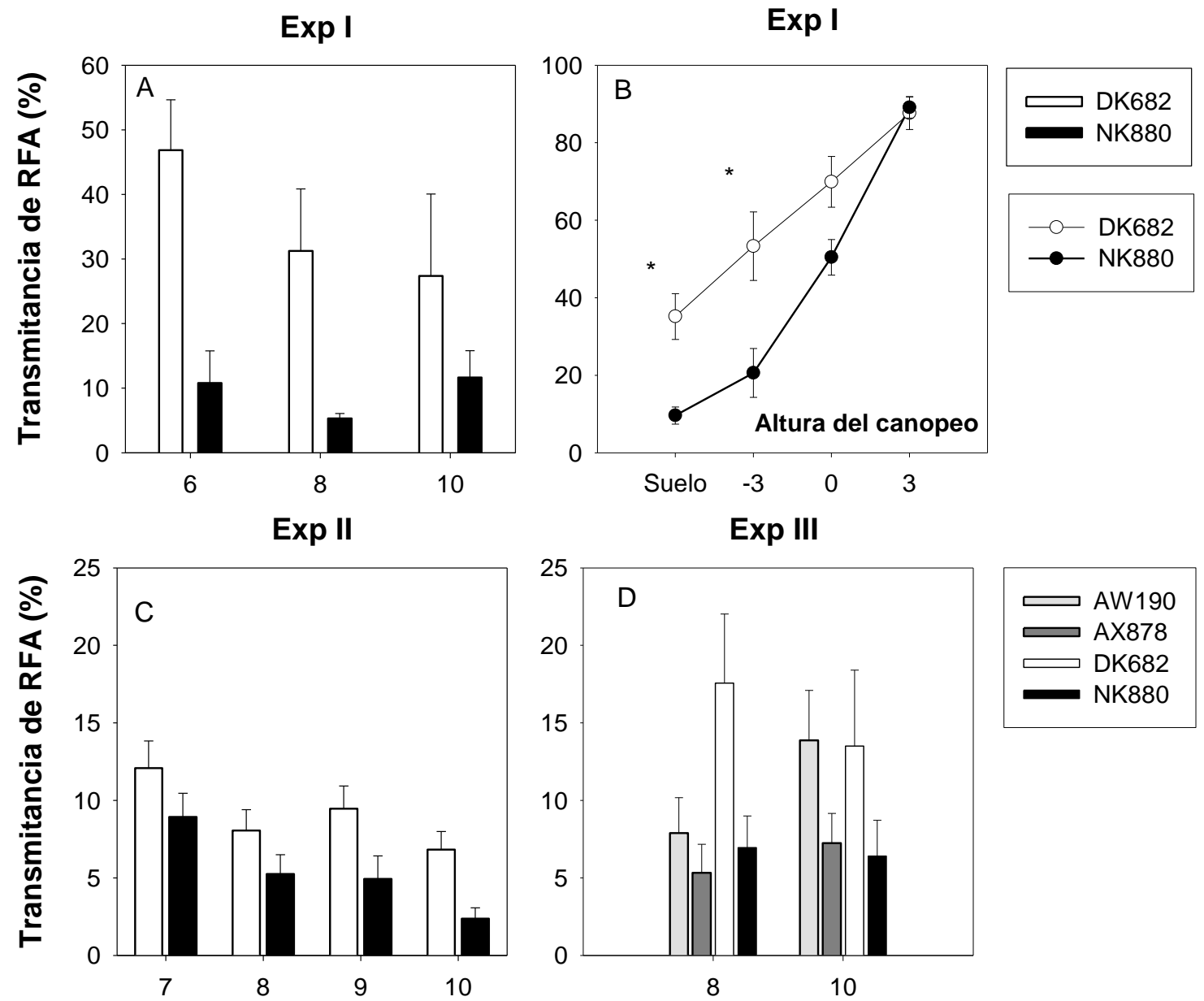

\section{Densidad poblacional $\left(\mathrm{pl} \mathrm{m}^{-2}\right) \quad$ Densidad poblacional $\left(\mathrm{pl} \mathrm{m}^{-2}\right)$}

Fig. 4: Radiación Fotosintéticamente Activa (RFA) transmitida a través del canopeo a nivel del suelo en el Exp. I (A, 7 DDF, $127^{\circ} \mathrm{Cd}$ ), Exp. II (C, 18 DDF y $299^{\circ} \mathrm{Cd}$ ) y Exp. III (D, 31 DDF y $443^{\circ} \mathrm{Cd}$ ). En la Fig. $B$, se muestra el perfil de transmitancia de luz (promedio entre densidades) a distintas alturas del canopeo (suelo, hoja -3 , hoja 0 y hoja +3 ) medido en el Exp. I (los asteriscos indican DMS< 0,05). 


\subsection{Rendimiento y componentes}

En todos los Exps., el rendimiento máximo se obtuvo a $8 \mathrm{pl} \mathrm{m}^{-2}$ en el híbrido SG (NK880) y a $10 \mathrm{pl} \mathrm{m}^{-2}$ en el híbrido NSG (DK682); es decir que, el rendimiento máximo del híbrido NSG se ubicó en densidades mayores (Tabla 2). En el Exp. I el ANOVA detectó interacción entre tratamientos; a $6 \mathrm{pl} \mathrm{m}^{-2}$ el rendimiento de los híbridos fue similar, a $8 \mathrm{pl} \mathrm{m}^{-2}$ el rendimiento del híbrido SG fue mayor $(P<0,05)$ pero a $10 \mathrm{pl} \mathrm{m}^{-2}$ la tendencia se invirtió y el híbrido NSG fue el que alcanzó mayor rendimiento (Tabla 2). En el Exp. II el ANOVA detectó diferencias significativas entre híbridos para el rendimiento: el híbrido NSG (DK682) presentó siempre mayores rendimientos (excepto a $8 \mathrm{pl} \mathrm{m}^{-2}$, diferencias no significativas, Tabla 2). Promediando entre Exps. I y II, los rendimientos obtenidos a $10 \mathrm{pl} \mathrm{m}^{-2}$ fueron un $12 \%$ mayores en el híbrido NSG (DK682) respecto al híbrido SG (NK880). A partir de los rendimientos obtenidos a $6-8 \mathrm{pl} \mathrm{m}^{-2}$ en Exp. $\mid$ o $7-8 \mathrm{pl} \mathrm{m}^{-2}$ en el Exp. II, se deduce que las diferencias en rendimiento observadas a altas densidades no pueden ser explicadas por diferencias en el potencial de rendimiento de los híbridos a una menor densidad poblacional.

Como era esperable, el aumento de la densidad incrementó el estrés por competencia reduciendo el rendimiento por planta en todos los experimentos (el rendimiento por planta no se presenta pero puede calcularse a partir del NG y PG presentados en la Tabla 2). El aumento de la densidad poblacional redujo el NG por planta en ambos experimentos y el PG en el Exp. I (y en el Exp. II con un valor de $P<$ 0,1). A $10 \mathrm{pl} \mathrm{m-2,} \mathrm{los} \mathrm{híbridos} \mathrm{prácticamente} \mathrm{no} \mathrm{se} \mathrm{diferenciaron} \mathrm{en} \mathrm{el} \mathrm{NG} \mathrm{mientras} \mathrm{que}$ el PG fue entre un $10 \%$ (Exp. I) y un 15\% (Exp. II) menor en el híbrido NK880. Estos resultados no pueden ser atribuidos a un menor PG potencial en el híbrido SG, pues estos genotipos no se diferenciaron en PG a 6 o $7 \mathrm{pl} \mathrm{m}^{-2}$ (en Exp. I y II respectivamente, Tabla 2).

En el Exp. III, el ANOVA detectó interacción entre tratamientos. Entre 8 y 10 pl $\mathrm{m}^{-2}$, el rendimiento de los híbridos AW190 y DK682 no varió significativamente; en cambio, el rendimiento del híbrido $A X 878(S G)$ aumentó $(P<0,05)$ y el rendimiento de NK880 (SG) se redujo $(P<0,05)$. El NG se redujo significativamente al aumentar la densidad, siendo esta reducción comparativamente menor en el híbrido AX878 (-5\%) en comparación al resto de los híbridos (entre 20 y 13\% de reducción respecto al NG alcanzado a $8 \mathrm{pl} \mathrm{m}^{-2}$ ) (calculado de la Tabla 2). Se detectó interacción Densidad $\mathrm{x}$ 
Híbrido para el PG; el PG se redujo muy poco en la mayoría de los híbridos (entre 1 y $5 \%$ de reducción respecto al PG alcanzado a $8 \mathrm{pl} \mathrm{m}^{-2}$ ) excepto en el híbrido NK880, donde esta reducción alcanzó el 20\% (Tabla 2). En promedio para los híbridos con la menor densidad óptima (AW190 y NK880) el NG se redujo un 19\% y el PG un $13 \%$ al pasar de 8 a $10 \mathrm{pl} \mathrm{m}^{-2}$. En cambio, en los híbridos con la mayor densidad óptima (AX878 y DK682), el NG se redujo un $9 \%$ y el PG un $2 \%$ al pasar de 8 a $10 \mathrm{pl} \mathrm{m}^{-2}$. Esto indica que el PG es el principal componente asociado a la estabilidad del rendimiento en altas densidades.

3.6. La relación entre el inicio de la fase rápida de senescencia en los distintos estratos y el rendimiento se corresponde con las diferencias genotípicas.

En los tres Exps., se analizó la relación entre el inicio de la fase rápida de senescencia (PQ) en cada estrato y el rendimiento (Fig. 5). A una densidad de $8 \mathrm{pl} \mathrm{m}^{-2}$, el rendimiento se relacionó positivamente con el PQ en los tres estratos (Figs 5A, 5B, 5C). $A 10 \mathrm{pl} \mathrm{m}^{-2}$, se mantuvo una relación positiva entre el rendimiento y el $P Q$, pero el coeficiente $r^{2}$ fue menor respecto a la relación encontrada a $8 \mathrm{pl} \mathrm{m}^{-2}$ (i.e., mayor dispersión de los datos) (Figs 5D, 5E, 5F). Además, tanto la pendiente de la regresión como el coeficiente $r^{2}$ disminuyeron desde el estrato superior al inferior. La relación más débil entre el $P Q$ y el rendimiento se registró a $10 \mathrm{pl} \mathrm{m}^{-2}$, y en el estrato inferior. A $10 \mathrm{pl} \mathrm{m}^{-2}$ se observa que, en general, los residuales de los híbridos AW190 y DK682 (caracterizados como NSG) se encuentran por encima de la línea de tendencia. En cambio, los residuales de los híbridos AX878 y NK880 (SG) se encuentran por debajo. Esto es especialmente evidente en el estrato inferior (Fig. 5F). 
Tabla 2: Rendimiento ( $\mathrm{kg} \mathrm{ha}^{-1}$ ), número de granos por planta (NG), peso de grano (PG), MS total a MF, y acumulación neta entre floración y MF (para el Exp. III no se dispone de datos de acumulación neta). Los promedios presentados corresponden a 6 (Exp. I) u 8 (Exps. II y III) plantas por tratamiento, excepto para rendimiento donde el promedio corresponde a 60 (Exp. I) u 80 (Exps. II y III) plantas por tratamiento. Resultados del ANOVA: NS, no significativo; $+\mathrm{P}<0,1 ; * \mathrm{P}<0,05:{ }^{* *} \mathrm{P}<0,01 ; * * * \mathrm{P}<0,001$.

\begin{tabular}{|c|c|c|c|c|c|c|c|}
\hline Exp & $\mathrm{Pl} \mathrm{m}^{-2}$ & Híbrido & $\begin{array}{l}\text { Rendimiento } \\
\qquad\left(\mathrm{kg} \mathrm{ha}^{-1}\right)\end{array}$ & NG pl-1 & $\begin{array}{l}\text { PG (mg } \\
\text { grano-1) }\end{array}$ & $\begin{array}{l}\text { MS total } \\
\text { (g pl-1) }\end{array}$ & $\begin{array}{l}\text { Asim. Neta } \\
\text { (g pl-1) }\end{array}$ \\
\hline \multirow{9}{*}{ I } & \multirow{2}{*}{6} & DK & 10941 & 583 & 313 & 310 & 185 \\
\hline & & NK & 11710 & 627 & 314 & 329 & 204 \\
\hline & \multirow{2}{*}{8} & DK & 12779 & 524 & 307 & 230 & 140 \\
\hline & & NK & 13920 & 590 & 299 & 283 & 133 \\
\hline & \multirow{2}{*}{10} & DK & 14618 & 481 & 305 & 238 & 148 \\
\hline & & NK & 13278 & 477 & 281 & 226 & 100 \\
\hline & \multicolumn{2}{|c|}{$P$ (Densidad) } & $* * *$ & $*$ & $*$ & $* * *$ & NS \\
\hline & \multicolumn{2}{|c|}{$P$ (Híbrido) } & NS & $*$ & + & NS & NS \\
\hline & \multicolumn{2}{|c|}{$P(\mathrm{D} \times \mathrm{H})$} & $* *$ & + & NS & NS & NS \\
\hline \multirow{11}{*}{ II } & \multirow{2}{*}{7} & DK & 11980 & 612 & 280 & 288 & 115 \\
\hline & & NK & 11517 & 591 & 282 & 294 & 145 \\
\hline & \multirow{2}{*}{8} & DK & 11791 & 549 & 269 & 254 & 84 \\
\hline & & NK & 12330 & 599 & 259 & 265 & 133 \\
\hline & \multirow{2}{*}{9} & DK & 13240 & 552 & 268 & 242 & 96 \\
\hline & & NK & 11809 & 479 & 266 & 227 & 111 \\
\hline & \multirow{2}{*}{10} & DK & 13322 & 492 & 272 & 238 & 107 \\
\hline & & NK & 11288 & 493 & 232 & 218 & 101 \\
\hline & \multicolumn{2}{|c|}{$P$ (Densidad) } & NS & $*$ & + & $* * *$ & $*$ \\
\hline & \multicolumn{2}{|c|}{$P$ (Híbrido) } & $*$ & NS & $*$ & NS & NS \\
\hline & \multicolumn{2}{|c|}{$P(\mathrm{D} \times \mathrm{H})$} & NS & + & NS & NS & NS \\
\hline \multirow{11}{*}{ III } & \multirow{4}{*}{8} & AW & 10895 & 563 & 243 & 262 & \\
\hline & & $A X$ & 10030 & 462 & 273 & 266 & \\
\hline & & DK & 10455 & 485 & 254 & 244 & \\
\hline & & NK & 11335 & 511 & 280 & 242 & \\
\hline & \multirow{4}{*}{10} & AW & 10566 & 464 & 228 & 215 & \\
\hline & & $A X$ & 11676 & 440 & 267 & 231 & \\
\hline & & DK & 11165 & 424 & 252 & 183 & \\
\hline & & NK & 9772 & 416 & 228 & 207 & \\
\hline & \multicolumn{2}{|c|}{$P$ (Densidad) } & NS & $*$ & $* *$ & $* * *$ & \\
\hline & \multicolumn{2}{|c|}{$P$ (Híbrido) } & NS & $*$ & $* *$ & $*$ & \\
\hline & \multicolumn{2}{|c|}{$P(\mathrm{D} \times \mathrm{H})$} & $*$ & NS & $*$ & NS & \\
\hline
\end{tabular}




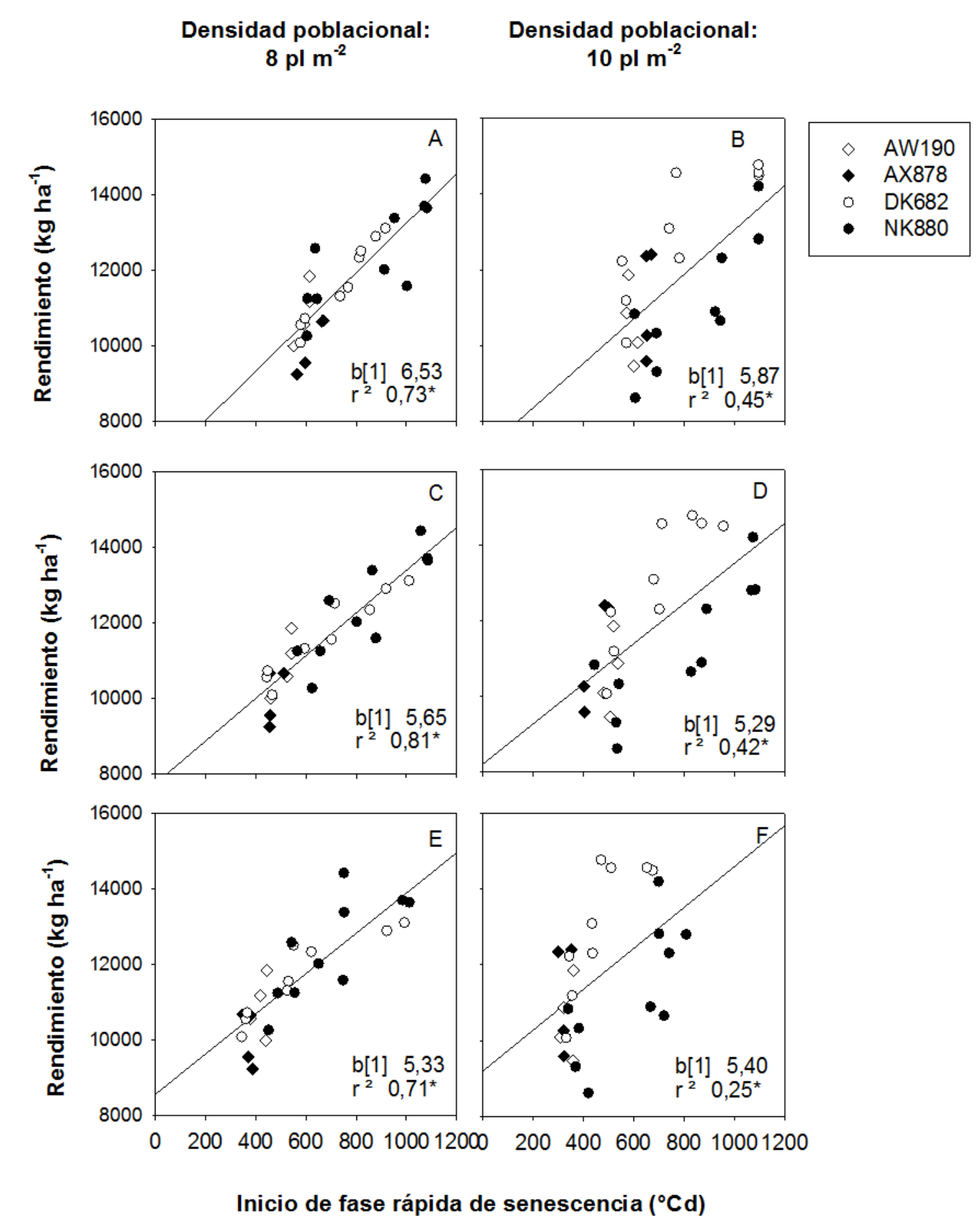

Fig. 5: Relación entre el inicio de la fase rápida de senescencia en el estrato superior ( $A$, $B)$, medio $(C, D)$ e inferior $(E, F)$, y el rendimiento en dos densidades: $8 \mathrm{pl} \mathrm{m}^{-2}(A, C, E)$ y $10 \mathrm{pl} \mathrm{m}^{-2}(B, D, F)$. En cada gráfico se muestran los promedios por repetición (parcela) a lo largo de los 3 Exps. 


\subsection{Las diferencias genotípicas pueden asociarse a diferencias}

en la asimilación neta (balance de C) y en la partición a espiga

En los Exps. I y II, el ANOVA no registró diferencias significativas entre híbridos en la asimilación neta durante el llenado (Tabla 2). Como fue observado en el Capítulo 3, nuevamente se detectaron pérdidas netas de MS hacia el final del llenado (datos no mostrados). Las pérdidas netas de MS fueron más acentuadas en el Exp. II y se detectaron a partir de los 66 DDF, en coincidencia con los registros de temperaturas mínimas por debajo de $10^{\circ} \mathrm{C}$ (Fig 1B). En sintonía con lo observado en el Capítulo 3 las pérdidas de MS fueron notablemente más importantes y se mantuvieron en todas las densidades en el híbrido SG NK880, mientras que en el híbrido NSG DK682 sólo se manifestaron ligeramente a $7 \mathrm{pl} \mathrm{m}^{-2}$ (datos no mostrados).

En el Exp. III no se realizaron muestreos alrededor de floración motivo por el cual no es posible calcular la asimilación neta de MS. Como se observa en la Fig. 6, la pendiente de la relación entre asimilación neta y crecimiento de espiga varió entre 0,69 en el Exp. I, y 0,56 en el Exp. II. En el Exp. I (Fig. 6A) y a $10 \mathrm{pl} \mathrm{m}^{-2}$ (señalado con flechas) la acumulación neta fue ligeramente mayor en el híbrido DK682. En cambio, en el Exp. II (Fig. 6B) y a $10 \mathrm{pl} \mathrm{m}^{-2}$ (señalado con flechas) las diferencias en acumulación neta entre híbridos fueron menores, y el híbrido DK682 presentó mayor partición a espiga. En la Fig. 6 también se puede observar (como la distancia que separa a los puntos que se encuentran por encima de la línea 1:1) que el aporte de MS proveniente de la removilización de asimilados no superó el $20 \%$ en ninguno de los dos Exps. La ausencia de diferencias en asimilación neta durante el llenado en altas densidades, aún cuando el híbrido SG presentó una demora significativa en la senescencia foliar, será analizada en la sección siguiente desde la perspectiva del balance de C. La menor partición a espiga registrada en el híbrido SG, especialmente en el Exp. II (donde la partición a espiga fue menor en relación al Exp. I), será analizada desde la perspectiva del balance de $\mathrm{N}$. 


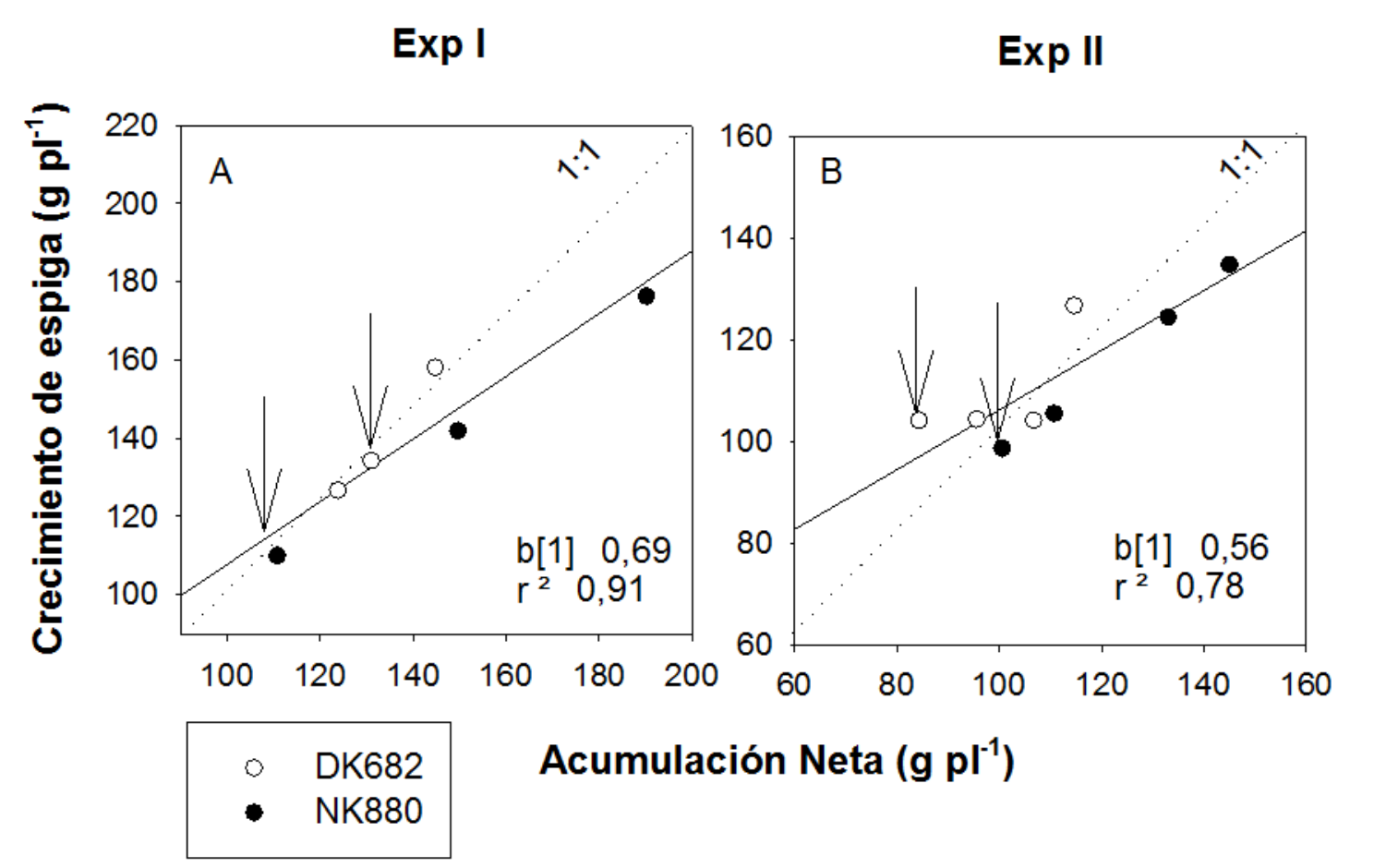

Fig. 6: Relación entre la asimilación neta de MS durante el llenado y el crecimiento de la espiga en el Exp. I (A, hasta los 71 DDF o $1045^{\circ} \mathrm{Cd}$ ) y Exp. II (B, hasta los 66 DDF o $962^{\circ} \mathrm{Cd}$ ). Cada punto representa un tratamiento (Densidad $x$ Híbrido). Las flechas indican resultados a $10 \mathrm{pl} \mathrm{m}^{-2}$. 
3.8. Balance de C: relación entre el carácter SG y la asimilación neta durante el llenado

En la Fig. 7 se presenta la relación entre el inicio de la fase rápida de senescencia y la acumulación neta durante el llenado en los Exps. I y II. Como se puede observar, a $8 \mathrm{pl} \mathrm{m}^{-2}$, la relación es significativa para todos los estratos (Figs 7A, 7C, 7E). En cambio a $10 \mathrm{pl} \mathrm{m}^{-2}$ la relación sólo es significativa en el estrato superior (Fig. 7B, $\mathrm{P}<$ $0,05)$.

En el Exp. III se realizaron mediciones de respiración foliar en dos de los híbridos: DK682 (NSG) y NK880 (SG). La tasa respiratoria por unidad de área foliar varío en función del estadio fenológico, la posición de la hoja en la planta, la densidad y el híbrido (Fig. 8). En el primer estadío de medición (7 DDF, $111^{\circ} \mathrm{Cd}$ ) no se detectaron diferencias significativas entre densidades, híbridos y hojas. En el segundo estadío de medición (17 DDF, $245^{\circ} \mathrm{Cd}$ ), las tasas respiratorias a $10 \mathrm{pl} \mathrm{m}{ }^{-2}$ fueron menores que a 8 pl m $\mathrm{m}^{-2}\left(\mathrm{P}<0,05 ; 0,69\right.$ vs. 1,06 micromoles $\mathrm{O}_{2} \mathrm{~h}^{-1} \mathrm{~cm}^{-2}$ de hoja, respectivamente) y las tasas de la hoja -3 fueron menores que las de la hoja 0 ( $P<0,05 ; 0,77$ vs 0,99 micromoles $\mathrm{O}_{2} \mathrm{~h}^{-1} \mathrm{~cm}^{-2}$ respectivamente). Finalmente, en el tercer estadío de medición (35 DDF, $500{ }^{\circ} \mathrm{Cd}$ ), el ANOVA detectó interacción entre híbridos y hojas: la tasa respiratoria se redujo significativamente en la hoja -3 del híbrido DK682 en ambas densidades, y más notoriamente a $10 \mathrm{pl} \mathrm{m}^{-2}$. Las tasas respiratorias a $10 \mathrm{pl} \mathrm{m}^{-2}$ se mantuvieron constantes entre los 250 y $500{ }^{\circ} \mathrm{C} \mathrm{día}^{-1}$ en el híbrido SG (NK880) mientras que en el híbrido NSG (DK682) se redujeron a cero como resultado de la senescencia (Fig. 8B). Estos resultados sugieren que a $10 \mathrm{pl} \mathrm{m}^{-2}$ la demora de la senescencia no tiene un fuerte impacto sobre la asimilación neta, y que, incluso, el mantenimiento de la actividad respiratoria en las hojas basales del genotipo SG podría tener un impacto negativo en el balance de $\mathrm{C}$. 


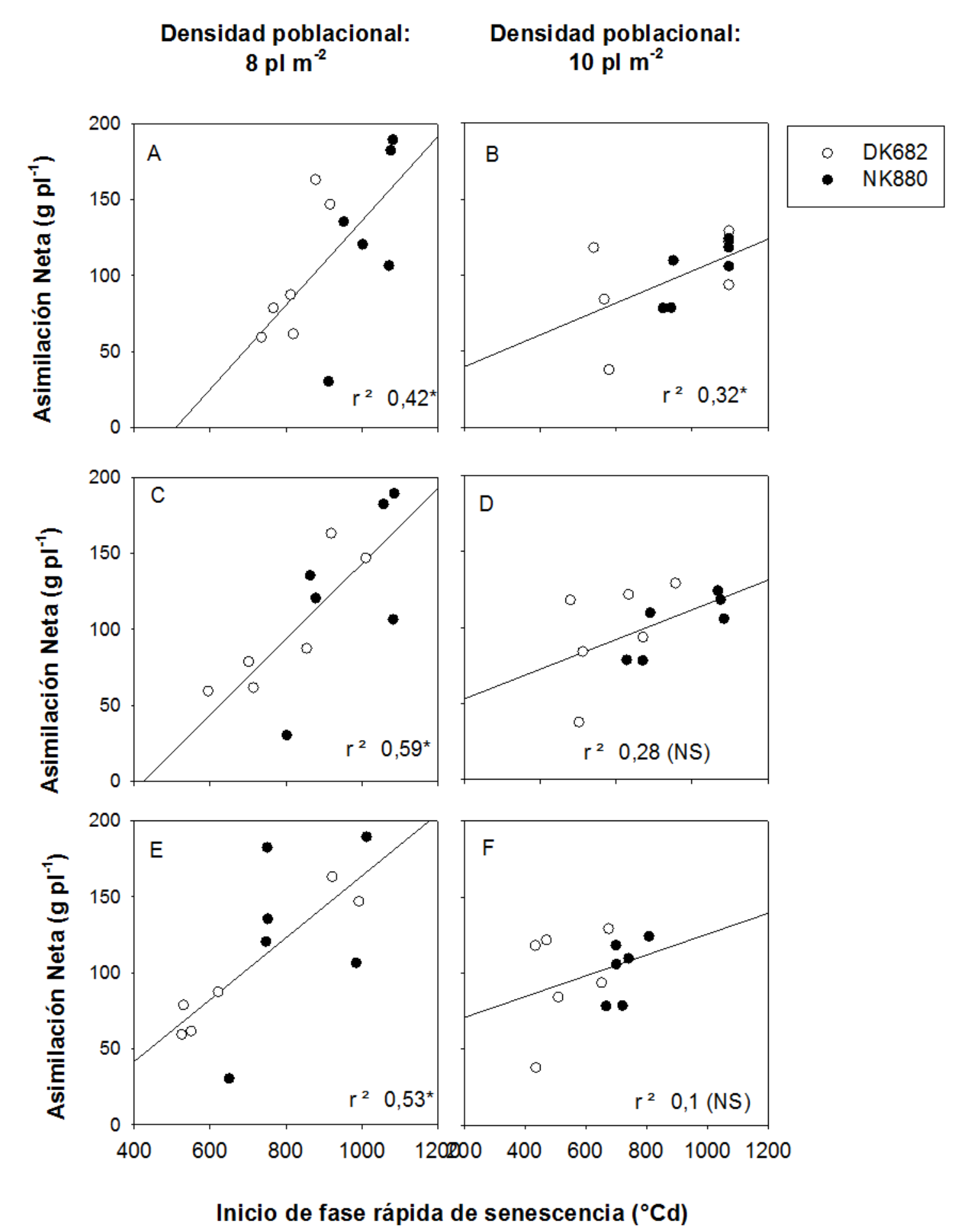

Fig. 7: Asimilación neta (entre 7 y 50 DDF en Exp. I o entre 17 y 50 DDF en Exp. II) vs inicio de fase rápida de senescencia a $8 \mathrm{pl} \mathrm{m}^{-2}(A, C, E)$ y a $10 \mathrm{pl} \mathrm{m}^{-2}(B, D, F)$. Cada gráfico representa un estrato diferente del canopeo: estrato superior $(A, B)$, medio $(C$, $D)$ e inferior $(E, F)$. Cada punto es el promedio de una repetición por tratamiento $(n=$ 12 en cada regresión). 


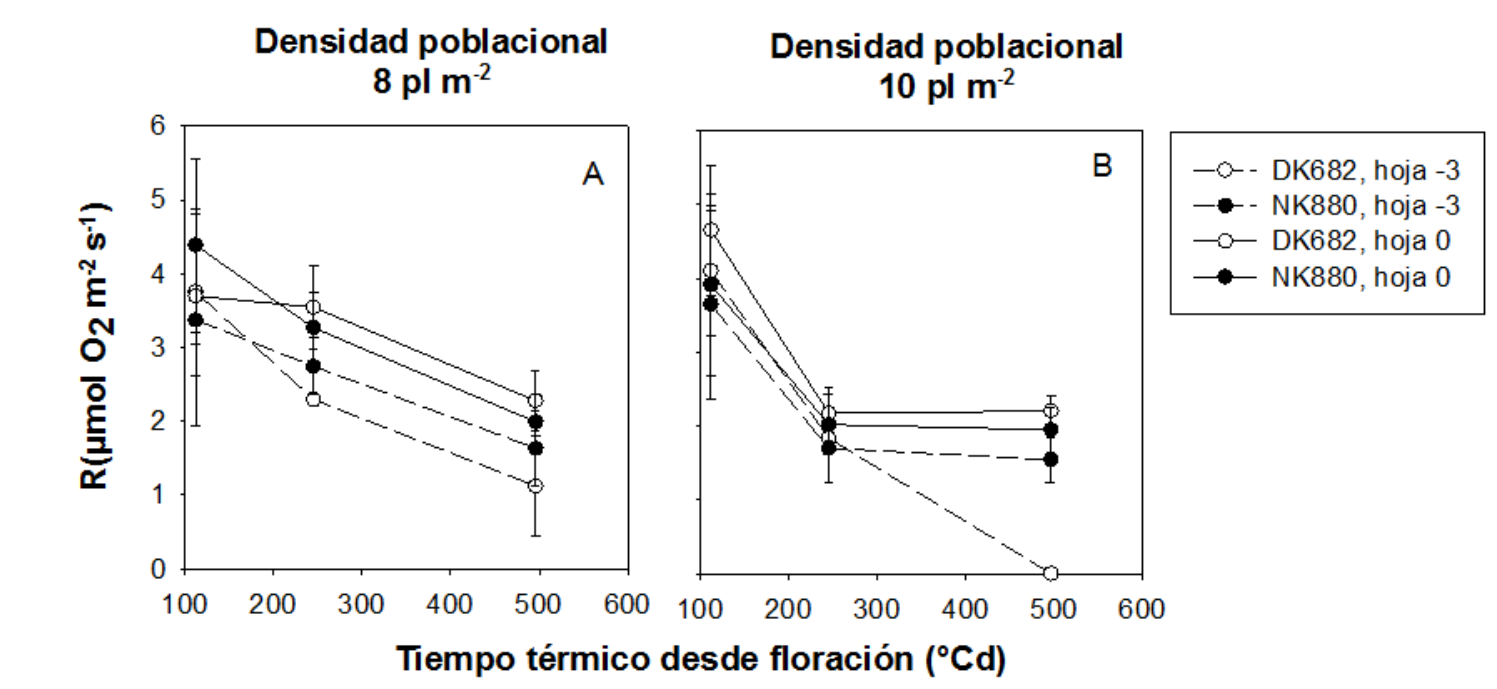

Fig. 8: Cambios en la tasa respiratoria foliar (expresada por unidad de área) en postfloración, medida en el Exp. III, en un híbrido NSG (DK682) y un híbrido SG (NK880). Las mediciones fueron realizadas en dos densidades: a $8 \mathrm{pl} \mathrm{m}^{-2}(\mathrm{~A})$ y a $10 \mathrm{pl} \mathrm{m}^{-2}(\mathrm{~B})$, y en dos hojas: en la hoja -3 (correspondiente al estrato inferior, línea punteada) y en la hoja 0 (correspondiente al estrato medio, línea llena). Las líneas verticales indican el error estándar. Cada punto es el promedio de 6 u 8 plantas por tratamiento.

3.9. Balance de $\mathrm{N}$ : dinámica del $\mathrm{N}$ en post-floración y posibles efectos sobre el rendimiento

En los Exps. I y II se analizó el contenido de $\mathrm{N}$ en tres compartimentos de la planta, en antesis y alrededor de madurez fisiológica. En ambos Exps. el aumento de la densidad redujo significativamente el contenido de $\mathrm{N}$ en planta alrededor de floración (Tabla 3). En el Exp. I, el contenido de $\mathrm{N}$ en floración no varió entre híbridos a 6 y a 10 $\mathrm{pl} \mathrm{m}^{-2}$, pero sí a $8 \mathrm{pl} \mathrm{m}^{-2}$, donde fue mayor ( $\left.<<0,05\right)$ en el híbrido SG (NK880) (Fig. 9A). En el Exp. II, el ANOVA detectó efectos del híbrido: en general, DK682 alcanzó mayores contenidos de $\mathrm{N}$ en floración aunque a $10 \mathrm{pl} \mathrm{m}^{-2}$ no existieron diferencias entre híbridos (Fig. 9B).

En el Exp. I, la absorción de $\mathrm{N}$ durante el llenado se redujo significativamente con el aumento en la densidad, y el híbrido NSG (DK682) absorbió mayor cantidad de N que el híbrido SG (NK880) (Tabla 3, Fig. 9). Estas diferencias se acentuaron con el aumento de la densidad; por ejemplo, DK682 absorbió un 4\% más de $\mathrm{N}$ en postfloración a $8 \mathrm{pl} \mathrm{m}^{-2}$ y un $40 \%$ más a $10 \mathrm{pl} \mathrm{m}^{-2}$, en comparación con NK880. En el Exp. II la absorción de $\mathrm{N}$ en post-floración fue (promedio entre tratamientos) un $70 \%$ menor que la registrada en el Exp. I. En consecuencia, el ANOVA no detectó efectos significativos de los tratamientos, aunque se mantuvieron las tendencias observadas 
en el Exp. I (mayor absorción de $\mathrm{N}$ en DK682, especialmente a $10 \mathrm{pl} \mathrm{m}^{-2}$ ) (Tabla 3, Fig. 9).

Tabla 3: Resultados de ANOVA para el contenido de $\mathrm{N}$ en la planta en antesis, la absorción de $\mathrm{N}$ en post-floración y el contenido de $\mathrm{N}$ en planta a cosecha, en los Exps. I y II.

\begin{tabular}{ccccccc}
\hline & \multicolumn{3}{c}{ Exp. I } & & Exp. II & \\
& Antesis & Absorción & Cosecha & Antesis & Absorción & Cosecha \\
\hline$P$ (Densidad) & $* * *$ & $* * *$ & $* * *$ & $* * *$ & NS & $* * *$ \\
$P$ (Híbrido $)$ & NS & $* *$ & $* * *$ & $* *$ & NS & $* *$ \\
$P($ D $\times \mathrm{H})$ & $*$ & + & NS & NS & NS & NS \\
\hline
\end{tabular}

\section{Exp I}

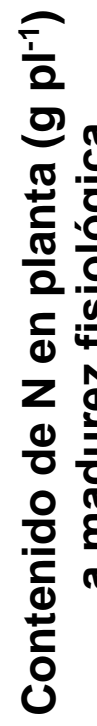

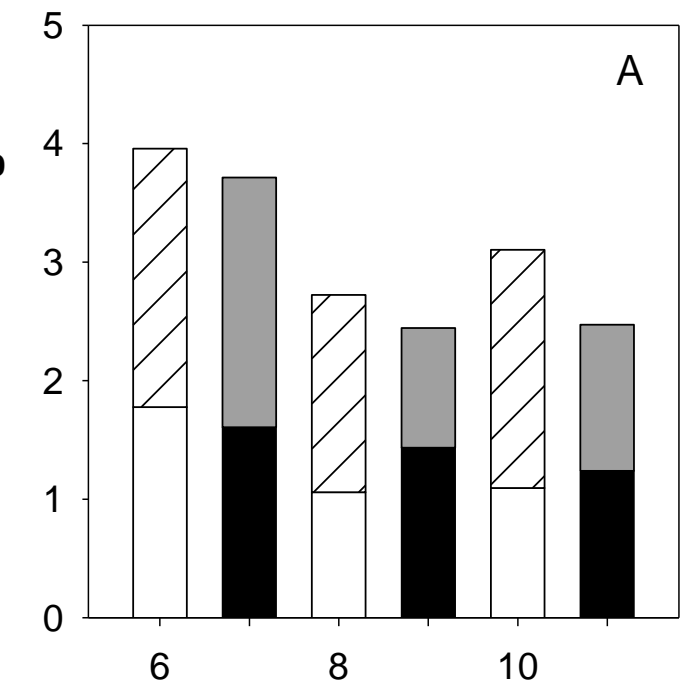

Densidad poblacional $\left(\mathrm{pl} \mathrm{m}^{-2}\right)$
Exp II

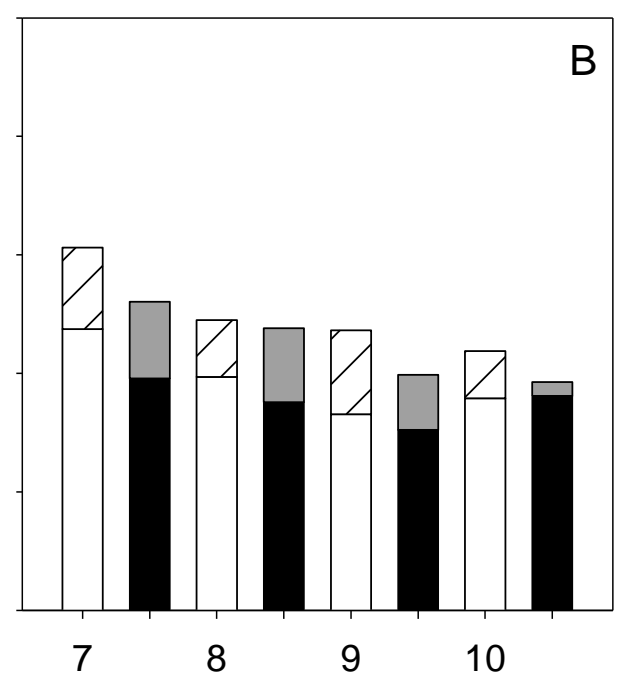

Densidad poblacional $\left(\mathrm{pl} \mathrm{\textrm {m } ^ { - 2 } )}\right.$

Fig. 9: Contenido de $\mathrm{N}(\mathrm{Nc})$ en la planta a madurez fisiológica, presentado como la suma entre el contenido de $\mathrm{N}$ presente en planta en antesis (barras blancas, DK682; barras negras, NK880), y el contenido de $\mathrm{N}$ absorbido en post-floración (barras blancas rayadas DK682; barras grises, NK880) en el Exp. I (A) y en el Exp. II (B). 
Como resultado de la cantidad de $\mathrm{N}$ acumulado durante el período vegetativo, y el $\mathrm{N}$ acumulado en post-floración, el $\mathrm{N}$ en planta hacia el final del llenado se redujo ( $\mathrm{P}$ $<0,05)$ con el aumento en la densidad en ambos Exps. En ambos Exps. y en todas las densidades, el híbrido NSG (DK682) presentó mayor contenido de $\mathrm{N}$ en planta que el híbrido SG (NK880) (Tabla 3, Fig. 9).

En ambos Exps., la concentración de $\mathrm{N}$ en granos no varió entre las densidades pero sí entre híbridos: fue siempre mayor en DK682 (Tabla 4). En el híbrido NK880, la concentración de $\mathrm{N}$ en granos se mantuvo por debajo del 1,4\% en el Exp. I, y por debajo del 1,1\% en el Exp. II, en todas las densidades; en el híbrido DK682 la concentración de $\mathrm{N}$ en granos se mantuvo por encima del 1,3\% en ambos Exps. La concentración de $\mathrm{N}$ en granos hacia el final del llenado se relacionó significativamente con el PG final (Fig. 10).

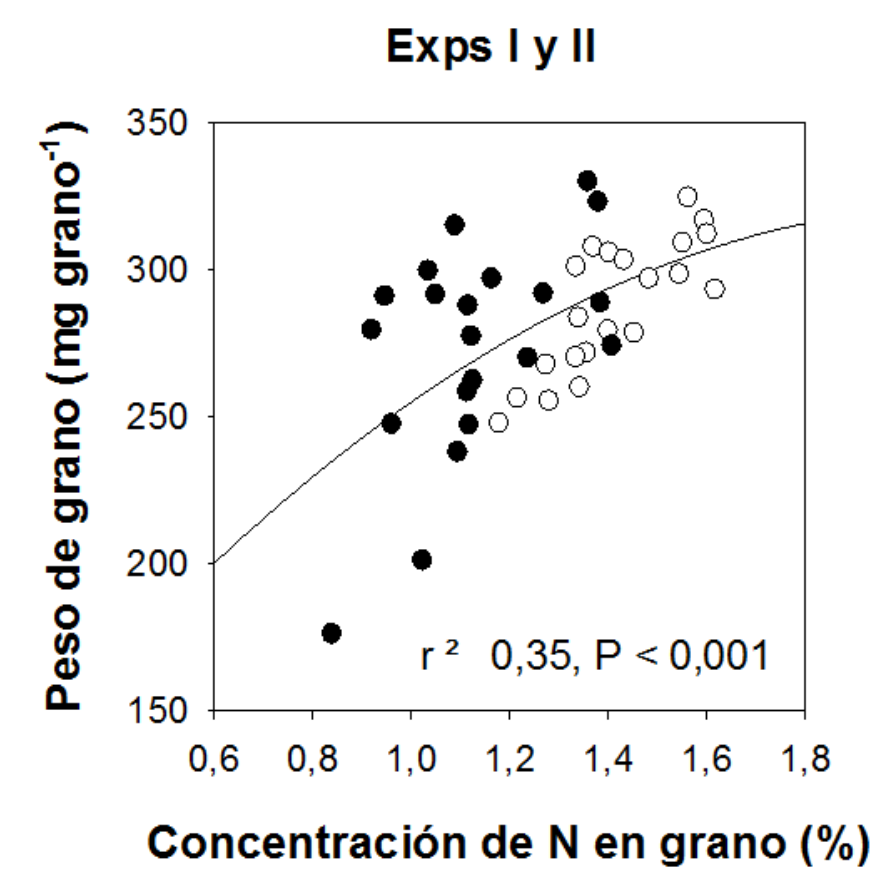

Fig. 10: Regresión entre la concentración de $\mathrm{N}$ en grano y el peso de grano, a lo largo de las distintas densidades y experimentos. Cada punto representa una repetición de cada tratamiento, en los dos Exps. ( $n=42)$. 
Tabla 4. Concentración de $\mathrm{N}$ en granos, hojas y cañas (\%),y eficiencia en el uso del $\mathrm{N}$ (EUtN, kg de granos por g de $\mathrm{N}$ absorbido) para cada tratamiento en los Exp.s I y II. En cada tratamiento, el promedio corresponde a 6 plantas por tratamiento. NS, no significativo; $+\mathrm{P}<0,1 ;{ }^{*} \mathrm{P}<0,05:{ }^{*} \mathrm{P}<0,01 ; * * * \mathrm{P}<0,001$.

\begin{tabular}{|c|c|c|c|c|c|c|}
\hline Exp. & $\mathrm{PI} \mathrm{m}^{-2}$ & Híbrido & $\begin{array}{c}\% \mathrm{~N} \text { en } \\
\text { grano }\end{array}$ & $\% \mathrm{~N}$ en hojas & $\begin{array}{c}\% \mathrm{~N} \text { en } \\
\text { cañas }\end{array}$ & EUtN \\
\hline \multirow{9}{*}{ I } & \multirow{2}{*}{6} & DK & 1,44 & 1,02 & 0,56 & 46 \\
\hline & & NK & 1,37 & 1,16 & 0,53 & 53 \\
\hline & \multirow{2}{*}{8} & DK & 1,45 & 1,03 & 0,37 & 59 \\
\hline & & NK & 1,16 & 1,09 & 0,44 & 73 \\
\hline & \multirow{2}{*}{10} & DK & 1,59 & 1,14 & 0,50 & 47 \\
\hline & & NK & 1,27 & 1,13 & 0,49 & 57 \\
\hline & \multicolumn{2}{|c|}{$P$ (Densidad) } & + & NS & NS & NS \\
\hline & \multicolumn{2}{|c|}{$P$ (Híbrido) } & $* * *$ & NS & NS & NS \\
\hline & \multicolumn{2}{|c|}{$P(\mathrm{D} \times \mathrm{H})$} & + & NS & NS & NS \\
\hline \multirow{11}{*}{ II } & \multirow{2}{*}{7} & DK & 1,35 & 1,01 & 0,33 & 53 \\
\hline & & NK & 1,06 & 1,33 & 0,38 & 62 \\
\hline & \multirow{2}{*}{8} & DK & 1,29 & 0,78 & 0,33 & 59 \\
\hline & & NK & 1,01 & 1,25 & 0,44 & 64 \\
\hline & \multirow{2}{*}{9} & DK & 1,34 & 0,94 & 0,30 & 61 \\
\hline & & NK & 1,01 & 1,15 & 0,41 & 73 \\
\hline & \multirow{2}{*}{10} & DK & 1,30 & 0,81 & 0,35 & 60 \\
\hline & & NK & 1,04 & 1,16 & 0,35 & 56 \\
\hline & \multicolumn{2}{|c|}{$P$ (Densidad) } & NS & NS & NS & NS \\
\hline & \multicolumn{2}{|c|}{$P$ (Híbrido) } & $* * *$ & $* * *$ & $* *$ & NS \\
\hline & \multicolumn{2}{|c|}{$P(\mathrm{D} \times \mathrm{H})$} & NS & NS & NS & NS \\
\hline
\end{tabular}

A diferencia de lo observado en los granos, la concentración de $\mathrm{N}$ en hojas y en cañas no varió entre híbridos en el Exp. I, y en el Exp. II fue significativamente mayor en el híbrido NK880 (Tabla 4). Como ya se mencionó, el contenido de $\mathrm{N}$ en planta (promedio de tratamientos) fue mayor en el Exp. I respecto al Exp. II. En el híbrido DK682 el índice de cosecha de $\mathrm{N}$ fue $78 \%$ en ambos Exps. (promedio entre tratamientos, datos no mostrados). En cambio, en el híbrido SG NK880, el índice de cosecha de $\mathrm{N}$ fue menor y se redujo aún más en el Exp. II (65\% en el Exp. I y $56 \%$ en el Exp. II, datos no mostrados). Esto implica que al disminuir el contenido de $\mathrm{N}$ en planta, el híbrido SG particionó proporcionalmente una mayor cantidad de $\mathrm{N}$ a cañas y hojas en detrimento de los granos. A pesar de las evidentes diferencias entre híbridos para la 
partición de $\mathrm{N}$ en la planta, no se registraron efectos significativos del híbrido para la eficiencia en la utilización del $\mathrm{N}\left(\mathrm{kg} \mathrm{ha}^{-1}\right.$ de rendimiento en grano/kg ha ${ }^{-1}$ de $\mathrm{N}$ absorbido, Tabla 4) e incluso la tendencia fue a mayor EUtN en el híbrido SG. Esto indica que en el cálculo de la EUtN los bajos contenidos de $\mathrm{N}$ en planta en el híbrido SG tuvieron mayor relevancia en el cálculo numérico que los bajos rendimientos obtenidos por este híbrido.

Se encontró una relación entre el inicio de la fase rápida de senescencia en el estrato medio e inferior, y la concentración de $\mathrm{N}$ en granos. Como se muestra en la Fig. 11, en el Exp. I, donde la absorción de $\mathrm{N}$ en post-floración fue más importante, la relación entre el $\mathrm{PQ}$ y la concentración de $\mathrm{N}$ en granos fue nula en el estrato inferior (Fig. 11C) o débil en el estrato medio (11B). En cambio, en el Exp. II, donde la absorción de $\mathrm{N}$ en post-floración representó sólo un $20 \%$ del $\mathrm{N}$ total en planta a madurez fisiológica (promedio entre tratamientos, Fig. 9B), la relación entre el PQ del estrato medio e inferior y la concentración de $\mathrm{N}$ en granos fue significativa y negativa (Fig. 11B y 11D). En la Fig. 11 resulta evidente que el híbrido NSG presentó mayor concentración de $\mathrm{N}$ en granos a lo largo de las densidades, y especialmente en el Exp. II, PQ menores. En general, en la Fig. 11 (ambos Exps. y estratos del canopeo), se puede observar también que los datos del híbrido SG se ubicaron frecuentemente por debajo de la línea de tendencia; es decir que para similares $P Q$ en el estrato inferior, el híbrido DK682 alcanzó mayores concentraciones de $\mathrm{N}$ en granos a cosecha. 


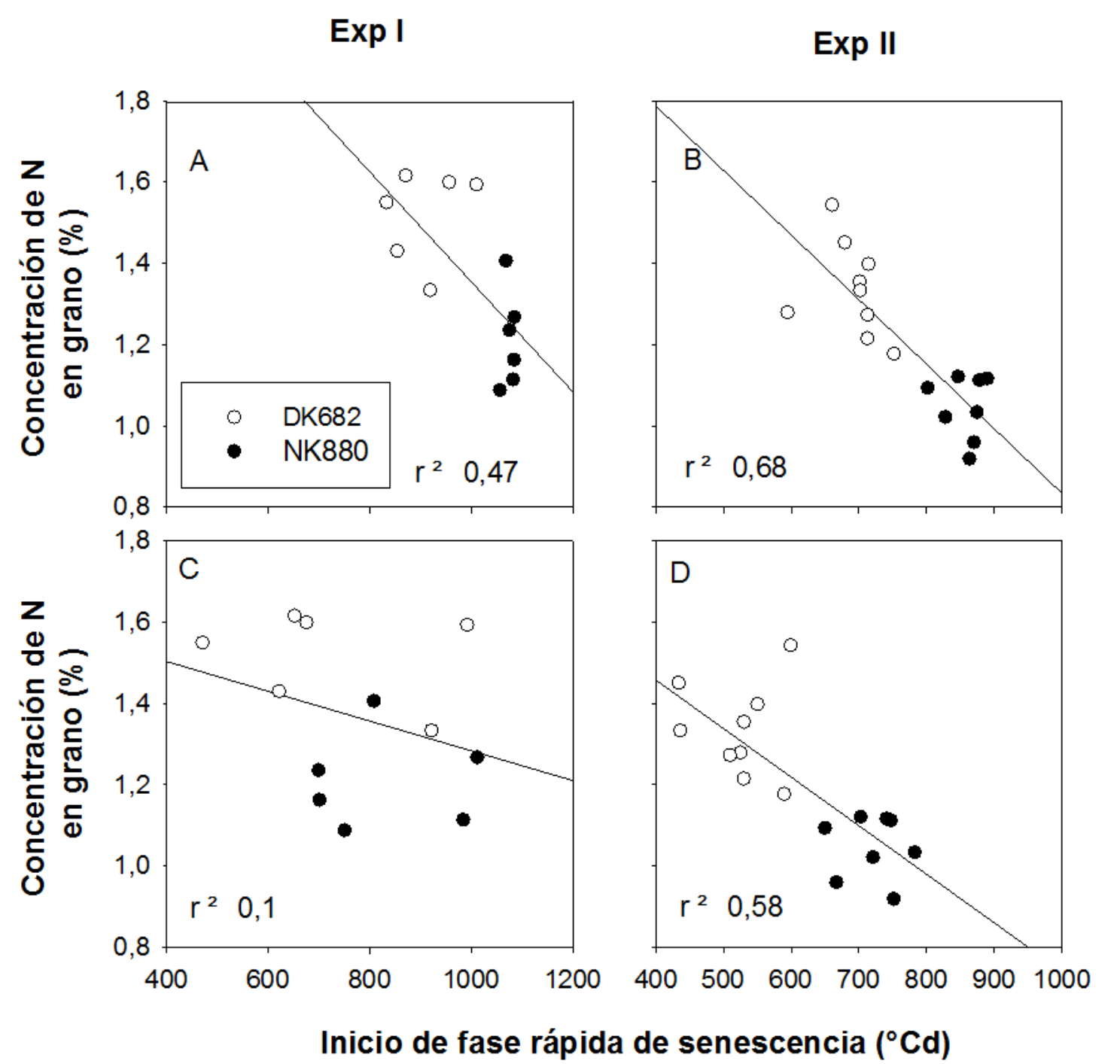

Fig. 11: Regresión entre el inicio de la fase rápida en el estrato medio (A, B) e inferior (C, D) y la concentración de $\mathrm{N}$ en granos (\%) a lo largo de las distintas densidades. Cada punto representa una repetición de cada tratamiento ( $n=18$ en Exp. I y $n=24$ en Exp. II). 


\section{Discusión}

\subsection{Evolución de la senescencia foliar}

En concordancia con Borrás et al. (2003), los resultados presentados en las Figs. 2 y 3 , muestran que el aumento en la densidad poblacional acelera la senescencia foliar. En los tres experimentos, el carácter SG del híbrido NK880 observado en el Capítulo 2 (en referencia al híbrido NSG DK682) se mantuvo en el rango de densidades. En el Exp. III, los dos híbridos incorporados (AX878 y AW190) presentaron un carácter moderadamente SG, en concordancia con lo observado en el Capítulo 3.

Borrás et al. (2003) reportaron que el inicio de la fase rápida de senescencia foliar no es afectado por el aumento en la densidad. Esto contrasta con los resultados presentados en este Capítulo, ya que el aumento de la densidad adelantó el inicio de la senescencia a nivel del canopeo (Exps. I y III, Tabla 1). Con respecto al efecto de la densidad sobre el PQ, la falta de respuesta reportada por Borrás et al. (2003) podría deberse a las mayores dosis de $\mathrm{N}$ empleadas por estos autores: $1,66 \mathrm{~g} \mathrm{de} \mathrm{N} \mathrm{pl}^{-1}$ para el tratamiento de $12 \mathrm{pl} \mathrm{m}^{-2}$ vs. $1 \mathrm{~g}$ (Exp. I) o 1,2 g (Exp. II) de $\mathrm{N} \mathrm{pl}^{-1}$ utilizados en el presente capítulo para el tratamiento de $10 \mathrm{pl} \mathrm{m}^{-2}$. Además, la variabilidad en el $\mathrm{PQ}$ encontrada entre híbridos en este capítulo es esperable considerando que los híbridos fueron seleccionados por sus diferencias para el carácter SG. En girasol, se ha reportado que la senescencia foliar puede estar promovida tanto por bajas irradiancias (Rousseaux et al., 1996) como por baja relación R/RL (Rousseaux et al., 2000). Estos aspectos se acentúan con el aumento de la densidad poblacional (Borrás et al., 2003), especialmente en los estratos inferiores del canopeo. En este sentido, los resultados presentados indican que la densidad afectó diferencialmente el inicio de la senescencia foliar dependiendo del estrato del canopeo. En todos los híbridos, al aumentar la densidad poblacional, el inicio de la senescencia se adelantó en el estrato inferior, mientras que en el estrato superior prácticamente no se observaron efectos de la densidad. Esto sugiere que el inicio de la senescencia no está necesariamente programado desde el nivel de planta entera, como se ha propuesto previamente (Borrás et al., 2003; Sadras et al., 2000), sino que distintos estratos pueden comportarse en forma relativamente independiente. 
Borrás et al. (2003) reportaron que a una densidad de $9 \mathrm{pl} \mathrm{m}^{-2}$, la variación en el espacio entre hileras $(0,35$ vs $0,7 \mathrm{~m})$ produjo diferencias significativas en la relación $\mathrm{R} / \mathrm{RL}$ pero no en la tasa de senescencia, lo que sugiere que en alta densidad poblacional, la calidad de luz no tiene efectos importantes sobre la tasa de senescencia. En este capítulo, los efectos del sombreo mutuo sobre la intensidad y de la luz no parecen explicar las diferencias genotípicas. Por ejemplo, en los dos primeros experimentos la senescencia se aceleró más en DK682 a pesar de que el estrato inferior del canopeo estuvo comparativamente más iluminado en este híbrido en etapas previas al inicio de la senescencia de dicho estrato (Fig. 4A y 4B). Es decir que las diferencias genotípicas fueron más importantes que las diferencias debidas al aumento de la densidad. La variabilidad genotípica también se hizo evidente cuando se analizó la relación entre estratos para el inicio de la senescencia. Por ejemplo, en el Exp. III, uno de los híbridos SG (AX878) combinó un comportamiento NSG en el estrato inferior y medio, con un comportamiento SG en el estrato superior. En contraste con los resultados presentados en este capítulo, Sadras et al. (2000) reportaron que frente a manipulaciones de la relación fuente/destino en maíz y girasol, no existió interacción entre el tratamiento y la posición de la hoja en el canopeo para el comienzo de la senescencia. Es decir que, según Sadras et al. (2000) la señal de senescencia, cualquiera sea su naturaleza, sería igualmente efectiva a lo largo de todo el gradiente vertical de la planta.

Tollenaar et al. (2006) afirman que la intercepción de PAR por planta se reducirá cuando el aumento poblacional intensifique el sombreo mutuo, pero la captura total de PAR por parte del canopeo aumentará o permanecerá igual. Los resultados presentados en este capítulo indican un aumento en la intercepción de PAR por el canopeo al aumentar la densidad poblacional (Fig. 4). Las diferencias encontradas entre híbridos para la transmitancia de luz a la altura de la hoja -3 y a nivel del suelo (Fig. 4B) indican que las hojas del estrato basal estuvieron comparativamente más sombreadas en el híbrido SG NK880, dejando para las hojas basales niveles de PAR cercanos al punto de compensación lumínico para maíz (Acciaresi, Tambussi y Guiamet, no publicado). En un perfil diario de asimilación de carbono, es probable que las hojas del estrato inferior hayan tenido un balance negativo, acentuado en días nublados. 


\subsection{Rendimiento y sus componentes}

En el rango de densidades exploradas en los tres experimentos, la existencia de interacción entre tratamientos (Exps. I y III, Tabla 2) sin efectos del híbrido, permite afirmar que en los genotipos estudiados existió variabilidad en la densidad óptima. En todos los experimentos, el aumento de la densidad poblacional trajo aparejada la reducción de ambos componentes del rendimiento, NG y PG, pero existió variabilidad genotípica en la intensidad de esta respuesta. En los Exps. I y II, las diferencias en rendimiento entre híbridos (a $10 \mathrm{pl} \mathrm{m}^{-2}$ en el Exp. I o en todas las densidades en el Exp. II) estuvieron asociadas a un menor PG en el híbrido SG (NK880). Esto contrasta con trabajos previos donde la demora en la senescencia foliar estuvo asociada a un aumento en el PG (Bänziger et al., 2002; Tollenaar \& Wu, 1999).

En el Exp. III, los híbridos caracterizados como NSG en el Capítulo 2 (AW190 y DK682) presentaron estabilidad del rendimiento entre 8 y $10 \mathrm{pl} \mathrm{m}^{-2}$. Por el contrario, los híbridos caracterizados como SG en el Capítulo 2 (AX878 y NK880) presentaron menor estabilidad del rendimiento y comportamiento contrastante. El rendimiento óptimo de $\mathrm{AX878}$ se alcanzó a $10 \mathrm{pl} \mathrm{m}^{-2}$ mientras que en NK880 el rendimiento óptimo se alcanzó a $8 \mathrm{pl} \mathrm{m}^{-2}$. A partir de la variación en los componentes del rendimiento entre híbridos, el PG parece ser el componente que mejor se asocia a la estabilidad del rendimiento en alta densidad.

A partir de estos resultados resulta evidente que la demora de la senescencia foliar, al menos en el estrato inferior, no resultó en mayor rendimiento a alta densidad (Fig. 5F). Estos resultados pueden ser atribuidos a (i) impactos neutros o negativos de la demora en la senescencia de las hojas basales sobre la disponibilidad de asimilados en post-floración (balance de C) o bien (ii) impactos negativos de la demora de la senescencia de foliar sobre la partición a espiga mediada por el balance de $\mathrm{N}$ (Fig. 6).

\subsection{Senescencia demorada y balance de $C$}

En concordancia con Borrás et al. (2004), el aporte de MS proveniente de la removilización no representó más del $20 \%$ del peso de granos por planta a cosecha. Esto implica que el aporte de asimilados a la espiga provino mayoritariamente de fotoasimilados producidos durante el llenado. 
Varios autores han reportado que la demora de la senescencia foliar implica un aumento de la disponibilidad de asimilados en post-floración. Esto también ha sido demostrado en forma parcial, en los Capítulos $\mathbf{2}$ y $\mathbf{3}$ de esta tesis. En este capítulo, a 8 $\mathrm{pl} \mathrm{m}^{-2}$, la demora en la senescencia foliar se relacionó con una mayor asimilación neta en todos los estratos del canopeo (Fig. 7). Sin embargo, a $10 \mathrm{pl} \mathrm{m}^{-2}$ esta relación sólo fue significativa en el estrato superior. Estos resultados no sorprenden, considerando la baja irradiancia incidente en el estrato inferior (Fig. 4). Borrás et al. (2003) reportaron que el aumento de la tasa de senescencia foliar observado al aumentar la densidad no se corresponde con una disminución de la relación fuente/destino, ya que en altas densidades también se reduce el NG.

Boonman et al. (2006) analizaron el desempeño de un genotipo transgénico de tabaco que demora la senescencia en comparación con un genotipo de referencia y encontraron que a pesar de que el transgénico tiene mejor o igual acumulación de materia seca en bajas densidades, en altas densidades es superado por el genotipo de referencia; los autores atribuyen estas diferencias a la respiración de las hojas basales. En el mismo sentido pero considerando las hojas superiores, Earl \& Tollenaar (1998) encontraron una relación negativa entre la asimilación de materia seca a cosecha y la respiración de las hojas superiores promediada durante el ciclo.

Las pérdidas de materia seca asociadas a la respiración pueden representar alrededor del $50 \%$ del carbono asimilado por un cultivo de maíz (Earl \& Tollenaar, 1998). Earl \& Tollenaar (1998) encuentran menores tasas respiratorias en hojas basales del canopeo en comparación con hojas superiores y proponen que las hojas basales podrían ajustar su tasa respiratoria de manera de mantener un balance de carbono ligeramente positivo. Este tipo de ajuste se observa en los resultados presentados para la hoja -3 (representativa del estrato inferior) de ambos híbridos al comparar la tasa respiratoria alrededor de los $245^{\circ} \mathrm{Cd}$ entre 8 y $10 \mathrm{pl} \mathrm{m}^{-2}$ (Fig. 8). En estadíos posteriores, el híbrido NK880 mantiene la tasa respiratoria de la hoja -3, aún a $10 \mathrm{pl} \mathrm{m}{ }^{-}$ 2 mientras que en el híbrido NSG la respiración de la hoja -3 se reduce significativamente a $8 \mathrm{pl} \mathrm{m}^{-2}$ y completamente a $10 \mathrm{pl} \mathrm{m}^{-2}$, como resultado de la senescencia. Boonman et al. (2006) sugieren que la senescencia inducida por sombreo es funcional para maximizar la ganancia de carbono en canopeos densos. Los datos 
presentados aquí indican que NK880 fue ineficiente para ajustar la respiración de las hojas basales a la menor irradiancia incidente en los estratos inferiores del canopeo.

\subsection{Senescencia demorada y balance de $N$}

La eficiencia en el uso del $N$ (EUN) puede definirse como el rendimiento en granos por unidad de $\mathrm{N}$ absorbido, y depende de (i) la absorción del $\mathrm{N}$ del suelo (EAbsN), dada por el tamaño y la actividad de las raíces y (ii) la capacidad de transformar el $\mathrm{N}$ absorbido en $\mathrm{N}$ en rendimiento (EUtN), relacionada al desarrollo de los granos (Ciampitti \& Vyn 2011).

Según Ciampitti \& Vyn (2012), el contenido crítico de N en planta a floración es de 2,3 $\mathrm{g} \mathrm{N} \mathrm{pl}^{-1}$ por lo que, valores inferiores afectan negativamente el rendimiento. Los resultados obtenidos en este capítulo indican que en ambos Exps. y en todos los tratamientos (exceptuando el Exp. II a $7 \mathrm{pl} \mathrm{m}^{-2}$ para el híbrido DK682, Fig. 9) el contenido de $\mathrm{N}$ en planta fue inferior al contenido crítico, y se mantuvo por debajo de $2 \mathrm{~g} \mathrm{pl}^{-1}$. Esto implica que, en ambos experimentos I y II, las diferencias observadas entre híbridos no pueden ser atribuidas sólo a la densidad sino que además es necesario considerar los efectos de la deficiencia de N. No sólo el contenido en planta, sino también la partición del $\mathrm{N}$ entre los diferentes órganos tendrán influencia sobre el rendimiento final. En general, e independientemente del valor absoluto de cada componente, las diferencias en el $\mathrm{N}$ absorbido por planta a cosecha fueron explicadas por diferencias en el $\mathrm{N}$ absorbido en post-floración, especialmente a $10 \mathrm{pl} \mathrm{m}^{-2}$ (Fig. 9).

La senescencia demorada en el híbrido SG (NK880) no estuvo acompañada de una mayor absorción de $\mathrm{N}$ en post-floración. Esto concuerda con trabajos previos, donde tampoco el carácter SG ha estado vinculado a mayor absorción de $\mathrm{N}$ en postfloración (Subedi \& Ma 2005; Martin et al. 2005). Otros trabajos sí han reportado mayor absorción de $\mathrm{N}$ en post-floración en genotipos SG. Sin embargo, a diferencia de los experimentos presentados en este capítulo, en estos trabajos se han utilizado líneas de maíz a una densidad de $5,3 \mathrm{pl} \mathrm{m}^{-2}$ (Bänziger et al., 1999) o bien, los estudios han involucrado genotipos SG de distintos años de liberación (i.e., involucrando no sólo el carácter SG sino también otros efectos del mejoramiento) (Ma \& Dwyer, 1998).

En este Capítulo, la menor absorción de $\mathrm{N}$ en post-floración encontrada en el híbrido SG (NK880) podría tener una relación directa con la menor irradiancia 
incidente en las hojas del estrato basal, en comparación con el híbrido NSG (DK682) en el que la penetración de luz en estratos basales fue significativamente mayor (Fig. 4B). Se ha reportado que las hojas de los estratos basales tendrían una importante función en la provisión de carbohidratos a las raíces (Palmer et al., 1973). Existen evidencias claras que apoyan esta idea. Osaki (1995) realizaron dos tratamientos en una línea de maíz tropical: (i) fertilización con $30 \mathrm{~g} \mathrm{de} \mathrm{N} \mathrm{m}^{-2}$; (ii) fertilización con $15 \mathrm{~g} \mathrm{~N} \mathrm{~m}^{-2}$ y raleo de plantas de una hilera en floración; de modo que la disponibilidad final de $\mathrm{N}$ en (ii) fue menor que en (i) (22,5 g vs. $30 \mathrm{~g}$ de $\mathrm{N} \mathrm{m}^{-2}$ ). Sin embargo, la cantidad de $\mathrm{N}$ absorbida a cosecha fue marcadamente mayor en el tratamiento (ii) y resultó en mayores PG (350 mg grano ${ }^{-1}$ ) que en (i) (266 mg grano ${ }^{-1}$ ). Los autores proponen que el aumento de la luz incidente en estratos basales producido por el tratamiento de raleo mejoró la absorción de N (Osaki, 1995). La competencia por luz a altas densidades reduce el índice raíz/tallo (Hébert et al., 2001), y esto afecta negativamente la capacidad de capturar recursos del suelo (Rossini et al., 2011). En este capítulo, las diferencias entre híbridos en el perfil de intercepción de luz muestran que las hojas basales del híbrido SG estuvieron expuestas a menores irradiancias que las del híbrido NSG, lo que resultaría en menor índice raíz/tallo. Boonmann et al. (2006) encontraron que la MS de raíces fue un 30\% menor en un genotipo stay green transgénico de tabaco a $6,3 \mathrm{pl} \mathrm{m}^{-2}$ comparado con un genotipo salvaje y que esta diferencia se incrementó a un $50 \%$ a 9,5 $\mathrm{pl} \mathrm{m}^{-2}$.

Ya sea que NK880 tuvo una menor actividad de raíces debido a un mayor consumo relativo de fotoasimilados por respiración de las hojas basales, o una menor relación raíz / tallo debido a mayor competencia por luz en el estrato inferior, la menor acumulación neta de $\mathrm{N}$ en postantesis sugiere diferencias entre híbridos relacionadas al sistema radical. Ciampitti \& Vyn (2011) además sugieren que en maíz, la absorción de $\mathrm{N}$ podría mantenerse aún después de la senescencia temprana del canopeo debido a una situación de estrés. Esto independizaría en cierta medida el adelanto de la senescencia foliar en DK682 en altas densidad con su capacidad de prolongar la absorción de $\mathrm{N}$ en postantesis.

En relación a la eficiencia de utilización del $\mathrm{N}$ absorbido, es interesante destacar que los resultados presentados no muestran diferencias significativas entre híbridos (Tabla 4). Esto no es sorprendente, considerando que la EAbsN y la EUtN suelen 
relacionarse en forma negativa (Gallais \& Coque, 2005) y por lo tanto, no son estadísticamente independientes.

En ambos experimentos y en todo el rango de densidades, la concentración de $\mathrm{N}$ en granos a cosecha estuvo siempre por encima del 1,3\% en el híbrido NSG (DK682) mientras que en el híbrido SG (NK880) permaneció por debajo del 1,4\% en el Exp. I, y por debajo del 1,1\% en el Exp. II. Dado que el PG final fue mayor en DK682, estas diferencias no pueden atribuirse a efectos de dilución. El $\mathrm{N}$ cumple una importante función durante las primeras etapas del llenado, determinando el peso de grano potencial. Es necesario para los procesos enzimáticos esenciales relacionados con la utilización del C, influencia la determinación del número de células en el endosperma y es un constituyente principal de las proteínas de reserva (Cazetta et al., 1999; Below et al., 2000). La relación encontrada entre la concentración de $\mathrm{N}$ en granos hacia el final del llenado y el PG final (Fig. 10) sugiere que el $\mathrm{N}$ tuvo un rol en la determinación del PG, especialmente en el híbrido NK880, por ser el que presentó menor concentración de $\mathrm{N}$ en granos en todas las densidades y experimentos.

Los resultados presentados en este capítulo indican que no existieron diferencias en la concentración de $\mathrm{N}$ en tejidos vegetativos a cosecha en el Exp. I, pero sí en el Exp. II (Tabla 4). En el Exp. II, la concentración de $\mathrm{N}$ en hojas y cañas fue mayor en el híbrido SG (lo mismo se observó para el contenido de $\mathrm{N}$, datos no presentados). Otros estudios también reportan mayor contenido de $\mathrm{N}$ en hojas y tallos de genotipos SG de sorgo (Borrell et al. 2000) y maíz (Ma \& Dwyer 1998; Rajcan \& Tollenaar 1999; Martin et al., 2005). Ma \& Dwyer (1998) señalaron que la mayor retención de Nt en hojas de genotipos SG estaba asociada a la mayor absorción de $\mathrm{N}$ en post-floración, y por lo tanto a menores requerimientos removilización de $\mathrm{N}$ desde los órganos vegetativos. Este argumento no se aplica al presente estudio, ya que a pesar de que el híbrido SG presentó menor (Exp. I) o similar (Exp. II) acumulación de $\mathrm{N}$ en postfloración, retuvo similar (Exp. I) o mayor (Exp. II) cantidad de $\mathrm{N}$ en órganos vegetativos, aún cuando los requerimientos de $\mathrm{N}$ en los granos parecieron no ser satisfechos completamente.

4.5. Posibles efectos de la fuente y los destinos sobre la removilización de $\mathrm{N}$ 
En ambientes deficientes en $\mathrm{N}$, la demanda de los destinos puede ser satisfecha con el $\mathrm{N}$ almacenado en estructuras vegetativas (Thomas et al., 2002). Existen algunas evidencias relacionadas a un control de la removilización de $\mathrm{N}$ desde la fuente. Borrás et al. (2003) encuentran que plantas donde el número de granos se redujo un $50 \%$ a través de tratamientos manipulativos, exportaron a los granos la misma cantidad de $\mathrm{N}$ que aquellas plantas donde el número de granos no fue alterado. También Christensen et al. (1981) encontraron que tanto en plantas control como en plantas cuyas espigas habían sido removidas en antesis, el contenido de $\mathrm{N}$ foliar disminuyó durante la primer mitad del llenado, indicando que en ausencia de espiga, el tallo funciona como destino alternativo para el $\mathrm{N}$ removilizado desde las hojas. En el mismo sentido, Seebauer et al. (2004) compararon el contenido de aminoácidos en el marlo de maíz a los 14 DDF combinando tratamientos de polinización impedida, y distintas dosis de N (0 vs $170 \mathrm{~kg}$ de $\mathrm{N} \mathrm{ha}^{-1}$ ). Cuando se previno la polinización, el contenido de aminoácidos en el marlo aumentó y fue un $40 \%$ mayor en las plantas fertilizadas, sugiriendo que ante ausencia de destinos la fuente mantiene el suministro de $\mathrm{N}$ a la espiga y el marlo actúa como destino alternativo.

Subedi \& Ma (2005) sugieren que cuando la capacidad de los destinos está restringida por $\mathrm{N}$ en las etapas tempranas de diferenciación de granos, las proporción de $\mathrm{N}$ particionado a las hojas puede ser mayor, porque la demanda de $\mathrm{N}$ de los destinos se reduce. La relación encontrada entre el inicio de la fase rápida de senescencia y la concentración de $\mathrm{N}$ en granos a cosecha (Fig. 11) varió entre Exps. Considerando que en el Exp. I la absorción de $\mathrm{N}$ en post-floración representó alrededor del $50 \%$ del $\mathrm{N}$ en planta a cosecha (Fig. 9), no es sorprendente que la concentración de $\mathrm{N}$ en granos no se relacione con la senescencia foliar. En cambio, en el Exp. II el tiempo térmico al inicio de la fase rápida de la senescencia foliar en el estrato inferior y medio se relacionó negativamente con la concentración de $\mathrm{N}$ en granos a cosecha. Esto implica que, en el híbrido SG, aún cuando el crecimiento de los granos pudo haber estado limitado por deficiencias de $\mathrm{N}$, y aún cuando en el Exp. Il la removilización del $\mathrm{N}$ foliar pudo haber sido la fuente más importante de $\mathrm{N}$ para los granos, la senescencia foliar no respondió a esta demanda. Es decir, que al menos en el híbrido SG, la removilización de $\mathrm{N}$ foliar parece haber ocurrido independientemente de los 
requerimientos de $\mathrm{N}$ en los granos sugiriendo un control por la fuente (y un nulo o muy leve control por los destinos).

\section{Conclusiones}

El aumento de la densidad poblacional promovió diferencialmente la senescencia del canopeo, dependiendo del estrato considerado y del híbrido. Dos de los híbridos caracterizados como contrastantes según la senescencia foliar en condiciones de sequía (Capítulo 2) mantuvieron su carácter en condiciones de alta densidad (NK880 y DK682) mientras que otros dos (AW190- NSG y AX878-SG) combinaron un carácter NSG en el estrato inferior y un carácter SG en el estrato superior.

Cuando el carácter SG se mantiene en alta densidad en todos los estratos del canopeo, como en NK880, puede tener impactos negativos sobre el balance de $\mathrm{C}$ y de $\mathrm{N}$ en la planta, afectando el rendimiento. A diferencia de lo observado en los estratos medio y superior, la demora de la senescencia en el estrato inferior no se relacionó con la asimilación neta de C en post-floración. Además, en el híbrido SG, las hojas del estrato inferior mantuvieron la tasa respiratoria aún en estadíos avanzados del Ilenado. Cuando la absorción de $\mathrm{N}$ en post-floración fue muy baja (en proporción al $\mathrm{N}$ en planta a cosecha, Exp. II), la demora de la senescencia del estrato medio e inferior se relacionó negativamente con la concentración de $\mathrm{N}$ en granos.

La concentración de $\mathrm{N}$ en granos fue menor en el híbrido SG (NK880) y se relacionó directamente con el PG. En consecuencia, el rendimiento fue menor en el híbrido SG y las diferencias entre híbridos fueron explicadas a través de un menor PG. La mayor o similar concentración de $\mathrm{N}$ en tallos y hojas observada en el híbrido SG parece haber ocurrido independientemente de los requerimientos de $\mathrm{N}$ en los destinos. Por lo tanto, al menos en este híbrido la senescencia foliar no ocurrió en respuesta a la demanda de $\mathrm{N}$ en los granos. Frente a un aumento en la densidad poblacional, el carácter SG puede ser desventajoso si reduce el aporte de $\mathrm{N}$ foliar por removilización para el crecimiento de los granos e impide que se ajuste la respiración de las hojas basales a la menor irradiancia en los estratos inferiores del canopeo. 
La incorporación de otro genotipo SG (AX878) al análisis, evidenció la existencia de plasticidad fenotípica para la expresión del carácter SG. El mayor rendimiento relativo obtenido por este genotipo SG (AX878) en condiciones de alta densidad poblacional implica que el carácter SG puede representar una ventaja en la medida en que pueda ser modulado por el ambiente (por ej. a través de las condiciones lumínicas o de los requerimientos de $\mathrm{N}$ en los destinos). Este aspecto se analizará también en condiciones de deficiencias de $\mathrm{N}$ en el Capítulo 5. 


\section{CAPÍTULO 5}

\section{ANÁLISIS DEL METABOLISMO DE COMPUESTOS NITROGENADOS \\ DURANTE LA SENESCENCIA DE MAÍZ}

\section{Introducción}

\subsection{Importancia del problema}

Como se mencionó en el Capítulo 3, la eficiencia en el uso del $\mathrm{N}$ se define como el rendimiento en grano por unidad de $\mathrm{N}$ disponible en el suelo, y es la resultante de: la eficiencia de absorción del $\mathrm{N}$ disponible en el suelo (EAbsN), y la eficiencia de utilización del N (EUtN, rendimiento alcanzado por unidad de $\mathrm{N}$ absorbido) (Hirel et al., 2007; Hirel et al., 2005). Según varios autores, la EUtN es el componente que mejor define el rendimiento en ambientes con deficiencias en N (Gallais \& Coque, 2005).

En general, los trabajos publicados en los que se reportan ventajas en rendimiento en genotipos SG respecto a genotipos NSG atribuyen estas ventajas a una mayor EAbsN (Ma \& Dwyer, 1998; Pommel et al., 2006; Rajcan \& Tollenaar, 1999b). Por otro lado, existen reportes de menor EUtN en híbridos SG (Pommel et al., 2006). Varios autores han reportado que los híbridos SG presentan mayor retención del $\mathrm{N}$ en estructuras vegetativas (Ma \& Dwyer, 1998; Pommel et al., 2006; Rajcan \& Tollenaar, 1999b). Esta característica podría implicar una penalidad en ambientes donde las deficiencias de $\mathrm{N}$ limitan la absorción de $\mathrm{N}$ en post-floración.

Durante el desarrollo vegetativo, una mayor EUtN estará relacionada con (i) mayor partición de $\mathrm{N}$ a las hojas (con respecto al tallo); (ii) mejor distribución del $\mathrm{N}$ foliar en función de la irradiancia incidente en cada estrato del canopeo; (iii) mayor tasa fotosintética por unidad de $\mathrm{N}$ en la hoja (mejor ajuste entre las proteínas involucradas en la fijación de $\mathrm{CO}_{2}$ ). A partir de floración, la EUtN se relaciona además, con la optimización del uso del $\mathrm{N}$ disponible en la planta, lo que implica la oportuna removilización del $\mathrm{N}$ desde los órganos vegetativos hacia los órganos reproductivos. En plantas expuestas a baja disponibilidad de $\mathrm{N}$, la fertilización produjo efectos significativos cuando fue aplicada alrededor de floración pero no a los 14 días después de floración (Paponov et al., 2005); i.e., los efectos del N sobre el rendimiento varían dependiendo de en qué momento del ciclo reproductivo el $\mathrm{N}$ esté disponible. 
Es posible que un uso eficiente del $\mathrm{N}$ disponible en la planta involucre la retención de $\mathrm{N}$ en las estructuras vegetativas y en consecuencia, una prolongación de la actividad fotosintética, siempre que el contenido de $\mathrm{N}$ en los granos sea suficiente para no afectar su crecimiento potencial. Sin embargo, en ambientes con severas deficiencias de $\mathrm{N}$, una mejor utilización del $\mathrm{N}$ disponible en la planta podría estar relacionada con una alta sensibilidad de la fuente (hojas y tallo) a la demanda de $\mathrm{N}$ en los destinos, lo que implicaría un adelanto de la senescencia para satisfacer las necesidades tempranas de $\mathrm{N}$ asociadas a la determinación del tamaño potencial de los granos. En genotipos SG, la senescencia de la mayoría de las hojas ocurre después de la determinación del PG potencial (i.e., después de los 15 DDF) por lo cual, la removilización del $\mathrm{N}$ foliar tendría un bajo impacto en la determinación del rendimiento. Por otro lado, aún en condiciones de buena disponibilidad de $\mathrm{N}$, la removilización de $\mathrm{N}$ desde las estructuras vegetativas hacia los granos tendrá influencia sobre la calidad nutricional de los granos (Borrás et al., 2002).

\subsection{Metabolismo de compuestos nitrogenados durante la senescencia.}

Antes del comienzo de la senescencia, la mayor parte del $\mathrm{N}$ de la planta de maíz se localiza en los tejidos foliares. En especies $\mathrm{C}_{4}$, alrededor del $25 \%$ del $\mathrm{N}$ foliar se encuentra en las proteínas liposolubles de la membrana cloroplástica y alrededor del $50 \%$ forma parte de las proteínas solubles (Sage et al., 1987). La enzima RuBisCO (ribulosa-1,5- bisfosfato carboxilasa/oxigenasa) representa entre el 5 y el $20 \%$ de las proteínas solubles, variando esta proporción en función del contenido de $\mathrm{N}$ foliar (Sage et al., 1987). Otra enzima importante es PEPcasa (fosfoenol-piruvato carboxilasa) que representa alrededor del $8 \%$ de las proteínas solubles (Sugiyama et al., 1984). Por lo tanto, al menos un $50 \%$ del $\mathrm{N}$ foliar se encuentra formando parte de proteínas involucradas en la fotosíntesis.

Durante la senescencia se incrementa la actividad proteolítica. La reducción del contenido de proteínas asociada a la actividad proteolítica produce un aumento del contenido de aminoácidos libres que se transforman en asparagina, glutamina y glutamato, para ser transportados hacia los órganos destinos (Hörtensteiner \& Feller, 2002). En este Capítulo se analizará el contenido de proteínas en estadíos avanzados de la senescencia foliar, considerando que un alto contenido de proteínas remanente 
es indicador de baja eficiencia de removilización del $\mathrm{N}$ foliar. También se analizará la degradación neta de proteínas en distintas hojas para estimar su importancia relativa en el suministro de $\mathrm{N}$ hacia los granos.

A partir de floración, los granos son el principal destino de N (Hirel et al., 2007). En suelos con alta disponibilidad de $\mathrm{N}$, el $\mathrm{N}$ absorbido en post-floración es transitoriamente particionado a las hojas, para ser asimilado y luego movilizado a los granos (Masclaux-Daubresse et al., 2010). En cambio, en suelos con baja disponibilidad de $\mathrm{N}$, la mayor parte del $\mathrm{N}$ edáfico habrá sido absorbida durante el período vegetativo por lo cual la principal fuente de $\mathrm{N}$ para los granos proviene de la degradación de proteínas. Cualquiera sea la disponibilidad de $\mathrm{N}$ edáfico, el contenido de aminoácidos libres en las hojas será un indicador del $\mathrm{N}$ potencialmente disponible para los granos en forma inmediata. En este Capítulo se analizará el contenido de aminoácidos libres en las hojas y su posible relación con los componentes del rendimiento.

Una consecuencia potencialmente desventajosa de la masiva degradación de proteínas durante la senescencia es la acumulación de amonio en los tejidos, que en especies $\mathrm{C}_{4}$ se produce por (i) la desaminación de aminoácidos, y (ii) el catabolismo de ácidos nucleicos. El amonio intracelular es tóxico ya que actúa como desacoplante en las membranas fotosintéticas y mitocondriales. La enzima glutamina sintetasa (GS) actúa en la reasimilación de amonio, catalizando la siguiente reacción: Glutamato + $\mathrm{NH}_{4}{ }^{+}+\mathrm{ATP} \rightarrow$ Glutamina $+\mathrm{ADP}+\mathrm{Pi}+\mathrm{H}^{+}$. Se han descrito dos isoformas de GS: GS1 (citosólica) y GS2 (cloroplástica), que en plantas $C_{4}$, se presentan en cantidades comparables. En maíz, durante el llenado de granos varias isoformas de GS1 participan en la reasimilación de amonio como glutamina, y su conversión en ácido glutámico y asparagina para ser exportados hacia los granos (Hirel et al., 2005). Se han encontrado tres QTLs para GS1 en maíz, que coincidieron con QTLs para rendimiento mientras que un QTL para GS2 coincidió con QTLs para senescencia foliar e intervalo antesis masculina-floración (Gallais \& Coque, 2005).

Hasta el presente los trabajos publicados en los que se demuestra la acumulación de amonio en las hojas se refieren solamente a plantas $C_{3}$ (Masclaux et al., 2000). Los pocos trabajos que analizan el contenido de amonio en maíz se restringen a un estadío específico (a los 15 DDF, Hirel et al., 2005). En maíz, el comienzo de la senescencia foliar varía en los distintos estratos del canopeo y las hojas 
de los estratos central y superior permanecen íntegramente verdes aún a los 26 DDF (Valentinuz \& Tollenaar, 2004). Below et al. (1981) encontraron que el $67 \%$ del contenido final de $\mathrm{N}$ en la espiga fue incorporado durante los primeros $28 \mathrm{DDF}$. Esto implica que la senescencia de las hojas en los estratos central y superior podría no estar asociada a una removilización eficiente del $\mathrm{N}$, y esto podría causar la acumulación de amonio en esos tejidos. En este Capítulo, se analizará la acumulación de amonio en hojas correspondientes a distintos estratos del canopeo durante distintos estadíos del llenado de granos.

\subsection{Fundamentos y planteo de la hipótesis}

Como se muestra en el Capítulo 3 (Figs. 1 y 2) demoras relativas en la senescencia foliar pueden resultar de (i) una mayor disponibilidad de $\mathrm{N}$ edáfico; (ii) diferencias genotípicas y (iii) dentro de una misma planta, por los distintos momentos de inicio de la senescencia en las hojas de diferentes estratos. La hipótesis que pretende ser contrastada en este Capítulo es:

(4) La demora en la senescencia está relacionada con una menor eficiencia de removilización del $\mathrm{N}$ foliar.

(4.1.) El aumento de la fertilización con $\mathrm{N}$, al demorar la senescencia foliar, reduce la eficiencia de removilización del $\mathrm{N}$ foliar.

(4.2.) Dentro del canopeo, la eficiencia de removilización del $\mathrm{N}$ foliar es menor en las hojas del estrato superior (cuya senescencia es más tardía).

(4.3.) Los genotipos SG presentan menor eficiencia de removilización del $\mathrm{N}$ foliar.

El objetivo general de este capítulo fue estudiar el ritmo de degradación de proteínas y la acumulación de aminoácidos y de amonio durante la senescencia foliar. Para contrastar las hipótesis planteadas se compararon: (1) plantas cultivadas en dosis contrastantes de N, (2) hojas correspondientes a distintos estratos del canopeo, y (3) genotipos con distinta duración del AFV. 


\section{Materiales y Métodos}

\subsection{Diseño experimental}

El material vegetal se obtuvo del Experimento I, descripto en el Capítulo 3, considerando sólo los tratamientos N0 y N200 (el tratamiento N100 no fue incluido en este Capítulo). Brevemente, los tratamientos consistieron en (i) dos dosis de N, y (ii) cuatro híbridos. Las dosis de $\mathrm{N}$ correspondieron a fertilización con $18 \mathrm{~kg}$ de $\mathrm{N} \mathrm{ha}^{-1}$ en forma de fosfato diamónico (FDA, tratamiento N0), y fertilización con 218 de $\mathrm{N}^{-1}$ en forma de urea (200 kg de $\mathrm{N} \mathrm{ha}^{-1}$ ) y FDA (18 $\mathrm{kg}$ de $\mathrm{N} \mathrm{ha}^{-1}$ ) (tratamiento N200). Los híbridos correspondieron a un híbrido estándar NSG (DK682) de senescencia temprana, un híbrido con moderada demora en la senescencia (AW190) y dos híbridos con carácter SG (AX878 y NK880). Más detalles del ensayo se presentan en la sección Materiales y Métodos del Capítulo 3.

En cada combinación de tratamientos (dosis de $\mathrm{N} x$ híbrido), se muestrearon tres hojas de la planta: hoja -3 (tercera por debajo de la espiga), hoja 0 (adyacente a la espiga) y hoja +3 (tercera por encima de la espiga).

\subsection{Procedimiento de muestreo}

A partir de floración, se realizaron tres muestreos representando distintos estadíos durante la senescencia foliar: madurez (alrededor de floración, M), SI y SII (dos estadios de senescencia, I y II). El estadío M se muestreó en simultáneo para todas las combinaciones de dosis de $\mathrm{N} x$ híbrido $\mathrm{x}$ posición de la hoja. Dado que el ritmo de senescencia fue significativamente afectado por la dosis de $\mathrm{N}$ y la posición de la hoja, en los estadíos posteriores (SI y SII) el momento de muestreo varío para cada combinación de dosis de $\mathrm{N}$ x posición de hoja, pero no para el híbrido (Tabla 1). Por lo tanto en cada combinación de dosis de $\mathrm{N}$ x posición de hoja, los cuatro híbridos fueron muestreados simultáneamente.

El criterio utilizado para definir los momentos de muestreo SI y SII en cada combinación dosis de $\mathrm{N}$ x posición de hoja, se basó en el valor de SPAD del híbrido de senescencia más rápida: DK682 (Fig. 1). El estadío SI fue muestreado en todos los híbridos cuando el valor de SPAD de DK682 disminuyó 10 unidades respecto del valor 
de SPAD alcanzado en M mientras que el estadío SII fue muestreado cuando el valor de SPAD de DK682 disminuyó en 20 unidades respecto del valor en M (se consideró el valor de SPAD en M para cada dosis de $\mathrm{N}$ y posición de hoja por separado).

En cada fecha de muestreo se realizaron 3 repeticiones (correspondientes a tres bloques del ensayo, ver Capítulo 3) por tratamiento ( $\mathrm{N}$ x Híbrido). Cada repetición consistió en una muestra compuesta de hojas de 2 plantas. Con un sacabocados se tomaron discos de hojas ( $1 \mathrm{~cm}$ de diámetro) en el tercio medio (en sentido longitudinal) de la hoja, en la región central entre la nervadura media y el borde. Alrededor de la zona donde se obtuvieron los discos de hoja se midió el contenido de clorofila (promedio de 5 medidas) con un medidor SPAD (Minolta SPAD 502). LoS discos fueron congelados en nitrógeno líquido y almacenados en freezer a -20 C.

\subsection{Determinación del contenido de proteínas}

Para la determinación de proteínas, los extractos se prepararon según el método descripto en Kingston-Smith \& Foyer (2000) con algunas modificaciones. Se prepararon los extractos a partir de 3 discos de hojas en $200 \mu \mathrm{L}$ de buffer de extracción (Tris $\mathrm{HCl}$ pH 7,8 con el agregado de 0,1\% v/v de Tritón-X100; $\mathrm{MgCl}_{2} 5$ mM; cisteína 5 mM; PMSF 1 mM y leupeptina $10 \mu \mathrm{M})$. El homogenato se agitó en un vortex durante 1 minuto y luego se sonicó durante 280 segundos. Se colocó en un baño térmico a $60^{\circ} \mathrm{C}$ durante 10 minutos y posteriormente se centrifugó a 9000 x g por 5 min.

Electroforesis: Se prepararon geles desnaturalizantes de poliacrilamida de acuerdo al método de Laemmli (1970). Se utilizaron geles de $10 \%$ de acrilamida y de 1,5 $\mathrm{mm}$ de espesor. En cada gel se sembraron cantidades iguales de las diferentes muestras a analizar ( $35 \mu \mathrm{L}$ de extracto, equivalentes a $0,4 \mathrm{~cm}^{2}$ de área foliar) y además se sembraron tres calles con distintas cantidades conocidas de una proteína de referencia (seroalbúmina bovina, BSA) para utilizar como estándar en la cuantificación de las muestras. En cada gel se disponía de 15 calles para sembrar muestras. Se utilizó un gel completo por cada híbrido, cada bloque y cada dosis, en el que se sembraron las tres hojas (hojas $-3,0$ y +3 ) y los distintos estadíos (M, SI y SII). Una vez sembrados los geles se aplicó un campo eléctrico de $12 \mathrm{~mA}$ por cada gel y se realizó la electroforesis durante aproximadamente 2,5 hs. Luego los geles fueron colocados en la solución fijadora-colorante (Coomassie-Blue) durante al menos 12 hs y finalmente se 
decoloraron hasta obtener las bandas azules correspondientes a las proteínas separadas en el gel.

Cuantificación de los geles: Los geles fueron escaneados para obtener imágenes digitales y proceder a la cuantificación de las proteínas. Para determinar el contenido de proteínas en las muestras se utilizó el programa SIGMA-Gel para cuantificar las bandas utilizando una curva de calibración obtenida a partir de los datos correspondientes a la proteína de referencia (BSA) en cada gel. Los resultados se presentan como mg de proteínas por área de tejido $\left(\mathrm{cm}^{2}\right)$.

\subsection{Determinación del contenido de aminoácidos}

Las mediciones de aminoácidos se realizaron según Moore (1968). Se utilizó un método espectrofotométrico basado en la determinación de la absorbancia a $570 \mathrm{~nm}$, correspondiente al producto de la reacción de los aminoácidos con ninhidrina. Cuando se calientan en presencia de ninhidrina, los aminoácidos que contienen un grupo $\alpha$ amino libre dan lugar a un producto de color púrpura que absorbe a $570 \mathrm{~nm}$. Para la cuantificación de aminoácidos por espectrofotometría se realizó una curva de calibración utilizando glutamina como patrón.

Se colocaron 3 discos de hojas de $1 \mathrm{~cm}$ de diámetro en un mortero, se agregó una pizca de arena de cuarzo y $500 \mu \mathrm{l}$ de etanol $80 \% \mathrm{v} / \mathrm{v}$, se homogeneizó y se centrifugó durante 10 minutos a 9000 x g a 4 으. El sobrenadante obtenido fue guardado. El pellet restante se resuspendió con $500 \mu \mathrm{l}$ de etanol $60 \% \mathrm{v} / \mathrm{v}$, se homogeneizó en el vortex y se centrifugó durante 10 minutos a 9000 x g y 4 ㅇ. Este segundo sobrenadante se combinó con el extracto anterior. El pellet restante se resuspendió con $500 \mu \mathrm{l}$ de agua bidestilada, se homogeneizó en el vortex y se centrifugó durante 10 minutos a 9000 x g y 4 o․ Finalmente, el sobrenadante se combinó con los 2 sobrenadantes anteriores. Es decir, que la muestra para medir aminoácidos fue el sobrenadante resultado de las tres extracciones sucesivas (etanol $80 \%$, etanol $60 \%$ y agua).

La reacción entre los aminoácidos y la ninhidrina se llevó a cabo en un medio AcO/CN [CNK 0,01M y buffer ácido acético - acetato de sodio pH 5,3-5,4 (Rosen, 1957)], a 100 oC durante 15 minutos. Para finalizar la reacción se agregó alcohol 
isopropílico al 50 \% (v/v) (Lamothe \& McCormick, 1972). Se midió la absorbancia a 570 $\mathrm{nm}$.

\subsection{Determinación del contenido de amonio}

Las medidas de amonio se realizaron según el método de Lin \& Kao (1996). Se utilizó un método espectrofotométrico basado en la medición de la absorbancia a 635 $\mathrm{nm}$ del complejo coloreado (azul de Indofenol) que se forma cuando reaccionan el amonio, el hipoclorito de sodio, y el fenol en presencia de nitroprusiato de sodio. Para la cuantificación de amonio por espectrofotometría se realizó una curva de calibración utilizando como patrón $\left(\mathrm{NH}_{4}\right)_{2} \mathrm{SO}_{4}$.

Se prepararon extractos a partir de 5 discos de hojas $(1 \mathrm{~cm}$ de diámetro) con $800 \mu \mathrm{L}$ de ácido $\mathrm{H}_{2} \mathrm{SO}_{4}$ 0,3 mM (pH 3,5). Los extractos fueron centrifugados a $9000 \times \mathrm{g}$ durante $10 \mathrm{~min}$ en una centrífuga a 4 ㅇ․ El sobrenadante se utilizó para la determinación de amonio. A una alícuota $(200 \mu \mathrm{l})$ de sobrenadante se le agregó $500 \mu \mathrm{l}$ de reactivo $A$ (fenol $1 \% \mathrm{p} / \mathrm{v}$, nitroprusiato de sodio, $0.005 \% \mathrm{p} / \mathrm{v}$ ), $500 \mu \mathrm{l}$ de reactivo $\mathrm{B}$ (hidóxido de sodio 0,5\% p/v, hipoclorito de sodio 0,84 \% v/v), y $100 \mu$ l de hipoclorito de sodio. Se dejó reaccionar y se midió la absorbancia en el espectrofotómetro a 635 $\mathrm{nm}$ luego de 30 minutos. Los resultados obtenidos fueron expresados como $\mu \mathrm{g} \mathrm{cm}^{-2}$. Las medidas se realizaron por triplicado para cada muestra.

\subsection{Análisis Estadístico}

Los datos se analizaron para cada estadío (M, SI y SII) y posición de hoja (hoja +3 , hoja 0 y hoja -3 ) por separado. Para conocer el efecto de los tratamientos ( $\mathrm{N} \mathrm{x}$ Híbrido) se realizó un ANOVA de factores fijos, donde los factores correspondieron a la dosis de $\mathrm{N}$ y al híbrido, y la variable dependiente a cada una de las variables (contenido de proteínas, aminoácidos y amonio). Los demás aspectos referidos a los análisis estadísticos se detallan en la sección Materiales y Métodos del Capítulo 2. 


\section{Resultados}

En la Tabla 1 se presentan los días después de floración en los que se realizaron los muestreos para cada estadío de cada hoja y dosis de N. En la Fig. 1 pueden observarse los valores de SPAD medidos en cada estadío de muestreo para cada hoja, dosis de $\mathrm{N}$ y genotipo.

Tabla 1: Estadío fenológico (DDF) correspondiente a los muestreos de cada hoja en cada dosis de $\mathrm{N}$ y resultados de ANOVA para el contenido de proteínas, aminoácidos y amonio por unidad de área foliar.

\begin{tabular}{|c|c|c|c|c|c|c|c|c|c|}
\hline & \multicolumn{3}{|c|}{ Hoja (-3) } & \multicolumn{3}{|c|}{ Hoja 0} & \multicolumn{3}{|c|}{ Hoja (+3) } \\
\hline & $M$ & SI & SII & $M$ & $\mathrm{SI}$ & SII & M & $\mathrm{SI}$ & SII \\
\hline & \multicolumn{9}{|c|}{ Estadío de muestreo (DDF) } \\
\hline NO & -4 & 15 & 22 & -4 & 22 & 31 & -4 & 22 & 31 \\
\hline \multirow[t]{2}{*}{ N200 } & -4 & 22 & 36 & -4 & 36 & 50 & -4 & 44 & 50 \\
\hline & \multicolumn{9}{|c|}{ Contenido de proteínas por $\mathrm{cm}^{2}$} \\
\hline$P(N)$ & 0,000 & 0,000 & 0,000 & 0,000 & 0,005 & 0,002 & 0,000 & 0,000 & 0,000 \\
\hline P (Híbrido) & 0,044 & 0,023 & 0,002 & 0,019 & 0,191 & 0,060 & 0,029 & 0,001 & 0,027 \\
\hline \multirow[t]{2}{*}{$\mathrm{P}(\mathrm{N} \times \mathrm{H})$} & 0,132 & 0,152 & 0,012 & 0,027 & 0,301 & 0,241 & 0,063 & 0,003 & 0,057 \\
\hline & \multicolumn{9}{|c|}{ Contenido de aminoácidos por $\mathrm{cm}^{2}$} \\
\hline$P(N)$ & 0,000 & 0,000 & 0,078 & 0,001 & 0,000 & 0,000 & 0,005 & 0,007 & 0,001 \\
\hline P (Híbrido) & 0,356 & 0,015 & 0,150 & 0,588 & 0,387 & 0,115 & 0,111 & 0,006 & 0,104 \\
\hline \multirow[t]{2}{*}{$\mathrm{P}(\mathrm{N} \times \mathrm{H})$} & 0,030 & 0,091 & 0,707 & 0,099 & 0,011 & 0,358 & 0,760 & 0,100 & 0,612 \\
\hline & \multicolumn{9}{|c|}{ Contenido de amonio por $\mathrm{cm}^{2}$} \\
\hline$P(N)$ & 0,000 & 0,003 & 0,000 & 0,000 & 0,000 & 0,000 & 0,000 & 0,000 & 0,000 \\
\hline P (Híbrido) & 0,001 & 0,020 & 0,003 & 0,000 & 0,095 & 0,544 & 0,159 & 0,000 & 0,003 \\
\hline$P(N \times H)$ & 0,044 & 0,041 & 0,009 & 0,002 & 0,019 & 0,239 & 0,270 & 0,005 & 0,038 \\
\hline
\end{tabular}




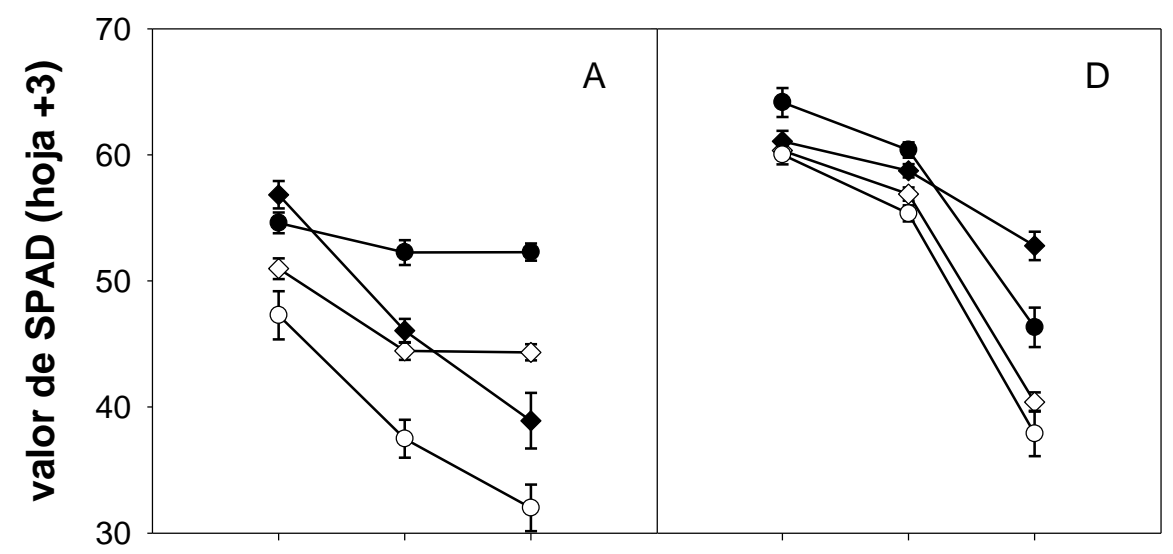

$$
\begin{aligned}
& \multimap \text { AW190 } \\
& \multimap \text { AX878 } \\
& \multimap \text { DK682 } \\
& \longrightarrow \text { NK880 }
\end{aligned}
$$
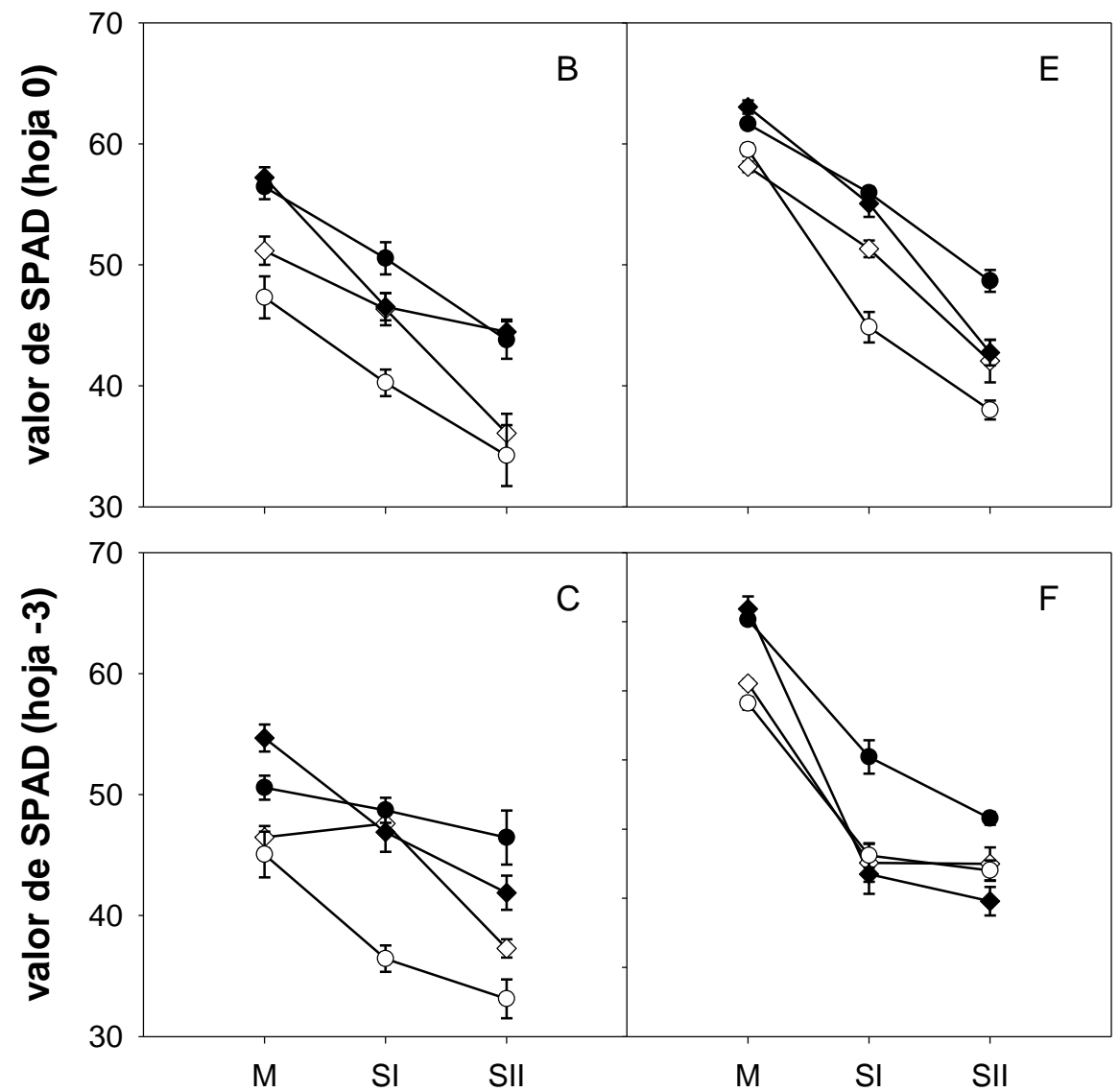

Fig. 1: Valores de SPAD de los cuatro híbridos en los tres estadíos de muestreo ( $M, S I$ y SII) para la dosis NO $(A, B, C)$ y la dosis N200 (D, E, F) de la hoja +3 (A, D), la hoja $0(B, E)$ y la hoja -3 (C, F). 
3.1. Variación entre híbridos para el contenido de proteínas en estadíos iniciales e intermedios del llenado

La dosis de $\mathrm{N}$ tuvo efectos significativos sobre el contenido de proteínas alcanzado en el estadio M (floración) en todas las hojas (Tabla 1); en cada hoja (promedio entre híbridos) el contenido de proteínas se redujo alrededor de un $50 \%$ en el tratamiento NO respecto del contenido alcanzado en N200. En NO, el contenido de proteínas alrededor de floración, (promediando entre híbridos) fue mínimo en la hoja 3, y similar entre las hojas 0 y $+3\left(363,431\right.$ y 415 microgramos de proteínas $\mathrm{cm}^{-2}$, respectivamente). En N200, el contenido a floración fue mínimo en la hoja -3, intermedio en la hoja 0 y máximo en la hoja +3 (534, 568 y 716 microgramos de proteína por $\mathrm{cm}^{-2}$ respectivamente).

En el estadío M, el ANOVA detectó efectos del híbrido en las tres hojas, e interacción entre tratamientos en la hoja 0 (Tabla 1). En el tratamiento N0, los híbridos SG (AX878 y NK880) presentaron los mayores contenidos de proteínas alrededor de floración (Fig. 2). El híbrido AW190 (que presentó moderada demora en la senescencia en términos de AFV, ver Capítulo 3) presentó mayor contenido de proteínas que el híbrido estándar (DK682) pero menor que los híbridos SG, especialmente en las hojas 0 y +3 (Fig. 2B, 2C). Entre los SG, el híbrido NK880 siempre tuvo mayores contenidos de proteína foliar que AX878. En N200, los híbridos alcanzan similares contenidos de proteínas en todas las hojas a excepción de AX878, cuya respuesta a la fertilización fue notablemente mayor.

De la Fig. 2 se destaca que el contenido de proteínas en NK880 fue mucho más estable entre dosis de $\mathrm{N}$ que el del resto de los híbridos. Promediando las tres hojas, el contenido de proteínas en NK880 aumentó un 20\% en el tratamiento N200, mientras que para el resto de los híbridos los incrementos fueron mayores (72, 56 y $61 \%$ para AW190, AX878, y DK682 respectivamente). No obstante, en esta comparación es necesario considerar el alto contenido de proteínas alcanzado por AX878 en N200. 

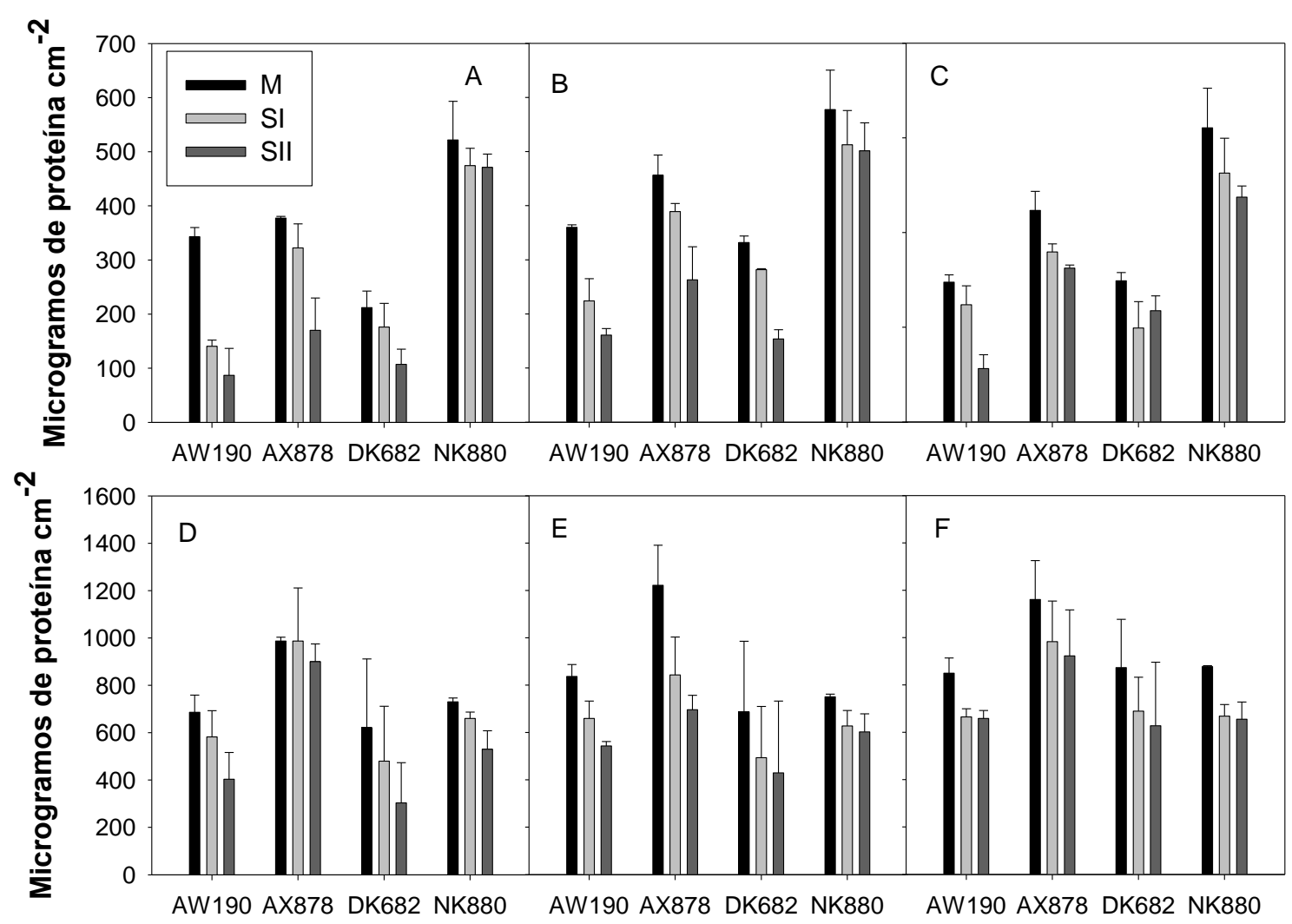

Fig. 2: Contenido de proteínas (microgramos por $\mathrm{cm}^{-2}$ ) en el tratamiento $N O(A, B, C)$ y N200 (D, E, F) y en la hoja -3 (A, D), hoja $0(B, F)$, y hoja $+3(C, F)$ a lo largo de tres estadios desde floración (M, SI, SII) en los cuatro híbridos. Las barras indican el error estándar. Notar la diferente escala del eje $\mathrm{Y}$ entre dosis de $\mathrm{N}$. 
En el tratamiento N0, el contenido de proteínas de la hoja 0 (a los 31 DDF, estadío SII) se relacionó positivamente con la tasa de transporte fotosintético de electrones (ETR, medida en la hoja 0 a los 30 DDF, Capítulo 3) $\left(r^{2}=0,49, P<0,05, n=12\right.$, Fig. 3A). Los híbridos SG (AX878 y NK880) presentaron mayor contenido de proteínas y por lo tanto, mayores valores de ETR que los híbridos NSG. En N200 no existió una relación aparente entre el contenido de proteínas (medido a los 36 DDF, estadío SI) y ETR (Fig. 3B). Tampoco se evidenció una tendencia relacionada al carácter SG.
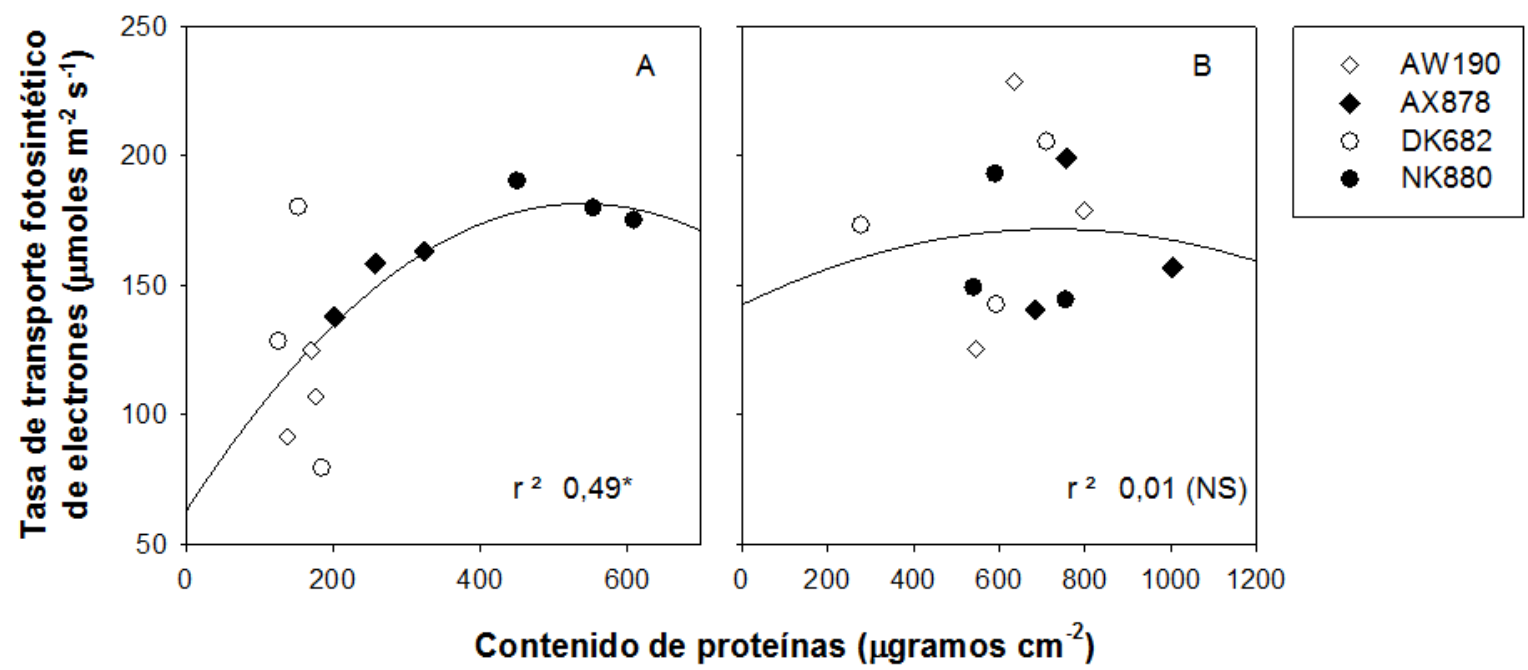

Fig. 3: Análisis de regresión entre el contenido de proteínas en la hoja 0 y la tasa de transporte fotosintético de electrones medida a los 30 DDF en la misma hoja. En el panel A, resultados en NO (proteínas en SII, a los 31 DDF). En el panel B, resultados en N200 (proteínas en SI, a los 36 DDF). Cada punto representa una repetición. 


\subsection{Variación en la degradación de proteínas entre dosis de $\mathrm{N}$ y hojas}

La dosis de $\mathrm{N}$ afectó significativamente el contenido de proteínas remanente en el estadío SII de las tres hojas analizadas (Tabla 1). Promediando hojas e híbridos, el contenido de proteínas foliares remanente en SII fue 255 microgramos $\mathrm{cm}^{-2}$ vs 606 microgramos $\mathrm{cm}^{-2}$ en el tratamiento NO vs N200 respectivamente. Desde otra perspectiva, si el contenido de proteínas remanente se analiza en referencia al contenido alcanzado en $\mathrm{M}$, el efecto de la dosis de $\mathrm{N}$ no fue tan importante (63 vs $70 \%$ en NO y N200 respectivamente).

Analizando cada hoja por separado (promedio entre híbridos), el menor contenido de proteínas en SIl se registró en la hoja -3, y el mayor en la hoja +3. En N0, el contenido de proteínas en SII varió entre 209, 270 y 287 microgramos de proteínas por $\mathrm{cm}^{-2}$ en las hojas $-3,0$ y +3 respectivamente (Figs. 2A, 2B y 2C). En N200, las diferencias entre hojas se mantuvieron, siendo los contenidos de proteínas en SII de 534,568 y 716 microgramos $\mathrm{cm}^{-2}$ en las hojas $-3,0$ y +3 respectivamente (Figs. 2D, 2E y 2 F). Por otra parte, la degradación neta de proteínas entre M y SII, está relacionada a la importancia relativa que puede tener una hoja en la removilización de $\mathrm{N}$ a los granos. En el tratamiento NO la cantidad de proteínas degradadas fue similar para las hojas -3 y 0 (entre 155 y 162 microgramos de proteína por $\mathrm{cm}^{-2}$ de hoja) mientras que en la hoja +3 este valor se redujo (128 microgramos de proteína por $\mathrm{cm}^{-2}$ ). En cambio, en el tratamiento N200, la degradación neta de proteínas en las hojas -3 y +3 fue similar (222-224 microgramos de proteína por $\mathrm{cm}^{-2}$ ) mientras que en la hoja 0 este valor fue comparativamente mayor (306 microgramos de proteína por $\mathrm{cm}^{-2}$ ).

Tomando como referencia el contenido de proteínas alcanzado en el estadío M de cada hoja, en el tratamiento N0, la hoja -3 fue la que presentó mayor eficiencia en la degradación de proteínas y la hoja +3 , la menor. En N0, la degradación de proteínas entre M y SII representó un 43\% del total alcanzado en M para la hoja -3, reduciéndose esta proporción a 37\% en la hoja 0 y 30\% en la hoja +3. En N200 la mayor eficiencia de degradación de proteínas se observó en la hoja 0 (35\%) mientras que en las hojas -3 y +3 esta proporción fue menor ( $29 \%$ y $23 \%$ respectivamente). 


\subsection{Variación en la degradación de proteínas entre genotipos}

Para los estadíos SI y SII, el contenido de proteínas varió significativamente entre híbridos en las hojas -3 y +3 , pero no en la hoja 0 (Tabla 1). El contenido de proteínas remanente en el estadío SII fue siempre mayor en los híbridos SG (AX878 y NK880, Fig. 2). En el tratamiento N0, NK880 retuvo $80 \%$ (hoja -3 ), 69\% (hoja 0) y 63\% (hoja +3) más proteínas que el promedio de los dos híbridos NSG (AW190 y DK682). La cantidad de proteínas retenidas en AX878 fue considerablemente menor que en NK880, pero mayor que en los híbridos NSG. Por el contrario, en el tratamiento N200, AX878 retuvo siempre un mayor contenido de proteínas que cualquiera de los demás híbridos, como consecuencia de sus altos contenidos iniciales (estadío M).

Analizando la eficiencia de degradación de proteínas se encuentra que, en NO y promediando las tres hojas, los híbridos degradaron (entre M y SII) el 64\% (AW190), $41 \%$ (DK682), 41\% (AX878) y 15\% (NK880) del contenido de proteínas que alcanzaron en M. En el tratamiento N200, la proporción de proteínas degradadas entre M y SII se redujo respecto a NO (excepto en NK880 donde aumentó) y representó el 32-38\% del contenido de proteínas alcanzado en M para los híbridos NSG (AW190 y DK682), o el $24 \%$ del contenido alcanzado en M para los SG (AX878 y NK880). Estas diferencias implican que la proporción de proteína degradada respecto al máximo alcanzado alrededor de floración en cada tratamiento, puede variar dependiendo de la dosis de $\mathrm{N}$. Es decir, que al reducirse la dosis de $\mathrm{N}$ aumenta la proporción de proteína degradada compensando en parte, el menor contenido de proteína alcanzado en M.

\subsection{La degradación de proteínas se relacionó con el PG final}

En las distintas hojas y para cada dosis de $\mathrm{N}$, se analizó la relación entre la degradación de proteínas foliares por grano fijado y el PG final. En el tratamiento NO, se encontró una relación significativa en la hoja -3 (Fig. 4A) considerando la degradación de proteínas entre $M$ y SI (i.e., entre $R_{1}-4$ días y $R_{1}+15$ días, Tabla 1 ). Una relación similar se halló en la hoja 0 (Fig. 4B) considerando el período entre M y SII (i.e., entre $R_{1}-4$ días y $R_{1}+30$ días, Tabla 1 ). En general, los híbridos $S G$ se ubicaron por debajo de la línea de tendencia, i.e., para similar cantidad de proteínas foliares degradadas, el PG final fue menor. En el tratamiento N200, sólo se encontró una relación significativa en la hoja 0 , con tendencia negativa (Fig. 4E); en este caso los 
híbridos SG se ubicaron por encima de la línea de tendencia. Esto muestra que en condiciones de baja disponibilidad de $\mathrm{N}$, la degradación de proteínas se relaciona de forma positiva con el PG final, mientras que cuando la disponibilidad de $\mathrm{N}$ aumenta, esta relación puede invertirse.

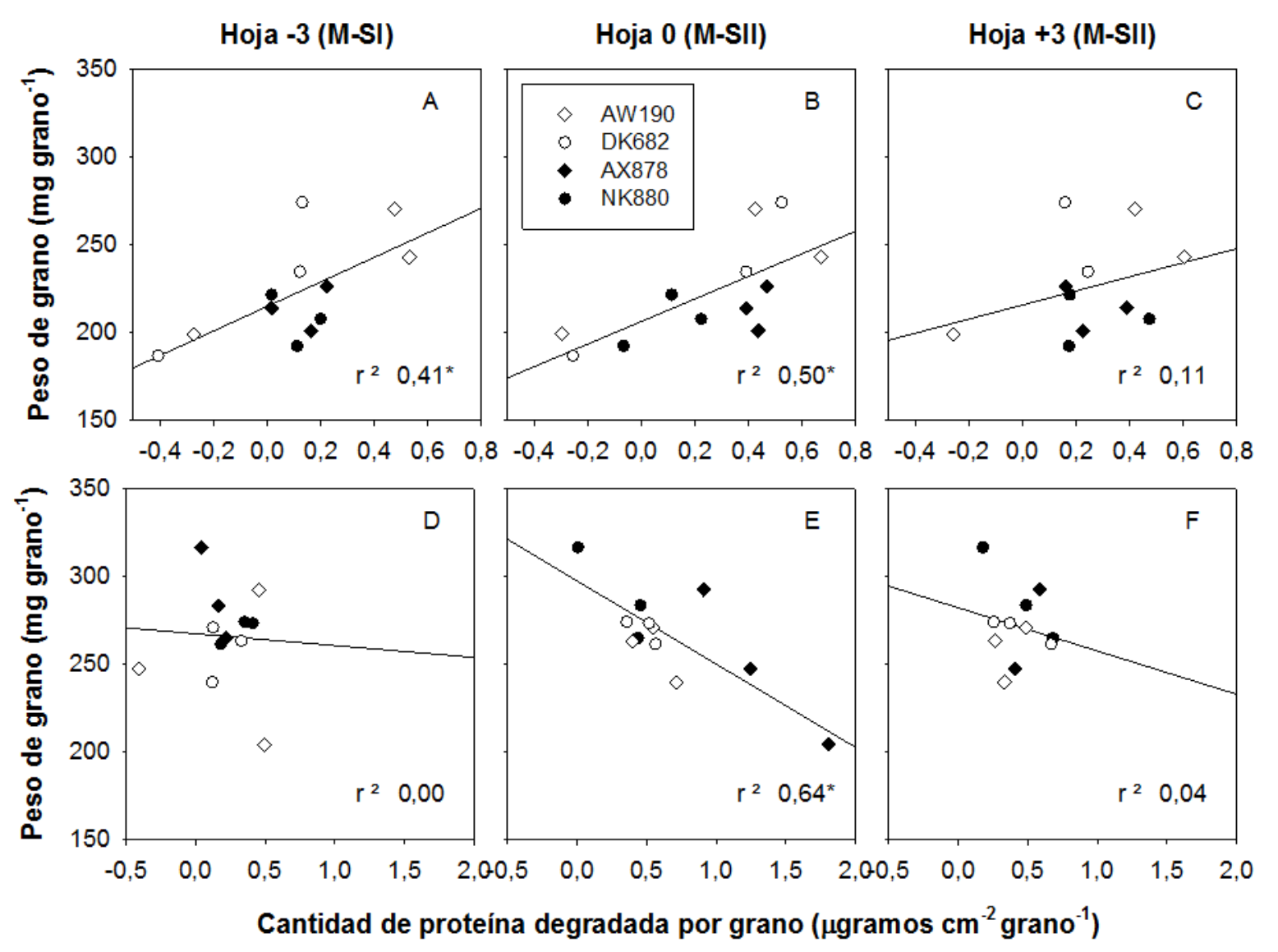

Fig. 4: Regresión entre la degradación de proteínas por grano fijado y el PG final. Las Figs $A, B$ y $C$ corresponden a las hojas $-3,0$ y +3 del tratamiento N0. Las Figs $D, E$ y $F$, corresponden a las hojas $-3,0$ y +3 del tratamiento N200. Cada punto representa una repetición $(n=12) . * P<0,05$. Notar la distinta escala en el eje de las $X$. 
3.5. El contenido de aminoácidos durante el llenado varió entre dosis de $\mathrm{Ne}$ híbridos y se relacionó con el PG final

El nivel de fertilización tuvo efectos significativos en el contenido de aminoácidos de todas las hojas y estadíos estudiados (excepto la hoja -3 en el estadío SII, Tabla 1); en todos los casos el contenido de aminoácidos fue menor en el tratamiento NO. En ambas dosis de N y para todas las hojas e híbridos, en general, el contenido de aminoácidos disminuyó entre M y SII.

En la hoja -3, el contenido de aminoácidos presentó interacción $\mathrm{N}$ x Híbrido en el estadío M (Tabla 1): los híbridos no se diferenciaron en NO (Fig. 5A), mientras que en N200 el contenido de aminoácidos fue mayor en los híbridos SG que en los NSG (DMS $<0,05$ respecto a AW190, Fig. 5D). En la hoja -3, en el estadío SI hubo diferencias dependientes del híbrido: los híbridos SG presentaron mayor contenido de aminoácidos que los NSG (DMS < 0,05) aunque esta tendencia fue más clara en NO para el híbrido NK880 y más clara en N200 para el híbrido AX878. En la hoja 0, existió interacción N x Híbrido en el estadío SI (Tabla 1): el contenido de aminoácidos tendió a ser menor en los híbridos SG en NO (Fig. 5B) pero mayor en los híbridos SG en N200 (Fig. 5E). La misma tendencia persistió (no significativamente) en el estadío SII. En la hoja +3, el contenido de aminoácidos varió dependiendo del híbrido en el estadío SI: el híbrido NSG DK682 presentó valores significativamente menores que el resto de los híbridos en ambas dosis de $\mathrm{N}$ (Fig. 5C y $5 \mathrm{~F}$ ).

El contenido de aminoácidos foliares por grano fijado se relacionó con el PG final, y esta relación varió entre hojas (Fig. 6). La relación entre el contenido de aminoácidos alrededor de floración y el $P G$ final, fue significativa $(P<0,05)$ en la hoja $3\left(r^{2}=0,84, n=12\right.$, Fig. $\left.6 A\right)$ y en la hoja $0\left(r^{2}=0,68, P<0,05, n=12\right.$, Fig. $\left.6 B\right)$, pero no significativa en la hoja +3 (Fig. 6C). 

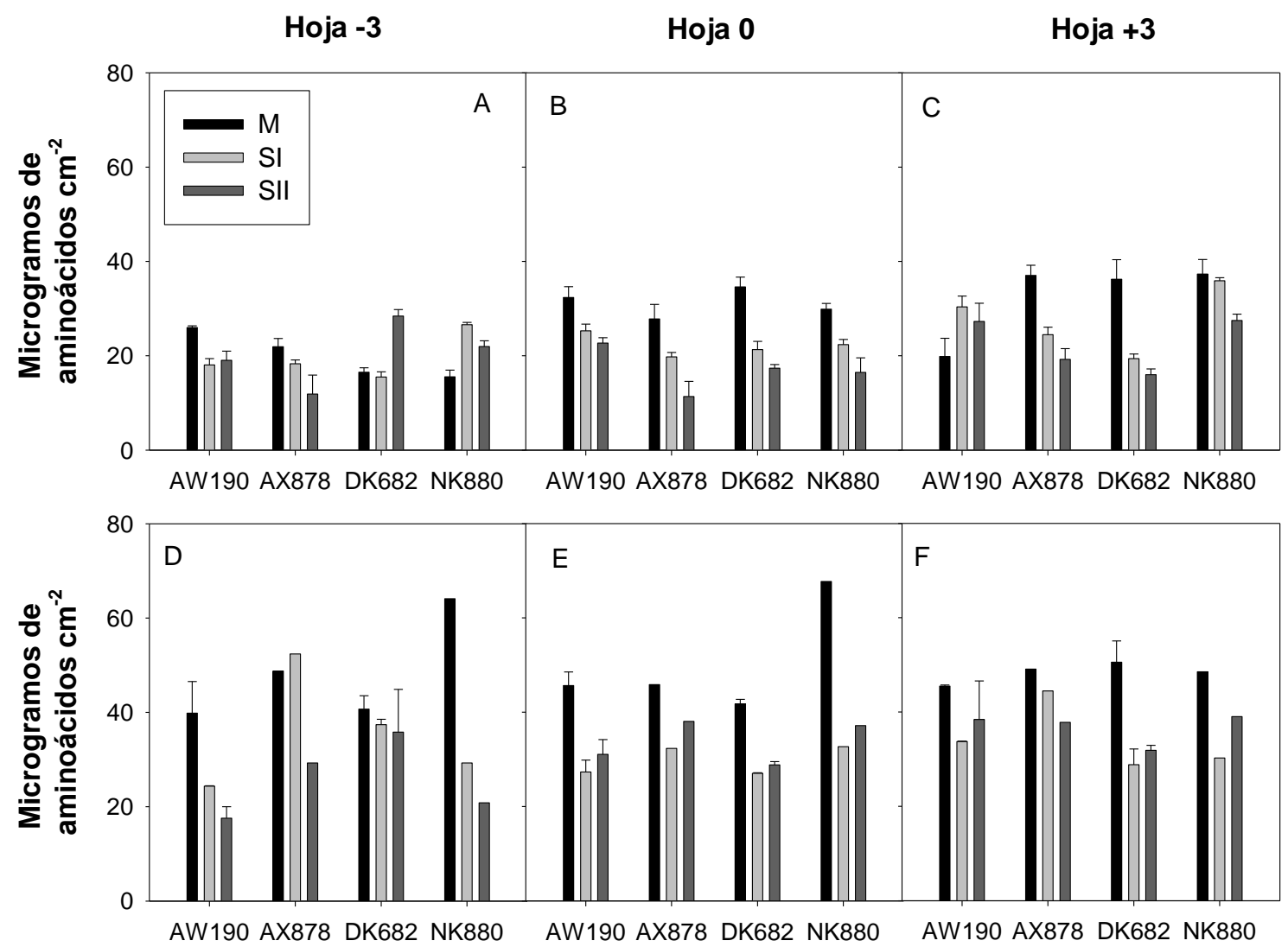

Fig. 5: Contenido de aminoácidos (microgramos por $\mathrm{cm}^{-2}$ ) en el tratamiento $N O(A, B, C)$ y $\mathrm{N} 200(D, E, F)$ y en la hoja $-3(A, D)$, hoja $0(B, F)$, y hoja $+3(C, F)$ a lo largo de tres estadios desde floración ( $\mathrm{M}, \mathrm{SI}, \mathrm{SII})$ en los cuatro híbridos. Las barras indican el error estándar.

\section{Estadío M}

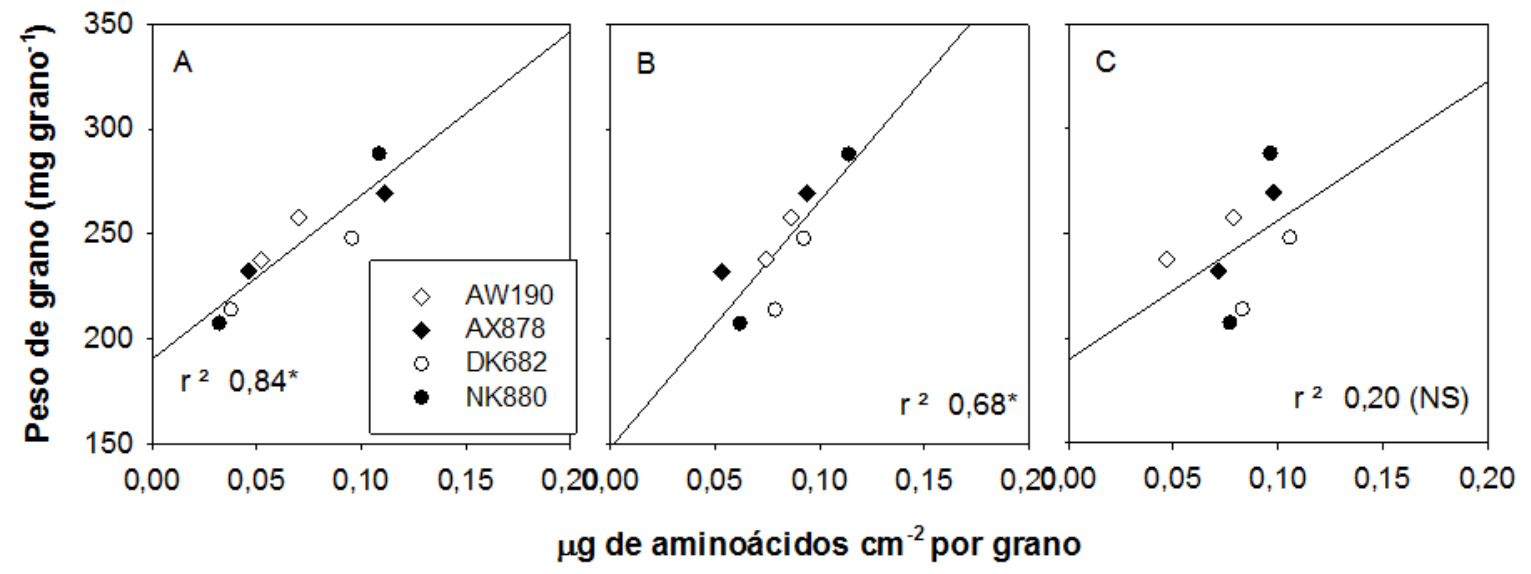

Fig. 6: Regresión entre el contenido de aminoácidos en el estadío M (floración) por grano fijado, y el peso de grano final, para ambos tratamientos de fertilización (NO y N200), en las hojas -3 (A), 0 (B) y +3 (C). Cada punto representa un tratamiento ( $\mathrm{N} \mathrm{x}$ Híbrido). 


\subsection{El contenido de amonio varió entre tratamientos y hojas}

En especies $C_{4}$, donde la fotorrespiración no es detectable, la principal fuente de amonio es la desaminación de aminoácidos producto de la degradación de proteínas durante la senescencia (Ghannoum, 2009). La producción de amonio puede representar una pérdida de $\mathrm{N}$ en forma volátil desde las hojas (Schjoerring et al., 1993) por lo que los resultados de amonio serán analizados en función de la máxima acumulación registrada en cada tratamiento, independientemente de los estadíos. En todas las hojas se detectó interacción significativa $\mathrm{N}$ x Híbrido (al menos en alguno de los tres estadíos analizados, Tabla 1). El tratamiento NO presentó mayor acumulación de amonio que el tratamiento N200 en las hojas -3 y +3 en todos los estadíos (Fig. 7A, 7C), pero menor en la hoja 0 (Fig. 7E). En general, y promediando las tres hojas muestreadas, en todos los estadíos, los niveles de amonio fueron mayores en NO que en N200.

Analizando la Fig. 7 en función de la máxima acumulación de amonio registrada en cada híbrido, puede observarse que, para ambos tratamientos no existe una tendencia clara en la hoja 0 (Figs. 7B y 7E). Considerando las demás hojas, en el tratamiento N0, los híbridos NK880 y DK682 son los que mayor acumulación de amonio presentaron en la hoja -3 en todos los estadíos (Fig. 7A) mientras que en la hoja +3 la mayor acumulación de amonio se registró en los híbridos SG (AX878 en M y NK880 en SI, Fig. 7C). En el tratamiento N200 los híbridos SG acumularon ligeramente mayor cantidad de amonio en la hoja -3 (AX878 en SI, y NK880 en M y SI, Fig. 7D) y en la hoja +3 (AX878 en SI y NK880 en SII, Fig. 7F). 

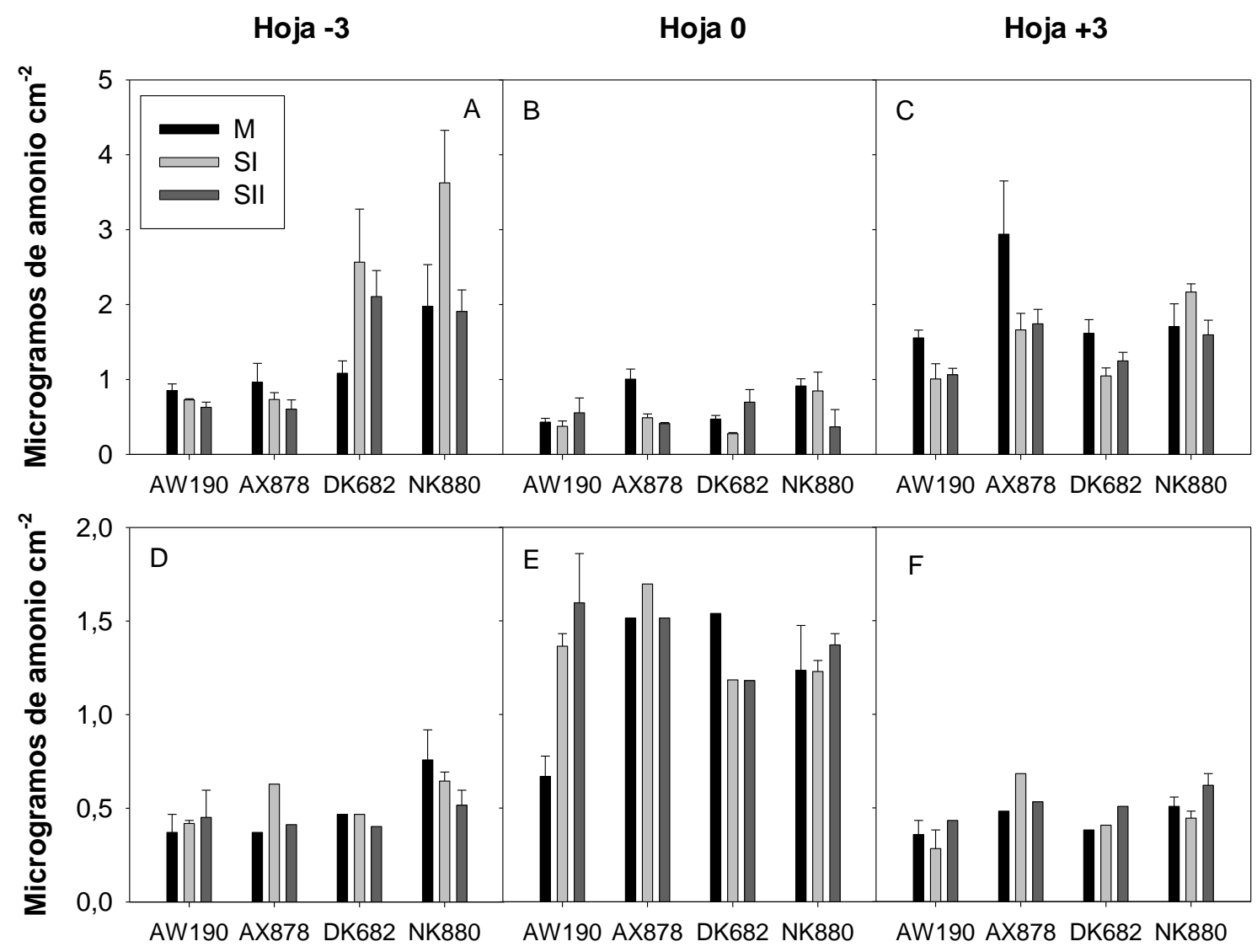

Fig. 7: Contenido de amonio (microgramos por $\mathrm{cm}^{-2}$ ) en el tratamiento NO $(A, B, C)$ y N200 (D, E, F) y en la hoja -3 (A, D), hoja 0 (B, F), y hoja +3 (C, F) a lo largo de tres estadios desde floración (M, SI, SII) en los cuatro híbridos. Las barras indican el error estándar. Notar la diferente escala del eje $\mathrm{Y}$ entre dosis de $\mathrm{N}$. 


\section{Discusión}

4.1. Variación genotípica para el contenido de proteínas en estadíos iniciales e intermedios del llenado

La disponibilidad de $\mathrm{N}$ se relaciona directamente con el contenido $\mathrm{N}$ en planta, y con el contenido de proteínas foliares. Por lo tanto, la reducción en el contenido de proteínas observada en NO es un resultado esperable. Borrell \& Hammer (2000) postulan la existencia de un valor umbral para el contenido de $\mathrm{N}$ por área foliar, por debajo del cual se desencadenaría el proceso de senescencia. En este sentido, el carácter SG (i.e. la demora relativa del inicio de la fase rápida de senescencia) podría resultar de un mayor contenido de proteínas en floración (Thomas \& Howarth, 2000). Los resultados presentados en este capítulo apoyan estas ideas, especialmente en condiciones de deficiencias de $\mathrm{N}$ (NO).

En NO, el contenido de proteínas foliares alrededor de floración (M) se correspondió con el carácter SG de los híbridos (ver Fig. 4A, Capítulo 3): el híbrido NSG DK682 presentó el menor contenido de proteínas en M, el híbrido AW190 (de moderado carácter SG) y AX878 (SG) presentaron contenidos intermedios, y los máximos se registraron en NK880 (de mayor expresión del carácter SG). Sin embargo, en N200 el contenido de proteínas en M no se correspondió directamente con el carácter SG, ya que AX878 presentó mayor contenido de proteínas en N200 pero inició la fase rápida de senescencia más temprano en comparación con NK880 (ver Fig. 4A, Capítulo 3). A partir de estos resultados es posible decir que (i) el carácter SG (de NK880) no necesariamente se asocia con mayor acumulación potencial de proteínas en foliares (en N200) y (ii) la demora relativa en la senescencia no siempre refleja diferencias en el contenido de proteínas alrededor de floración (a partir de la comparación entre AX878 y NK880 en N200).

Gallais \& Coque (2005) señalan que un mayor contenido de proteínas a floración permitiría la removilización parcial del $\mathrm{N}$ foliar sin que se resienta sustancialmente la capacidad fotosintética. Un comportamiento de este tipo se observó en AX878 y AW190, ya que el contenido de proteínas foliares en las tres hojas analizadas cae durante el llenado (Fig. 2) aún cuando estos híbridos exhiben una moderada demora en la senescencia, prácticamente similar a la encontrada en el 
híbrido NK880. Se ha sugerido que, cuando la disponibilidad de $\mathrm{N}$ es alta, parte del exceso de $\mathrm{N}$ absorbido puede acumularse en las hojas en forma de RuBisCO (Sage et al., 1987). Los resultados presentados en este Capítulo (Figs. 2D, 2E y 2F) sugieren que una estrategia de este tipo pudo haber sido adoptada por AX878 en N200, mientras que en el resto de los híbridos, si existió $\mathrm{N}$ en exceso, pudo haberse a acumulado en los tallos.

Paponov et al. (2005) reportaron reducciones en la tasa fotosintética cuando el contenido de $\mathrm{N}$ en la hoja cae por debajo de $1,5 \mathrm{~g} \mathrm{~N} \mathrm{~m}^{-2}$ de área foliar. Los resultados presentados en este capítulo muestran que en estadíos intermedios del llenado (30 DDF), existió una reducción en la tasa fotosintética cuando el contenido de proteínas foliares fue inferior a 400 microgramos $\mathrm{cm}^{-2}$ (tramo lineal del polinomio presentado en la Fig. 3A). Asumiendo que el contenido de $\mathrm{N}$ en las proteínas foliares es alrededor del 16\% (Sage et al., 1987), contenidos de proteína inferiores a 400 microgramos $\mathrm{cm}^{-2}$ equivalen a contenidos de $\mathrm{N}$ inferiores a $0,64 \mathrm{~g} \mathrm{~m}^{-2}$, i.e. valores notablemente más bajos que los reportados por Paponov et al. (2005). En este contexto, el mayor contenido de proteínas alcanzado en los híbridos SG representó una ventaja en términos de actividad fotosintética. Según Sage et al. (1987), entre el 21 y $27 \%$ del N foliar está representado por proteínas asociadas a clorofila (de la cadena de transporte de electrones) mientras que alrededor del 6,5\% está representado por RubisCO.

\subsection{Variación en la degradación de proteínas entre dosis de $\mathrm{N}$ y hojas}

La degradación de proteínas cloroplásticas se considera como un marcador de senescencia y removilización de nutrientes (Masclaux et al., 2000; Thomas et al., 2000). El contenido de proteínas foliares remanente en estadíos avanzados de la senescencia de una hoja en particular (estadío SII del presente estudio) estaría relacionado con la eficiencia de removilización del $\mathrm{N}$ foliar. Varios trabajos muestran que las deficiencias de $\mathrm{N}$ inducen la removilización de $\mathrm{N}$ foliar (Paponov et al., 2005; Masclaux et al., 2000). Los resultados presentados en este capítulo concuerdan con las evidencias previas. El contenido de proteínas remanente en estadíos avanzados de la senescencia fue mayor en N200 respecto a N0, sugiriendo que la eficiencia de removilización del $\mathrm{N}$ foliar disminuye con la fertilización. 
Considerando las diferentes hojas estudiadas, en ambos tratamientos de $\mathrm{N}$, el contenido remanente de proteínas foliares (en SII) aumentó conforme se demoró la senescencia de las distintas hojas. Es decir, el menor remanente de proteínas se registró en la hoja -3, cuya senescencia comenzó más temprano. En la hoja 0 el remanente fue intermedio, y en la hoja +3 fue máximo. Dado que en NO la senescencia de la hoja 0 y +3 comenzó aproximadamente en el mismo momento (Tabla 1, Fig. 1A y 1C), el comparativamente menor remanente de proteínas encontrado en la hoja 0 no puede ser explicado solamente a través del inicio más tardío de la senescencia en relación con la hoja -3. La menor distancia de la hoja 0 a los granos estaría relacionada con una mayor eficiencia de removilización, en comparación con la observada en la hoja +3. Por otra parte, la degradación neta de proteínas es un indicador de la importancia relativa de cada hoja como fuente de $\mathrm{N}$ para los granos, y en ambas dosis de $\mathrm{N}$ fue más importante la hoja 0 . Reportes previos indican una mayor removilización de $\mathrm{N}$ durante el llenado de granos y un mayor aporte total de $\mathrm{N}$ a los granos, en las tres hojas alrededor de la espiga (adyacente, por encima y por debajo) (Cliquet et al., 1990; Reed et al., 1980).

\subsection{Variación en la degradación de proteínas entre genotipos}

La variabilidad genotípica encontrada en este trabajo para el remanente de proteínas en estadíos avanzados de la senescencia foliar concuerda con reportes previos. Varios trabajos indican una mayor retención de $\mathrm{N}$ foliar, presumiblemente proteínas en su mayor parte, en híbridos SG (Borrell \& Hammer, 2000; Ma \& Dwyer, 1998; Pommel et al., 2006). En un ensayo a campo donde la disponibilidad de $\mathrm{N}$ (fertilizante $+\mathrm{N}$ edáfico) fue de $230 \mathrm{~kg}$ de $\mathrm{N} \mathrm{ha}^{-1}$, Martin et al. (2005) muestran que el contenido de proteínas foliares hacia el final del llenado (55 DDF) permanece prácticamente constante con respecto a floración en el híbrido SG, mientras que disminuye en el híbrido estándar. En este capítulo, este tipo de diferencias genotípicas persisten incluso en N0, y especialmente en uno de los híbridos SG (NK880). Distintos autores han sugerido que la actividad proteolítica estaría ligada a la declinación en el contenido de clorofila (Reed et al., 1980). Esto implicaría una relación inversa entre el carácter SG (valorado en términos de clorofila foliar) y la degradación de proteínas. Sin embargo, el hecho de que los híbridos SG (AX878 y NK880) hayan presentado 
importantes diferencias en el remanente de proteínas respalda la posibilidad de encontrar variación en la retención de proteínas entre distintos genotipos SG.

4.4. La degradación de proteínas podría tener un impacto directo sobre el PG final en ambientes con deficiencias de $N$ edáfico en post-floración

Durante un período de 2 semanas después de floración, la disponibilidad de $\mathrm{N}$ tiene influencia sobre la determinación del PG potencial (Below et al., 2000; Cazetta et al., 1999). El déficit de $\mathrm{N}$ en esta etapa reduce el contenido de gránulos de almidón y células del endosperma, y por lo tanto la capacidad de los destinos (Cazetta et al., 1999). En un ensayo a campo, Paponov et al. (2005) combinaron tratamientos de déficit de fertilización nitrogenada desde la siembra con fertilización en floración o 18 DDF y reportaron que en ambos casos la fertilización aumentó el PG final respecto de plantas no fertilizadas, aunque este efecto fue más pronunciado cuando la fertilización fue suministrada en floración. En este capítulo, la relación encontrada entre la degradación de proteínas foliares y el PG final (Fig. 4) sugiere que la removilización del $\mathrm{N}$ foliar podría tener un impacto positivo sobre el rendimiento en ambientes con deficiencias de $\mathrm{N}$ edáfico en post-floración. En este sentido, el impacto de la removilización sobre el rendimiento sería más relevante en aquellas hojas cuya senescencia comienza relativamente más temprano en el llenado (hojas del estrato basal, como la hoja -3) o en hojas que por su cercanía a los granos representan una fuente importante de $\mathrm{N}$ (la hoja 0). Esto explicaría la baja relación encontrada para la hoja +3 (Fig. 4C). Además, estas evidencias se corresponden directamente con la relación hallada entre el inicio de la fase rápida de senescencia del estrato basal y medio del canopeo y la concentración de $\mathrm{N}$ en granos (Fig. 11, Capítulo 4).

Por otro lado, la relación negativa encontrada entre la degradación de proteínas en la hoja 0 y el PG final en el tratamiento N200 (Fig. 4E), podría indicar que cuando la disponibilidad de $\mathrm{N}$ para los granos es suficiente, la degradación de proteínas foliares impacta negativamente sobre el balance de $C$, y entonces, sobre el PG final. Hirel et al. (2001) encontraron que entre varios QTLs para la actividad de GS, la colocalización con los componentes del rendimiento varió dependiendo de la dosis de N. 
4.5. El contenido de aminoácidos durante el llenado varió entre dosis de $\mathrm{Ne}$ híbridos y se relacionó con el PG final

Hirel et al. (2005) demostraron que el nivel de aminoácidos en plantas adultas de maíz permanece bajo en comparación con plantas jóvenes, probablemente porque la tasa de asimilación de $\mathrm{N}$ se reduce a lo largo del ciclo. Después de floración, tanto la asimilación primaria de $\mathrm{N}$ por la raíz como la removilización de $\mathrm{N}$ desde las hojas pueden ocurrir simultáneamente contribuyendo al pool de aminoácidos foliares y a abastecer la demanda de $\mathrm{N}$ de los órganos destinos (Hirel et al., 2007). No obstante, en ambientes contrastantes es esperable que uno de éstos procesos (removilización vs. asimilación) predomine sobre el otro (Below et al., 1981). Estos procesos se vinculan directamente con los componentes de la EUN analizados en el Capítulo 3. Así, cuando la disponibilidad de $\mathrm{N}$ es alta, la EAbsN (y la asimilación de $\mathrm{N}$ asociada) tendrían mayor importancia relativa, mientras que en ambientes deficientes en $\mathrm{N}$ la EUtN (y la removilización asociada) adquieren más relevancia en la definición del rendimiento (Gallais \& Coque, 2005).

En general, el proceso de removilización de $\mathrm{N}$ está acelerado en ambientes deficientes en N (Masclaux-Daubresse et al., 2010). En estos casos, el contenido de aminoácidos libres en las hojas aumentará como consecuencia de la actividad proteolítica asociada a la senescencia. Se ha reportado que la removilización neta de $\mathrm{N}$ foliar puede comenzar entre 5 y 20 DDF según el híbrido (Below et al., 1981). Los resultados presentados en capítulo muestran que en el tratamiento NO y en las hojas 3 y 0 (Fig. $5 \mathrm{~A}$ y $5 \mathrm{~B}$ ) el contenido de aminoácidos libres alrededor de floración es mayor en los híbridos NSG (especialmente en DK682) respecto de los SG, lo que presumiblemente esté asociado a removilización neta de $\mathrm{N}$ foliar. Es esperable que, debido a la senescencia más tardía de la hoja +3 no se registren diferencias genotípicas en esta hoja alrededor de floración. Similares resultados reportaron (He et al., 2001). Estos autores analizaron la identidad de los compuestos nitrogenados (básicamente, aminoácidos, proteínas y $\mathrm{N}$ residual) en floración en dos híbridos de maíz. El porcentaje correspondiente a aminoácidos fue mayor en el híbrido senescente (más del $30 \%$ del total vs. $20 \%$ en el híbrido SG) en el tratamiento sin fertilizar, y las diferencias se redujeron en plantas fertilizadas. Los resultados presentados en este capítulo y las evidencias previas sugieren entonces, que el contenido de aminoácidos 
libres durante la senescencia foliar es un indicador del ritmo de degradación de proteínas y removilización de $\mathrm{N}$.

Por otra parte, en ambientes con abundante disponibilidad de $\mathrm{N}$, el $\mathrm{N}$ absorbido por la raíz después de floración puede representar hasta un $60 \%$ del $\mathrm{N}$ aportado a los granos (Coque \& Gallais, 2007). En estos casos, el contenido de aminoácidos foliares en estadíos tempranos del llenado estará vinculado a la asimilación de $\mathrm{N}$ edáfico ya que las hojas actúan como destino transitorio del $\mathrm{N}$ absorbido (Masclaux-Daubresse et al., 2010). En los resultados presentados, el mayor contenido de aminoácidos registrado en el híbrido NK880 (Figs. 5D, 5E) sumado a la mayor demora relativa en el inicio de la senescencia sugieren mayores tasas de asimilación de $\mathrm{N}$ edáfico en este híbrido. Martin et al. (2005) compararon el contenido de aminoácidos entre un híbrido SG y uno senescente (que dispusieron de $230 \mathrm{~kg}$ de $\mathrm{N}$ $\mathrm{ha}^{-1}$ sumando fertilización y $\mathrm{N}$ edáfico). El híbrido SG presentó mayor contenido de aminoácidos desde floración y hasta 35 DDF y mayor absorción de $\mathrm{N}$ en post-floración (Martin et al., 2005) sugiriendo que el contenido de aminoácidos foliares refleja diferencias en la asimilación de $\mathrm{N}$ edáfico cuando el suministro de $\mathrm{N}$ es abundante.

Asumiendo que el contenido de aminoácidos foliares refleja en parte, la cantidad de $\mathrm{N}$ potencialmente removilizable en forma inmediata, la relación entre el contenido de aminoácidos foliares y el PG final (Fig. 6) reafirma la idea de que el $\mathrm{N}$ tiene un impacto relevante sobre el PG. Distintos aspectos asociados al contenido de aminoácidos foliares, como son la disponibilidad de N, y las reacciones mediadas por las enzimas glutamina sintetasa y nitrato reductasa, son piezas claves que definen la EUtN (Hirel et al., 2001). A partir de los resultados presentados en la Fig. 4 de este capítulo, se asume que la mayor parte de los aminoácidos foliares en NO estarán asociados a la degradación de proteínas. En cambio, en N200 el contenido de aminoácidos detectado alrededor de floración, reflejaría más probablemente la asimilación transitoria del $\mathrm{N}$ absorbido (Masclaux-Daubresse et al., 2010).

La hoja de la espiga tiene un rol principal como destino transitorio del $\mathrm{N}$ asimilado (Masclaux-Daubresse et al., 2010). Reed et al. (1980) analizan la actividad de la nitrato reductasa en la hoja adyacente a la espiga, y la cuarta hoja por encima y por debajo de la espiga y encuentran que en todas las hojas, la actividad de la enzima disminuye durante el llenado pero siempre es mayor en la hoja de la espiga. La baja 
relación encontrada en la hoja +3 (Fig. 6C) estaría relacionada con que, frente a deficiencias de $\mathrm{N}$, la senescencia de esta hoja ocurre relativamente tarde en el llenado (por ej, a partir de los 22 DDF en el tratamiento NO de este capítulo). Por otro lado, cuando hay disponibilidad de $\mathrm{N}$ edáfico, la mayor parte de éste será asimilado en hojas más cercanas a la raíz (i.e. de los estratos basales) o en la hoja de la espiga. Es decir, las hojas del estrato superior tendrían una baja incidencia en el aporte de $\mathrm{N}$ a los granos durante la etapa de determinación del PG potencial.

\subsection{El contenido de amonio varió entre tratamientos y hojas}

En plantas $C_{3}$ las principales fuentes de amonio son la fotorrespiración (se libera una molécula de amonio durante la oxidación de la glicina) y la desaminación de aminoácidos. En cambio, en plantas $\mathrm{C}_{4}$, dado que la fotorrespiración es prácticamente nula, la principal fuente de amonio es la desaminación de aminoácidos. Por otra parte, el amonio liberado por cualquiera de esta vías es re-asimilado por la glutamina sintetasa (GS). Los niveles de GS permanecen relativamente constantes en maíz, aún en plantas sin fertilizar (Hirel et al 2005) mientras que en plantas $C_{3}$ como tabaco, el nivel de GS decae drásticamente durante la senescencia (Masclaux et al., 2000; Schjoerring, 1993). Considerando entonces la menor liberación de amonio y los mayores niveles de GS durante la senescencia de plantas $C_{4}$, resultan esperables los bajos niveles de amonio detectados en este capítulo en comparación con los niveles reportados en plantas $C_{3}$. Sin desconocer estas marcadas diferencias, vale destacar que a menudo las comparaciones entre plantas $C_{3}$ y $C_{4}$ involucran cultivos de invierno y de verano respectivamente. Siendo que la volatilización de amonio aumenta con la temperatura, similares cantidades de amonio en los tejidos implicarán distintas tasas de volatilización dependiendo del ciclo del cultivo.

Hirel et al. (2005) analizaron el contenido de amonio en dos niveles de N (230

vs $90 \mathrm{~kg} \mathrm{~N} \mathrm{ha}{ }^{-1}$ aportados por la fertilización y por el $\mathrm{N}$ edáfico) y encontraron una ligera acumulación de amonio en hojas de maíz muestreadas a los 15 DDF; además los contenidos de amonio aumentaron con el incremento de la fertilización. Esto contrasta con los resultados presentados en este capítulo ya que el contenido de amonio fue mayor en el tratamiento NO (en las hojas $-3 y+3$ ), y se redujo con la fertilización. 
Los resultados presentados no indican una relación clara entre el carácter SG y la acumulación de amonio en los tejidos. No obstante, existió una tendencia a mayor acumulación de amonio en los híbridos SG, especialmente en la hoja +3 (Figs. 7C y 7F). Martin et al. (2005) reportaron que los niveles de GS1 fueron mayores en un híbrido SG respecto al estándar en las primeras etapas del llenado, pero a partir de los 35 DDF los niveles de GS1 fueron más abundantes en el híbrido estándar. Según los autores, cuando GS se expresa en el citosol en etapas avanzadas del llenado estaría involucrada en la reasimilación de amonio liberado durante la senescencia, mientras que en etapas tempranas los mayores niveles de GS en el híbrido SG estarían relacionados a una mayor tasa de asimilación de $\mathrm{N}$ edáfico (Martin et al., 2005).

\section{Conclusiones}

Los resultados encontrados en este capítulo indican que la demora de la senescencia foliar reduce la eficiencia de removilización del $\mathrm{N}$ foliar. Esto pudo observarse independientemente de cuál fue la fuente de demora de la senescencia foliar: fertilización, posición de la hoja en el canopeo, y genotipo.

En condiciones de deficiencias de N, la degradación de proteínas en estadíos iniciales del llenado (ca. en las primeras 2 semanas post-floración) acompañada por la removilización del $\mathrm{N}$ foliar, tendría un impacto positivo sobre el crecimiento de los granos. En cambio, en condiciones de suficiente disponibilidad de $\mathrm{N}$ edáfico, la menor eficiencia de removilización del $\mathrm{N}$ foliar no actuaría en detrimento del crecimiento de los granos, sino que favorecería el balance de C (al retrasar la declinación fotosintética) y entonces, el PG final.

A partir de estas evidencias, y sumando las presentadas en el Capítulo 4, es posible especular que frente a deficiencias de $\mathrm{N}$, la demora de la senescencia foliar asociada al carácter SG podría tener un impacto negativo sobre la provisión de $\mathrm{N}$ a los granos. No obstante, genotipos SG con alta plasticidad a las condiciones ambientales, podrían resolver esta disyuntiva acelerando la senescencia de las hojas basales pero manteniendo un carácter SG en el estrato medio y superior. 


\section{CAPÍTULO 6 CONSIDERACIONES FINALES}

En el desarrollo de esta tesis se estudió el impacto de la senescencia foliar sobre el rendimiento en diversas situaciones de estrés. Se analizó la variabilidad genotípica para un carácter fisiológico que podría tener incidencia sobre la tolerancia del rendimiento al estrés: la demora en la senescencia foliar. Se estudió si la demora en la senescencia foliar representa una ventaja de rendimiento en condiciones de estrés hídrico en post-floración (Capítulo 2), estrés por deficiencias de N (Capítulo 3) y estrés por alta densidad poblacional (Capítulo 4). Adicionalmente, se analizó la dinámica del $\mathrm{N}$ foliar durante la senescencia con el propósito de detectar variabilidad genotípica asociada al carácter de senescencia demorada (Capítulo 5).

\section{Contrastación de hipótesis}

A partir de las evidencias presentadas a lo largo de esta tesis, es posible responder a las hipótesis originales como se indica a continuación.

\section{Hipótesis 1:}

(1) En condiciones de sequía en post-floración, la demora en la senescencia foliar está asociada a mayor producción de fotoasimilados y mayor rendimiento.

(1.1) En condiciones de sequía en post-floración, los genotipos SG presentan mayor producción de fotoasimilados en post-floración. Aceptada (Tabla 1, Fig. 7, Capítulo 2)

(1.2) En condiciones de sequía en post-floración, los genotipos SG presentan mayor rendimiento. Aceptada (Tabla 1, Capítulo 2).

\section{Hipótesis 2:}

(2) En condiciones de deficiencias de nitrógeno, la demora en la senescencia foliar está asociada a mayor producción de fotoasimilados y mayor rendimiento. 
(2.1.) En condiciones de deficiencias nitrógeno, los genotipos SG presentan mayor producción de fotoasimilados en post-floración. Rechazada en forma parcial (Fig. 9, Capítulo 3). En estadíos tempranos del llenado, la demora de la senescencia se relaciona con mayor asimilación neta, pero en estadíos tardíos (asociados con ocurrencia de bajas temperaturas) la demora de la senescencia se asocia con pérdidas netas de MS.

(2.2.) En condiciones de deficiencias nitrógeno, los genotipos SG presentan mayor rendimiento. Rechazada (Tabla 1, Fig. 8A, Capítulo 3).

\section{Hipótesis 3:}

(3) En condiciones de alta densidad poblacional, la demora en la senescencia foliar está asociada a mayor producción de fotoasimilados y mayor rendimiento.

(3.1.) En condiciones de alta densidad poblacional, los genotipos SG presentan mayor producción de fotoasimilados en post-floración. Rechazada (Tabla 2, Capítulo 4).

(3.2.) En condiciones de alta densidad poblacional, los genotipos SG presentan mayor rendimiento. Rechazada (Tabla 2, Capítulo 4).

\section{Hipótesis 4:}

(4) La demora en la senescencia está relacionada con una menor eficiencia de removilización del $\mathrm{N}$ foliar.

(4.1.) El aumento de la fertilización con N, al demorar la senescencia foliar, reduce la eficiencia de removilización del N foliar. Aceptada (Fig. 2, Capítulo 5). (4.2.) Dentro del canopeo, la eficiencia de removilización del $\mathrm{N}$ foliar es menor en las hojas del estrato superior (cuya senescencia es más tardía). Aceptada (Fig. 2, Capítulo 5).

(4.3.) Los genotipos SG presentan menor eficiencia de removilización del $\mathrm{N}$ foliar. Aceptada (Fig. 2, Capítulo 5) 


\section{Aportes originales al conocimiento científico}

A partir de los ensayos descritos en los diferentes capítulos de esta tesis, se han obtenido resultados que constituyen un aporte al conocimiento existente sobre aspectos relacionados a la estabilidad del rendimiento del cultivo de maíz frente a diversos tipos de estrés, y al impacto de la senescencia foliar sobre la estabilidad del rendimiento. Los aportes originales al conocimiento existente se detallan a continuación.

1. En esta tesis, se ha evidenciado interacción genotipo $\mathrm{x}$ ambiente para el carácter SG. En ambientes con bajo estrés el carácter SG de algunos genotipos puede no expresarse cuando es comparado con genotipos NSG de referencia. En ambientes con estrés más severo, algunos genotipos pueden presentar un carácter moderadamente SG dependiendo del tipo de estrés implementado. Este es el caso del híbrido AW190, que presenta comportamiento NSG bajo estrés hídrico (Capítulo 2), pero moderadamente SG bajo estrés por deficiencias de N (Capítulo 3) y frente a alta densidad poblacional (Capítulo 4). Este es un aporte original considerando que, hasta el momento, pocos estudios evaluaron la manifestación del carácter SG en híbridos modernos de maíz utilizando los mismos genotipos y variando la fuente de estrés.

2. Borrás et al. (2003) reportaron que el inicio de la fase rápida de senescencia foliar es un carácter altamente conservado y con poca interacción con el ambiente. Un resultado novedoso presentado en esta tesis es la variación en el inicio de la senescencia foliar dependiendo del ambiente (Capítulos 3 y 4). Además, la variabilidad observada entre estratos para el inicio de la fase rápida de senescencia también es un resultado novedoso, considerando que, hasta el momento, ésta variable ha sido analizada a escala del canopeo pero nunca discriminando estratos.

3. Un hallazgo novedoso es que el ambiente puede afectar diferencialmente la senescencia foliar, dependiendo del estrato del canopeo considerado (Capítulo 4), i.e., que algunos estratos son proporcionalmente más afectados que otros en respuesta al ambiente. Aún más interesante resulta el hecho de que existe variabilidad genotípica para la respuesta diferencial de los estratos. Esto se evidenció en la variación de la relación entre el punto de quiebre del estrato 
superior y del estrato inferior, que en algunos genotipos se mantuvo mientras que en otros aumentó cuando se incrementó la densidad poblacional (Capítulo 4).

4. El carácter SG ha sido asociado a mayor asimilación neta en postfloración en condiciones de estrés hídrico, en sorgo (Borrell et al., 2000b) y en híbridos de maíz de diferente año de liberación (Tollenaar \& Lee, 2002). En el Capítulo 2 de esta tesis se muestra que en híbridos simples de maíz el carácter SG también se asocia a mayor asimilación neta en post-floración bajo condiciones de estrés hídrico. Otro resultado novedoso es que la mayor asimilación neta se relaciona no sólo con la duración del AFV sino también con una mayor eficiencia fotosintética, y con una mayor conductancia estomática. Esto sugiere la existencia de variabilidad genotípica para la eficiencia fotosintética y presuntamente también, para la capacidad de extracción de agua edáfica.

5. Los resultados presentados indican que en condiciones de estrés hídrico en post-floración, el carácter SG se asocia a mayores rendimientos a través de un mayor PG (Capítulo 2). Este es un resultado novedoso considerando que hasta el momento, los estudios que analizan las ventajas de genotipos SG en condiciones de sequía han sido realizados en sorgo (Borrell, 2000b) y en líneas de maíz (Bänziger, 2002), pero no en híbridos actuales, contemporáneos de maíz.

6. El carácter SG ha sido asociado a mayor asimilación neta de MS en postfloración en condiciones de deficiencias de N (Borrell \& Hammer, 2000). Los resultados presentados en esta tesis muestran que los híbridos SG de maíz presentarían mayor asimilación neta en post-floración frente a deficiencias de $\mathrm{N}$, tanto a través de la demora en el inicio de la senescencia (Capítulo 3) como a través de una mayor eficiencia fotosintética asociada al contenido de proteínas foliares (Capítulo 5). Sin embargo, en determinados ambientes, esta ventaja podría no manifestarse en la MS total debido a pérdidas de MS hacia el final del llenado, asociadas a la respiración.

7. Un hallazgo novedoso de esta tesis es que las bajas temperaturas hacia el final del llenado pueden tener efectos considerables sobre la asimilación neta en este período, y por lo tanto, sobre el rendimiento. Los resultados presentados en el Capítulo 3 también fueron observados en el Capítulo 4 (datos no mostrados). Esto implica que dependiendo del área de distribución del cultivo, el carácter SG puede no 
representar una ventaja en rendimiento si la duración del AFV se prolonga más allá del comienzo de temperaturas mínimas críticas (ca., $10^{\circ} \mathrm{C}$ ).

8. Reportes previos indican que el carácter SG estaría asociado a mayores rendimientos frente a deficiencias de $\mathrm{N}$ en líneas de maíz (Bänziger et al., 1999). Un hallazgo novedoso de esta tesis (Capítulo 3) es que el en híbridos de maíz, el carácter SG no se asocia a mayores rendimientos cuando las deficiencias de $\mathrm{N}$ son severas. Esto se relaciona principalmente con un menor PG.

9. Hasta el momento no existían estudios previos que analizaran el impacto del carácter SG en condiciones de alta densidad poblacional. Los resultados presentados indican que el carácter SG en alta densidad puede tener un impacto negativo sobre el balance de $\mathrm{C}$ y $\mathrm{N}$ durante el llenado. El impacto sobre el balance de $\mathrm{C}$ estaría relacionado con una menor inducción de la senescencia por sombreo en algunos genotipos SG (v.g. NK880) respecto a genotipos NSG, y consiguientemente, con el mantenimiento de tasas respiratorias excesivas en hojas basales (fotosintéticamente poco productivas). El impacto sobre el balance de $\mathrm{N}$, estaría asociado a una baja capacidad de inducción de la senescencia en respuesta a la demanda de $\mathrm{N}$ en los granos. Este es un resultado novedoso e implica que, no en todas las situaciones de estrés que aceleren la senescencia foliar (i.e., alta densidad poblacional) la demora de la senescencia foliar representará una ventaja en términos de balance de $\mathrm{C}$ y $\mathrm{N}$.

10. Distintos autores han sugerido que los genotipos SG presentarían mayor asimilación de $\mathrm{N}$ en post-floración respecto a genotipos NSG (Ma \& Dwyer, 1998; Rajcan \& Tollenaar, 1999b). Esto redundaría en una mayor retención de $\mathrm{N}$ en estructuras vegetativas (Ma \& Dwyer, 1998; Rajcan \& Tollenaar, 1999b). Un aporte novedoso es que (i) no siempre el carácter SG se asocia a una mayor absorción de $\mathrm{N}$ en post-floración (Capítulo 4); y que (ii) la mayor retención de $\mathrm{N}$ en estructuras vegetativas (hojas y cañas) de híbridos SG puede ocurrir independientemente de la cantidad de $\mathrm{N}$ absorbido en post-floración (Capítulo 4).

11. En el Capítulo 4, se muestra que el carácter SG se mantiene aún cuando la disponibilidad de $\mathrm{N}$ para los granos parece haber estado por debajo de la óptima para maximizar el crecimiento de los granos. En forma complementaria, en el Capítulo 5 se muestra que, aún en ausencia de fertilización, la degradación de proteínas foliares 
en uno de los genotipos SG, fue muy baja y comenzó en estadíos posteriores a la determinación del PG potencial. Estas evidencias indican que, en algunos genotipos, la retención del $\mathrm{N}$ foliar puede actuar independientemente de los requerimientos de $\mathrm{N}$ en los granos. Este es un aporte novedoso que contrasta con la idea de que el carácter SG sólo se expresa cuando hay suficiente disponibilidad de N (Ma \& Dwyer, 1998; Subedi \& Ma, 2005). Además, aporta nuevas evidencias para soportar la hipótesis de que la removilización del $\mathrm{N}$ foliar está, al menos en parte, regulada por la fuente.

12. Las relaciones presentadas entre la degradación de proteínas foliares y el peso de grano (Fig. 5, Capítulo 5) aportan evidencias de que la removilización del N foliar puede representar una ventaja o una penalidad dependiendo del ambiente. Esto implica que en algunos casos, la demora en la senescencia foliar, especialmente si ésta es regulada por la fuente, puede impactar negativamente sobre el rendimiento.

13. Hasta el momento no se conocen trabajos donde la degradación de proteínas foliares durante la senescencia se analizara comparativamente en distintas hojas del canopeo y durante el llenado de granos, en híbridos contrastantes para el carácter SG. De los resultados presentados, se destaca que la eficiencia de removilización del $\mathrm{N}$ foliar se reduce en las hojas de senescencia más tardía (representativas del estrato superior), resaltando la importancia de las hojas basales en el suministro de $\mathrm{N}$ a los granos (Capítulo 5). La baja degradación de proteínas observada en híbridos SG, incluso en ambientes con limitaciones de $N$ (NO) complementa la idea de que los granos de genotipos SG pueden experimentar deficiencias de $\mathrm{N}$ sin que por ello se induzca la senescencia foliar (Capítulo 5).

\section{Implicancias para futuras investigaciones}

Los resultados presentados a lo largo de esta tesis representan avances en el conocimiento del carácter SG y sus efectos sobre el rendimiento en híbridos de maíz. No obstante, numerosos aspectos no han sido completamente dilucidados y al mismo tiempo surgen nuevos interrogantes para abordar en futuras investigaciones. 
1. Detección de los mecanismos involucrados en la plasticidad del carácter SG

Las evidencias presentadas a lo largo de esta tesis indican que la capacidad de modular el carácter SG en función del ambiente (i.e., la plasticidad del carácter SG) puede tener un impacto positivo sobre el rendimiento. Por lo tanto, sería interesante profundizar el estudio de diversas variables asociadas a la percepción y modulación de señales ambientales, y su relación con la plasticidad observada para el carácter SG.

En esta tesis se detectó variabilidad genotípica para la plasticidad del carácter SG en función del ambiente. Por ejemplo, la plasticidad del carácter SG fue alta en el híbrido AX878 y muy baja en el híbrido NK880. Esto significa que, en algunas situaciones de estrés, los híbridos presentaron igual grado de expresión del carácter SG (por ejemplo en el Capítulo 2). Sin embargo, en otras situaciones, la expresión del carácter SG varió entre híbridos, especialmente en el estrato inferior del canopeo (Capítulos 3 y 4). La plasticidad del carácter SG en el estrato inferior ya había sido reportada: en dos híbridos de maíz la diferencia en el carácter SG a bajo $\mathrm{N}$ se manifestó en las hojas por encima de la espiga, mientras que las hojas basales de ambos híbridos mostraron similar comportamiento (Pommel et al., 2006).

Parte de la variabilidad observada en la expresión y plasticidad del carácter podría tener una explicación a nivel genético. Martin et al. (2005) reportaron que entre dos híbridos contrastantes para el carácter SG, existieron dos genes de función desconocida para los que la expresión en el inicio de la senescencia fue mayor en el híbrido estándar. Por otro lado, los mismos autores destacan que el momento de expresión de genes asociados a la senescencia fue similar para ambos híbridos, pero la senescencia procedió más lentamente en el híbrido SG (Martin et al., 2005). Esto sugiere que la señal de senescencia foliar estaría regulada a nivel genético, pero el proceso estaría modulado (¿a nivel post-transcripcional?) por variables fisiológicas.

De acuerdo a lo anterior, es esperable que, como ha sido propuesto por Valentinuz \& Tollenaar (2004), el patrón de senescencia en los nuevos híbridos sea relativamente independiente de la edad de las hojas. Es decir, que existen mecanismos fisiológicos que actúan promoviendo o retrasando la senescencia en las distintas hojas, independientemente de su edad. Entre los mecanismos que podrían actuar a nivel fisiológico, el contenido de clorofila foliar podría influir sobre la tasa de senescencia ya 
que las proteínas, cuando se encuentran asociadas a pigmentos, son más resistentes al ataque por proteasas (Thomas et al., 2002). En el mismo sentido pero variando la escala de análisis, Borrell \& Hammer (2000) reportaron que en sorgo, el contenido de clorofila en antesis se relacionó con el inicio y la tasa de senescencia foliar. Adicionalmente, numerosas evidencias indican que el proceso de degradación de proteínas cloroplásticas ocurre dentro y fuera de los cloroplastos (Martínez et al., 2008). Se ha sugerido que la vía plastídica y extra-plastídica de degradación de componentes cloroplásticos permitiría a las hojas senescentes ajustar la capacidad de intercepción lumínica y la eficiencia de carboxilación a las condiciones ambientales (Martínez et al., 2008). Por lo tanto, es posible que durante el proceso de degradación de proteínas asociado a la senescencia, las condiciones ambientales modulen el efecto de la señal inicial de senescencia. La existencia de variabilidad genotípica en la capacidad para percibir y modular las señales ambientales podría redundar en la plasticidad observada para el carácter SG.

Un aspecto que podría reflejar diferencias subyacentes en la respuesta de la senescencia foliar al ambiente es el patrón de avance de la senescencia dentro de la hoja (Fig. 1). A lo largo de los ensayos realizados, se detectó variabilidad genotípica para esta característica. En general, la senescencia procede desde los bordes hacia la nervadura media (Fig. 1A); sin embargo, en los genotipos SG es común encontrar que la senescencia proceda en sentido inverso, i.e., desde la nervadura central hacia los bordes (Fig. 1B). Es interesante indagar si este patrón espacial diferencial se relaciona con el carácter SG y con su plasticidad.

Ampliar la variedad de tratamientos inductores de la senescencia con los que se desafía a los distintos genotipos puede ser una primera aproximación para mejorar la comprensión de la plasticidad en la expresión del carácter SG. Entre los tratamientos que podrían ensayarse, y que complementarían los datos obtenidos en esta tesis, figuran la manipulación severa de la relación fuente/destino (v.g., desfoliación parcial, remoción de la espiga, polinización parcial, etc), exposición a patógenos foliares, incubación en oscuridad continua, etc. 

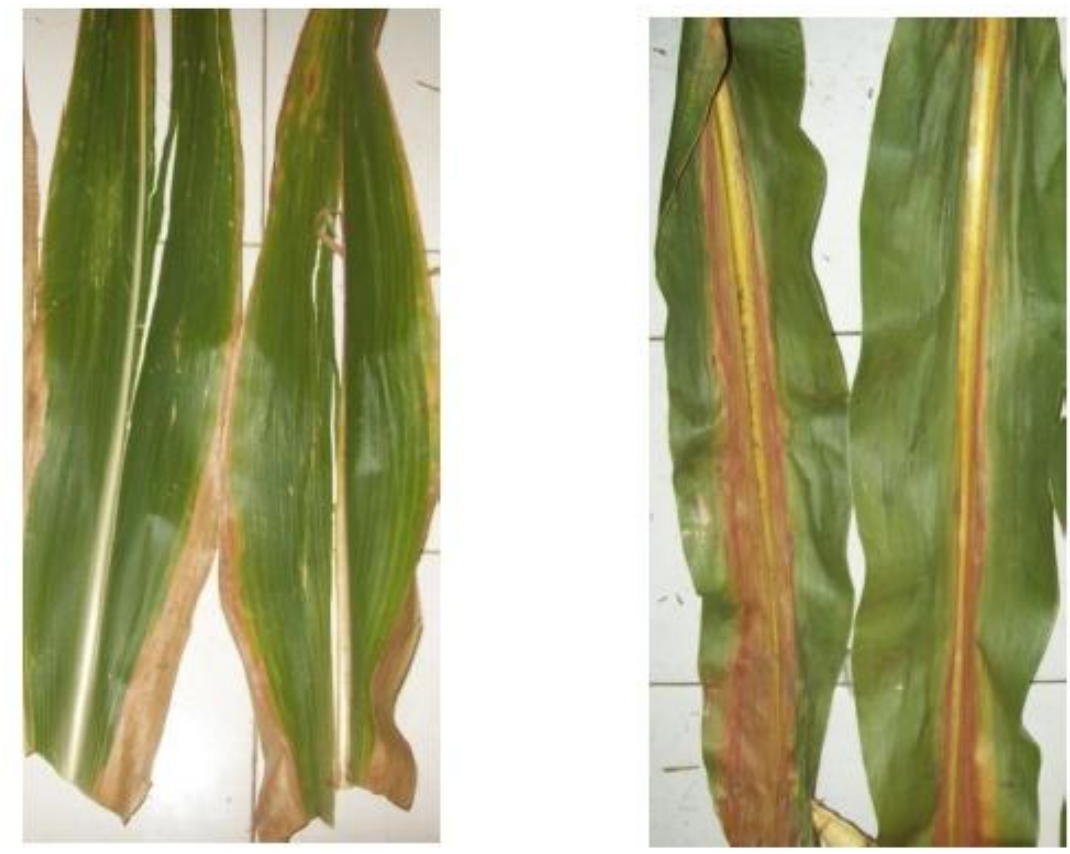

Fig 1: Patrón de senescencia foliar estándar, donde la senescencia progresa desde los bordes hacia la nervadura central (panel izquierdo, la foto corresponde al híbrido NSG DK682); patrón de senescencia encontrado con frecuencia en híbridos SG (panel derecho, la foto corresponde a AX878), donde la senescencia progresa desde la nervadura central hacia los bordes.

\section{Implicancias de la plasticidad del carácter SG sobre el mejoramiento}

En general, el rendimiento de híbrido AX878 (de mayor plasticidad de carácter SG) fue más estable que el del híbrido NK880 (con un carácter SG más "constitutivo"). Desde el punto de vista del mejoramiento esto complejiza la selección de genotipos, ya que la selección por carácter SG no debería basarse simplemente en la intensidad con la que se manifiesta el fenotipo SG. Existirán ambientes en los que una expresión moderada del fenotipo SG será más ventajosa que una expresión extrema. Unas pocas evidencias sustentan la especulación de que el carácter SG podría estar exacerbado en los híbridos respecto a las líneas. Chapman \& Edmeades (1999) analizaron un conjunto de poblaciones obtenidas a partir de ciclos recurrentes de selección donde el carácter primario de selección fue la tolerancia al estrés hídrico, y entre los caracteres secundarios, se seleccionó la demora en la senescencia. Las poblaciones obtenidas tras los ciclos de selección, mejoraron el rendimiento frente a estrés hídrico pero no presentaron senescencia demorada en relación con las poblaciones originales. Monneveux et al. (2006) obtuvieron similares resultados, y sugieren que, el mayor NG obtenido en las poblaciones mejoradas implica un aumento de la competencia intra- 
planta por N, lo que impediría reducir la tasa de senescencia foliar. Es decir que, tanto en condiciones de sequía donde la absorción de $\mathrm{N}$ esté reducida, como en condiciones de deficiencias de $\mathrm{N}$, el llenado de granos podría estar estimulado por la senescencia foliar, ya que ésta permite la liberación del $\mathrm{N}$ foliar para los granos (Uhart \& Andrade, 1995). Tollenaar et al. (2004) compararon una serie de 12 híbridos y sus líneas parentales; en promedio, la heterosis para el rendimiento fue de un $167 \%$ y para el carácter SG fue de un 90\%. Sin embargo, resulta llamativo que el rango de variación de la heterosis para el carácter SG fue el más amplio de todos los rangos en los caracteres estudiados. La variación de la heterosis para el carácter SG varió en un rango de entre 7 y $575 \%$ (Tollenaar et al., 2004).

Las evidencias mencionadas sugieren que, en los híbridos, la expresión del carácter SG puede exacerbarse más allá de sus potenciales ventajas sobre el rendimiento. En parte, esto puede observarse en los resultados presentados en esta tesis: en los Capítulos 3 y $\mathbf{4}$, el híbrido NK880, con carácter SG más extremo no presentó los mayores rendimientos en el tratamiento de estrés más severo (déficit de $\mathrm{N}$ o alta densidad). En casos donde la duración del llenado se acorte prematuramente por un efecto del estrés, la prolongación del área foliar no representará ventajas en el PG e incluso puede tener efectos negativos. Por lo tanto, complementariamente al estudio de los mecanismos que subyacen a la plasticidad observada para el carácter SG, sería interesante indagar sobre los mecanismos que conducen a la expresión del carácter SG en los híbridos. Algunos avances se han presentado en sorgo. Borrell \& Hammer (2000) analizaron las bases fisiológicas que conducen a la expresión del carácter SG en híbridos de sorgo obtenidos a partir de distintas líneas (i.e., variando la fuente genética del carácter SG) y encontraron diferencias. Aproximaciones similares podrían realizarse en híbridos de maíz. Esto permitiría distinguir líneas donde la fuente del carácter SG conduzca a híbridos SG de alta plasticidad y otras líneas que conduzcan a híbridos SG "constitutivos".

\section{Estudio de posibles desbalances fuente-destino en genotipos SG}

En el rango de ambientes evaluados en los capítulos de esta tesis, los híbridos SG en general presentaron rendimientos superiores al índice ambiental (Fig. 2, 23 valores por encima, 10 por debajo). En cambio, los híbridos caracterizados como NSG, 
presentaron sólo 9 valores de rendimiento por encima del índice ambiental y 22 por debajo (Fig. 2). Esto aporta nuevas evidencias para sostener la idea de que el carácter SG confiere estabilidad en un rango de ambientes, y al mismo tiempo, alto potencial de rendimiento.

Como se describe en cada capítulo, cuando los genotipos SG no presentaron ventajas en rendimiento, esto fue explicado, en la mayoría de los casos, por un menor PG. La mayor variación del PG en los híbridos SG contrasta con la idea de que el carácter SG confiere estabilidad del rendimiento a través del PG (Bänziger et al., 1999; Borrell \& Hammer, 2000). Esto puede explicarse porque los procesos fisiológicos que limitan el rendimiento varían entre líneas e híbridos (Tollenaar et al., 2004). Por ejemplo, en las líneas los requerimientos de $\mathrm{N}$ del grano son menores (Seebauer et al., 2010) y entonces posiblemente las restricciones de $\mathrm{N}$ en los destinos sean menos frecuentes. A esto se suma una posible exacerbación del carácter SG en los híbridos, como se discute en la sección anterior.

Las evidencias presentadas a lo largo de los capítulos sugieren que las deficiencias de $\mathrm{N}$ en los granos pueden afectar directamente el PG final, y entonces, el rendimiento. Cuando no existe disponibilidad de $\mathrm{N}$ edáfico en post-floración, los híbridos SG podrían experimentar mayores limitaciones de $\mathrm{N}$ en los granos. Esto se fundamenta en la menor capacidad de removilizar $\mathrm{N}$ foliar asociada al carácter SG, especialmente en estadíos iniciales del llenado, e independientemente del $\mathrm{N}$ absorbido antes de floración. En estas situaciones, la mayor asimilación neta producto de la retención de AFV durante el llenado no representaría ninguna ventaja en términos de rendimiento, ya que estaría acompañada de una menor partición a espiga. Es decir, existiría un exceso de fuente en términos de $C$ pero un déficit de fuente en términos de N.

Es esperable que genotipos con un carácter SG de tipo "constitutivo" (como NK880) no representen ventajas en rendimiento, especialmente cuando el crecimiento de los granos requiera de la inducción de la senescencia. Situaciones como ésta se presentarían en canopeos densos donde la inducción de senescencia por sombreo puede mejorar el balance de C. Una situación similar (i.e., ventaja de una moderada inducción de la senescencia) podría ocurrir también en situaciones de deficiencias de $\mathrm{N}$ edáfico en post-floración, donde es necesaria la inducción de la senescencia al menos 
en las hojas basales, para satisfacer los requerimientos de los granos. También en situaciones de estrés hídrico severo, donde podría ser más provechoso reservar el consumo de agua para las hojas más iluminadas (del estrato central y superior) e inducir la senescencia de hojas menos eficientes fotosintéticamente (del estrato basal).

Distintas evidencias presentadas a lo largo de esta tesis sugieren que, al menos en los híbridos SG, la removilización del N foliar presentaría una importante regulación por la fuente. Por lo tanto, resulta de interés profundizar el estudio de mecanismos subyacentes a la relación fuente-destino que actúen regulando la removilización del $\mathrm{N}$ foliar. Además, es interesante profundizar el estudio de las restricciones de $\mathrm{N}$ en los granos, para conocer si los granos de híbridos SG experimentan mayores limitaciones de $\mathrm{N}$ en comparación con híbridos NSG, cuando no existe disponibilidad de $\mathrm{N}$ edáfico en post-floración. En este tipo de estudios sería necesario continuar explorando diversas fuentes y niveles de estrés. Una aproximación al estudio de las restricciones de $\mathrm{N}$ en los destinos podría realizarse en hidroponía, variando la oferta de $\mathrm{N}$ durante el período de determinación del PG potencial.

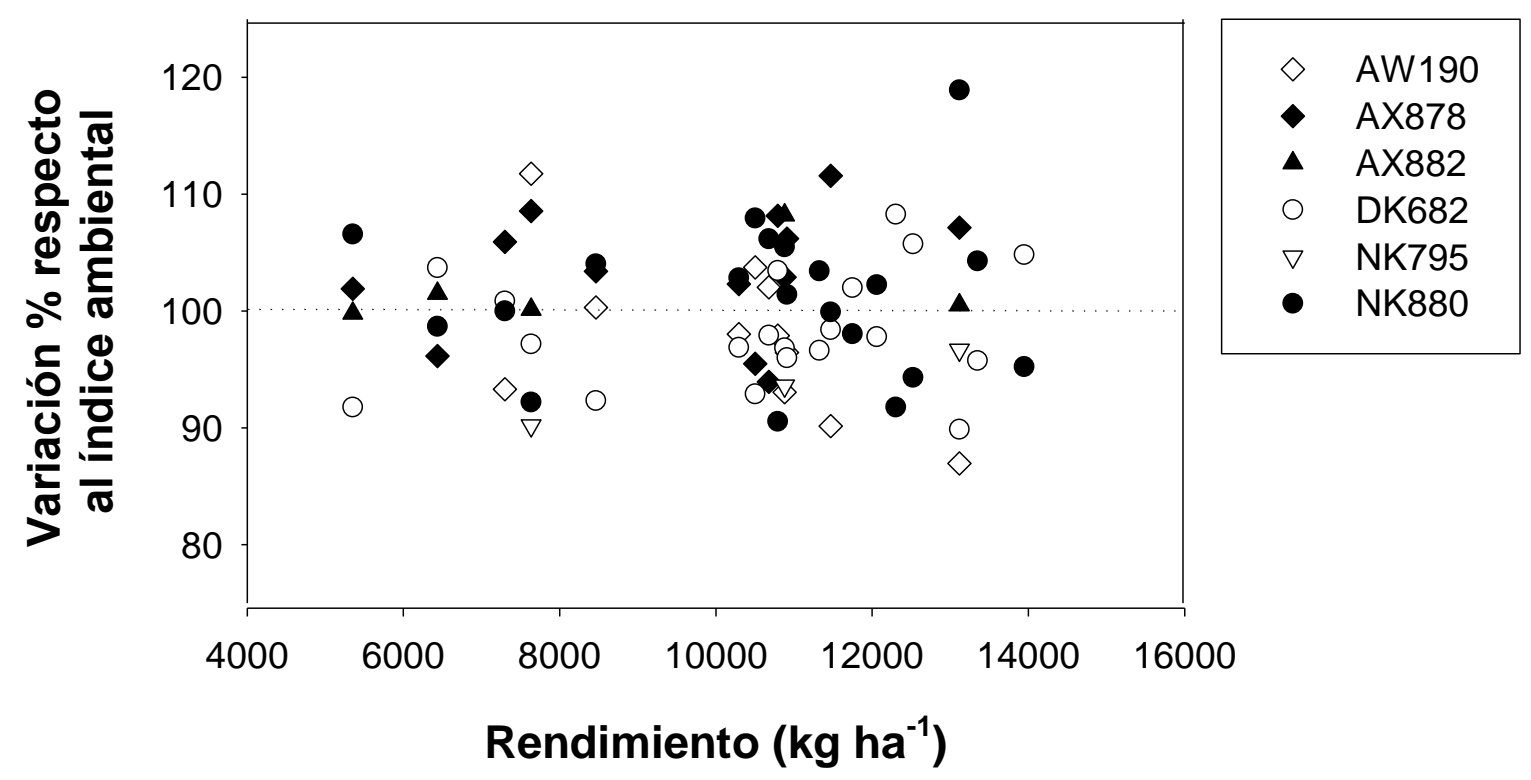

Fig. 2: Variación porcentual del rendimiento en función del índice ambiental, en el rango de ambientes evaluados en los Capítulos 2, 3 y 4. 


\section{Relación entre el carácter SG y el sistema radical}

Distintas evidencias sugieren que los genotipos SG presentarían mayor actividad de raíces en post-floración (Ambler et al., 1992; He et al., 2003). Esto se relaciona de forma directa con el consumo de agua y nutrientes durante esta etapa (Borrell et al., 2000b; He et al., 2003; Ma \& Dwyer, 1998; Martin et al., 2005). Diferencias en la actividad del sistema radical son de sumo interés ya que se relacionan directamente con el uso de insumos (eficiencia, tasa de consumo y capacidad de consumo). La prolongación de la actividad radical en post-floración puede resultar ventajosa ya que permitiría mantener el suministro de agua y nutrientes a los órganos vegetativos y reproductivos. Los resultados de esta tesis sugieren que, al menos en relación con la absorción de $\mathrm{N}$ en post-floración (Capítulo 4), los híbridos SG no necesariamente muestran una mayor actividad radical en post-antesis.

Sería de especial interés estudiar la actividad y supervivencia del sistema radical en distintos contextos. Por ejemplo, en ambientes expuestos a sequía en postfloración podrían ser deseables genotipos con una baja tasa de consumo de agua que no agoten rápidamente la reserva hídrica del suelo. Es decir, que presenten un consumo bajo o moderado de agua, para prolongar la disponibilidad hídrica en el tiempo. Especialmente considerando que el consumo de agua suele asociarse inversamente con la eficiencia instantánea en el uso del agua (Blum, 2009). En este sentido, no existen estudios donde se analice si el carácter SG se asocia a mayor tasa de consumo de agua, mayor duración del período de consumo de agua, mayor eficiencia instantánea del uso del agua, etc.

Considerando lo anterior, resultaría interesante analizar diferencias en la actividad del sistema radical entre genotipos contrastantes para el carácter SG. Para ello, diversas aproximaciones son válidas, entras las que podrían incluirse: (i) estudiar variaciones en el contenido de agua y $\mathrm{N}$ edáfico durante post-floración; (ii) muestreos de biomasa de raíces; (iii) imágenes digitales del sistema radical; (iv) aproximaciones bioquímicas relacionadas a la identificación y análisis de actividad de enzimas relacionadas a la absorción de nutrientes desde el suelo. Algunos de estos experimentos (v.g., estudios de la absorción de nutrientes) podrían ser realizados más fácilmente en cultivos hidropónicos. 


\section{Respiración y susceptibilidad a las bajas temperaturas}

Diferentes evidencias sugieren mayores costos respiratorios asociadas al carácter SG, que podrían resultar de: (i) la inhibición de la fotosíntesis por acumulación de azúcares en hojas asociada a una menor partición de carbohidratos a la espiga; (ii) baja inducción de la senescencia por sombreo (retención de hojas basales del canopeo con balance neutro o negativo de C); (iii) mayores costos de mantenimiento de las estructuras vegetativas y reproductivas.

(i) En el Capítulo 3 se evidenció una pérdida neta de MS en los genotipos SG, especialmente en el tratamiento con déficit de N. Es posible especular que estas pérdidas estén, en parte, asociadas a una menor tasa de exportación de asimilados desde las hojas hacia los granos, por restricciones de los granos (menor PG potencial) en la capacidad de utilizar los asimilados disponibles. En este caso, el mayor costo respiratorio en los híbridos SG estaría asociado a la inhibición de la fotosíntesis e incremento de la respiración neta, por acumulación de azúcares en hojas.

(ii) Alternativamente, en el Capítulo 4, se evidencia que la respiración de las hojas basales del híbrido SG persiste a lo largo del llenado, aún cuando estas hojas están expuestas a irradiancias prácticamente por debajo del punto de compensación lumínico. Esto sugiere una baja capacidad de ajuste de la respiración (que en los genotipos NSG ocurre también por inducción de la senescencia) en hojas que no presentan un aporte positivo al balance de C. A esta evidencia se suma un experimento no presentado en esta tesis, donde plantas de los híbridos SG (NK880) y NSG (DK682) fueron sombreadas completamente a los 30 días después de floración en condiciones de campo, atenuando en un $80 \%$ el PAR incidente; las pérdidas netas de MS a cosecha en el híbrido SG fueron el doble de las registradas en el híbrido NSG (30 vs. 15 g por planta respectivamente).

(iii) Un tercer aspecto que sustenta la idea de mayores costos espiratorios en genotipos SG se relaciona a la composición de los tejidos. En el Capítulo 5 se muestra que los híbridos SG presentan mayor contenido 
de proteínas foliares que los genotipos estándar, especialmente a partir de estadíos intermedios del llenado, algo que incrementa el costo de mantenimiento (Mc Cree et al., 1983). Además, a cosecha, los tallos de los genotipos SG permanecen con alto contenido de humedad, y probablemente de carbohidratos (He et al., 2001; Fig. 3B), lo que incrementaría las pérdidas respiratorias. Otro aspecto que merece atención es el mayor contenido de humedad en los granos a madurez fisiológica asociado al carácter SG, que podría estar asociado a mayores tasas respiratorias de los granos.

Considerando estas evidencias, analizar las pérdidas respiratorias hacia el final del llenado y su posible exacerbación en genotipos SG resultaría de suma importancia. Especialmente considerando que en contextos productivos de clima templado, estas pérdidas podrían exacerbarse debido a la común ocurrencia de temperaturas mínimas inferiores a $10^{\circ} \mathrm{C}$ en los estadíos finales del llenado. Como se muestra en el Capítulo 3 , estas pérdidas podrían tener un impacto directo sobre el crecimiento de los granos, y entonces, sobre el rendimiento.

Aproximaciones para el estudio de los costos respiratorios en híbridos SG podrían incluir ensayos variando la oferta de $\mathrm{N}$ donde se analice el contenido de carbohidratos solubles en hojas, la tasa fotosintética y el crecimiento de la espiga como una estimación de la tasa de transporte de asimilados a la espiga. También sería interesante cuantificar la tasa respiratoria de los granos, especialmente en estadíos intermedios y finales del llenado. Por otro lado, sería interesante analizar las pérdidas respiratorias en una serie de genotipos en distintas regiones de producción del cultivo (i.e., variando las temperaturas mínimas hacia el final del llenado en condiciones de campo). 


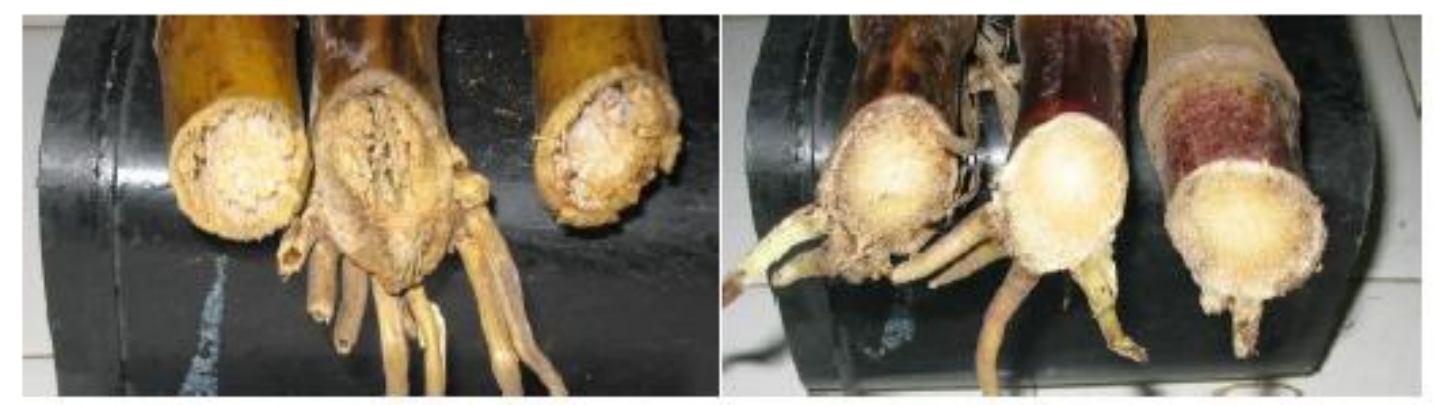

Fig. 3: Imágenes de la porción basal de cañas a cosecha, en híbridos NSG ( $A$, la foto corresponde a DK682) y híbridos SG (B, la foto corresponde a NK880).

\section{Balance hormonal en genotipos SG}

Son pocos los trabajos que estudiaron el balance de hormonas en genotipos SG no transgénicos (Ambler et al., 1992; He et al., 2005a), es decir, donde el fenotipo SG no es el resultado, por ejemplo, del incremento del contenido de citocininas a través de la introducción del gen ipt (v.g., Robson et al., 2004). En estos trabajos con SG no transgénicos se ha encontrado que las raíces de genotipos SG presentan mayor contenido relativo de citocininas y $A B A$, mientras que las hojas presentan mayor contenido de citocininas y menor contenido de ABA (Ambler et al., 1992; He et al., 2005a).

He et al. (2005a) sugieren que el transporte de ABA desde raíces a tallos estaría parcialmente bloqueado en genotipos SG. Un aumento del contenido de ABA en raíces podría ser ventajoso en condiciones de estrés hídrico. En las raíces, el ABA actua en la inhibición del crecimiento de las raíces laterales bajo estrés hídrico (Xiong et al., 2006). De esta forma, los asimilados particionados a raíces serían preferentemente destinados al crecimiento en profundidad (donde es esperable que exista mayor disponibilidad de agua en condiciones de sequía) (Xiong et al., 2006).

Con respecto a la biomasa aérea, algunas evidencias halladas en esta tesis aportan a la idea de menor contenido de ABA en genotipos SG. En el Capítulo 2, se evidenció una mayor conductancia estomática en los genotipos SG bajo condiciones de estrés hídrico, algo que estaría relacionado a bajos niveles de $A B A$ en el xilema (Tardieu et al., 1992). También hemos encontrado a lo largo de todos los experimentos, mayor contenido de humedad en granos a cosecha (datos no mostrados) e incluso germinación de granos en algunas espigas de plantas de los 
genotipos SG (Fig. 4). Dado que el ABA está involucrado en el secado de los granos (Kermode, 2005), estas evidencias sugieren menores contenidos de ABA en espigas de genotipos SG.

Con respecto a las citocininas, distintos trabajos destacan la importancia de esta hormona en el control de la senescencia (Gan \& Amasino, 1995). Se presume que el control de las citocininas actuaría a nivel transcripcional, i.e., altos niveles de citocininas inhibirían la expresión de ciertos genes asociados a la senescencia (Buchanan-Wollaston, 1997). Un mayor contenido de citocininas, tanto en hojas como en raíces, podría reprimir la señal de inicio de la senescencia en los genotipos SG.

También las giberelinas podrían estar involucradas en la expresión del genotipo SG. A lo largo de los distintos ensayos hemos encontrado con cierta frecuencia, plantas enanas y con granos en la panoja en las parcelas correspondientes a híbridos SG (Fig. 5). Dado que las giberelinas están involucradas en la determinación del sexo (Irish \& Nelson, 1989) esto podría implicar un déficit en la síntesis o una menor sensibilidad a las giberelinas asociada la carácter SG.

Considerando el conjunto de estas evidencias, es posible que el balance hormonal presente diferencias en genotipos SG respecto a genotipos estándar NSG. Sería interesante avanzar en este aspecto, analizando el rol de las distintas hormonas en los genotipos SG. Para ello podrían utilizarse aproximaciones descriptivas, como ser la medición del contenido de hormonas en distintos estadíos del ciclo. Complementariamente podrían realizarse tratamientos de aplicaciones de hormonas en distintos estadíos y órganos (por ej. en estadío de plántula o en granos in vitro) para analizar posibles diferencias en la sensibilidad a las distintas hormonas. 


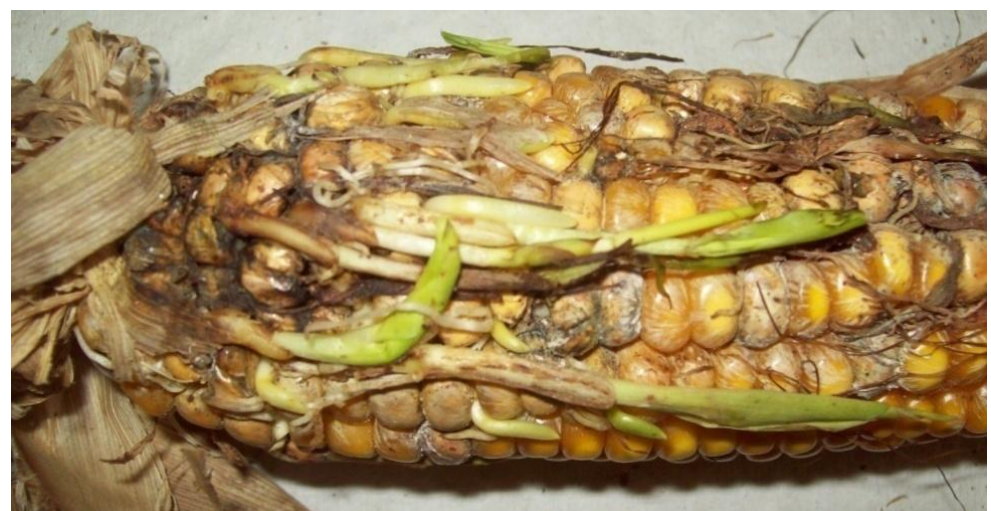

Fig. 4: Germinación de granos en espigas de genotipos SG a cosecha (la foto corresponde al híbrido SG NK880).

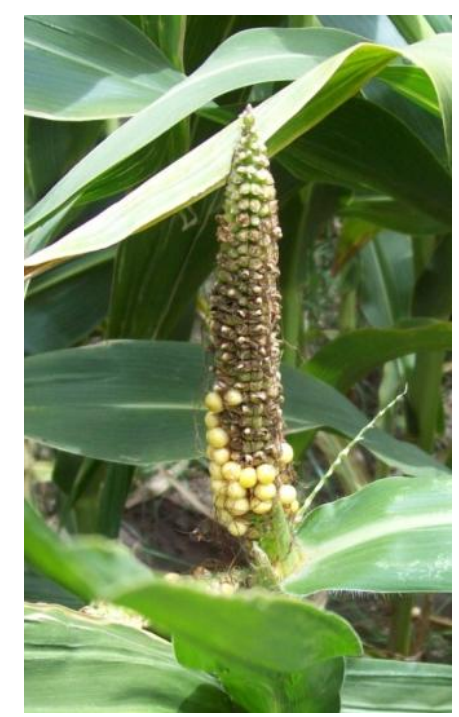

Fig. 5: Granos en panoja en genotipos SG (la foto corresponde a NK880).

\section{Conclusión general}

La demora en la senescencia foliar es una de las variables fisiológicas que más ha cambiado como resultado del mejoramiento (Duvick, 2005; Tollenaar \& Wu, 1999) y es posible que esta tendencia continúe en el futuro. Según Lee \& Tollenaar (2007) es fundamental que durante el proceso de mejoramiento exista un balance entre fuente $y$ destino. Un desbalance entre fuente y destino actúa en detrimento del rendimiento y reduce la eficiencia en el uso de insumos. A partir de los resultados obtenidos en los distintos experimentos, puede decirse que las ventajas del carácter SG sobre el rendimiento, al menos en los genotipos con mayor plasticidad (v.g., AX878), parecen auspiciosas. Sin embargo, genotipos con un carácter SG exacerbado (v.g., NK880) 
advierten sobre las limitaciones que pueden emerger de continuar aumentando la capacidad de la fuente a través del carácter SG. Es decir que, la contribución del carácter SG a la estabilidad del rendimiento depende de la capacidad que presenten los genotipos SG para ajustar la expresión del carácter en función del ambiente (por ejemplo, induciendo la senescencia en respuesta al sombreo, o por deficiencias de $\mathrm{N}$ edáfico).

Por otro lado, esta tesis también deja en evidencia la importancia de contextualizar el desempeño de distintos genotipos en un amplio rango de ambientes y estrategias de manejo. Como ya se ha mencionado en el transcurso de esta tesis, habitualmente los productores pueden enfrentar ambientes con estrés más severo que el que suelen presentar los ambientes donde se realiza el mejoramiento de genotipos. En este sentido, es esperable que las líneas de investigación y los criterios para realizar el mejoramiento de genotipos en el sector privado estén regidos por la rentabilidad empresarial, y que no necesariamente coincidirán con los criterios definidos en función de un desarrollo sustentable entendido desde un enfoque interdisciplinario.

El desafío de duplicar la producción de alimentos entre el 2000 y el 2050, en una agricultura que ha sido subsidiada por la energía fósil durante los últimos 200 años, en un mundo donde el deterioro ambiental avanza a ritmo acelerado, y considerando además los efectos del cambio climático, es un desafío enorme. Para encarar este desafío, no será suficiente con delegar el mejoramiento vegetal enteramente al sector privado. Este debate convoca de manera urgente e indelegable a las instituciones estatales, que deberán pensar criterios de desarrollo científico y tecnológico que estén de acuerdo con un desarrollo sustentable. 


\section{BIBLIOGRAFÍA}

Acciaresi H., Videla L., Chidichimo H., Guiamet J. (2005) Actas del VIII Congreso Nacional de Maíz 32-35.

Ambler J.R., Morgan P.W., Jordan W.R. (1992) Amounts of zeatin and zeatin riboside in xylem sap of senscent and nonsenescent sorghum. Crop Science 32:411-419.

Andrade F.H. (2011) La tecnología y la producción agrícola. El pasado y los actuales desafíos. Ediciones INTA.

Andrade F.H., Otegui M.E., Vega C. (2000) Intercepted radiation at flowering and kernel number in maize. Agronomy Journal 92:92-97.

Andrade F.H., Sadras V. (2000) Bases para el manejo del maíz, el girasol y la soja. Ed. Médica Panamericana.

Bänziger M., Edmeades G.O., Lafitte H.R. (1999) Selection for drought tolerance increases maize yields across a range of nitrogen levels. Crop Science 39:10351040.

Bänziger M., Edmeades G.O., Lafitte H.R. (2002). Physiological mechanisms contributing to the increased $\mathrm{N}$ stress tolerance of tropical maize selected for drought tolerance. Field Crops Research 75:223-233.

Bänziger M., Setimela P.S., Hodson D., Vivek B. (2006) Breeding for improved abiotic stress tolerance in maize adapted to southern Africa. Agricultural Water Management 80:212-224.

Below F.E., Christensen L.E., Reed A.J., Hageman R.H. (1981) Availability of reduced N and carbohydrates for ear development of maize. Plant Physiology 68:11861190.

Below F., Cazetta J., Seebauer J. (2000) Carbon/nitrogen interactions during ear and kernel development of maize. In Physiology and Modeling Kernel Set in Maize. Crop Science Society of America and American Society of Agronomy special publication number 29.

Blum A. (2009) Effective use of water EUW and not water-use efficiency WUE is the target of crop yield improvement under drought stress. Field Crops Research 112:119-23. 
Boonman A., Anten N.P., Dueck T.A., Jordi W.J., van der Werf A., Voesenek L.A., Pons T.L. (2006) Functional significance of shade-induced leaf senescence in dense canopies: an experimental test using transgenic tobacco. The American naturalist 168: 597-607.

Borras L., Otegui M.E. (2001) Maize kernel weight response to post-flowering sourceSink Ratio. Crop Science 41:1816.

Borrás L., Curá J.A., Otegui M.E. (2002) Maize kernel composition and post-flowering source-sink ratio. Crop Science 42:781.

Borrás L., Maddonni G.A., Otegui M.E. (2003) Leaf senescence in maize hybrids: plant population, row spacing and kernel set effects. Field Crops Research 82:13-26.

Borrás L., Slafer G.A., Otegui M.E. (2004) Seed dry weight response to source-sink manipulations in wheat, maize and soybean: a quantitative reappraisal. Field Crops Research 86:131-146.

Borrell A.K., Hammer G.L. (2000) Nitrogen dynamics and the physiological basis of staygreen in sorghum. Crop Science 40:1295-1307.

Borrell A.K., Hammer G.L., Douglas A.C.L. (2000a) Does maintaining green leaf area in sorghum improve yield under drought? I. Leaf growth and senescence. Crop Science 40:1026-1037.

Borrell A.K., Hammer G.L., Henzell R.G. (2000b) Does maintaining green leaf area in sorghum improve yield under drought? II. Dry matter production and yield. Crop Science 40:1037-1048.

Bossio D., Geheb K., Critchley W. (2010) Managing water by managing land: Addressing land degradation to improve water productivity and rural livelihoods. Agricultural Water Management 97:536-542.

Bringezu S., O'Brien M., Pengue W., Swilling M., Kauppi L. (2010) Assessing global land use and soil management for sustainable resource policies. Scoping Paper. International Panel for Sustainable Resource Management. UNEP.

Bruinsma J. (2009) The Resource Outlook to 2050: By how much do land, water, and crop yields need to increase by 2050? Paper presented at the FAO Expert Meeting, 24-26 June.

Buchanan-Wollaston V. (1997) The molecular biology of leaf senescence. Journal of Experimental Botany 48:181-199. 
Casas R.R. (2001) La conservación de los suelos y la sustentabilidad de los sistemas agrícolas. Academia nacional de Agronomía y Veterinaria. Tomo LV; Buenos Aires.

Cazetta J.O., Seebauer J.R., Below F.E. (1999) Sucrose and nitrogen supplies regulate growth of maize kernels. Annals of Botany 84:747-754.

Ceppi D., Sala M., Gentinetta E., Verderio A., Motto M. (1987) Genotype dependent leaf senescence in maize. Plant Physiology 85:720-725.

Chapman S.C., Edmeades G.O. (1999) Selection improves drought tolerance in tropical maize populations: II. Direct and correlated responses among secondary traits. Crop Science 39:1315-1324.

Christensen L.E., Below F.E., Hageman R.H. (1981) The effects of ear removal on senescence and metabolism of maize. Plant Physiology 68:1180-5.

Ciampitti I.A., Vyn T.J. (2012) Physiological perspectives of changes over time in maize yield dependency on nitrogen uptake and associated nitrogen efficiencies: A review. Field Crops Research 133:48-67.

CIMMYT (2009) Annual Report 2008-2009 Farming for our grandchildren's future. Maize and wheat agriculture and changing climates in developing countries. http://www.cimmyt.org.

Cirilo A.G., Dardanelli J., Balzarini M., Andrade F.H., Cantarero M., Luque S., Pedrol H.M. (2009) Morpho-physiological traits associated with maize crop adaptations to environments differing in nitrogen availability. Field Crops Research 113:116-124.

Cliquet J.-B., Deléens E., Mariotti A. (1990) C and N Mobilization from stalk and leaves during kernel filling by $13 \mathrm{C}$ and $15 \mathrm{~N}$ tracing in Zea mays L. Plant Physiology 94:1547-1553.

Coque M., Gallais A. (2007) Genetic variation for nitrogen remobilization and postsilking nitrogen uptake in maize recombinant inbred lines: heritabilities and correlations among traits. Crop Science 47:1787-1796.

Cruzate G., Casas R. (2009) Extracción de nutrientes en la agricultura argentina. Informaciones agronómicas del cono sur. 44:21-26.

da Silva J.M., Arrabacxa M.C. (2004) Contributions of soluble carbohydrates to the osmotic adjustment in the C4 grass Setaria sphacelata: a comparison between 
rapidly and slowly imposed water stress. Journal of Plant Physiology 161:551555.

de la Vega A.J., Cantore M.A., Sposaro M.M., Trápani N., López Pereira M., Hall A.J. (2011) Canopy stay-green and yield in non-stressed sunflower. Field Crops Research 121:175-185.

Ding L., Wang K.J., Jiang G.M., Liu M.Z., Niu S.L., Gao L.M. (2005) Post-anthesis changes in photosynthetic traits of maize hybrids released in different years. Field Crops Research 93:108-115.

Doehlert D.C., Min Kuo T, Felker F.C. (1988) Enzymes of sucrose and hexose metabolism in developing kernels of two inbreds of maize. Plant Physiology 86:1013-1019.

Duncan R.R., Bockholt A.J., Miller F.R. (1981) Descriptive comparison of senescent and nonsenescent sorghum genotypes. Agronomy Journal 73:849-853.

Duvick D.N. (1997) What is yield? In: Edmeades, G.O., et al. Eds., Developing Drought and Low N-tolerant maize CIMMYT, El Batan, Mexico: 332-335.

Duvick D.N. (2005) The contribution of breeding to yield advances in maize Zea mays L., in:L. S. Donald Ed., Advances in Agronomy, Academic Press. 83-145.

Duvick D.N., Cassman K.G. (1999) Post-green revolution trends in yield potential of temperate maize in the north-central United States. Crop Science 39:16221630.

Earl H. J., Tollenaar M. (1998) Differences among commercial maize (Zea mays L.) hybrids in respiration rates of mature leaves Field Crops Research 59:9-19

Earl H.J., Tollenaar M. (1999) Using chlorophyll fluorometry to compare photosynthetic performance of commercial maize Zea mays L. hybrids in the field. Field Crops Research 61:201-210.

Earl H.J., Davis R.F. (2003) Effect of drought stress on leaf and whole canopy radiation use efficiency and yield of maize. Agronomy Journal 95:688-696.

Echarte L., Andrade F.H., Sadras V.O., Abbate P. (2006) Kernel weight and its response to source manipulations during grain filling in Argentinean maize hybrids released in different decades. Field Crops Research 96: 307-312. 
Echarte L., Rothstein S., Tollenaar M. (2008) The response of leaf photosynthesis and dry matter accumulation to nitrogen supply in an older and a newer maize hybrid. Crop Sci. 48:656-665.

Edgerton, M.D. (2009) Increasing crop productivity to meet global needs for feed, food and fuel. Plant Physiology 149:7-13.

FAO (2002) World agriculture:Towards 2015/2030. Food and Agriculture Organization of the United Nations Rome.

FAO (2007) La bioenergía y la seguridad alimentaria en América Latina y el Caribe. http://www.fao.org/

FAO (2009) Food and Agriculture Organization of the United Nations, Rome. FAO Statistical database. http://www.fao.org/

Farrar J.F., Jones D.L. (2000) The control of carbon acquisition by roots. New Phytologist 147:43-53.

Fasoula V.A., Fasoula D.A. (2002) Principles underlying genetic improvement for high and stable crop yield potential. Field Crops Research 75, 191-209.

Flexas J., Medrano H. (2002) Drought-inhibition of photosynthesis in C3 plants: stomatal and non-stomatal limitations revisited. Annals of Botany 89:183-189.

Frei O.M. (2000) Changes in yield physiology of corn as a result of breeding in northern Europe. Maydica 45:173-183.

Gallais A., Hirel B. (2004) An approach to the genetics of nitrogen use efficiency in maize. Journal of Experimental Botany 55:295-306.

Gallais A., Coque M. (2005) Genetic variation and selection for nitrogen use efficiency in maize: a synthesis. Maydica 50:531-547.

Gan S., Amasino R.M. (1995) Inhibition of leaf senescence by auto-regulated production of cytokinin. Science 270:1986-1988.

Garay J.A., Veneciano J.H. (2005). La agricultura de cosecha en San Luis. INTA, San Luis. Información Técnica, 170.

Ghannoum O. (2009) $C_{4}$ photosynthesis and water stress. Annals of Botany 103:635644.

Giller K.E., Witter E., Corbeels M., Tittonell P. (2009) Conservation agriculture and small-holder farming in Africa: The heretics' view. Field Crops Research 114:2334. 
Godfray H.C.J., Beddington J.R., Crute I.R., Haddad L., Lawrence D., Muir J.F., Pretty J., Robinson S., Thomas S.M., Toulmin C. (2010) Food Security:The Challenge of Feeding 9 Billion People. Science 327:812-818.

Good A.G., Shrawat A.K., Muench D.G. (2004) Can less yield more? Is reducing nutrient input into the environment compatible with maintaining crop production? Trends in Plant Science 9:597-605.

Guiamét J.J., Teeri J.A., Noodén L.D. (1990) Effects of nuclear and cytoplasmic genes altering chlorophyll loss on gas exchange during monocarpic senescence in Soybean. Plant and Cell Physiology 31:1123-1130.

He P., Jin J., Zhou W. (2001) Effect of nitrogen application on accumulation and translocation of carbon and nitrogen compunds in two maize cultivars with different senescence appearance. Journal of Plant Nutrition. 24:671-681.

He P., Osaki M., Takebe M., Shinano T. (2003) Comparison of whole system of carbon and nitrogen accumulation between two maize hybrids differing in leaf senescence. Photosynthetica 41:399-405.

He P., Zhou W., Jin J. (2005a) Carbon and nitrogen metabolism related to grain formation in two different senescent types of maize. Journal of Plant Nutrition 27:295-311.

He P., Osaki M., Takebe M., Shinano T., Wasaki J. (2005b) Endogenous hormones and expression of senescence-related genes in different senescent types of maize. Journal of Experimental Botany 56:1117-1128.

Hikosaka K. (2005) Leaf canopy as a dynamic system: ecophysiology and optimality in leaf turnover. Annals of Botany 95:521-533.

Hirasawa T., Hsiao T.C. (1999) Some characteristics of reduced leaf photosynthesis at midday in maize growing in the field. Field Crops Research 62:53-62.

Hirel B., Bertin P., Quilleré I., Bourdoncle W., Attagnant C., Dellay C., Gouy A., Cadiou S., Retailliau C., Falque M., Gallais A. (2001) Towards a Better Understanding of the Genetic and Physiological Basis for Nitrogen Use Efficiency in Maize. Plant Physiology 125:1258-1270.

Hirel B., Martin A., Tercé-Laforgue T., Gonzalez-Moro M.-B., Estavillo J. M. (2005) Physiology of maize I: A comprehensive and integrated view of nitrogen metabolism in a $C_{4}$ plant. Physiologia Plantarum 124:167-177. 
Hirel B., Le Gouis J., Ney B., Gallais A. (2007) The challenge of improving nitrogen use efficiency in crop plants: towards a more central role for genetic variability and quantitative genetics within integrated approaches. Journal of Experimental Botany 58:2369-2387.

Hörtensteiner S., Feller U. (2002) Nitrogen metabolism and remobilization during senescence. Journal of Experimental Botany 53:927-937.

INDEC (2002) Censo Nacional Agropecuario, 2002. http://www.indec.gov.ar IINDEC (2008) Censo Nacional Agropecuario, 2008. http://www.indec.gov.ar Instituto Nacional de Tecnología Agropecuaria. http://www.inta.gov.ar IGC (2012) Mercado de Cereales. www.igc.int. IPCC (2007) Climate Change 2007: Synthesis Report. IPCC Plenary XXVII Valencia, Spain, 12-17 November 2007.

Irish E.E., Nelson T. (1989) Sex determination in monoecious and dioecious plants. The Plant Cell 1:737-744.

Jiang G.H., He Y.Q., Xu C.G., Li X.H., Zhang Q. (2004) The genetic basis of stay-green in rice analyzed in a population of doubled haploid lines derived from an indica by japonica cross. Theoretical and Applied Genetics 108:688-698.

Kang S., Shi W., Zhang J. (2000) An improved water-use efficiency for maize grown under regulated deficit irrigation. Field Crops Research 67:207-214.

Kermode A.R. (2005). Role of abscisic acid in seed dormancy. Journal of Plant Growth Regulation 24:319-344.

Kichey T., Hirel B., Heumez E., Dubois F., Le Gouis J. (2007) In winter wheat Triticum aestivum L., post-anthesis nitrogen uptake and remobilization to the grain correlates with agronomic traits and nitrogen physiological markers. Field Crops Research 102:22-32.

Kingston-Smith A.H., Foyer C.H. (2000) Bundle sheath proteins are more sensitive to oxidative damage than those of the mesophyll in maize leaves exposed to paraquat or low temperatures. Journal of Experimental Botany 51:123-130.

Kiniry J.R., Tischler C.R., Rosenthal W.D., Gerik T.J. (1992) Nonstructural carbohydrate utilization by sorghum and maize shaded during grain growth. Crop Science 32:131-37. 
Koch K.E., Wu Y., Xu J. (1996) Sugar and metabolic regulation of genes for sucrose metabolism: potential influence of maize sucrose synthase and soluble invertase responses on carbon partitioning and sugar sensing. Journal of Experimental Botany 47 (Special Issue): 1179-1185.

Laemmli U. (1970) Cleavage of structural proteins during the assembly of the head of bacteriophage $T_{4}$. Nature 227:680-685.

Lal A., Edwards G. (1996) Analysis of inhibition of photosynthesis under water stress in the $\mathrm{C}_{4}$ species Amaranthus cruentus and Zea mays: electron transport, $\mathrm{CO}_{2}$ fixation and carboxylation capacity. Functional Plant Biology 23:403-412.

Lamothe P.J., McCormick P.G. (1972) Influence of acidity on the reaction of ninhydrin with amino acids. Analytical Chemistry 44:821-825.

Lee E.A., Tollenaar M. (2007) Physiological basis of successful breeding strategies for maize grain yield. Crop Science 47:202-215.

Lemaire G., van Oosterom E., Jeuffroy M. H., Gastal F., Massignam A. (2008) Crop species present different qualitative types of response to $\mathrm{N}$ deficiency during their vegetative growth. Field Crops Research 105:253-265.

Lin C.C., Kao C.H. (1996) Disturbed ammonium assimilation is associated with growth inhibition of roots in rice seedlings caused by $\mathrm{NaCl}$. Journal of Plant Growth Regulation 18:233-238. .

Luque S.F., Cirilo A.G., Otegui M.E. (2006). Genetic gains in grain yield and related physiological attributes in Argentine maize hybrids. Field Crops Research 95:383-397.

Ma B.L., Dwyer L.M. (1998) Nitrogen uptake and use of two contrasting maize hybrids differing in leaf senescence. Plant and Soil 199:283-291.

Manschadi A.M., Christopher J., deVoil P., Hammer G.L. (2006) The role of root architectural traits in adaptation of wheat to water-limited environments. Functional Plant Biology formerly Australian Journal of Plant Physiology 33:823.

Martin A., Belastegui-Macadam X., Quilleré I., Floriot M., Valadier M.-H., Pommel B., Andrieu B., Donnison I., Hirel B. (2005). Nitrogen management and senescence in two maize hybrids differing in the persistence of leaf greenness: agronomic, physiological and molecular aspects. New Phytologist 167:483-492. 
Martínez D.E., Costa M.L., Guiamet J.J. (2008) Senescence-associated degradation of chloroplast proteins inside and outside the organelle. Plant Biology 10:15-22.

Masclaux C., Valadier M. H., Brugière N., Morot-Gaudry J. F., Hirel B. (2000) Characterization of the sink/source transition in tobacco (Nicotiana tabacum L.) shoots in relation to nitrogen management and leaf senescence. Planta 211:510-518.

Masclaux-Daubresse C., Reisdorf-Cren M., Orsel M. (2008). Leaf nitrogen remobilization for plant development and grain filling. Plant Biology 10:23-36.

Masclaux-Daubresse C., Daniel-Vedele F., Dechorgnat J., Chardon F., Gaufichon L., Suzuki A. (2010) Nitrogen uptake, assimilation and remobilization in plants: challenges for sustainable and productive agriculture. Annals of Botany 105:1141-1157.

Maxwell K., Johnson G.N. (2000) Chlorophyll fluorescence-a practical guide. Journal of Experimental Botany 51, 659-668.

McCree K.J. (1983) Carbon balance as a function of plant size in sorghum plants. Crop Science 23:1173-1177.

Messmer R., Fracheboud Y., Bänziger M., Stamp P., Ribaut J.M., (2011) Drought stress and tropical maize: QTLs for leaf greenness, plant senescence, and root capacitance. Field Crops Research 125:93-103.

Mi G. Liu J., Chen F. Zhang F. Cui Z., Liu X. (2003) Nitrogen Uptake and Remobilization in Maize Hybrids Differing in Leaf Senescence. Journal of Plant Nutrition 26:237247.

Monneveux P., Sánchez C., Beck D., Edmeades G.O. (2006) Drought tolerance improvement in tropical maize source populations. Crop Science 46:180-191.

Moore S. (1968) Amino Acid Analysis:aqueous dimethyl sulfoxide as solvent for the ninhydrin reaction. Journal of Biological Chemistry 243:6281-6283.

Naidu S.L., Moose S.P., Al-Shoaibi A.K., Raines C.A., Long S.P. (2003) Cold Tolerance of $\mathrm{C}_{4}$ photosynthesis in Miscanthus giganteus:adaptation in amounts and sequence of $\mathrm{C}_{4}$ photosynthetic enzymes. Plant Physiology 132:1688-1697.

Noodén L.D., Guiamét J.J., John I. (1997) Senescence mechanisms. Physiologia Plantarum 101:746-753. 
Ögren E., Öquist G. (1985) Effects of drought on photosynthesis, chlorophyll fluorescence and photoinhibition susceptibility in intact willow leaves. Planta 166:380-388.

Pagano E., Maddonni G.A. (2007) Intra-specific competition in maize: Early established hierarchies differ in plant growth and biomass partitioning to the ear around silking. Field Crops Research 101:306-320.

Palmer A.F.E., Heichel G.H., Musgrave R.B. (1973) Patterns of translocation, respiratory loss, and redistribution of ${ }^{14} \mathrm{C}$ in maize labeled after flowering. Crop Science 13:371-376.

Paponov I.A., Sambo P., Erley G.S., Presterl T., Geiger H.H., Engels C. (2005) Grain yield and kernel weight of two maize genotypes differing in nitrogen use efficiency at various levels of nitrogen and carbohydrate availability during flowering and grain filling. Plant and Soil 272:111-123.

Paul M.J., Foyer C.H. (2001) Sink regulation of photosynthesis. Journal of Experimental Botany 52:1383-400.

Peña Zubiate C.A., Garay. (2003) Agrupamiento de las tierras de San Luis por su aptitud para el cultivo de maíz. INTA San Luis, Información Técnica, 161.

Pierce R.O., Knowles P.F., Phillips D. (1984) Inheritance of delayed leaf senescence in soybean. Crop Science 24:515-517.

Plénet D., Lemaire G. (2000) Relationships between dynamics of nitrogen uptake and dry matter accumulation in maize crops. Determination of critical $\mathrm{N}$ concentration. Plant and Soil 216:65-82.

Pommel B., Gallais A., Coque M., Quilleré I., Hirel B., Prioul J.L., Andrieu B., Floriot M. (2006) Carbon and nitrogen allocation and grain filling in three maize hybrids differing in leaf senescence. European Journal of Agronomy 24:203-211.

Presterl T., Groh S., Landbeck M., Seitz G., Schmidt W., Geiger H.H. (2002) Nitrogen uptake and utilization efficiency of European maize hybrids developed under conditions of low and high nitrogen input. Plant Breeding 121:480-486.

Prochazkova D., Sairam R.K., Srivastava G.C., Singh D.V. (2001). Oxidative stress and antioxidant activity as the basis of senescence in maize leaves. Plant Science 161:765-771. 
Rajcan I., Tollenaar M. (1999a) Source-sink ratio and leaf senescence in maize: I. Dry matter accumulation and partitioning during grain filling. Field Crops Research $60: 245-253$.

Rajcan I., Tollenaar M. (1999b) Source-sink ratio and leaf senescence in maize: II. Nitrogen metabolism during grain filling. Field Crops Research 60:255-265.

Rajcan I., Dwyer L.M., Tollenaar M. (1999) Note on relationship between leaf soluble carbohydrate and chlorophyll concentrations in maize during leaf senescence. Field Crops Research 63:13-17.

Reed A.J., Below F.E., Hageman R.H. (1980) Grain protein accumulation and the relationship between leaf nitrate reductase and protease activities during grain development in maize Zea mays L. Plant Physiology 66:164-170.

Ribaut J. M., Monneveux P., Glaszman J. C., Leung H., Hintum T.V., Vicente C. (2008) Drought tolerance in maize. International Programs and the Use of Modern Biotechnologies for Crop Improvement. New York. pp. 21-61.

Richards R.A. (2000). Selectable traits to increase crop photosynthesis and yield of grain crops. Journal of Experimental Botany 51:447-458.

Richards R.A. (2006) Physiological traits used in the breeding of new cultivars for water-scarce environments. Agricultural Water Management 80:197-211.

Rijsberman F.R. (2006) Water scarcity: Fact or fiction? Agricultural Water Management 80:5-22.

Ripley B.S., Gilbert M.E., Ibrahim D.G., Osborne C.P. (2007) Drought constraints on $C_{4}$ photosynthesis: stomatal and metabolic limitations in $C_{3}$ and $C_{4}$ subspecies of Alloteropsis semialata. Journal of Experimental Botany 58:1351-1363.

Ritchie J.T., NeSmith D.S. (1991) Temperature and crop development. In: Hanks, J., Ritchie, J.T. Eds., Modelling Plant and Soil Systems, Agronomy Series 31. American Society of Agriculture Crop Science Society of America, Soil Science Society of America. Madison, pp. 5-29.

Robson P.R.H., Donnison I.S., Wang K., Frame B., Pegg S.E., Thomas A., Thomas H. (2004) Leaf senescence is delayed in maize expressing the Agrobacterium IPT gene under the control of a novel maize senescence-enhanced promoter. Plant Biotechnology Journal 2:101-112. 
Rosen H. (1957) A modified ninhydrin colorimetric analysis for amino acids. Archives of Biochemistry and Biophysisc 67:10-15.

Rossini M.A., Maddonni G.A., Otegui M.E. (2011) Inter-plant competition for resources in maize crops grown under contrasting nitrogen supply and density: Variability in plant and ear growth. Field Crops Research 121:373-380.

Rousseaux M.C., Hall A.J., Sánchez R.A. (1996) Far-red enrichment and photosynthetically active radiation level influence leaf senescence in fieldgrown sunflower. Physiologia Plantarum 96: 217-224.

Rousseaux M.C., Hall A.J., Sanchez R.A. (2000) Basal leaf senescence in a sunflower (Helianthus annuus) canopy: responses to increased R/FR ratio. Physiologia Plantarum 110: 477-482.

Sadras V.O., Echarte L., Andrade F.H. (2000) Profiles of leaf senescence during reproductive growth of sunflower and maize. Annals of Botany 85:187-195.

Sage R., Pearcy R., Seemann J. (1987) The nitrogen use efficiency of $C_{3}$ and $C_{4}$ plants. Plant Physiology 85:355-359.

Schjoerring J.K., Kyllingsbaek A., Mortensen J.V., Byskov-Nielsen S. (1993) Field investigations of ammonia exchange between barley plants and the atmosphere. II. Nitrogen reallocation, free ammonium content and activities of ammonium-assimilating enzymes in different leaves. Plant, Cell and Environment 16:169-178.

Seebauer J.R., Singletary G.W., Krumpelman P.M., Ruffo M.L., Below F.E. (2010) Relationship of source and sink in determining kernel composition of maize. Journal of Experimental Botany 61:511-519.

Senigagliesi C. (1991) Estado actual y manejo de los recursos naturales, particularmente el suelo, en el sector norte de la Pampa Húmeda. Seminario Juicio a nuestra agricultura. INTA. De. Hemisferio Sur. Pag:29-51.

Servicio Meteorológico Nacional. http://www.smn.gov.ar

Sistema Integrado de Información Agropecuaria (SIIA) (2010). http://www.siia.gov.ar/

Spano G., Di Fonzo N., Perrotta C., Platani C., Ronga G., Lawlor D.W., Napier J.A., Shewry P.R. (2003) Physiological characterization of 'stay green' mutants in durum wheat. Journal of Experimental Botany 54:1415-1420. 
Subedi K.D., Ma B.L. (2005) Nitrogen uptake and partitioning in stay-green and leafy maize hybrids. Crop Science 45:740-747.

Sugiyama T., Masuhiko M., Masanori H. (1984) Partitioning of nitrogen among ribulose-1,5-bisphosphate carboxylase/oxygenase, phosphoenolpyruvate carboxylase, and pyruvate orthophosphate dikinase as related to biomass productivity in maize seedlings. Plant Physiology 75:665-669.

Ta C.T., Weiland R.T. (1992) Nitrogen partitioning in maize during ear development. Crop Science 32:443-451.

Tardieu F., Zhang J., Katerji N., Bethenod O., Palmer S., Davies W.J. (1992) Xylem ABA controls the stomatal conductance of field-grown maize subjected to soil compaction or soil drying. Plant, Cell and Environment 15:193-197.

Tardieu F., Davies W.J. (1992) Stomatal response to ABA is a function of current plant water status. Plant Physiology $98 \mathrm{XXX:XXX.}$

Tenhunen J.D., Lange O.L., Gebel J., Beyschlag W., Weber J.A. (1984). Changes in photosynthetic capacity, carboxylation efficiency, and CO2 compensation point associated with midday stomatal closure and midday depression of net $\mathrm{CO} 2$ exchange of leaves of Quercus suber. Planta 162:193-203.

Tezara W., Mitchell V., Driscoll S.P., Lawlor D.W. (2002) Effects of water deficit and its interaction with $\mathrm{CO} 2$ supply on the biochemistry and physiology of photosynthesis in sunflower. Journal of Experimental Botany 53:1781-1791.

Thomas H., Howarth C.J. (2000) Five ways to stay green. Journal of Experimental Botany 51:329-337.

Thomas H., Thomas H.M., Ougham H. (2000) Annuality, perenniality and cell death. Journal of Experimental Botany 51:1781-1788.

Thomas H., Ougham H., Canter P., Donnison I. (2002) What stay-green mutants tell us about nitrogen remobilization in leaf senescence. Journal of Experimental Botany 53:801-808.

Tokatlidis I.S., Koutroubas S.D. (2004) A review of maize hybrids' dependence on high plant populations and its implications for crop yield stability. Field Crops Research 88:103-114. 
Tokatlidis I.S., Has V., Melidis V., Has I., Mylonas I., Evgenidis G., Copandean A., Ninou E., Fasoula V.A. (2011) Maize hybrids less dependent on high plant densities improve resource-use efficiency in rainfed and irrigated conditions. Field Crops Research 120:345-351.

Tollenaar M., Wu J. (1999) Yield Improvement in temperate maize is attributable to greater stress tolerance. Crop Science 39:1597-1604.

Tollenaar M., Lee E.A. (2002) Yield potential, yield stability and stress tolerance in maize. Field Crops Research 75:161-169.

Tollenaar M., Ahmadzadeh A., Lee E.A. (2004) Physiological basis of heterosis for grain yield in maize. Crop Science 44:2086-2094.

Tollenaar M., Deen W., Echarte L., Liu W. (2006) Effect of crowding stress on dry matter accumulation and harvest index in maize. Agronomy Journal 98:930937.

Tsai C.Y., Huber D.M., Warren H.L. (1978) Relationship of the kernel sink for N to maize productivity. Crop Science 18:399-404.

Uauy C., Distelfeld A., Fahima T., Blechl A., Dubcovsky J. (2006) A NAC Gene Regulating senescence improves grain protein, zinc, and iron content in wheat. Science 314:1298-1301.

Uhart S.A., Andrade F.H. (1995a) Nitrogen deficiency in maize:I. effects on crop growth, development, dry matter partitioning, and kernel set. Crop Science 35:13761383.

Uhart S.A., Andrade F.H. (1995b) Nitrogen deficiency in maize: II. Carbon-Nitrogen interaction effects on kernel number and grain yield. Crop Science 35:13841389.

UN (2008). United Nations Population division. World population prospects. The 2008 revision. http://www.un.org/esa/population/

USDA (2010). Feed grains database. Economic Research Service. http://www.ers.usda.gov/

Vadez, V., Krishnamurthy, L., Hash, C.T., Upadhyaya, H.D., Borrell, A.K. (2011) Yield, transpiration efficiency, and water-use variations and their interrelationships in the sorghum reference collection. Crop and Pasture Science 62:645-655. 
Valentinuz O.R., Tollenaar M. (2004) Vertical profile of leaf senescence during the grain-filling period In older and newer maize hybrids. Crop Science 44:827-834.

van Oosterom, E.J., Jayachandran, R., Bidinger, F.R. (1996) Diallel analysis of the staygreen trait and its components in sorghum. Crop Science 36:549-555.

Wang R.L., Stec A., Hey J., Lukens L., Doebley J. (1999) The limits of selection during maize domestication. Nature 398:236-239.

Xiong L., Wang R., Mao G., Koczan J.M. (2006) Identification of drought tolerance determinants by genetic analysis of root response to drought stress and abscisic acid. Plant Physiology 142:1065-1074.

Ying J., Lee E.A., Tollenaar M. (2000) Response of maize leaf photosynthesis to low temperature during the grain-filling period. Field Crops Research 68:87-96.

Young T.E., Giesler-Lee J., Gallie D.R. (2004) Senescence-induced expression of cytokinin reverses pistil abortion during maize flower development. The Plant Journal 38:910-922. 